DOE/NASA/7653-79/1

NASA CR-159530

IO NGT NESTRQ

TRS-101

\title{
EVALUATION OF URETHANE FOR FEASIBILITY OF USE IN WIND TURBINE BLADE DESIGN
}

Seymour Lieblein

Technical Report Services

Robert S. Ross

Concept Development Institute

and

Demeter G. Fertis

University of Akron

April 1979

Prepared for

NATIONAL AERONAUTICS AND SPAGE AOMINISTRATION

Lewis Research Center

Under Purchase Order C-7653

25 APR 1979

MCDONNELI DOUG'AS

RESEARCH \& INCING.RING LIBRARY

eT. Louis

for

U.S. DEPARTMENT OF ENERGY

Office of Energy Technology

Division of Distributed Solar Technolgy

$$
\text { M79-12959 }
$$


This report was prepared to document work sponsored by the United States Government. Neither the United States nor its agent, the United States Department of Energy. nor any Federal employees, nor any of their contractors, subcontractors or their employees, makes any warranty, express or implied, or assumes any legal liability or responsibility for the accuracy, completeness, or usefulness of any information, apparatus, product or process disclosed, or represents that its use would not infringe privately owned rights. 
EVALUATION OF URETHANE

FOR FEASIBILITY OF USE IN

WIND TURBINE BLADE DESIGN

Seymour Lieblein

Technical Report Services

Rocky River, Ohio

Robert S. Ross

Concept Development Institute

Hudson, Ohio

and

Demeter G. Fertis

University of Akron

Akron, Ohio

April 1978

Prepared for

National Aeronautics and Space Administration

Lewis Research Center

Cleveland, Ohio 44135

Under Purchase Order C-7653

for

U.S. DEPARTMENT OF ENERGY

Office of Energy Technology

Division of Distributed Solar Technology

Washington, D. C. 20545

Under Interagency Agreement E(49-26)-1028 
Page intentionally left blank

Page intentionally left blank 
FOREWORD

The research work described herein resulted from two contract efforts managed by Mr. Thomas P. Cahill, Wind Energy Project Office, NASA-Lewis Research Center. The first, under NASA Contract NAS3-20062, was with the Concept Development Institute of Hudson, Ohio. This effort involved the experimental determination of urethane mechanical properties from specimen and blade-section tests, and a preliminary evaluation of full-scale blade weight. Urethane specimens were prepared by the Goodyear Tire and Rubber Company, and testing was conducted at the University of Akron. This contract effort was directed by Robert S. Ross of Concept Development Institute and by Demeter G. Fertis of the University of Akron.

The second effort, under NASA Order C-7653 with Technical Report Services of Rocky River, Ohio, involved a revision and expansion of the material developed in the first effort and a more detailed preliminary design analysis of a full-scale reinforced urethane blade. These two parts were then integrated into the single report contained herein by Seymour Lieblein of Technical Report Services. 
Page intentionally left blank

Page intentionally left blank 


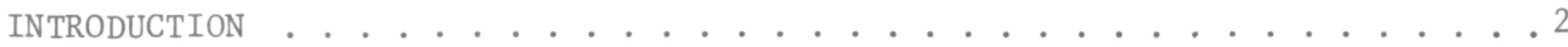

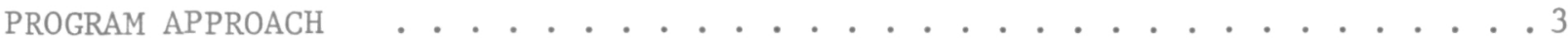

PART I. PROPERTIES EVALUATION . . . . . . . . . . . . . . . . . . . . . . . . . 4

SMALL SPECIMEN TESTS . . . . . . . . . . . . . . . . . . . . . . . 4

Tensile Strength . . . . . . . . . . . . . . . . . . . 4

Effect of load rate .. . . . . . . . . . . . . . . . . 8

Effect of temperature . . . . . . . . . . . . . . . . . 8

Flexural Strength . . . . . . . . . . . . . . . . . . . 10

Modulus . . . . . . . . . . . . . . . . . . . . . . 10

U1timate stress . . . . . . . . . . . . . . . . . 15

Flexural Strain ...................... . 18

Material D . . . . . . . . . . . . . . . . . . . . 18

Material E . . . . . . . . . . . . . . . . . . . . . . . 23

Creep Resistance . . . . . . . . . . . . . . . . . . . . 26

Bending creep . . . . . . . . . . . . . . . . . . . . . . . 27

Tensile creep . . . . . . . . . . . . . . . . . . . . . . . 33

Fatigue Strength . . . . . . . . . . . . . . . . . . . . . . . 34

MODEL BLADE SECTION TESTS . . . . . . . . . . . . . . . . . . . 36

Design . . . . . . . . . . . . . . . . . . . . . . 36

Fabrication . . . . . . . . . . . . . . . . . . . . . . . . . 40

Tests . . . . . . . . . . . . . . . . . . . . . . . . . . 46

Bending . . . . . . . . . . . . . . . . . . . . . . . . . . 47

Torsion . . . . . . . . . . . . . . . . . . . . . . . . 54

Vibration . . . . . . . . . . . . . . . . . . . . . . 54

PART II. BLADE DESIGN ANALYSIS . . . . . . . . . . . . . . 57

APPROACH AND ASSUMPTIONS . . . . . . . . . . . . . . . . . 57

REFERENCE BLADE SECTION . . . . . . . . . . . . . . . . . . 60

Analysis . . . . . . . . . . . . . . . . . . . . 60

Results ........................... . . 61

MODIFIED BLADE SECTION . . . . . . . . . . . . . . . . . . . . 69

Analysis . . . . . . . . . . . . . . . . . . . . . . . 69

Results............................. . 71

WEIGHT COMPARISON . . . . . . . . . . . . . . . . . . . . . . . . 71

CONCLUDING REMARKS . . . . . . . . . . . . . . . . . . . . . . . 78 


\section{APPENDIXES}

A - TEST SPECIMENS AND FLEXURE TESTS . . . . . . . . . . . . 79

B - FLEXURAL STRAIN TESTS . . . . . . . . . . . . . 117

C - CREEP RESISTANCE DATA . . . . . . . . . . . . . . . 127

D - MODEL BLADE SECTION . . . . . . . . . . . . . . 133

E - DESIGN ANALYSIS . . . . . . . . . . . . . . . . . . 139

F - MODIFIED BLADE SECTION . . . . . . . . . . . . 148

REFERENCES . . . . . . . . . . . . . . . . . . . . . 151 


\section{SUMMARY}

A preliminary evaluation was conducted of the feasibility of urethane as a material for low-cost rotor blades for wind turbines. The study involved two major phases: results of tests for determination of urethane mechanical properties; and a theoretical analysis of a full-scale blade design based on the results of these tests.

Specimen tests of nine urethane formulations showed that the best material had a modulus of 457000 psi and an ultimate tensile strength of 6054 psi. Tensile strength decreased substantially with increasing temperature (around 1000 psi between room temperature and $120^{\circ} \mathrm{F}$ ). Strain-gage measurements on beam specimens revealed normal flexural behavior for urethane.

Urethane showed creep in both bending and tensile specimen tests. At a steady load that produced a bending stress of 2000 psi, the bending deflection increased by around $40 \%$ after 60 days. No fatigue failures occurred in tensile specimens after 2 million cycles. However, this test duration was very small compared to the design life requirements of wind turbine blades ( $4 \times 10^{8}$ cycles).

Test results were also obtained from a large-scale model blade section installed as a cantilever beam. The blade section was composed of two joined cast halves of a symmetrical airfoil section with a length of 85 inches, a chord length of 30 inches, and a maximum thickness of 4.5 inches. When the blade section was loaded at the free end, it failed at the restrained end at a calculated stress of around half the ultimate tensile strength for the material and with around twice the calculated deflection (measured tip deflection was 22.25 in.). Although the insertion of two steel reinforcing rods along the length of the cast urethane blade reduced the tip deflection substantially, it did not materially affect the base failure. The behavior and premature failure of the model blade section is believed due to stress concentration effects at the bolt holes in the fixed end of the urethane, and to incomplete rigidity involved in the base attachment of the blade.

A theoretical analysis of a full-scale urethane blade that meets the design specifications of the 62.5-foot rotor blades for the MOD-0 wind turbine was conducted based on the urethane properties and configuration determined in the previous tests. Results indicated that metal reinforcement is needed, and that the stiffness criterion is the governing factor that determines the reinforcement requirements.

Blade designs were conducted for two levels of design strength specifications and for two arbitrarily selected blade cross-sectional configurations. The design calculation produced the radial variation of reinforcement width and total unit weight for a complete blade with 0.25 -inch-thick steel or aluminum plates imbedded in the upper and lower surfaces of the urethane. Results indicated that blade weight varied little with design specification level but substantially with blade cross-sectional area. For the conditions used in the analysis, the calculated total weight of a full-scale reinforced urethane blade varied from around 3000 to 4000 pounds compared to around 2000 pounds for the aluminum blades of the MOD-0 rotor.

Further studies would be required to determine whether a reinforced cast urethane blade can be fabricated at low cost and whether the urethane blade sections can be constructed with thinner walls to reduce overall blade weight. 


\section{INTRODUCTION}

It is generally recognized that new forms of replenishable energy sources must be developed and exploited in order to maintain the standard of living now available and to improve it in the future. One of these sources is the Sun, and one of its energy components is the wind. Wind is a form of energy that is readily available, and is one of the forces of nature in constant existence that man is attempting to harness and to put in a useable form. A1though wind energy has long been recognized, and even in many places used, it has not obtained general acceptance on a large scale because of the vagaries of the wind and the difficulty of storing it in a form which could be drawn upon at will.

Recently, the Department of Energy (DOE) was given the task of trying to find some way to harness wind energy on a large enough scale to become significant as a national energy source. In preliminary investigations, DOE has determined that large size wind turbines might be one solution to this problem (ref. 1). However, studies have indicated that the cost of the initial insta1lation is considerable, and if these systems are to be economically viable, the capital cost of the equipment must be reduced. Wind turbine costs can be divided into three major components: (1) the rotor blades; (2) the tower that supports the rotor and power generating equipment; and (3) the electrical and electro-mechanical equipment. The program described in this report was directed at means for reducing the cost of the rotor blades.

In the first experimental wind turbine installations investigated by NASA for DOE (e.g., the 100-kW MOD-0 wind turbine, ref. 2), the rotor blades were based on either propeller or airfoil design and fabrication techniques. These provided workable blades, but at a relatively high cost. This rotor blade technology was derived from the aircraft industry which has made aluminum or fiber glass propellers and rotors for many years and, therefore, has probably reduced blade manufacturing techniques to their practical minimums in costs. It appeared, therefore, that an entirely new approach would be required if a significant cost reduction was to be obtained.

A new approach to the blade cost problem would involve the search for new blade materials. Since urethanes have a wide variety of structural properties, and can be cast in low-cost molds where they generate their own internal heat during the casting process, it appeared that these may be likely candidates for rotor components. However, urethanes are relatively new materials, and very little is known regarding their properties and structural behavior as a construction material. It appeared desirable, therefore, to investigate the mechanical properties of the urethanes and also to look into blade fabrication techniques to determine if a potential cost benefit might be realized from the use of these materials in wind turbine rotor blade design.

It was recognized at the beginning of the program that the use of cast urethane blades might entail some sacrifice in aerodynamic efficiency. Also, some increase in rotor weight would be expected, since the mechanical properties of the urethanes do not match those of the metals, or of fiber glass. However, it was recognized also that wind turbines are not flight vehicles, 
and weight is not as critical to their efficient operation as it would be to a helicopter or airplane.

In view of these considerations, NASA-Lewis Research Center funded an unsolicited program to experimentally determine the significant mechanical properties of several types of urethanes, and to analytically determine the characteristics and weight of a full-scale rotor blade design using this material. The program involved not only physical testing of specimens, but also the fabrication and test of several model blade sections and a preliminary analytical study of a full-scale blade design to determine the practicality of the approach. It was believed that information obtained from such a program could then serve as a data base for a further evaluation if warranted. The results of the experimental and analytical phases of the program, preceeded by a discussion of the program approach, are presented herein.

\section{PROGRAM APPROACH}

The experimental phase of the program was initiated with a survey of urethane types having a wide variety of physical properties. These consisted of cast elastomers, microcellular foams, rigid foams, and flexible foams. It was decided during this preliminary study that materials of low-elongation microcellular foams and rigid foams would be examined based on their relatively high structural stiffness.

Samples of nine urethane compositions were prepared in shapes which could be readily tested in bending for strength and elastic modulus determination. While tests of these samples were continued to establish other properties, new urethanes were formulated that yielded even higher elastic modulus values.

Tests were conducted on flat, round, and beam specimens to determine elastic modulus and tensile, creep, and fatigue properties. Temperature effects on tensile stress were determined for three temperatures. In addition, strain gage and other tests were performed on beam specimens to further evaluate the structural behavior of these materials. Two of the formulations had elastic modulus values two to three times greater than had been achieved before for urethanes. One of the formulations was a rigid foam urethane, and the other was a microcellular foam.

On the basis of the material properties obtained for these urethane formulations, an untwisted airfoil test section was designed and cast for structural tests. The basic test sections were manufactured to simulate the cross section of a 62.5-foot rotor blade at 80 percent of the radius. The sample sections had a chord length of 30 inches, a maximum thickness ratio of 15 percent, and a spanwise length of 7 feet. They were cast of two symmetrical parts which were cemented together to form the airfoil section.

Although it may be possible to make rotor blades entirely of urethane (they would be relatively heavy), it was felt desirable to examine reinforcing metal rods cast into the sections so that a greater overall structural efficiency could be obtained. Therefore, three blade sections were cast: two 
with reinforcing metal; and one without. The blade sections were mounted in a cantilever fashion and loaded separately in both torsion and bending. While the test blades were mounted on the cantilever fixture, an accelerometer was used to determine the blade natural frequency in bending.

In order to determine the potential of cast urethane blades, the information obtained from the tests of the blade models was applied to the design of an actual full-size blade in the second phase of the program. The blade design utilized urethane as the prime construction element with judiciously placed metall reinforcement to increase stiffness and bending moment resistance. For the purpose of this study, it was assumed that the full-sized reinforced blade would be the 62.5-foot-radius MOD-0 configuration, but with symmetrical airfoil sections. Analytical methods were derived to determine blade section properties along the span, and blade weight was calculated for two levels of design strength specifications and for two blade cross-sectional configurations.

\section{PART I. PROPERTIES EVALUATION}

The discussion of the evaluation of the mechanical properties of urethane foam is presented in two main sections. The first deals with the results of the tests with conventional small specimens. The second part covers the tests of the large-scale model blade sections.

\section{SMALL SPECIMEN TESTS}

The types and formulations of urethane foam used for the small specimen tests, together with some of their known basic properties, are listed in table I. Except for sample A, the foams are low-elongation materials. Details of the individual test specimens used for the urethane samples are shown in appendix A. Unless indicated otherwise, the material specimens were tested at room temperature. The results of these property evaluation tests are presented herein in groupings of the major mechanical properties involved: tensile strength; flexural strength; flexural strain; creep resistance; and fatigue strength.

\section{Tensile Strength}

Ultimate tensile load tests were performed on the nine urethane foam samples of table I by using flat specimens that were prepared in accordance with figure 1 of the D638 ASTM standards (p. 201, vo1. 35) for plastic materials as a guideline. The test specimens had an overall length of 12 inches, a gage length of 3 inches, and a thickness of 0.25 inch (fig. 1). Exact specimen dimensions were recorded before the material was placed in the testing machine and after it failed.

Rod specimens (fig. 2) were also used in some cases for comparison purposes. These were prepared by following figure 3, page 204, volume 35 of the ASTM standards. Additional tensile tests were also performed according to 
TABLE I - URETHANE FOAM TEST MATERIALS

(a) Microcellular foam

\begin{tabular}{|c|c|c|c|c|}
\hline \multirow[t]{2}{*}{ Property } & \multicolumn{4}{|c|}{ Sample material } \\
\hline & A & D & F & $\mathrm{H}$ \\
\hline Specific gravity & 1.05 & 0.91 & 1.038 & 1.00 \\
\hline Density, $1 b / f t^{3}$ & 65.4 & 56.3 & 64.7 & 62.4 \\
\hline Elongation, percent & 80 & 3 & 3 & 3 \\
\hline Crescent tear, 1b/in. & 563 & 558 & $-\cdots$ & $\ldots$ \\
\hline Heat sag, in. & 0.1875 & 1.6875 & ---- & --- \\
\hline $\begin{array}{l}\text { Notched Izod impact, } \\
\text { lb/in. }\end{array}$ & ----- & $---\cdot-$ & 0.69 & --- \\
\hline
\end{tabular}

(b) Rigid foam

\begin{tabular}{|c|c|c|c|c|c|}
\hline \multirow[t]{2}{*}{ Property } & \multicolumn{5}{|c|}{ Sample material } \\
\hline & B & C & $\mathrm{E}$ & G & GG \\
\hline Specific gravity & 0.86 & 0.70 & 1.05 & 1.00 & 1.00 \\
\hline Density, $1 \mathrm{~b} / \mathrm{ft}^{3}$ & 53.6 & 43.4 & 65.4 & 62.4 & 62.4 \\
\hline Elongation, percent & 3 & 2 & 3 & 3 & 3 \\
\hline Crescent tear, lb/in. & 394 & 316 & $-\cdots$ & --- & $-\cdots$ \\
\hline Heat sag, in. & 1.1875 & 0.5625 & $-\cdots$ & --- & $-\cdots$ \\
\hline $\begin{array}{l}\text { Notched Izod impact, } \\
\text { lb/in. }\end{array}$ & 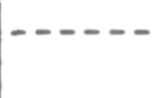 & $-\cdots--$ & 0.53 & --- & $-\cdots$ \\
\hline
\end{tabular}

D-412 ASTM standards for the microcellular foams and the D1623 ASTM standards for the rigid foams in order to compare results.

A Riehle Universal Testing Machine (60 000 lb capacity) was used for the tensile tests. The load was applied at a speed which produced an elongation of 0.2 inch per minute on the specimen. Three to five specimens were tested for each material. A sample test record for the flat specimen tensile tests at room temperature is shown on page 7 . 


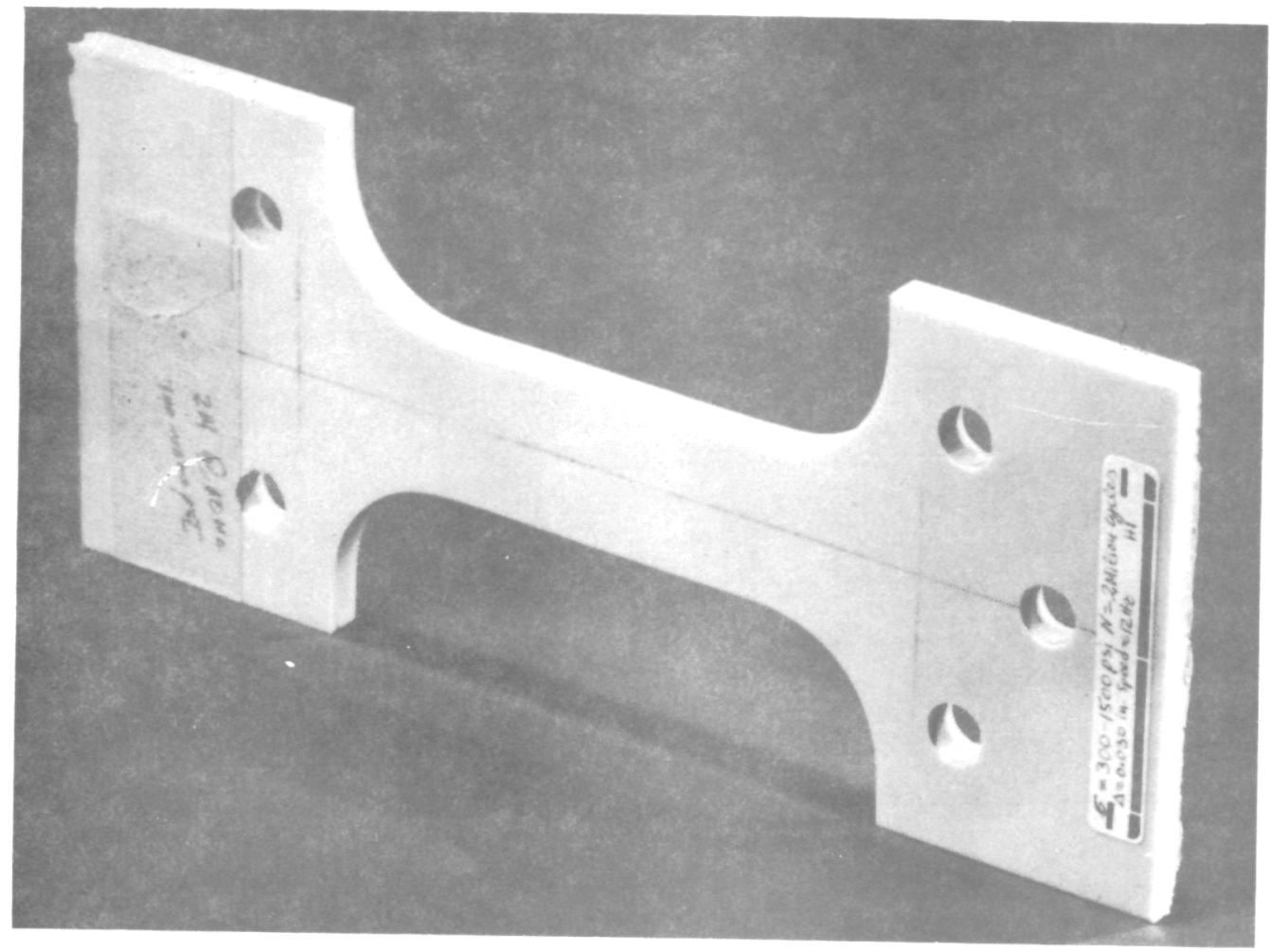

Figure 1. - Flat tensile test specimen.

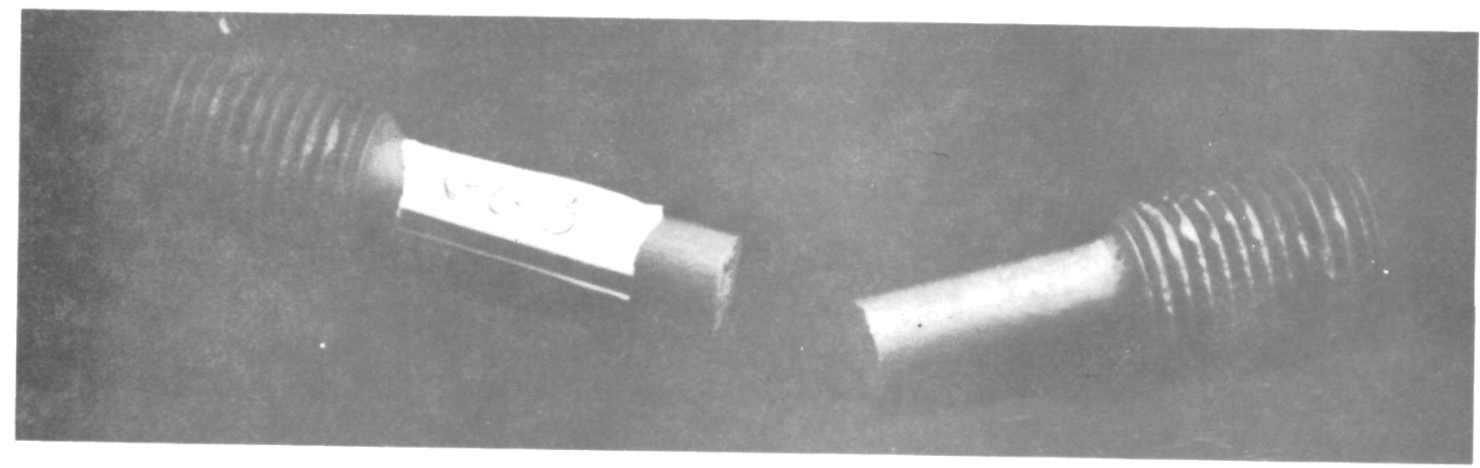

Figure 2. - Round bar tensile test specimen. 


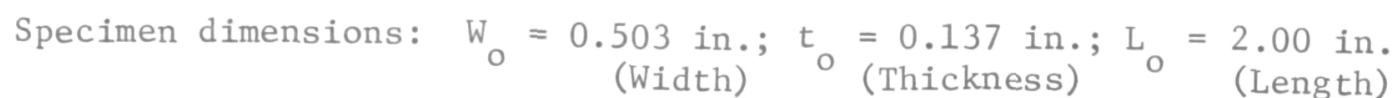

U1timate load: $3701 \mathrm{~b}$

Final dimensions: $L_{f}=2.05$ in.; $W_{f}=0.501$ in.; $t_{f}=0.137$ in.

U1timate stress: $\quad \sigma_{\mathrm{u}}=\frac{370}{(0.501)(0.137)}=5391 \mathrm{psi}$

Average values of ultimate tensile stress, $\sigma_{u}$, and ratio of ultimate stress to density $\sigma_{\mathrm{u}} / \rho$ for the nine urethane materials are given in table II. The rigid foam material $\mathrm{E}$ showed the highest value of ultimate tensile strength and had the second highest strength/density ratio, with material $D$, the best for the microcellular foams. These results indicate that a design or working stress in tension of the order of $20001 \mathrm{~b} / \mathrm{in}^{2}$ may be feasible for these materials.

TABLE II. - TENSILE STRENGTH OF URETHANE

(a) Microcellular foam

\begin{tabular}{|c|c|c|c|c|}
\hline Sample & A & D & $\mathrm{F}$ & $\mathrm{H}$ \\
\hline $\begin{array}{l}\text { U1timate tensile } \\
\text { stress, } \sigma_{\mathrm{u}}, 1 \mathrm{~b} / \mathrm{in}^{2}\end{array}$ & 3838 & 5349 & 5455 & 5473 \\
\hline $\begin{array}{l}\text { Strength/density ra- } \\
\quad \text { tio, } \sigma_{\mathrm{u}} / \rho \text {, in. } \times 10^{3}\end{array}$ & 101.4 & 164.2 & 145.7 & 151.6 \\
\hline
\end{tabular}

(b) Rigid foam

\begin{tabular}{|c|c|c|c|c|c|}
\hline Sample & B & C & E & G & GG \\
\hline $\begin{array}{c}\text { Ultimate tensile } \\
\text { stress, } \sigma_{\mathrm{u}} \text {. 1b/in }\end{array}$ & 4837 & 3021 & 6054 & 5470 & 5179 \\
$\begin{array}{c}\text { Strength/density ra- } \\
\text { tio, } \sigma_{\mathrm{u}} / \rho, \text { in.x10 }\end{array}$ & 155.9 & 120.3 & 160.0 & 151.5 & 143.4 \\
\hline
\end{tabular}

The urethanes, of course, are considerably weaker than the materials currently used in rotor design. However, it is interesting to note that the urethane materials are about as strong as concrete in tensile strength, a1though their weight is close to one third of that of concrete. Furthermore, urethane is equally strong in both tension and compression, while concrete is strong only in compression. 
Effect of load rate. - In order to get some idea about the effect of loading rate on the ultimate tensile strength of the urethane materials, a number of 12-inch flat specimens were tested at elongation speeds of 0.05 inch per minute, 0.2 inch per minute, and 0.8 inch per minute. The microcellular foam material $D$ was selected for this purpose. The results are shown in table III. Also included in the table is another data value for room temperature from table II to indicate the degree of repeatability.

\section{TABLE III. - ULTIMATE TENSILE \\ STRESS FOR MATERIAL D}

\begin{tabular}{|c|c|}
\hline $\begin{array}{c}\text { Rate of } \\
\text { deformation, } \\
\text { in./min }\end{array}$ & $\begin{array}{c}\text { Ultimate stress, } \\
\text { lb/in }{ }^{2}\end{array}$ \\
\hline 0.25 & 5225 \\
.20 & 5325 \\
.80 & 5478 \\
\hline 0.20 & 5349 (table II) \\
\hline
\end{tabular}

These results indicate that the ultimate stress of the material is lower at the lower rates of deformation or loading, as expected, because some creeping in the material is taking place as the loading is applied at lower speeds. The reduction in ultimate stress due to creep, however, is very small - the difference in ultimate stress between rates of 0.05 inch per minute and 0.80 inch per minute (a ratio of 16) is less than 5 percent.

Effect of temperature. - Rotor blades for wind generator systems are expected to be subjected to large temperature variations due to climatic conditions prevailing in the region of their location. Such temperatures are expected to be not lower than around $50^{\circ} \mathrm{F}$ below zero and not higher than about $130^{\circ} \mathrm{F}$ above zero. It is expected that, like other materials, urethanes will also be affected by temperature change.

It was decided to run four temperature tests for one material, preferably a rigid foam material, in order to find out how the ultimate load, or ultimate tensile stress, is affected by temperature. The four temperatures selected were $-20^{\circ} \mathrm{F}$, room temperature, $130^{\circ}$ and $150^{\circ} \mathrm{F}$. Since these studies are preliminary in nature, it was believed that these temperatures would, at this time, provide a sufficient input to the evaluation of this material as a rotor blade candidate.

The tests for the above three temperatures were performed with material GG. Flat 12-inch specimens were used, with preparation as described earlier. The tests were performed using an Instron Environmental Chamber and a CGS Closed Loop Hydraulic Machine (fig. 3). The tensile specimen was placed into the Instron Environmental Chamber (fig. 4) and preheated to the required temperature. A United Systems Corporation Thermocouple was used to record the 


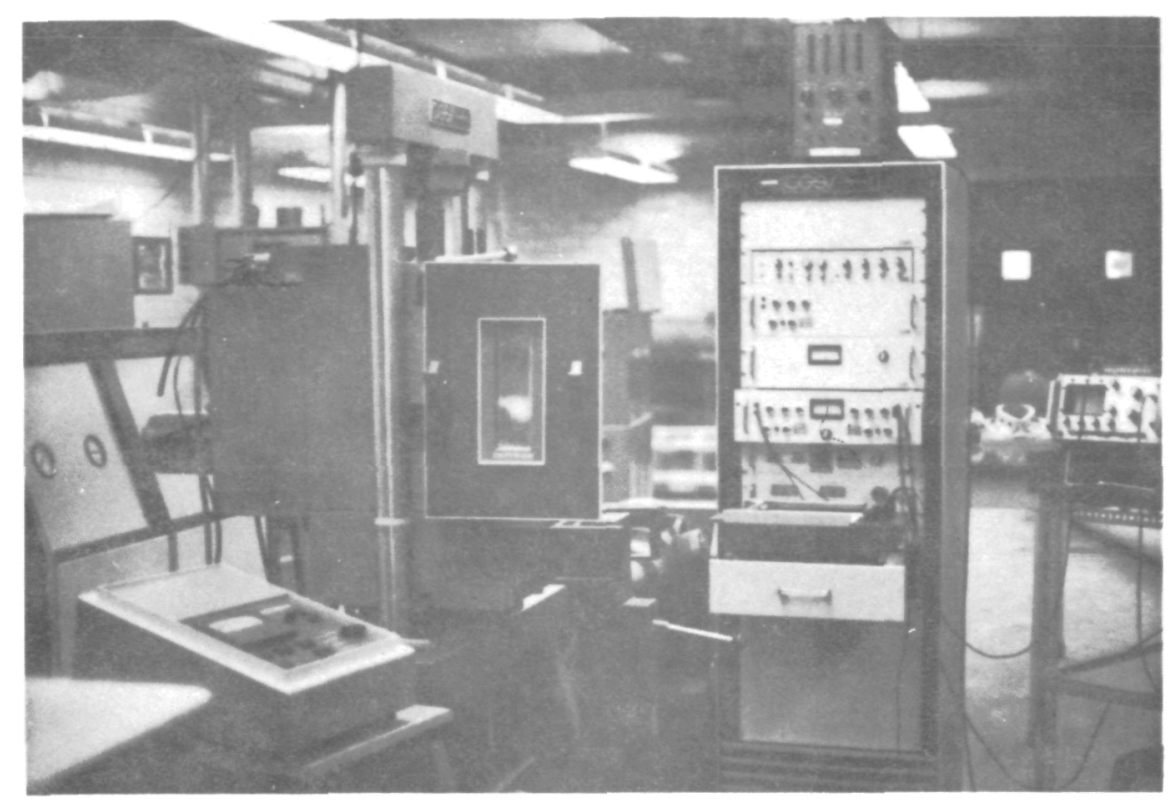

Figure 3. - Variable temperature test set up.

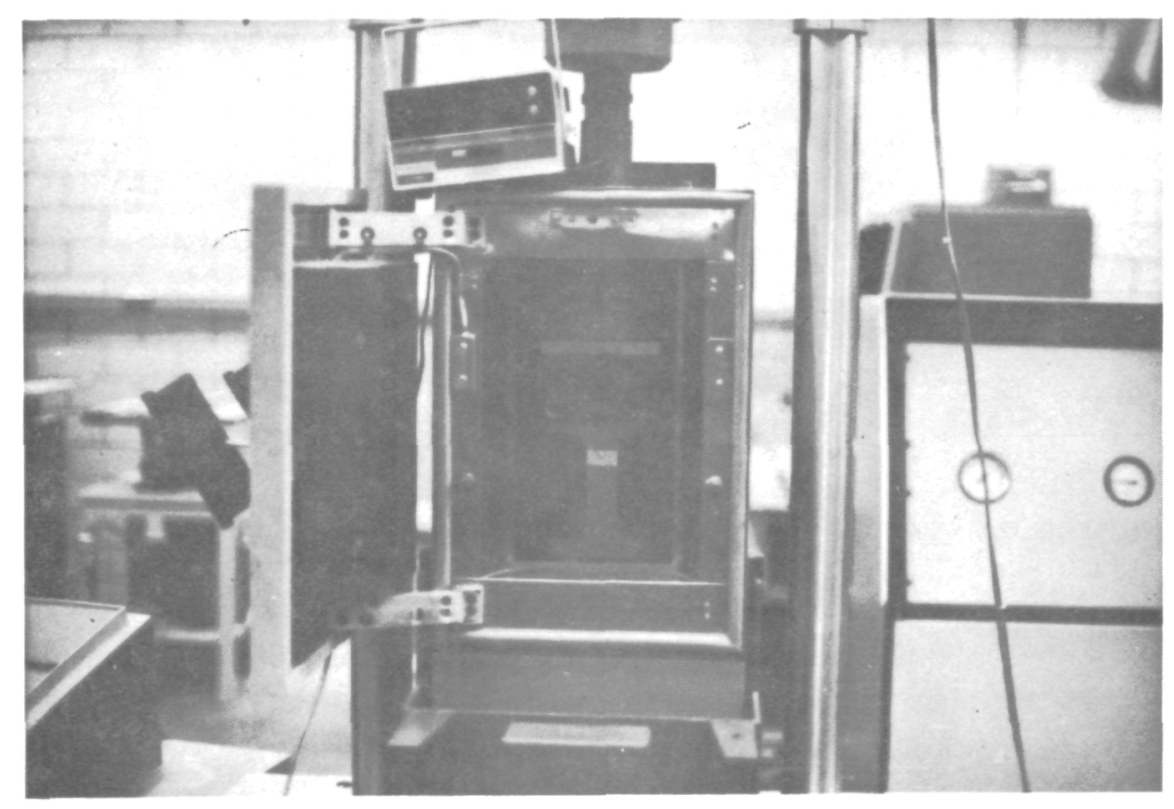

Figure 4. - Test specimen in environmental chamber. 
temperature of the specimen. The specimen was conditioned to the required temperature for about 2 hours.

The environmental chamber was attached to the CGS closed loop hydraulic machine. The tensile load was applied to the specimen by the CGS machine at a speed of 0.2 inch per minute until the specimen failed. The results for ultimate load and ultimate tensile stress are shown in table IV. Also included in the table is another value for room temperature from table II.

TABLE IV. - TEMPERATURE EFFECTS

ON MATERIAL GG

\begin{tabular}{|c|c|c|}
\hline $\begin{array}{c}\text { Temperature, } \\
\text { OF }\end{array}$ & $\begin{array}{c}\text { Ultimate } \\
\text { load, } \\
1 \mathrm{~b}\end{array}$ & $\begin{array}{c}\text { U1timate tensile } \\
\text { stress, } \\
\text { 1b/in }\end{array}$ \\
\hline-20 \\
64 (Room temp.) & 2520 & 6167 \\
130 & 1700 & 5094 \\
150 & 1480 & 3490 \\
\hline Room temp. & & 5179 (table II) \\
\hline
\end{tabular}

As indicated in the table, increasing temperature produces a significant decrease in ultimate tensile strength. The observed variation in ultimate tensile strength with temperature is plotted in figure 5. For the range of extreme climatic temperature variation $\left(-50^{\circ}\right.$ to $\left.130^{\circ} \mathrm{F}\right)$ the variation of ultimate tensile strength is estimated from these results to be of the order of 35 percent for material GG. From room temperature $\left(64^{\circ}\right.$ to $\left.120^{\circ} \mathrm{F}\right)$, the ultimate stress for this material decreased by about 20 percent. Thus, the expected maximum environmental temperature for the blade will be an important determinant of the working stress level for the material.

\section{Flexural Strength}

Modulus. - The flexural modulus of the nine urethane materials were obtained by using the D790 ASTM standards for flexural properties of plastics. Two types of beam specimens are used: one with dimensions $3 / 4$ in. by $3 / 4$ in. by 30 inches; and the other with dimensions $3 / 4$ in. by $3 / 4$ in. by 15 inches. Four-point loading (two applied loads) is used for the first specimen configuration with a gage length of 24 inches and a length-to-depth ratio equal to 32. Three-point loading (one applied load) was used for the second one with a gage length of 12 inches and a length-to-depth ratio of 16 .

Sample laboratory load-deflection data (for specimen H2) are shown in table V. The specimen was loaded gradually from 0 to 25000 grams, and then gradually unloaded to zero. The maximum bending stress on the specimen 


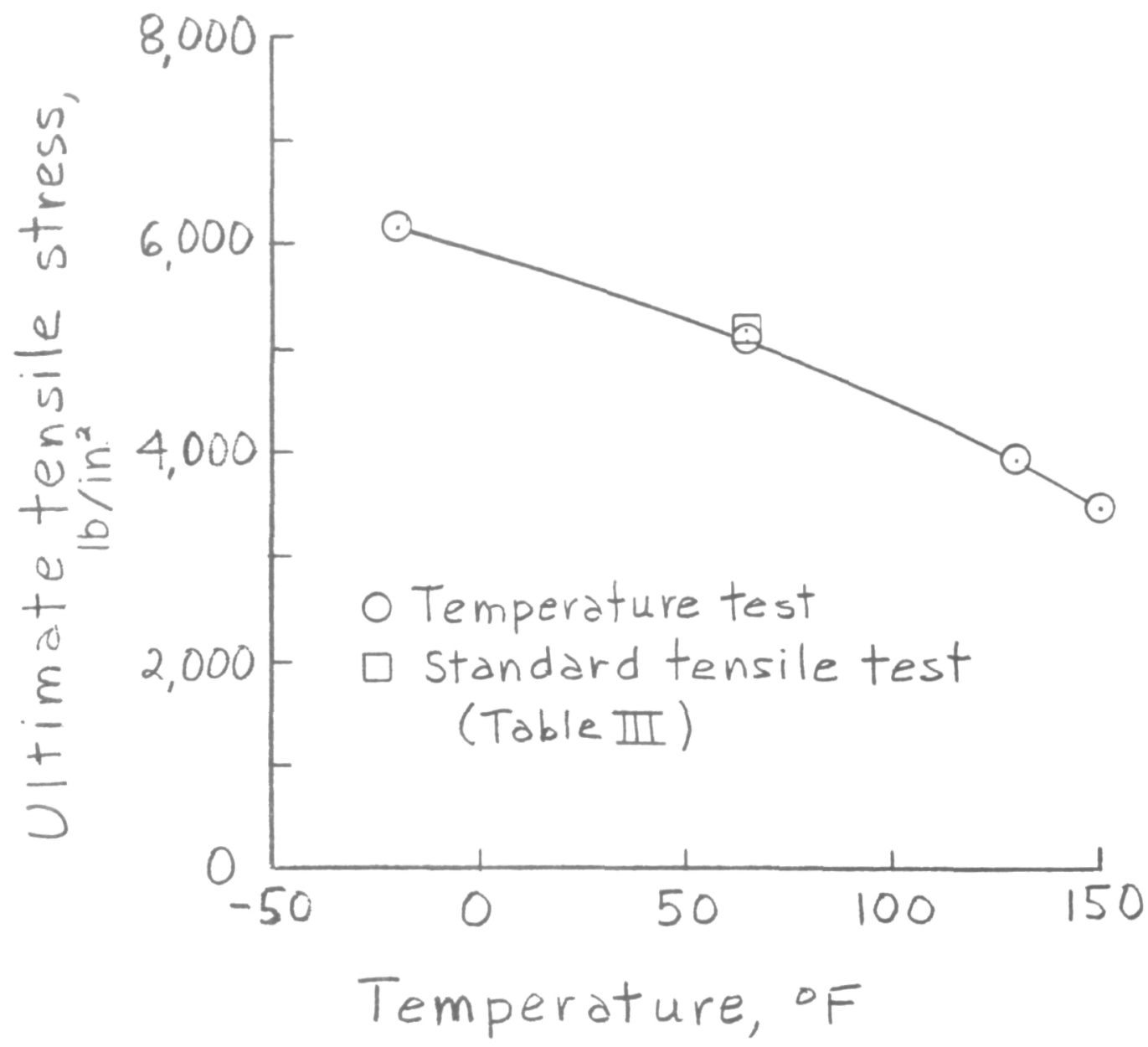

Figure 5. - Effect of temperature on ultimate
tensile strength of urethane material $G G$.

reached 2634 psi for the loading of 25000 grams. The load-deflection curve for both loading and unloading is plotted in figure 6 . The shape of this curve is nearly linear. When the load on the member was removed, a deflection equal to 0.007 inch was indicated on the dial as shown in table V. This so-called permanent deformation is not very permanent. The material recovers almost completely in about 10 to 15 minutes. This is characteristic of all specimens tested even when the stresses are much higher.

The flexural modulus $E$ was computed from the experimental deflection values as described in appendix A. The flexural modulus values for the load deflection readings for material $\mathrm{H}$ are shown in table $\mathrm{V}$. The average value for this specimen is 230740 psi. Similar values were obtained when other 
TABLE V. - LOAD-DEFLECTION AND MODULUS DATA

FOR MATERIAL H

\begin{tabular}{|c|c|c|c|c|}
\hline \multirow{2}{*}{$\begin{array}{l}\text { Load, } \\
\text { P, } \\
\text { gr }\end{array}$} & \multicolumn{2}{|c|}{ Deflection, $\Delta$, in. } & \multirow{2}{*}{$\begin{array}{l}\text { Slope, } \\
(\mathrm{P} / \Delta), \\
\text { lb/in. }\end{array}$} & \multirow{2}{*}{$\begin{array}{c}\text { Modulus, } \\
\text { E } \\
\text { lb/in }{ }^{2}\end{array}$} \\
\hline & Loading & Unloading & & \\
\hline $\begin{array}{l}0 \\
1000 \\
2000 \\
3000 \\
4000 \\
5000 \\
6000 \\
7000 \\
8000 \\
9000 \\
10000 \\
11000 \\
12000 \\
13000 \\
14000 \\
15000 \\
16000 \\
17000 \\
18000 \\
19000 \\
20000 \\
21000 \\
22000 \\
23000 \\
25000\end{array}$ & $\begin{array}{r}0 \\
.0120 \\
.0250 \\
.0395 \\
.0515 \\
.0645 \\
.0775 \\
.0910 \\
.1040 \\
.1170 \\
.1300 \\
.1430 \\
.1560 \\
.1695 \\
.1825 \\
.1970 \\
.2090 \\
.2230 \\
.2360 \\
.2495 \\
.2630 \\
.2770 \\
.2900 \\
.3050 \\
.3320\end{array}$ & $\begin{array}{l}.0070 \\
.0200 \\
.0330 \\
.0440 \\
.0600 \\
.0730 \\
.0860 \\
.1005 \\
.1145 \\
.1280 \\
.1410 \\
.1545 \\
.1680 \\
.1810 \\
.1950 \\
.2075 \\
.2200 \\
.2340 \\
.2470 \\
.2590 \\
.2725 \\
.2840 \\
.2965 \\
.3090 \\
.3320\end{array}$ & $\begin{array}{l}17 .---- \\
176.368 \\
167.438 \\
171.231 \\
170.899 \\
170.679 \\
169.535 \\
169.585 \\
169.535 \\
169.585 \\
169.585 \\
169.585 \\
169.084 \\
169.120 \\
167.863 \\
168.773 \\
168.064 \\
168.147 \\
167.385 \\
167.650 \\
167.136 \\
167.246 \\
166.249 \\
166.009\end{array}$ & $\begin{array}{l}----- \\
240775 \\
228584 \\
233762 \\
233309 \\
233009 \\
231515 \\
231515 \\
231515 \\
231515 \\
231515 \\
231515 \\
230931 \\
230881 \\
229165 \\
230407 \\
229439 \\
229552 \\
229195 \\
228874 \\
228172 \\
228322 \\
226961 \\
226633\end{array}$ \\
\hline & & & & 230740 \\
\hline
\end{tabular}

COMMENTS:

Creep does not appear to be significant. Specimen No.: H2 $\mathrm{SD}_{0} \cdot \mathrm{x}_{0}=1.00$

Specimen dimensions: $3 / 4^{\prime \prime} \times 3 / 4^{\prime \prime} \times 15^{\prime \prime}$ 3-Pt. loading

Experimental Date: February 5, 1977

specimens of the same material batch were tested. The repeatability of results by using various batches of the same material was considered good. Details of test results for the other urethane materials are given in appen$\operatorname{dix} A$.

The average flexural modulus for each of the nine urethane materials are shown in table VI, in which the values of ultimate tensile strength and 


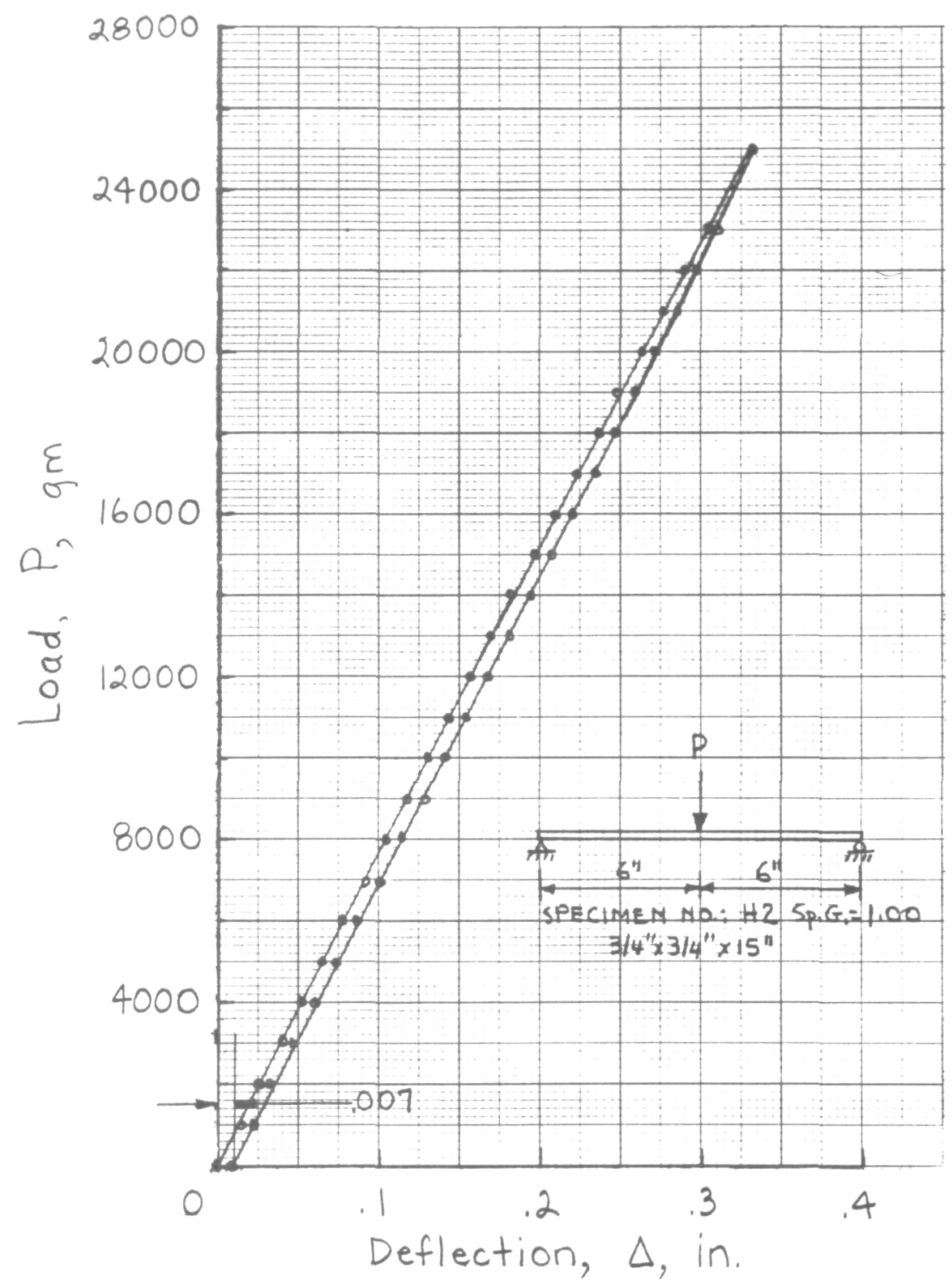

Figure 6. - Load-deflection curve for material $H$. 
TABLE VI. - FLEXURAL PROPERTIES OF URETHANES

(a) Microcellular foam

\begin{tabular}{|c|c|c|c|c|}
\hline \multirow{2}{*}{ Property } & \multicolumn{3}{|c|}{ Sample material } \\
\cline { 2 - 5 } & A & D & F & H \\
\hline $\begin{array}{c}\text { Bending modulus, E, } \\
\text { lb/in2 x 1000 } \\
\text { Calculated ultimate } \\
\text { bending stress, } \\
\text { lb/in2 }\end{array}$ & 52.2 & 261 & 268 & 231 \\
\hline $\begin{array}{c}\text { Ultimate tensile } \\
\text { stress, ou, } \\
\text { lb/in2 } \\
\text { Tensile stress/ } \\
\text { density ratio, } \\
\text { oulp, in.x103 }\end{array}$ & 3838 & 5349 & 5455 & 5473 \\
\hline
\end{tabular}

(b) Rigid foam

\begin{tabular}{|c|r|r|r|r|r|}
\hline \multirow{2}{*}{ Property } & \multicolumn{5}{|c|}{ Sample material } \\
\cline { 2 - 6 } & B & C & E & G & GG \\
\hline $\begin{array}{c}\text { Bending modulus, E, } \\
\text { lb/in2 x 1000 } \\
\text { Calculated ultimate } \\
\text { bending stress, } \\
\text { lb/in2 }\end{array}$ & 4767 & 162 & 458 & 389 & 356 \\
\hline $\begin{array}{c}\text { Ultimate tensile } \\
\text { stres , ou, } \\
\text { lb/in2 } \\
\text { Tensile stress/ } \\
\text { density ratio, } \\
\text { ou/p, in.x103 }\end{array}$ & 155.9 & 120.3 & 160.0 & 151.5 & 143.4 \\
\hline
\end{tabular}

strength/density ratio are repeated from table II. Material E is seen to produce the largest values of both bending modulus and ultimate tensile stress.

The values of flexural modulus for the urethanes is considerably lower than that for conventional structural materials. Such low values of modulus would result in relatively large values of deformation under load, so that 
some degree of reinforcement would probably be necessary in a practical design. It is, therefore, important to carefully examine the deformation limitations in any full-scale blade design in order to determine the proper working stresses and which parts would have to be constructed of reinforced urethane. Higher values of modulus, of course, would be more desirable, but it is not known to what extent that can be achieved with current urethane formulations.

U1timate stress. - Materials B, D, and E were tested for ultimate bending moment and stress. Material $\mathrm{D}$ is microcellular foam with modulus of elasticity $E=261000$ psi, and materials $B$ and $E$ are rigid foams with moduli of elasticity equal to 271000 and 458000 psi, respectively. The specimens used for these tests were $3 / 4 \mathrm{in}$. by $3 / 4 \mathrm{in}$. by 15 inches beam specimens with a gage length equal to 12 inches, giving a length-to-depth ratio equal to 16 . The specimens were prepared in accordance with the D790 ASTM specifications.

The load was applied gradually at the center of the beam specimen (threepoint loading) by the Rickle Universal Testing Machine until the specimen failed. The rate of the applied load was about 0.2 inch per minute. Maximum bending stress, tension or compression, was computed from the experimental maximum load at failure and the assumption that the bending stresses throughout the specimen at the ultimate load vary linearly from the neutral axis. The stress distribution at the ultimate load, however, is not expected to be linear, so that the actual maximum bending stress would be lower than the one computed on the basis of linear distribution.

Load-deflection data up to the failure point for two specimens of material $\mathrm{E}$ are shown in table VII, and the corresponding load-deflection plots are shown in figure 7. The deflection variation is essentially linear for half of the range. The calculated maximum bending moment was 795 inch-pounds for the first specimen and 840 inch-pounds for the second specimen. The corresponding calculated ultimate bending stresses were 11307 and 11947 psi, respectively, for an average value of 11627 psi.

For material D, the beam specimen failed at the center of the gage length when the maximum load was 220 pounds (deflection of 1.30 in.). The maximum bending moment was 660 inch-pounds which corresponds to a maximum bending stress of 9387 psi. Material B also failed at the center of the gage length when the load reached 175 pounds to produce a maximum bending moment of 525 inch-pounds and a calculated maximum bending stress of 7467 psi.

The specimens of the three materials were also examined visually in order to determine if other types of failures, such as shear and bearing stress, have occurred. No other failures, except those due to bending, were observed.

Values of calculated ultimate bending stress for materials B, D, and E are listed in table VI. For these materials, the calculated ultimate bending stress (tension or compression) appears to parallel the values of ultimate tensile stress obtained from the tensile tests. As expected, the calculated ultimate bending stress is considerably larger than the measured ultimate tensile stress. Material $\mathrm{E}$ is seen to produce the highest values of modulus 
TABLE VII. - LOAD-DEFLECTION DATA FOR MATERIAL E
(a) First specimen.
(b) Second specimen.

U1timate load $=280 \mathrm{lb}$

Ultimate load $=2651 \mathrm{~b}$

Deflection at failure $=1.03$ in. Deflection at failure $=0.93$ in.

Load, P, Ib Deflection, $\Delta$, in. Load, $P, 1 b$ Deflection, $\Delta$, in.

$\begin{array}{rrrr}0 & 0 & 0 & 0 \\ 25 & .087 & 25 & .0690 \\ 50 & .179 & 50 & .1530 \\ 75 & .262 & 75 & .2430 \\ 100 & .339 & 100 & .3220 \\ 125 & .410 & 125 & .3960 \\ 150 & .492 & 150 & .4770 \\ 175 & .584 & 175 & .5650 \\ 200 & .671 & 200 & .6540 \\ 225 & .776 & 225 & .7470 \\ 250 & .878 & 250 & .8600 \\ 275 & 1.000 & 265 & .930 \\ 280 & 1.030 & & \end{array}$

COMMENTS- First speGimen:

The specimen broke suddenly without clear warning. It broke at the centre length. Two large pleces and four small ones. The test went very well.

Specimen No.: E7-3-1406 Sp.G. $=1.05$

Specimen Dimensions: $3 / 4 " \times 3 / 4^{\prime \prime} \times 15^{"} 3$-Pt. Loading

Experiment Date: Decomber 8, 1976

COAMENTS - Second specimen:

The specimen broke suddenly without very clear warning. It broke into three large pieces and two small ones. The test went very well.

Specimen No.: E6-3-1406 Sp.G. $=1.05$

Specimen Dimensions: $3 / 4^{\prime \prime} \times 3 / 4^{\prime \prime} \times 15^{\prime \prime} 3$-pt. Loading Experiment Date: December 6, 1976 


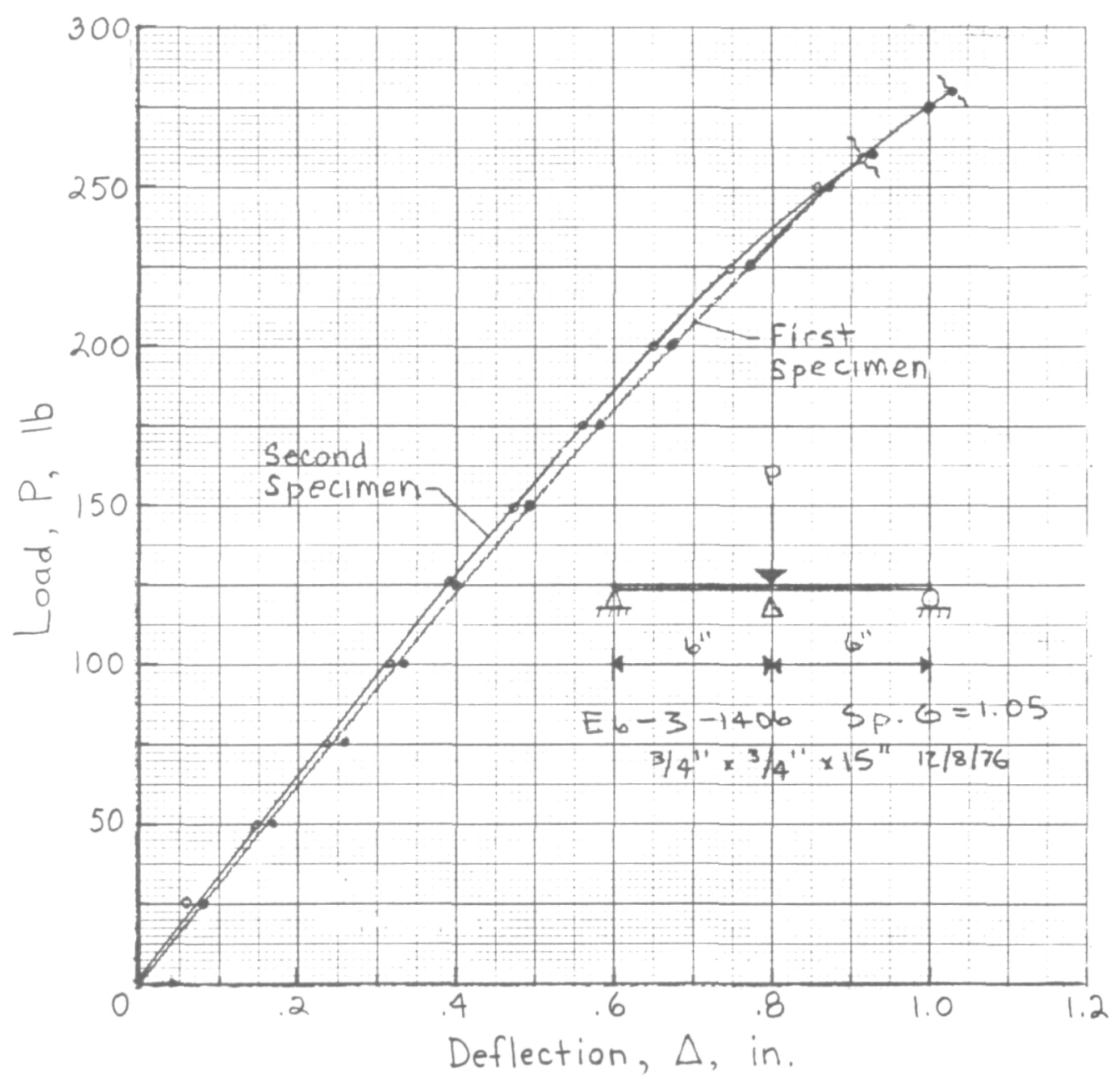

Figure 7. - Load-deflection curve for material $E$ tested to failure. 
and tensile stress and the next to the highest value of stress/density ratio.

\section{Flexural Strain}

Strain gage tests were performed for beam specimens of microcellular foam material $\mathrm{D}$, and for rigid foam material $\mathrm{E}$. The purpose of these tests was to determine:

(1) Load-strain relationships for structural beam specimens under loading

(2) Bending tensile and compressive characteristics

(3) Poisson's ratio

(4) Location of neutral axis

(5) Hysteresis characteristics

(6) Agreement between computed and experimental stresses

Because the beam specimens were loaded almost to the failure point, these tests also provided valuable information on how these materials behave under high levels of shear force and bearing stress.

The specimens used to perform these tests were $3 / 4 \mathrm{in}$. by $3 / 4 \mathrm{in}$. by 15 inches beam specimens with a 12-inch gage length. The loading increments were applied at the location of 4 and 8 inches from the support (four-point loading). The type of strain gage used is EA13-250BF-350 ohm, Option W, with M-Bond AE-10/15 adhesive.

In addition to the strain gages, dial indicators were placed at the load application points in order to measure deflections under the loading points for cross checking purposes and modulus of elasticity computations. Figure 8 shows a photograph of an instrumented beam specimen, and figure 9 shows the beam specimen under test with light and heavy loads.

Material D. - The first strain gage bending tests were performed on the microcellular foam material D. Six strain gages were used with locations as indicated in figure 10. A maximum load of $\mathrm{P}_{\mathrm{L}}=\mathrm{P}_{\mathrm{R}}=17500$ grams was used, which corresponds to around 38 percent of ultimate strength. Some permanent deformation was observed after unloading, but the beam specimen regained very closely its initial undeformed status shortly after unloading. Most of the recovery took place during the first 30 minutes after unloading.

The strain gage readings in microinches per inch ( $\mu$ in./in.) for strain gages 1 to 6 are recorded in appendix B, and the load-strain curves for all strain gages are plotted in figure 11 (absolute values of strain). The variation of strain with load is very nearly linear. Strain gages 1 and 3 , which should give the same numerical value, do so within about 3 percent. The same applies for the pair of strain gages 2 and 4 and strain gages 5 and 6 . Such results are considered excellent in view of experimental inaccuracies and 


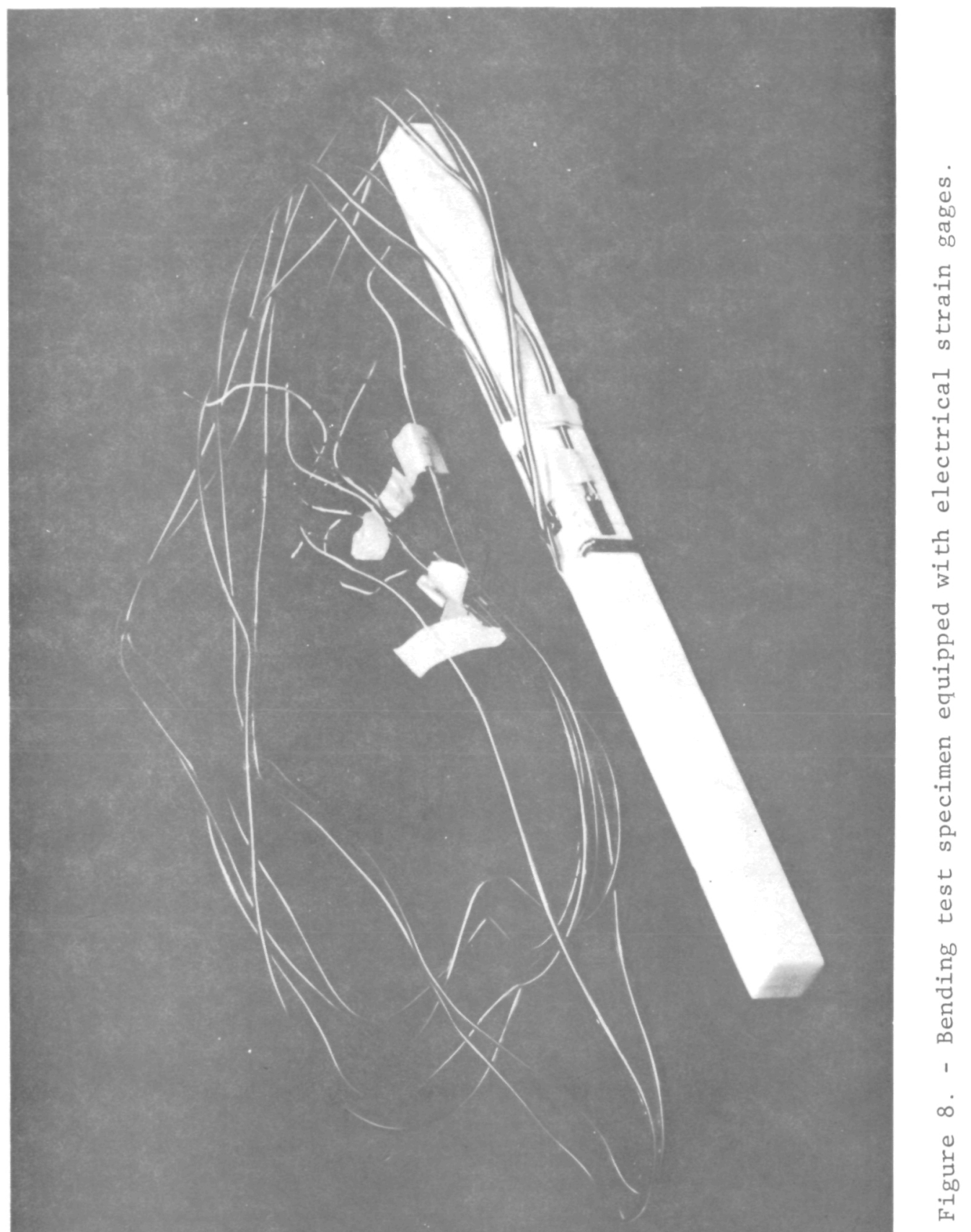




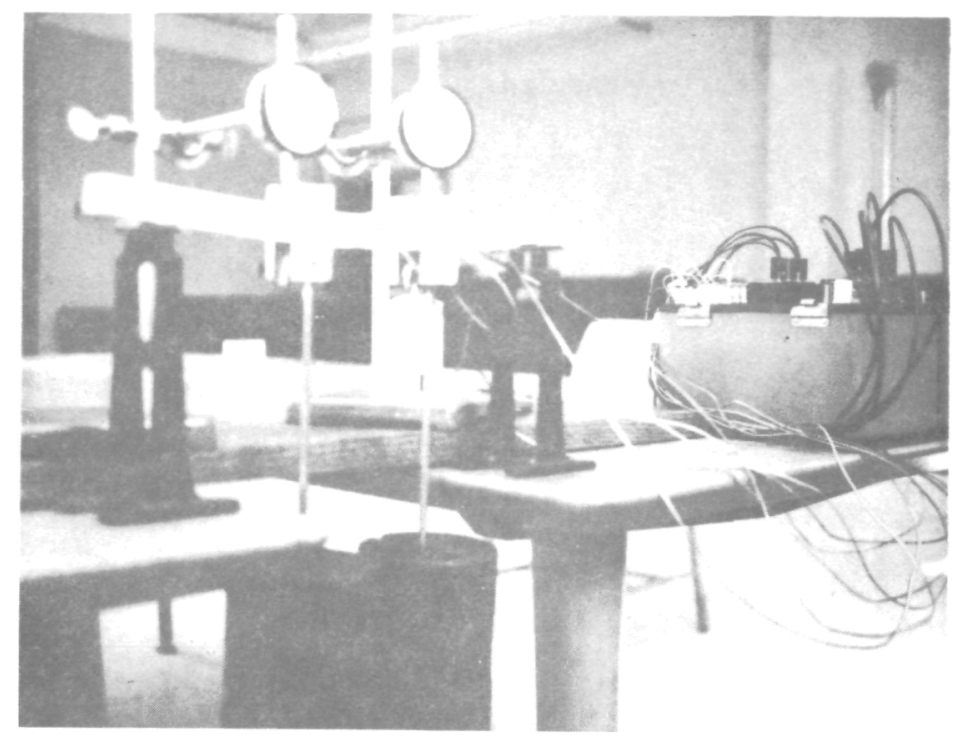

(a) Low loading.

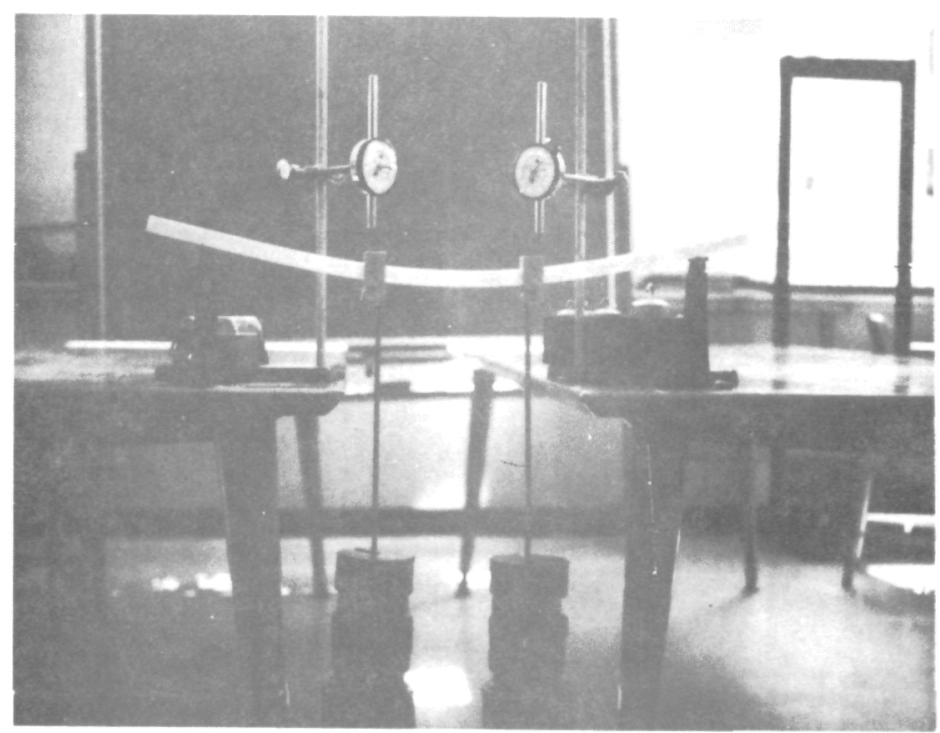

(b) High loading.

Figure 9. - Strain gage test of beam specimen. 
Specimen No.: D7-7556-93-3.1365 Sp.G. $=0.91$

Specimen dimensions: $3 / 4^{\prime \prime} \times 3 / 4^{\prime \prime} \times 15^{\prime \prime} 4$-pt. loading Number of strain gases: 6

Testing date: September 18, 1976

Gage length: $12 \mathrm{in}$.

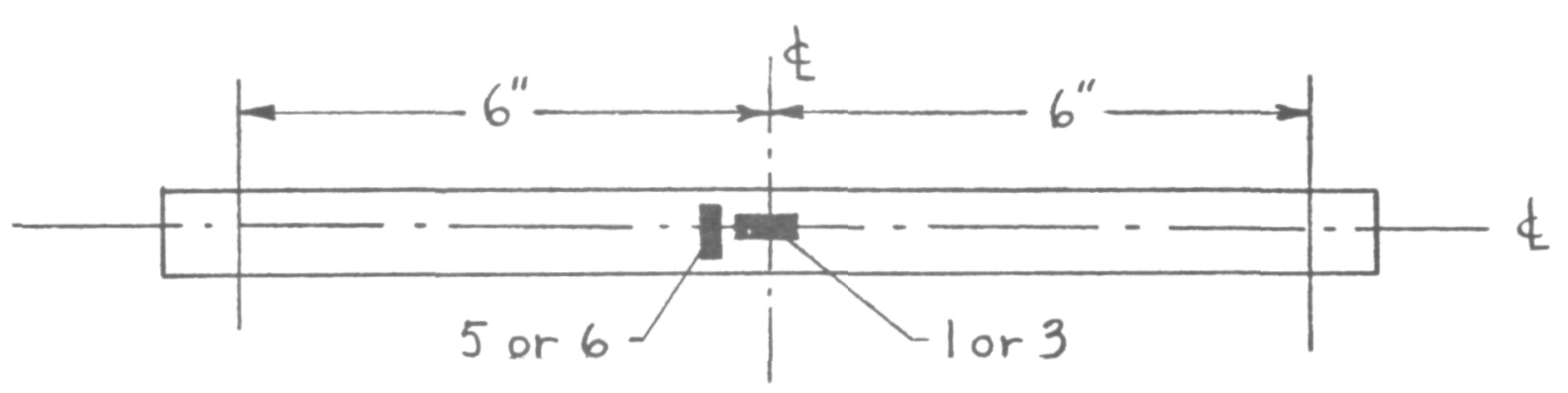

(a). Top or bottom.

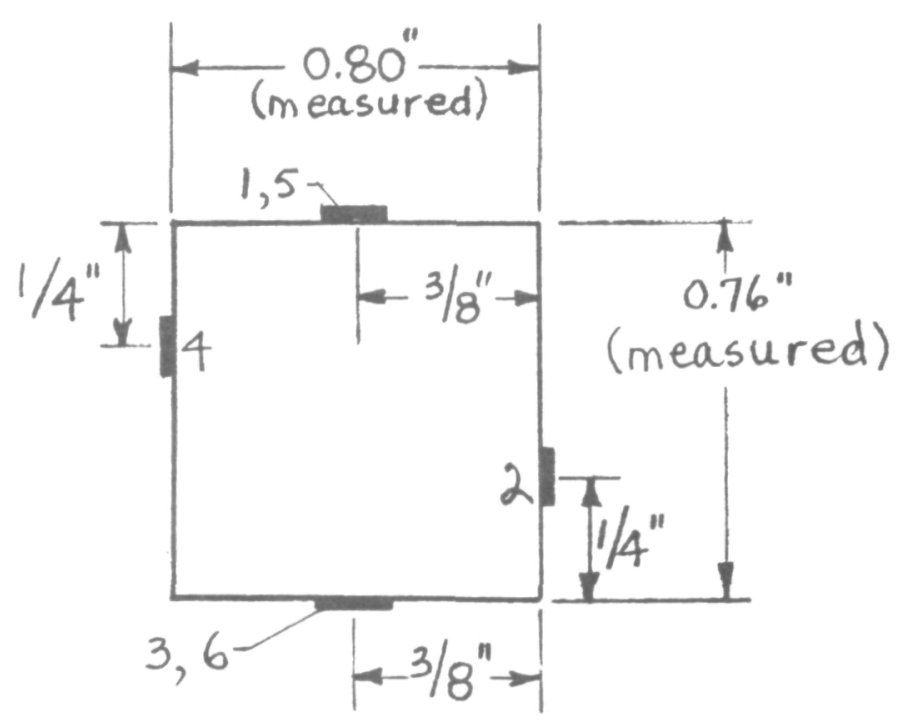

(b). Cross section at $\notin$.

Figure 10. - Strain gage setup for material D.

21 


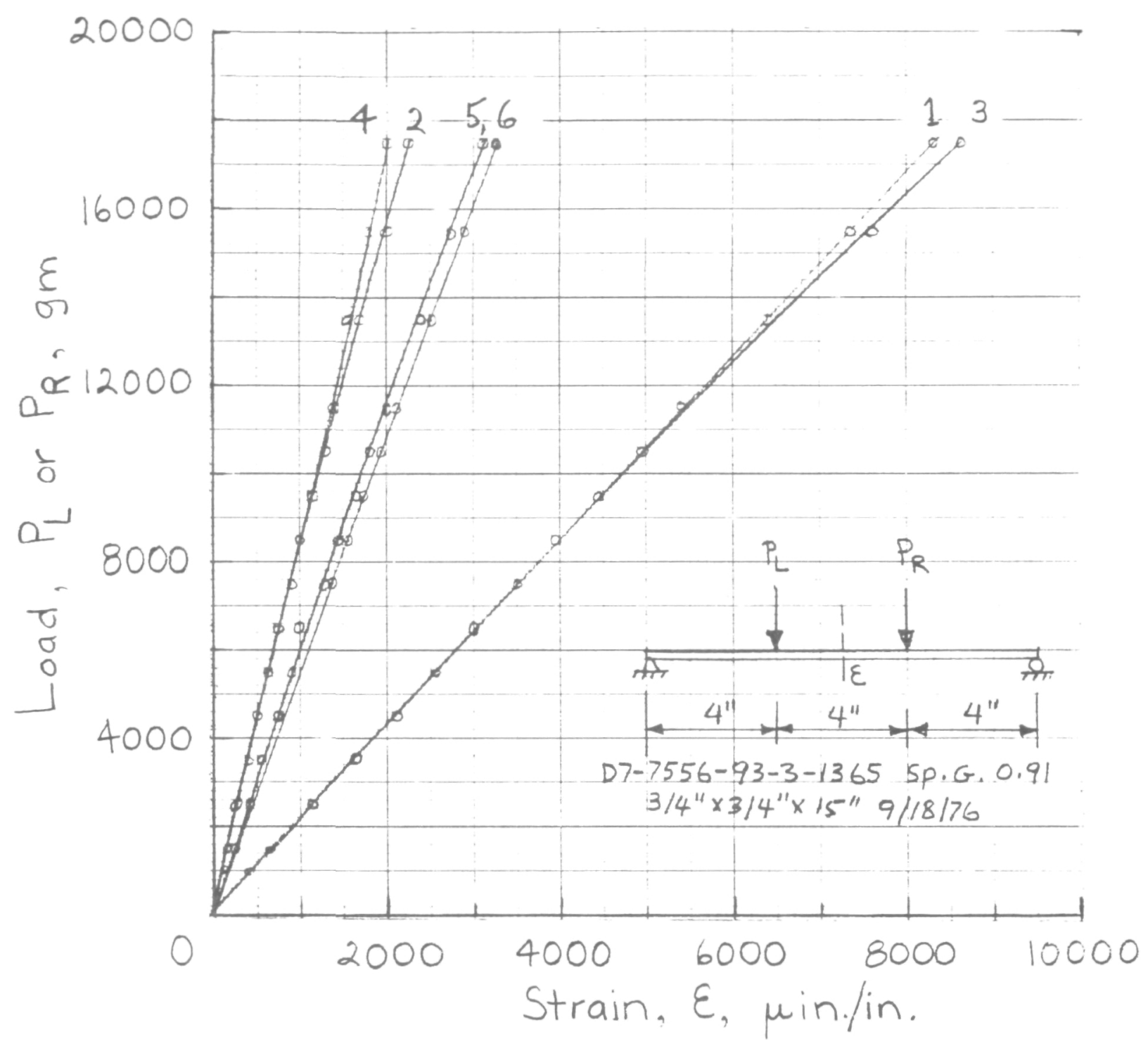

Figure 11. - Load-strain curves for strain gages for material $D$.

small differences in the cross sectional dimensions of the specimen.

The approximately equal numerical values of gages 1 and 3 , and gages 2 and 4 indicate that the neutral axis coincides with the centroidal axis of the cross section. This result is illustrated for the values of the maximum strains in appendix B.

The Poisson's ratio for material $D$ was determined by using the readings of strain gages 1 and 5 for compression, and the strain gage readings of strain gages 3 and 6 , for tension (table B2). The average value of the Pois- 
son's ratio for compression and for tension are given in table VIII. For compression, the Poisson's ratio values ranged between 0.388 and 0.396 , and for tension the values ranged between 0.357 and 0.366 . These values indicate good consistency of results.

\section{TABLE VIII. - MATERIAL PROPERTIES FROM FLEXURAL STRAIN TESTS}

\begin{tabular}{|l|c|r|}
\hline \multicolumn{1}{|c|}{ Property } & \multicolumn{2}{|c|}{ Material } \\
\cline { 2 - 3 } & D & \multicolumn{1}{|c|}{ E } \\
\hline Modulus, E, lb/in ${ }^{2} \times 10^{3}$ & 248 & 433 \\
Poisson 's ratio: & & \\
$\quad$ Compression & 0.393 & 0.366 \\
Tension & 0.362 & 0.364 \\
Maximum deflection, in. & 0.315 & 0.196 \\
Beam equation & 0.320 & $0.190 / 0.197$ \\
Measured & & \\
Maximum stress, 1b/in ${ }^{2}:$ & 2195 & 2383 \\
Beam equation & 2137 & 2350 \\
Strain equation & & \\
\hline
\end{tabular}

The modulus of elasticity $E$ for this specimen was calculated from the measured deflections (appendix B) and listed in table VIII. The value obtained is somewhat less than the value of 261000 psi determined in the earlier bending strength tests (table VI). The experimental value of modulus E, in conjunction with the experimental maximum strain value, was then used to compute maximum bending stress. The value of maximum stress was also computed by solving the beam problem for the maximum load. The results of the calculation (given in detail in appendix B) are listed in table VIII. Experimental and computed values of stress differ by only about 2 percent.

The deflection of the beam specimen at the maximum load was calculated by using the conjugate beam method and then compared to the measured deflections under the two loading points. Results of the calculation, detailed in appendix B, are shown in table VIII. The difference between the computed and experimental values of maximum deflection is also about 2 percent. Close agreement is expected, however, inasmuch as the modulus value used in the deflection equation was originally determined from the beam equation with measured values of deflection. The comparison agreement is basically a reflection of the agreement between the value of modulus at maximum loading and the average value (i.e., linearity of load-deflection curve).

Material E. - The rigid foam material E was also tested in bending by using six strain gages. The location of the six strain gages is shown in figure 12. Strain gages 3 and 5 and gages 1 and 6 were used to determine Poisson's ratios for tension and compression, respectively. Dial indicators were 
Specimen No.: E5-3-1406 SP.G. $=1.05$ Specimen Dimensions: 3/4" $\times 3 / 4^{\prime \prime} \times 15^{\prime \prime} 4$-pt Loading Number of Strain Gages : 6

Testing Date: November B, 1976 Gage length: 12 in.

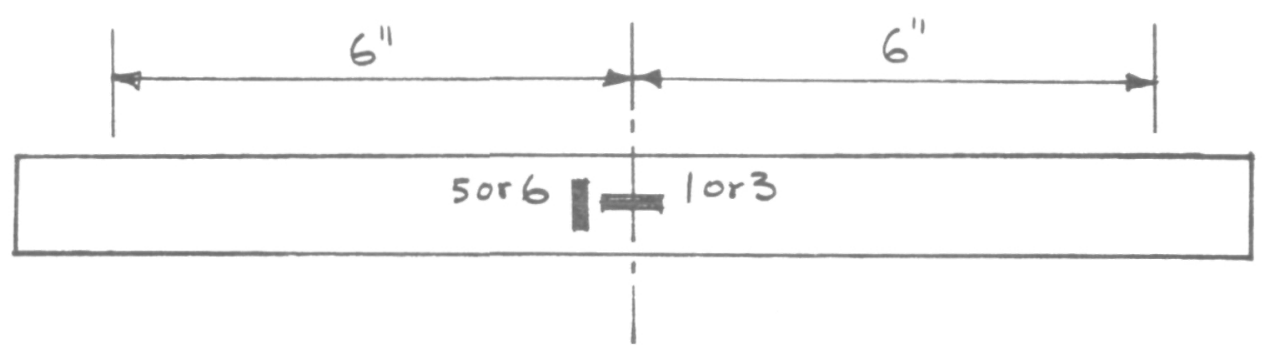

(a). TOP OR BOTTOM

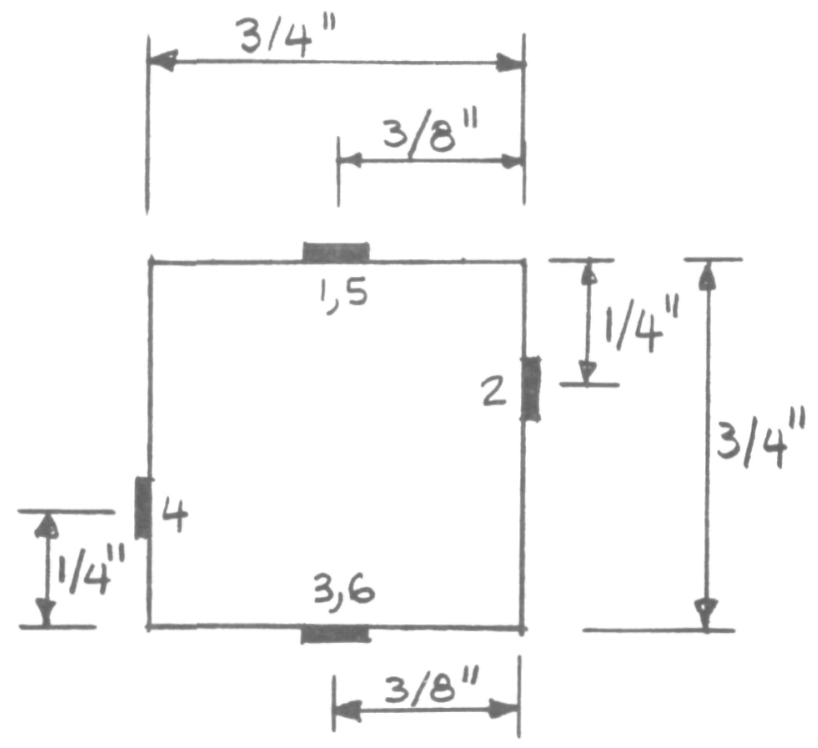

(b). CROSS SECTION

Figure 12.- Strain gage set-up for material $E$. 
also placed at the local application points in order to measure the deflection points for the same reasons as for material D. The maximum load applied to the beam at each load application point was 19000 grams for a total load of 38000 grams. This corresponds to a maximum tensile or compressive stress of 2383 psi. Measured values of deflection and strain resulting from the loading increments are given in appendix B.

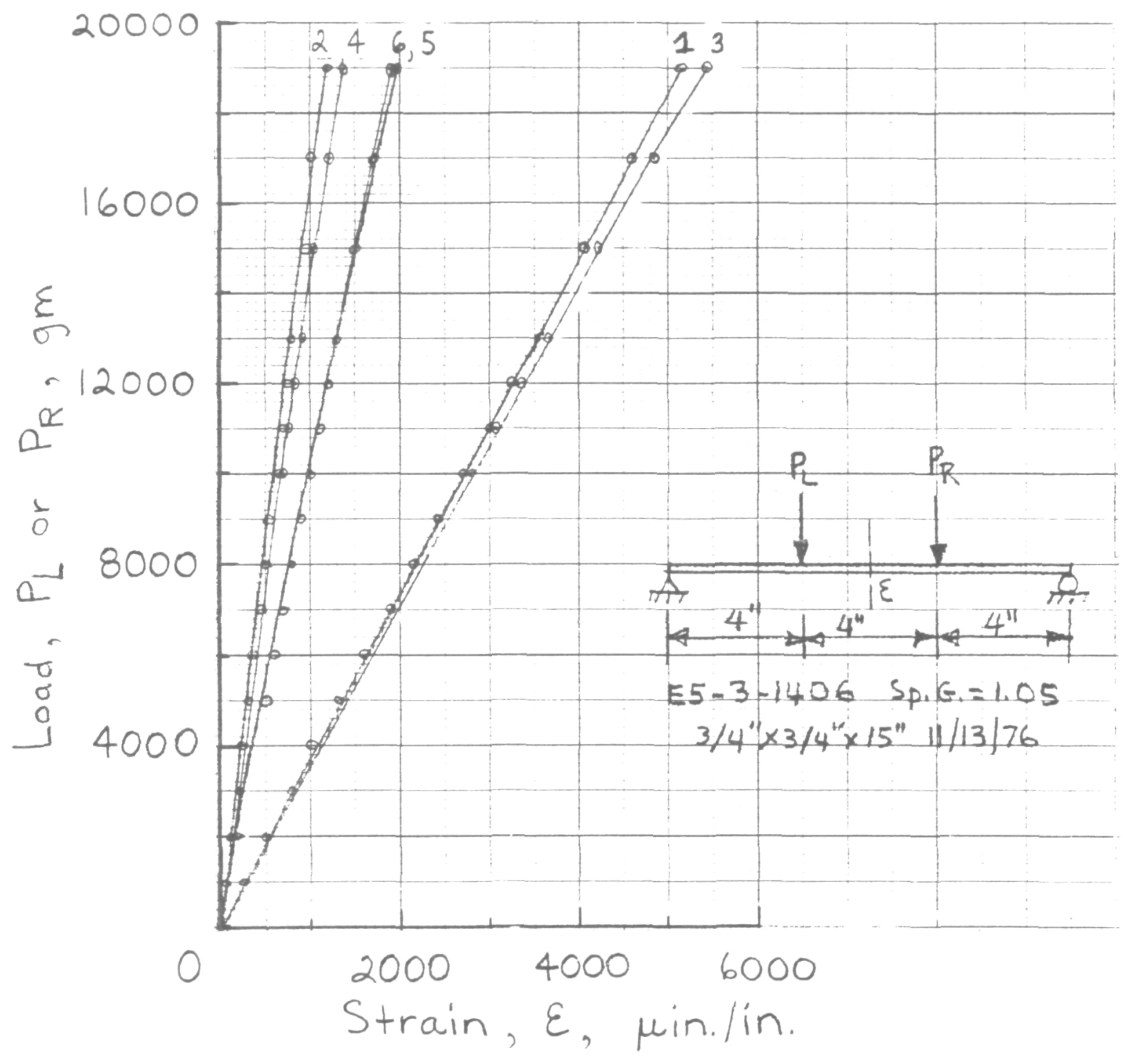

Figure 13. - Load-strain curves for strain gages 1 through 6 for material E.

The load-strain curves for all gages are plotted in figure 13. These curves are about linear for these levels of stress, just as it was for material D. Strain gages 1 and 3, for compression and tension, respectively, read nearly the same values, which indicates that the material performs 
equally well for tension and compression. Similar observations are made by examining the results from the pairs of strain gages 2 and 4 , and gages 5 and 6 . These results also indicate that the neutral axis of the beam specimen coincides with the centroidal axis of the cross sections.

The range of Poisson's ratio for compression was between the values 0.362 and 0.372 , and that for tension was between 0.360 and 0.367 , which indicates good consistency of results. Average values for material E are listed in table VIII.

As in the case of material D, comparison calculations of maximum bending stress and maximum deflection were made for material E. Maximum stress was computed from the beam equation and compared to the value obtained from the modulus and maximum strain. Maximum deflection was calculated from the conjugate beam method and compared to the measured value. Details of the calculations are given in appendix B, and results are listed in table VIII. Once again, as expected, there is good comparison between calculated and measured values. Also, the value of flexural modulus is reasonably close to the value determined earlier for material $\mathrm{E}$ in table VI.

After recovery from the 19000 gram loading, the beam specimen of material E was loaded gradually a second time to a maximum load of $\mathrm{P}_{\mathrm{L}}=\mathrm{P}_{\mathrm{R}}=38556$ grams $(85 \mathrm{lb})$ which is about 80 percent of the ultimate capacity of the specimen. After several days of recovery, the beam specimen was loaded for the third time up to 90 percent of ultimate load strength (90 1b). For this test, strain gage readings were obtained for both loading and unloading. Then, after several days of recovery, the loading of the specimen was repeated for the fourth time, again up to 90 percent of ultimate strength. Strain gage readings and load-strain curves for these tests are presented in appendix $B$.

The results of these tests of repeated loadings indicate essentially no change in the load-strain variations of the individual strain gages. The loading at higher levels produced an extention of the individual strain gage variations established in figure 13. A high degree of linearity was maintained for gages 1 and 3, and a tendency toward an increased rate of strain was observed for the other gages at the higher loadings.

Examination of data values indicates that the neutral axis coincides with the centroidal axis of the beam specimens. Comparisons of calculated bending stress obtained from the strain relation and from the flexure formula agree to within 4 percent at these higher levels of loading. Other properties of the material such as Poisson's ratio, shear strength, and bearing capacity are well in order at 90 percent of ultimate strength. No failures of any kind were observed in the material during or after loading, and the specimen appeared to recover rather well its initial shape shortly after unloading.

\section{Creep Resistance}

The four microcellular foams and the five rigid foams were tested for creep resistance by following the D674 and D2990 ASTM standards for plastics. 
Two types of creep tests are performed; bending creep and tensile creep. The purpose of these tests was to find out how much these materials deform under constant stress for long periods of time. Although creep may be negligible at low stress levels, it could create undesirable structural distortion in the course of time. Creep can occur at any temperature, but its rate depends upon the magnitude of the temperature and the level of stress. Since these tests are of a preliminary diagnostic nature only, they were performed at room temperature with various levels of stress.

Bending creep. - Bending creep tests were performed with $3 / 4$ in. by $3 / 4$ in. by 15 inches beam specimens with a gage length of 12 inches. Two test series were conducted. The first was a screening test of all nine materials at relatively short time duration (hours). The best material from this test was then evaluated over a much longer period of time (days). The screening bending creep tests for the nine materials were limited to about 240 to 300 minutes of constant load application. For these tests, two or three judiciously selected load or stress levels were used for each material. The vertical load was applied at the center of the gage length (three-point loading) at specified intervals of time for each specified bending stress level.

Material B, for example, was subjected to three constant loads of time durations 270, 240, and 210 minutes. The magnitude of the first load was 6000 grams which corresponds to a calculated maximum bending stress of 564 psi; the second was 8000 grams producing a calculated stress of 753 psi; and the third was 14000 grams with a calculated bending stress of 1317 psi. The deflections $\Delta$ at the center of the specimen were recorded every 10 minutes as shown in appendix $\mathrm{C}$. The loading of the specimens as well as the unloading was gradual. The deflection against time graphs are shown in figure 14. These plots show that creep rate is much higher during the first hour, with decreasing values thereafter. The figure also shows that higher stress levels produce higher values of bending creep. Theoretically, these results follow in principle those observed in metals that are commonly used as structural materials, except that the stress levels for equivalent amounts of creep are much higher.

When the specimens were unloaded gradually to zero, a certain amount of permanent deformation was left in the material. However, this permanent deformation is not really permanent. The tests showed that the deformation is recovered almost completely in time. Almost 80 percent of the permanent deformation was recovered during the first 20 to 30 minutes after unloading, because the recovery rate is very high during this interval of time. Additional testing however, is needed to accurately establish the pattern of recovery.

The bending creep $\left(\Delta-\Delta_{0}\right)$ for materials $A, B, C$, and $D$ are shown plotted in figure 15(a). Materials $A$ and $D$ are microcellular foams and materials $B$ and $C$ are rigid foams. The bending creep for rigid foam materials E, F, and $G$ are shown in figure 15(b). For these materials, loads of 14000 grams corresponding to a calculated maximum bending stress of 1317 psi, and 24000 grams producing a calculated bending stress of 2258 psi were applied. The bending creep variation for material GG was about the same as that of material G (slightly less resistance), and therefore, it is not included in the plot. Materials $G$ and GG are about the same materials, the 


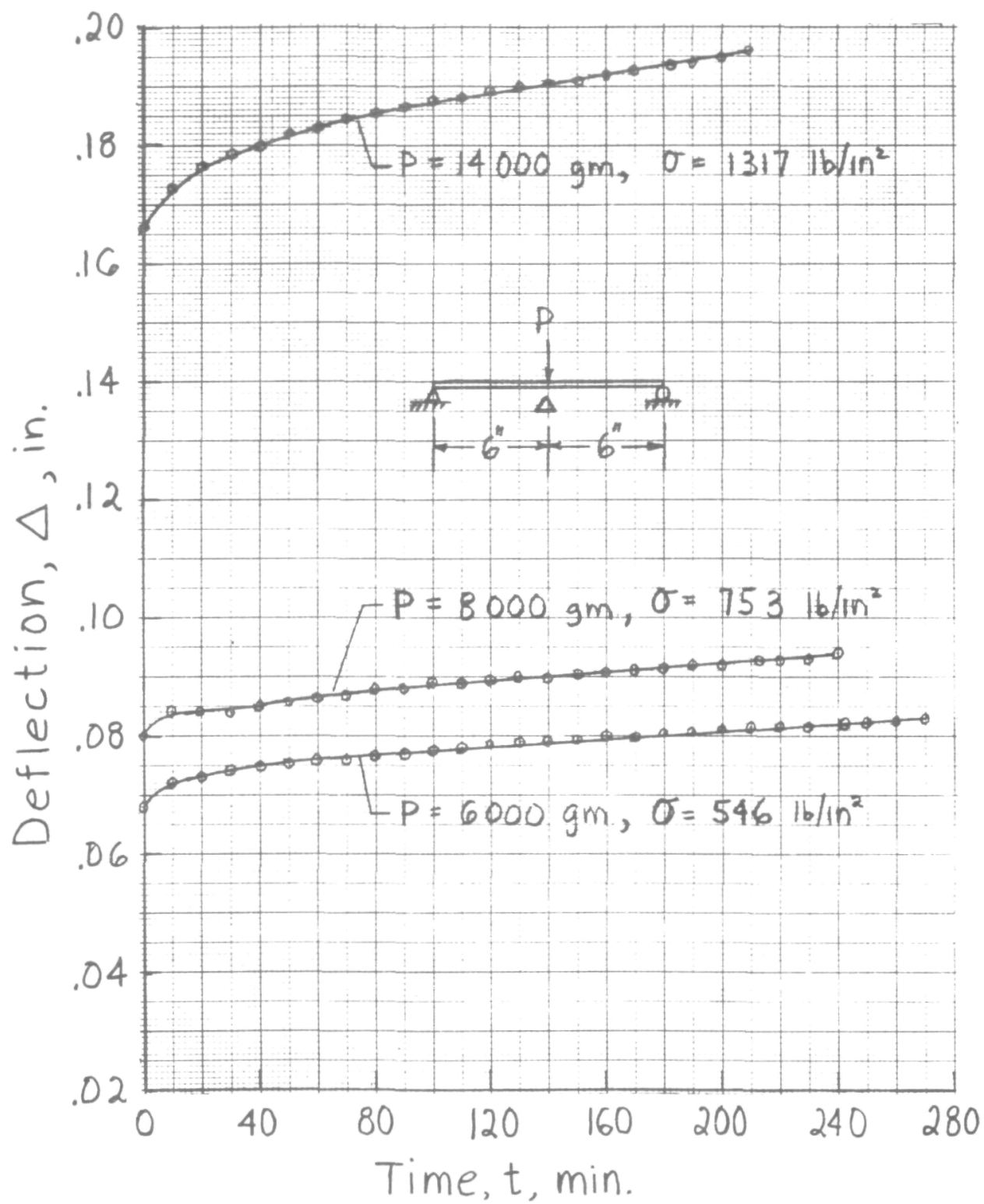

Figure 14.- Deflection variation for creep test of material $B$. 


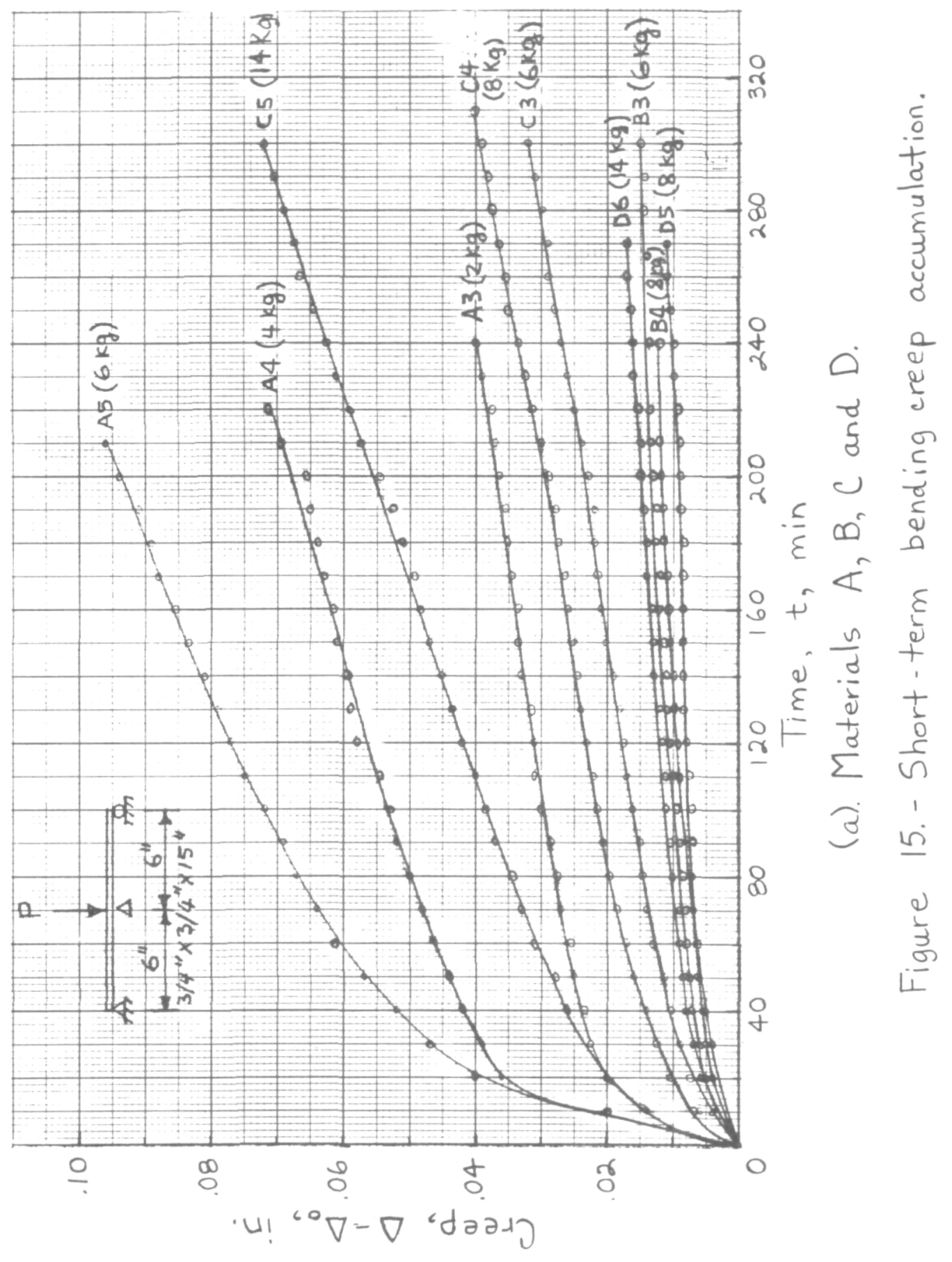




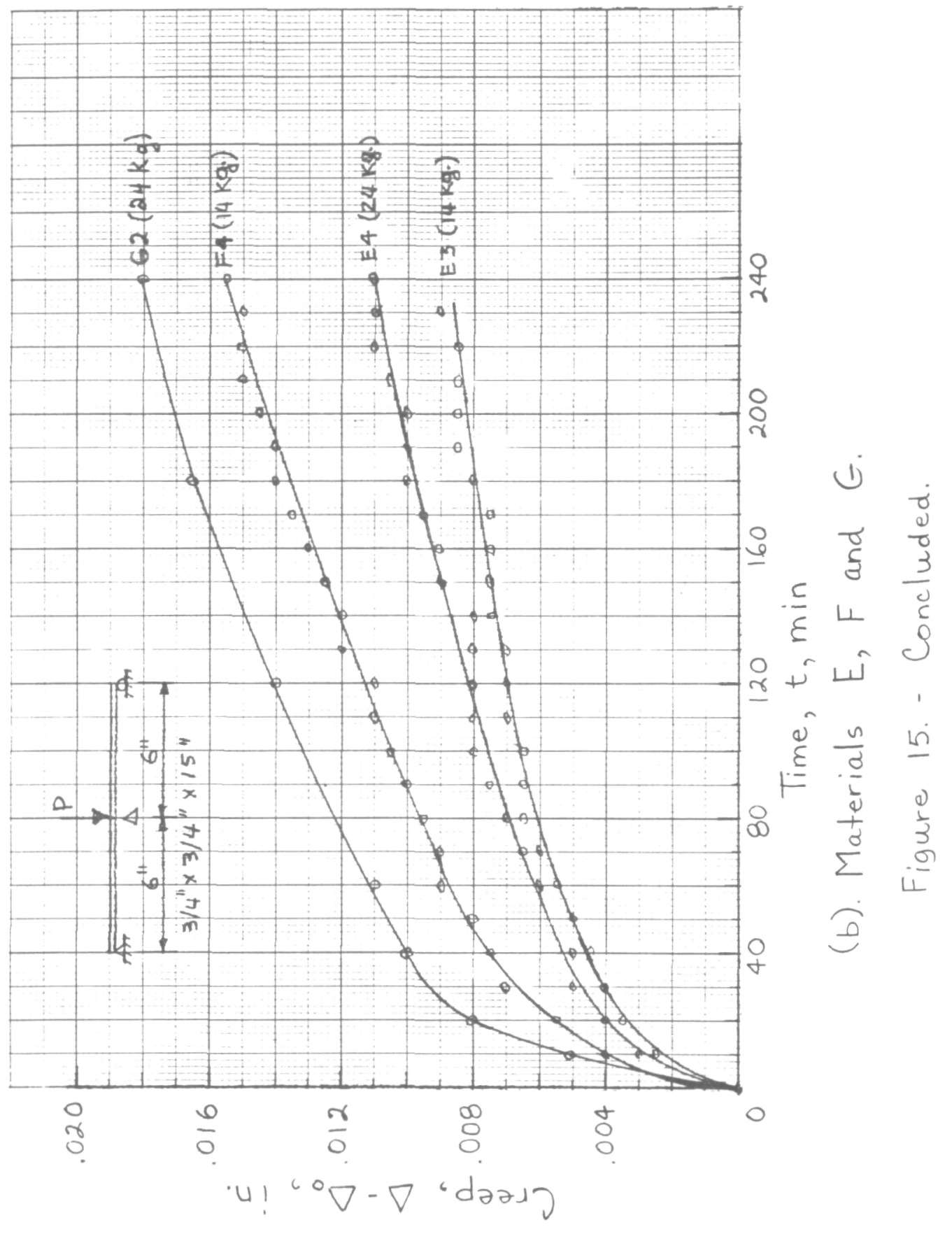




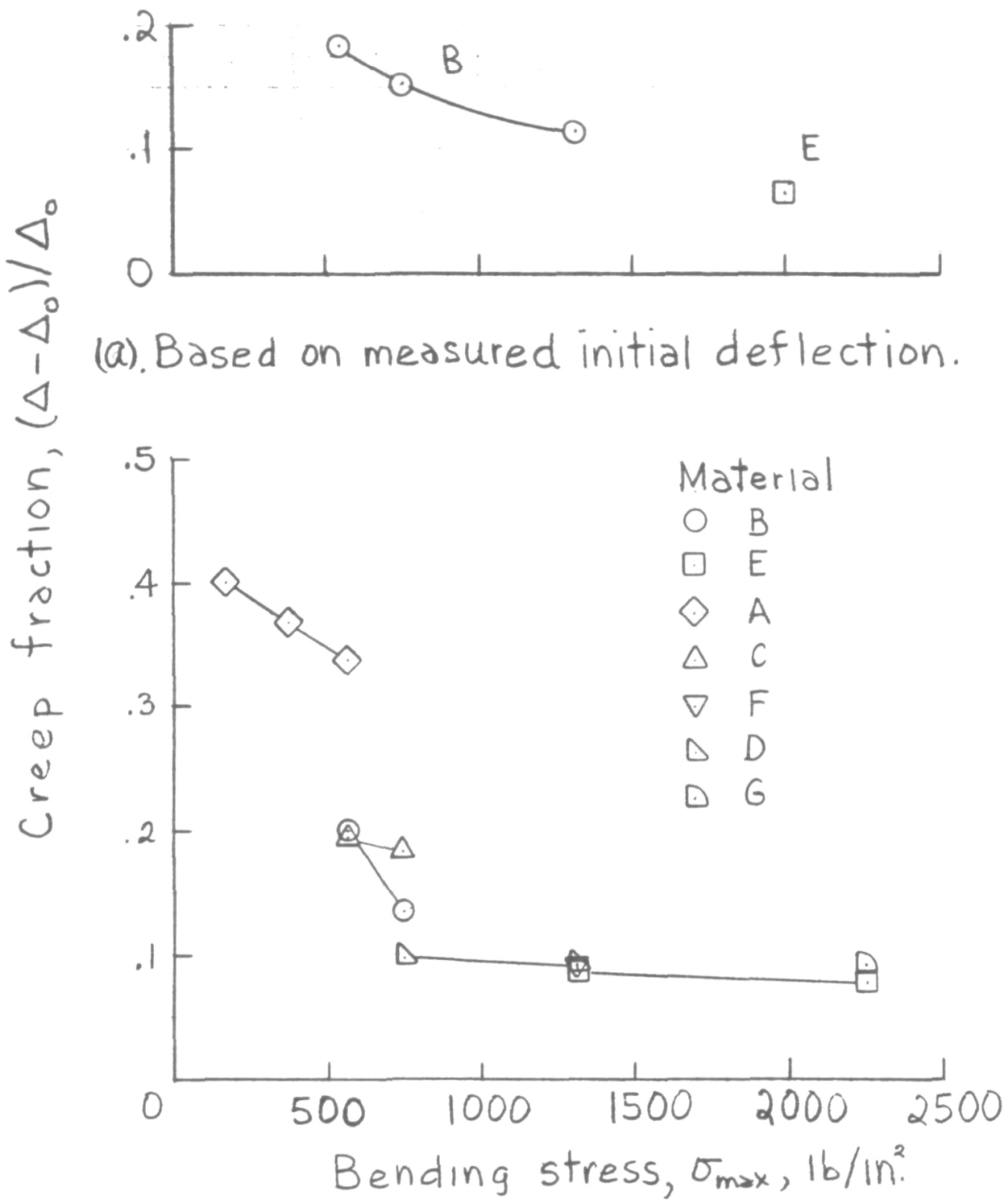

(b). Based on calculated initial deflection.

Figure 16:- Bending creep fraction at 200 minutes. 
difference being primarily in the curing or stress relief process.

On the basis of the least amount of creep, figure 15 shows that materials $E$ and $G$ are the best (material GG is also as good as G). Another comparison can be made on the basis of the fractional increase in elongation over the initial value of deflection caused by the applied load. The variation of this parameter $\left(\Delta-\Delta_{0}\right) / \Delta_{0}$ at 200 minutes with calculated bending stress is shown in figure 16 for the materials tested. Values of fractional creep in figure 16(a) were obtained from measured initial deflections $\Delta_{0}$ presented in appendix $C$, and in figure 16(b) they were obtained from initial deflections calculated from the beam equation.

Figure 16 shows that the creep fraction for these materials tends to decrease with increasing stress levels, and that materials D, E, F, and G produce the lowest values. Inasmuch as material $E$ also has the best values of modulus and ultimate tensile stress (table VI), it was selected for the long-duration creep test.

For the long-duration bending creep test performed on material E, the beam specimen was loaded at the center of the gage length by a constant load of 21000 grams for 60 days, that is, 1440 hours. This load corresponds to a constant calculated maximum bending stress of 2000 psi applied to the beam specimen. The purpose of selecting the maximum bending stress of 2000 psi for this test is to find out how well this material resists bending creep if this stress is selected as the design stress.

The values of the measured deflections $\Delta$ and the bending creep $\Delta-\Delta_{0}$ for each time interval are tabulated in appendix C. A plot of the bending creep is shown in figure 17. This plot shows that the highest creep rate occurs during the first few days. The rate of creep slows gradually until

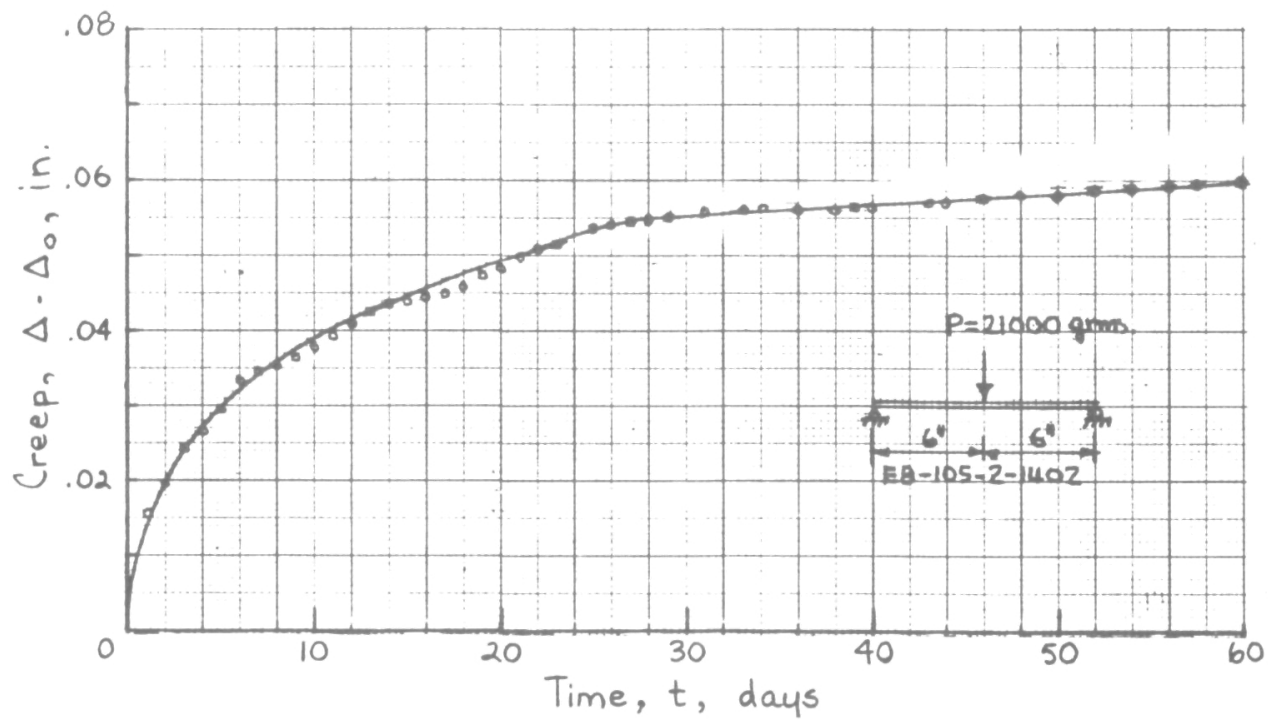

Figure 17. - Long-term bending creep for material E. 
around 26 days. From there on the curve shows a very small and essentially constant increase in creep. These results are similar to those observed in structural metal materials such as structural steel.

The experimental values of the bending creep during the time interval between 16 and 32 days indicate that the curve is somewhat wavy within this interval. This small abnormality is attributed to the appreciable changes in room temperature during the night hours due to energy conservation policies adopted by the test laboratory. The temperatures indicated in the table are the room temperatures during the day and at the time deflections were recorded.

The above results indicate that the total deflection due to bending creep during the 60 days is 0.06 inch. This is about 40 percent of the initial deflection of 0.1435 inch at zero time due to the $21000-$ gram load, and only about 4 percent of the amount the beam specimen will deflect if it is loaded to failure (test results indicate that the beam specimen will deflect 1.4 inch when the load is gradually increased until the beam specimen fails).

Tensile creep. - The tensile creep tests were performed with standard 0.5 inch round specimens which were prepared in accordance with the requirements set by the D2990 ASTM standards. The ends of the specimen were threaded so that it could be connected to the Baldwin Testing Machine for tension loading. Figure 18 is a photograph of a specimen in the tensile creep test setup.

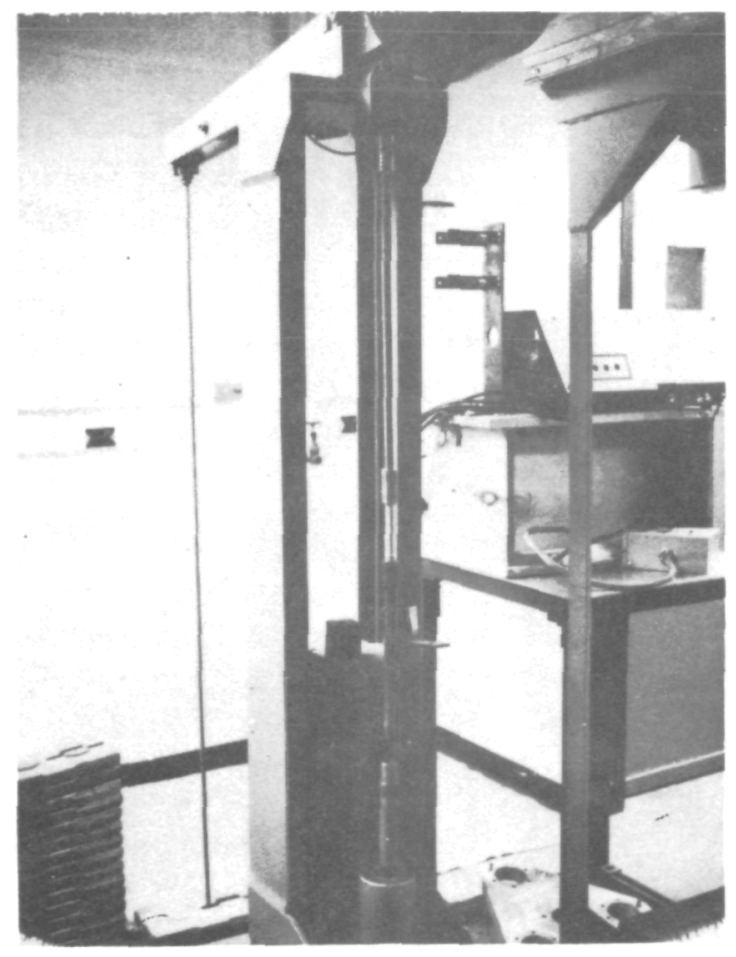

Figure 18. - Tensile creep test apparatus. 
Material GG, which is a rigid foam material, was selected for the tension creep test. A load of 20 pounds was placed on the testing machine which produced an equivalent axial tensile load on the specimen equal to 420 pounds which corresponds to a stress of 2140 psi. The specimen was subjected to this stress continuously for 35 days. A gage length of 1.934 inches was selected, and the changes of this length during the 35 day interval were recorded. The tension creep deflections and accumulations for material GG are tabulated in appendix C. The plot of these accumulations against time is shown in figure 19.

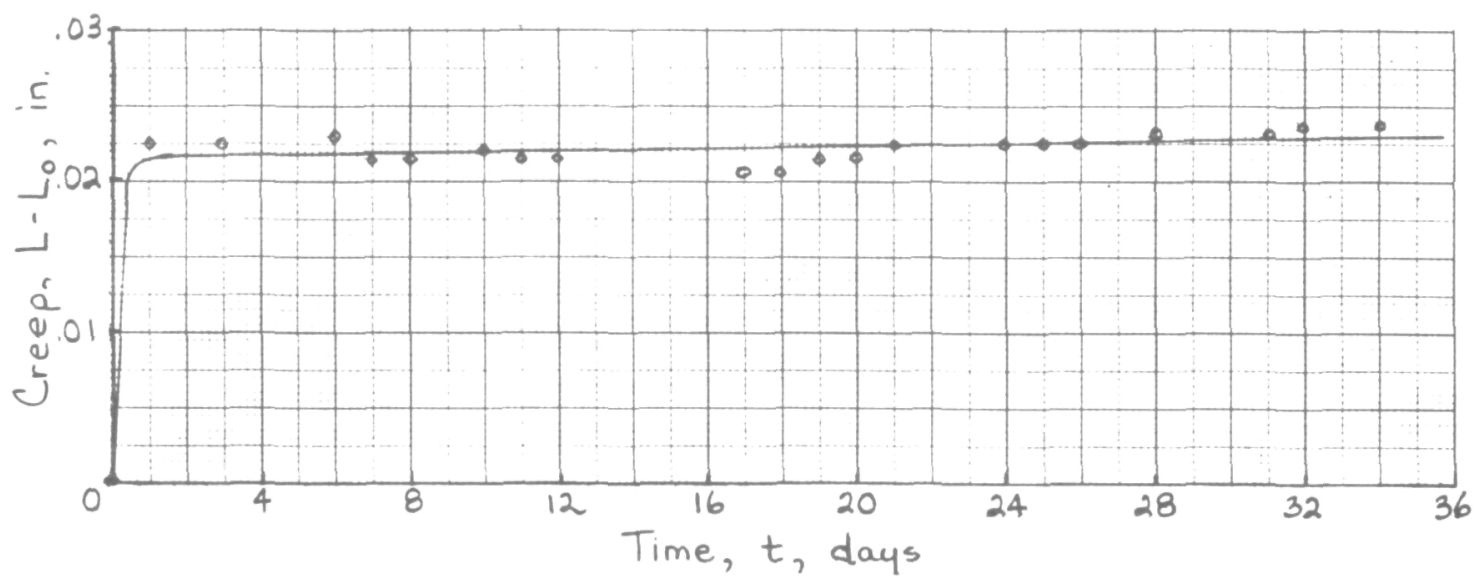

Figure 19. - Tension creep for material GG.

Figure 19 indicates that almost all of the creep occurs during the first 24 hours of loading. After the first day, the curve is practically horizontal, which means that the creep is essentially constant and the creep rate is practically zero. The small variations of the experimental values of the creep during the flat portion of the curve are attributed practically to the temperature variations of the laboratory between day and night previously mentioned.

The results up to this point indicate that the creep data for material GG (and presumably for material E) follow acceptable patterns. Since these tests are exploratory in nature in order to define if urethanes can be used as a potential wind blade material, additional tests are needed to accurately define the acceptable levels of creep that can be used in the design of wind turbine blades. Also it should be taken into consideration that a design would most likely require that the blade or part of it be constructed of reinforced urethane. Further resistance to creep would be provided in that case.

\section{Fatigue Strength}

The materials of rotating wind turbine rotor blades are expected to be subjected to repeated stress of various magnitudes resulting from the aerodynamic, gravity, and centrifugal forces acting on the blade. These effects can be flexural, torsional, plain tension, or some combination of all three. It is, therefore, important to determine how urethane materials resist deteri- 
oration resulting from repeated stress.

The urethane materials tested for fatigue strength are the rigid foam GG and the microcellular foam $\mathrm{H}$. Since the nature of this investigation is diagnostic, this fatigue property was evaluated by performing a limited number of tension fatigue tests at room temperature. The specimen used is the same type as the ones used for the temperature tests. The thickness for the fatigue specimens, however, is somewhat larger ( $3 / 8 \mathrm{in.}$ ), the gage length is the same (3 in.), and the width is either 2 or 1.5 inches. The overall length of the specimen is 12 inches. A photograph of the specimen in the CGS test machine is shown in figure 20.

Specimen eccentricity during the conduct of these tests did not exceed 0.005 inch. Slight eccentricity of axial load can cause serious flexural stresses on the loaded specimens which can cause the specimens to fail much sooner than when prefectly alined.

The rigid foam material GG was tested first by applying repeated tension stress levels of 2200, 1500, and 1000 psi. The fatigue tensile load was applied by the CGS closed loop hydraulic machine at a speed of 5 and 10 cycles per second. The specimen tested at the repeated tensile stress of 2200 psi was left on the CGS machine until it reached 2 million cycles. At the 2-million mark, the specimen was taken out of the machine and examined. No visible sign of any kind of failure was observed. However, in view of the in-

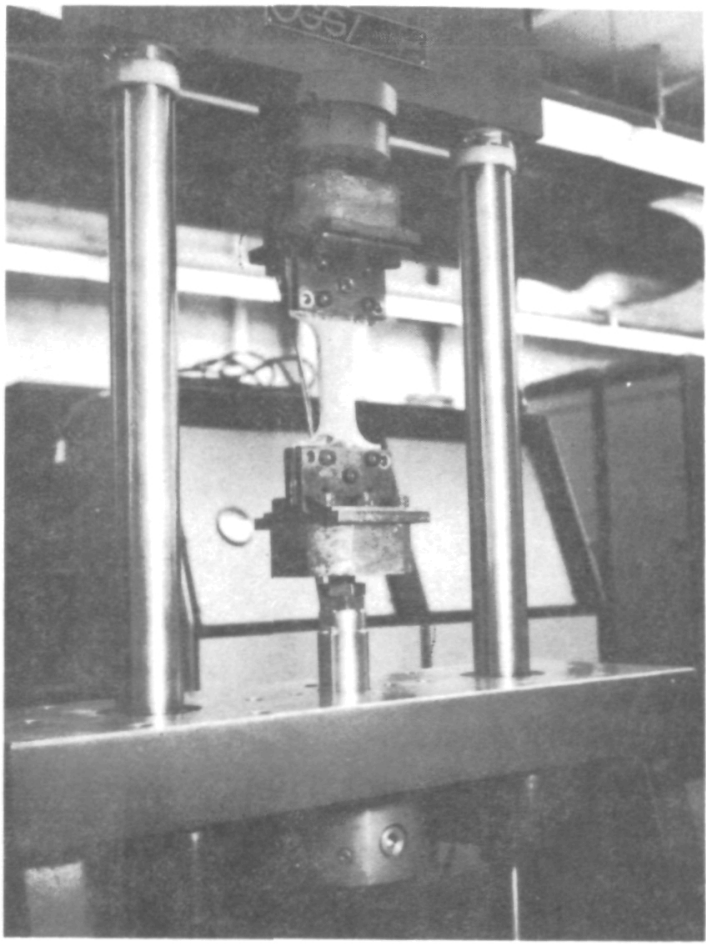

Figure 20. - Tensile fatigue test setup. 
dicated design life for wind turbine blades of the order of 20 to 100 million cycles, the extended fatigue life of the urethanes will have to be demonstrated by further testing.

Due to some changes introduced in the cure process during the preparation of the specimens, a number of these specimens exhibited imperfections in the form of circular or eliptical holes of various size inside the material. These types of imperfections were not observed in other batches of the same or similar rigid foam materials during the performance of other tests. Although such imperfections can be eliminated in a practical application, it was decided to investigate any potential deliterious effect of this factor on fatigue strength.

A specimen tested at a repeated tensile stress of 1000 psi and a speed of 5 cycles per second, had a sizeable eliptical hole in its $3 / 8$ inch thickness with a major axis of 0.10 inch and a minor axis of 0.05 inch. This specimen broke at the eliptical imperfection after 755900 cycles of stress were completed. Another specimen tested at a repeated stress of 1500 psi and a speed of 5 cycles per second had three small circular imperfections, about 0.03 inch in dianeter. This specimen also broke at the circular imperfections after it completed 729000 stress cycles. Additional tests showed that larger imperfections produced further reductions in the fatigue resistance of rigid foam materials. The conclusion from these limited tests is that rigid foam materials may have acceptable fatigue properties as long as serious material imperfections can be eliminated.

The microcellular foam material $\mathrm{H}$ was also tested to some extent for fatigue resistance. The specimen was subjected to a repeated tensile stress of 1500 psi at the speed of 12 cycles per second. The specimen was left in the CGS machine until 1 million cycles of stress were completed. After the specimen was taken out of the machine and examined, no visual signs of any kind of failure were observed. No visual signs of any kind of imperfections inside this material were observed during all tests performed on this material. Thus, microcellular foam as well as rigid foam may have acceptable fatigue properties over the life ranges tested.

\section{MODEL BLADE SECTION TESTS}

The second phase of the program involved the design, construction, and testing of a large-scale urethane blade section. The purpose was to demonstrate the fabrication techniques, and to obtain the structural capabilities of urethane in a realistic rotor blade configuration. Three model blade sections were cast for testing. The results of such large-scale model blade tests could then be used as inputs to an analysis of a full-scale blade design to be covered in a succeeding section.

Design

The 23000 series airfoils are of ten used for wind turbine rotor blade 
shapes. Thus, this profile was considered for the test models. In order to keep the costs at a minimum and still obtain realistic values, a symmetrical airfoil with approximately the same distribution of cross-sectional area as the 23000 airfoil series was selected. Thus, only one mold need be used for both the top and bottom surface. Figure 21 illustrates how closely a symmetrical configuration (0012) matches an actual airfoil section (23012) for a representative profile of 12 percent maximum thickness.

Examination of the blade developed for the 125-foot-diameter MOD-0 system (ref. 2) indicated that a chord length of 30 inches and a maximum thickness ratio of approximately 15 percent would be representative of a cross section at 80 percent of the radius from the hub on the existing full-scale blade. For the purpose of this program, a test section approximately 7-foot-long with a chord length of 30 inches was selected. The test section length was selected so that it would be large enough to get realistic values and yet could be made using existing mixing equipment. The coordinates of a symmetrical 15 percent thick (0015) airfoil section of 30-inch chord length are given in table IX. Once the surface configuration was established, tooling for the test section was initiated. The physical properties of the blade from then on were a function of the design of the interior part of the mold.

The selected cross-sectional shape for the blade model is shown in figure 22(a). A two-spar type of hollow arrangement was used to provide stiffness and sufficient surface area to bond the two halves together. A total contact area of approximately 750 square inches were provided for this purpose.

\section{TABLE IX. - COORDINATES OF 0015 AIRFOIL SECTION}

[Leading edge radius, 1.975 in., nominal chord length, 30 in.] "X" o of

Chord

$\begin{array}{rl}0 & 0 \\ 1.25 & .375 \\ 2.50 & .750 \\ 5.00 & 1.500 \\ 7.50 & 2.25 \\ 10.00 & 3.00 \\ 15.00 & 4.50 \\ 20 & 6.00 \\ 25 & 7.50 \\ 30 & 9.00 \\ 40 & 12 \\ 50 & 15 \\ 60 & 18 \\ 70 & 21 \\ 80 & 24 \\ 90 & 27 \\ 95 & 28.5 \\ 00 & 30\end{array}$

\section{"Y" 응 Chord}

0

2.368

3.269

4.444

5.250

5.854

6.681

7.173

7.426

7.503

7. 254

6.618

5.704

4.580

3. 279

1.810

1.009

0
"Y" Inches

0

0.7104

0.9807

1. 332

1. 575

1. 756

2.004

2. 152

2. 228

2. 251

2.176

1.985

1. 711

1. 374

0.984

0.543

0.303

0 

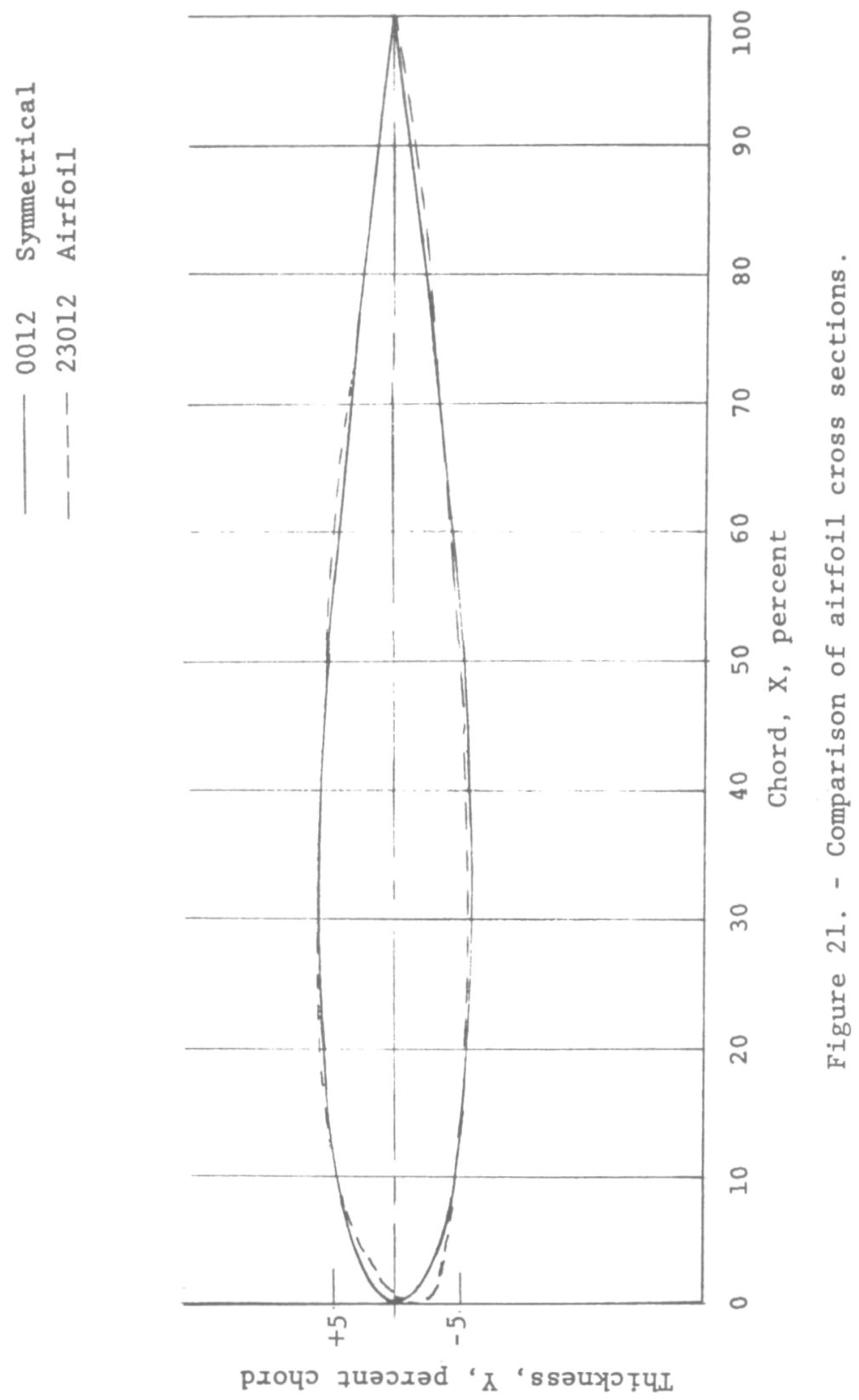

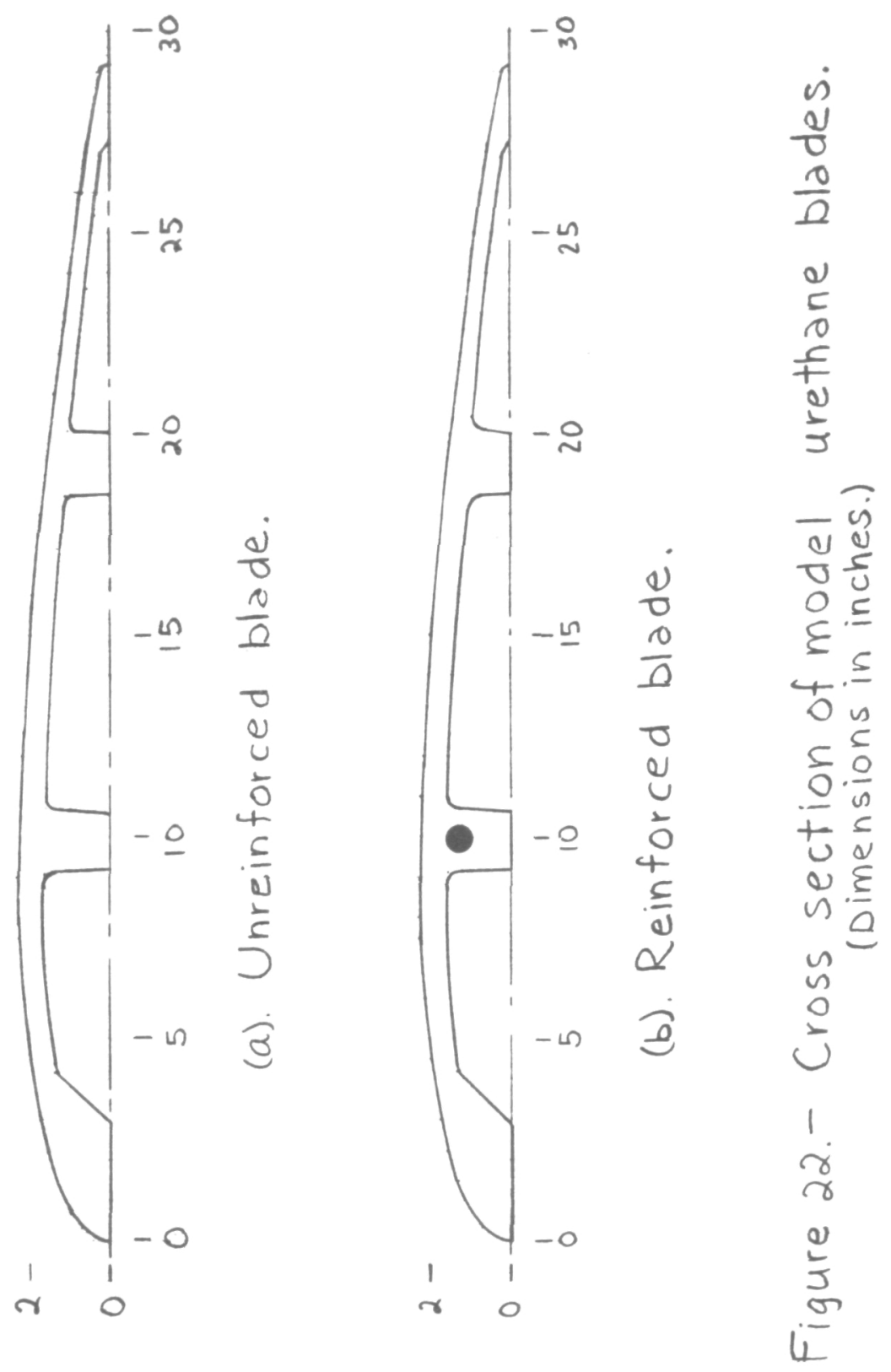
The skin thickness varied from 5/8-inch in the forward part of the blade to $3 / 8$ inch at the trailing edge.

In order to analytically determine the moment resisting capability of the model blade, the section was divided into 19 chordwise segments. The actual blade thickness in each segment was then approximated by a rectangular element, and the total area and moment of inertia of the blade was then obtained from the sums of the individual segments. Details of the calculation are given in appendix D.

The calculated values of section modulus and cross section area allowed calculation of the moment resisting capability and weight/foot of span of the blade. These are illustrated in figure 23. The moment resistance is shown for a design bending stress range of 1000 to 4000 pounds per square inch, and the weight is shown for densities corresponding to specific gravities from around 0.80 to 1.2 . Thus, for a urethane material with a design bending stress of 2000 pounds per square inch and a density of 65 pounds per cubic foot, the blade section moment resistance is 56600 in-1b, and the weight per foot of span is 20.43 pounds per foot.

The model blade section thus designed had its weight distributed about the 31 percent chord point. To determine if the section could support the same bending moment with its weight further toward the nose, a redistributed profile was examined. For the same total area, the new distribution produced a section modulus within less than 5 percent of the original configuration with a shift in center of weight from the 31 percent chord position to about the 27 percent point.

Since the earlier property tests indicated that metal reinforcement would be required to increase the load-carrying capability of urethane, a second model blade test section was designed for the inclusion of two 5/8-inchdiameter standard reinforcement rods. These bars were to be placed about $1 \frac{1}{4}$ inch from the centerline at approximately one third of the chord from the nose, as shown in figure 22(b). No attempt was made to obtain any specified value of stiffening with the rods.

\section{Fabrication}

The urethane blade test section was cast in a single mold as two separate halves that were then bonded together to form the complete blade section. A photograph of the mold and the urethane injection head located at the base of the mold is shown in figure 24. The inside surface of the urethane is shown in figure 25, and the removed half section is shown in figure 26. The completed blade section after bonding of the two halves is shown in figure 27 . Adhesive number 7556-136-1A was utilized for the bond. After bonding, the blade section surface was filled and painted.

The material used to make the test blade section was microcellular foam material $\mathrm{H}$. This urethane formulation has a modulus of $231 \times 10^{3}$ pounds per 


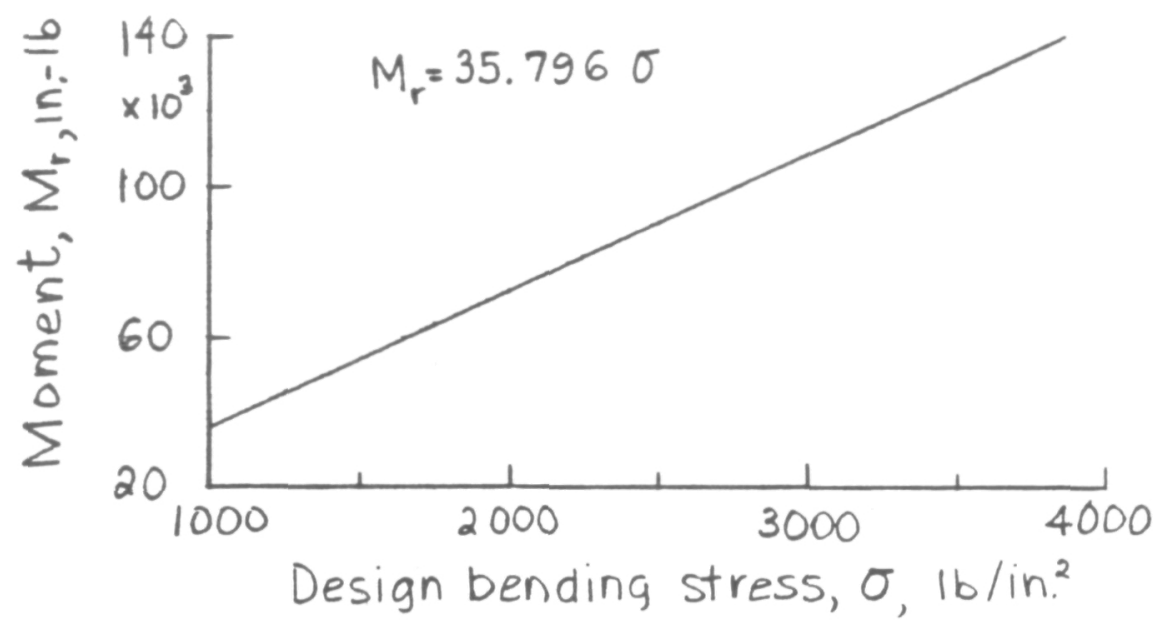

(a) Moment resistance.

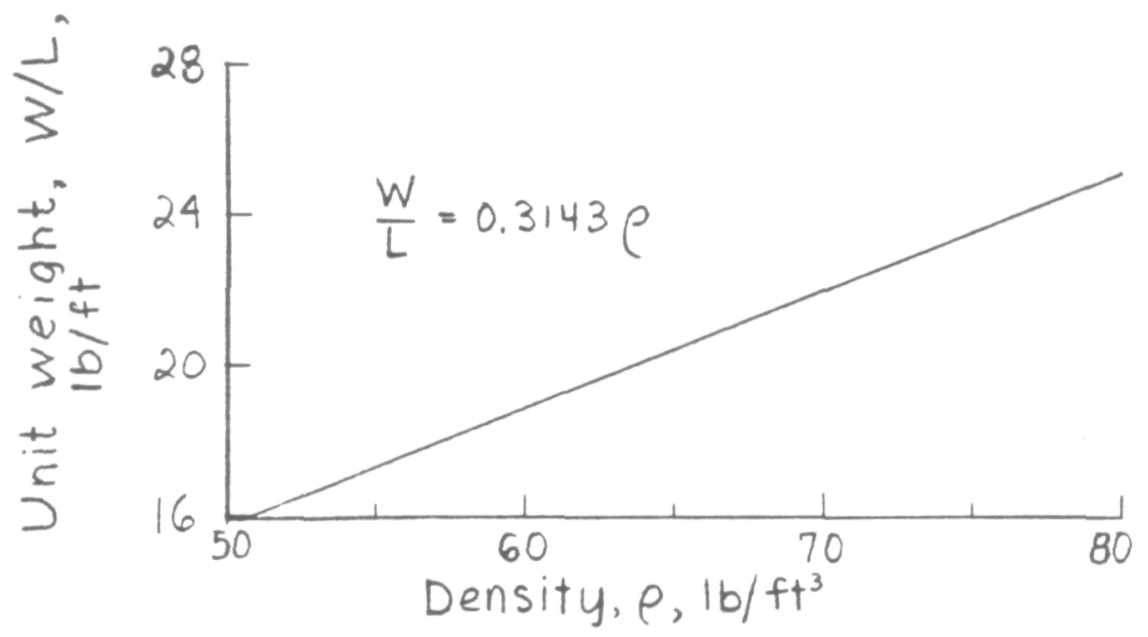

(b). Weight

Figure 23.- Calculated properties of model blade section of unreinforced urethane. 


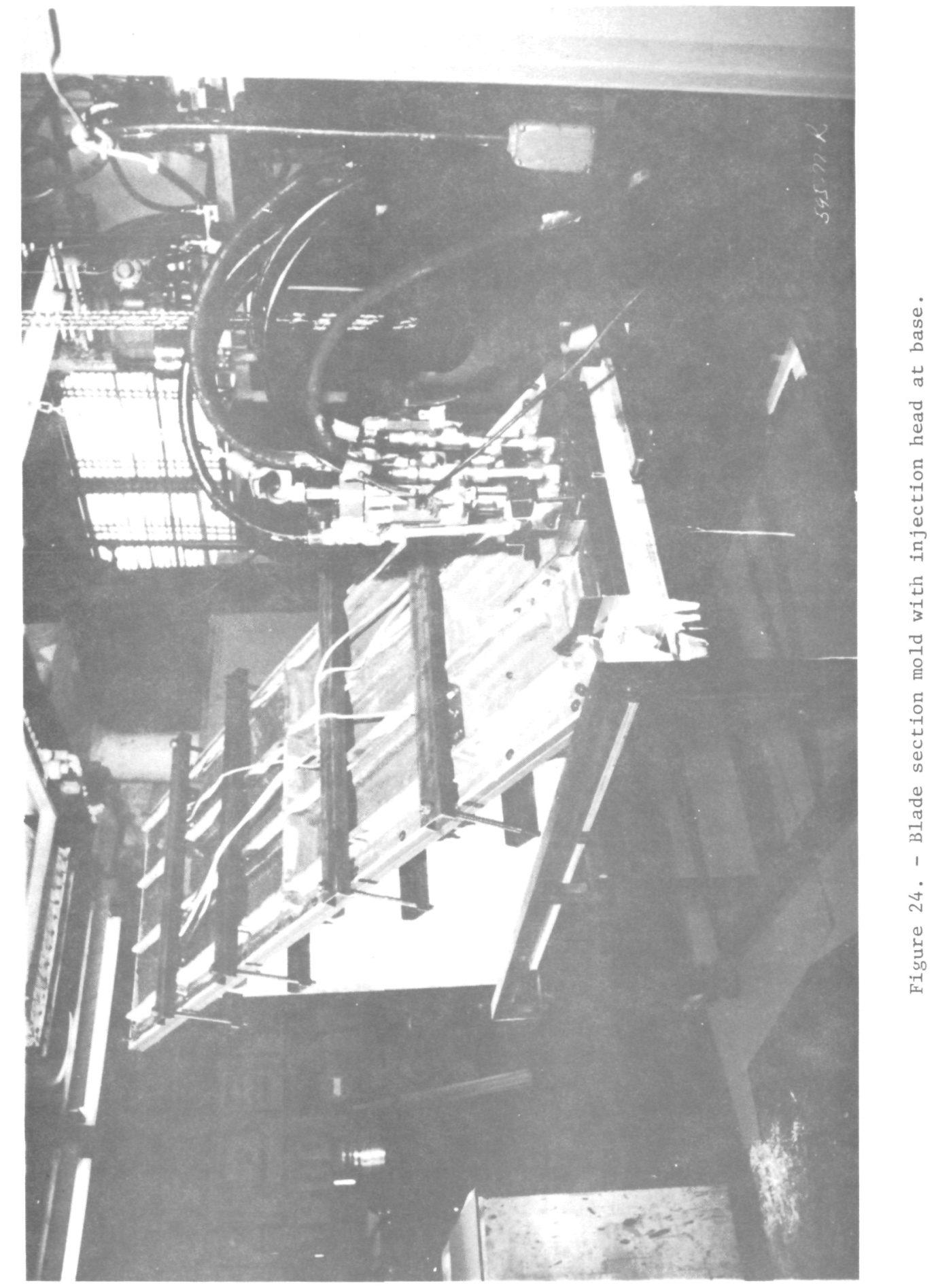




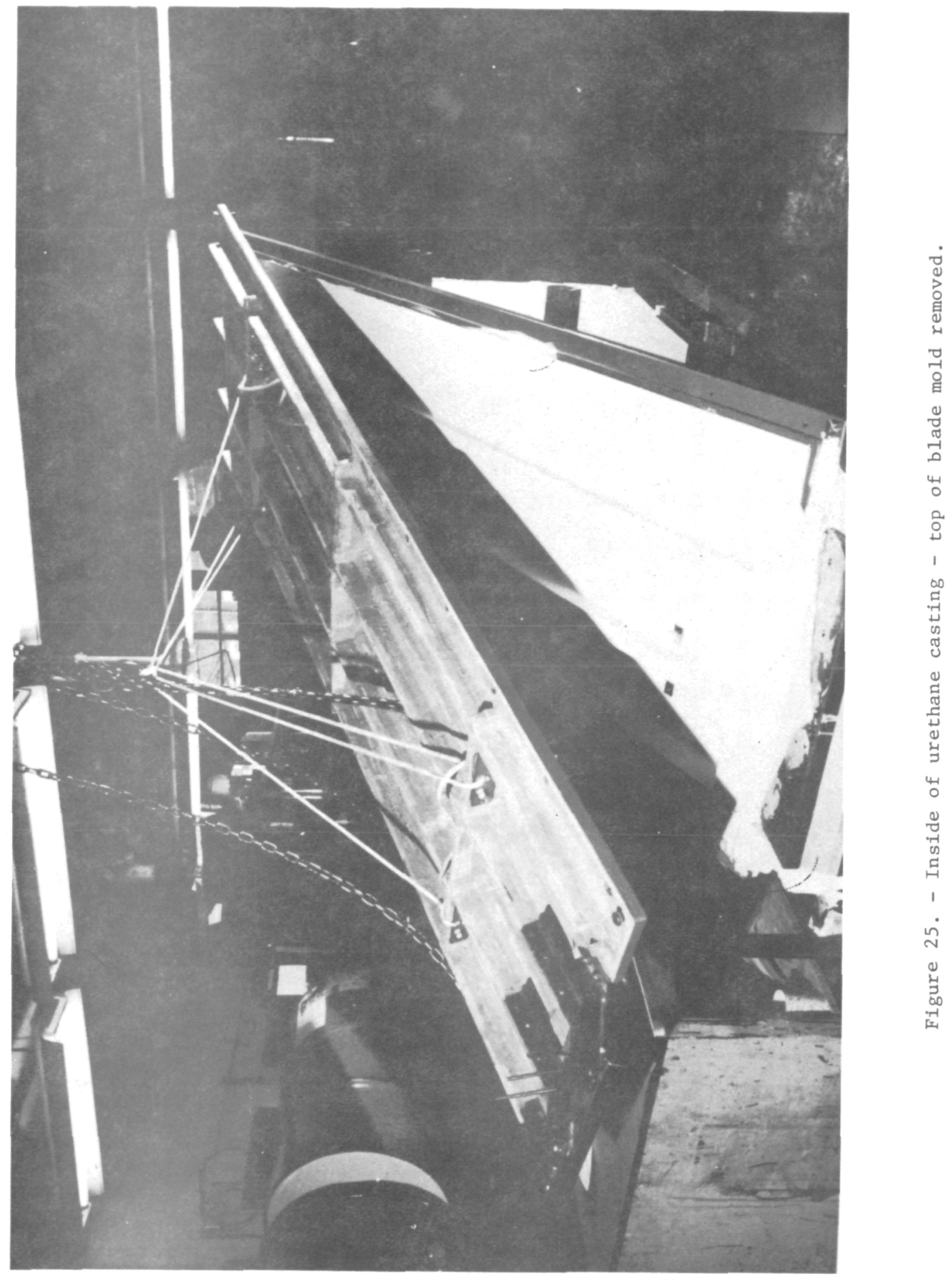




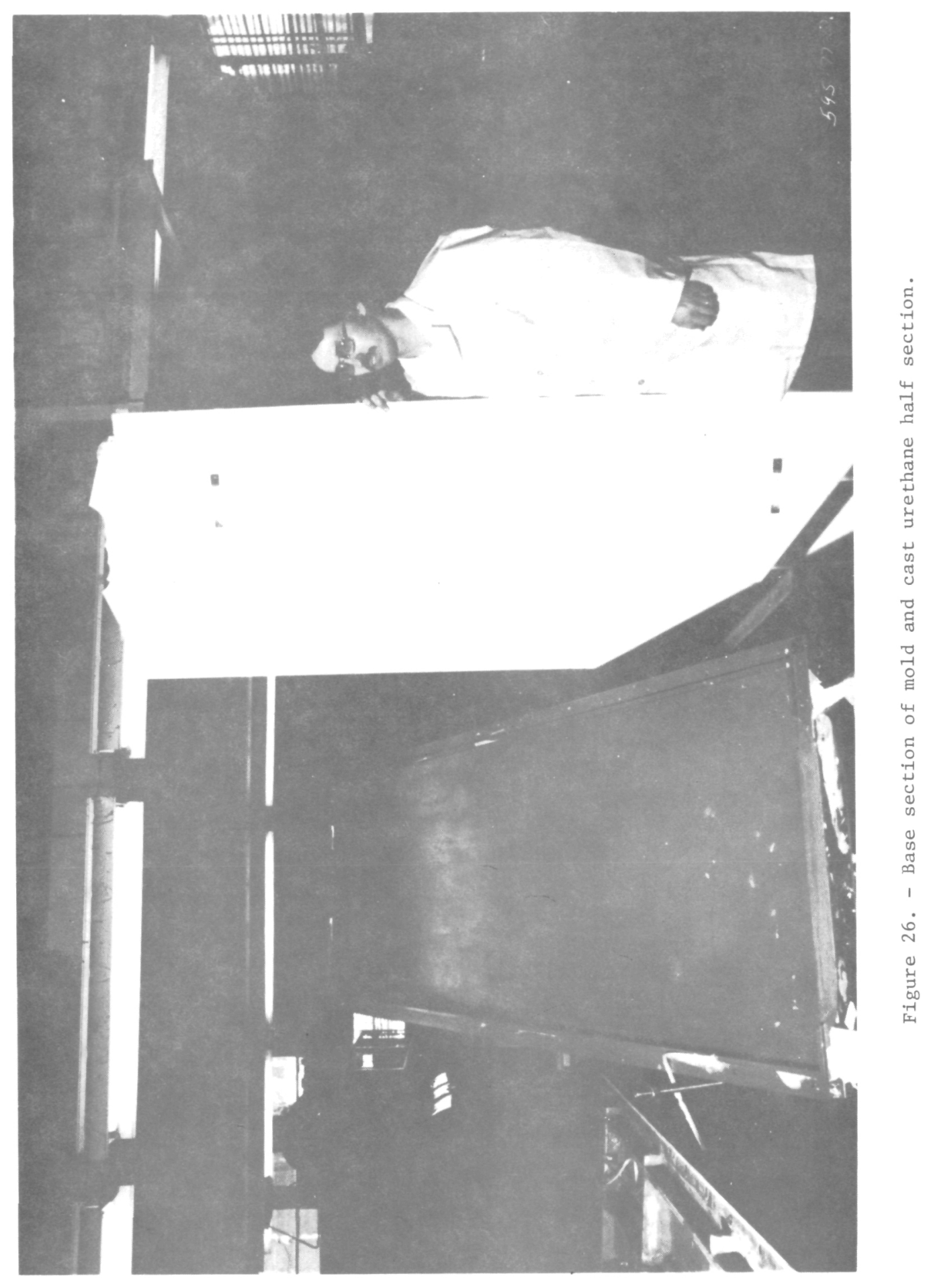




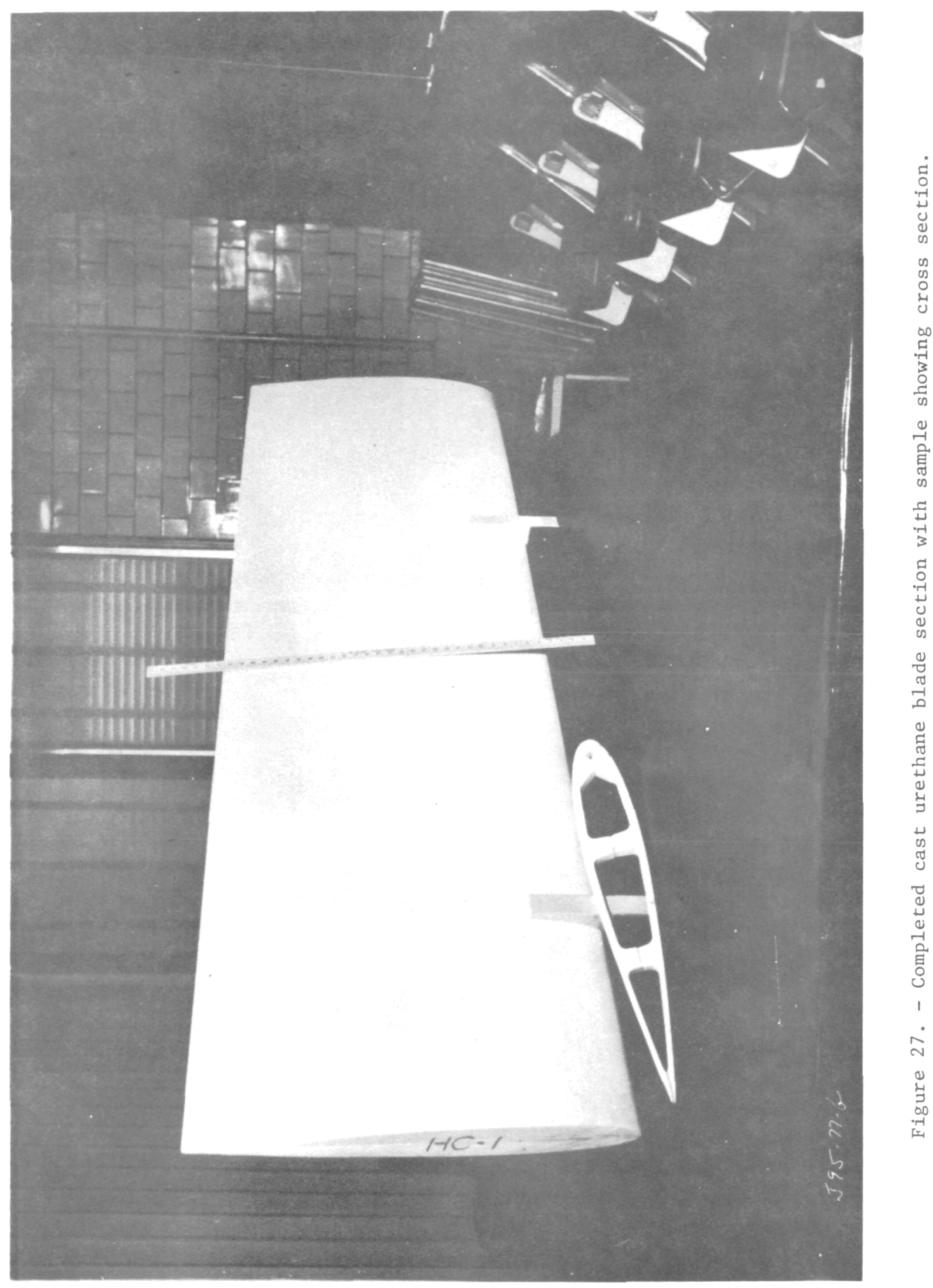


square inch and an ultimate tensile strength of 5473 pounds per square inch (table VI). The length of the blade section is about 7 feet, the chordwise dimension is about 29 inches, and the maximum cross-sectional thickness is about 4.6 inches. The model blade was designed to represent a simplified version of a 7-foot section of the MOD-0, 62.5-foot blade located at about the 80 percent radius point. The cross-sectional dimensions are uniform throughout the span of the section, and there is no twisting of the section. Details of the blade dimensions are given in appendix D.

Three complete blade sections were constructed: one of all urethane material (fig. 22(a)); and two with reinforcing rods added (fig. 22(b)). The reinforcement consisted of two 5/8-inch steel rods running throughout the length of the blade, one in each half section, located about 10 inches from the leading edge of the blade. The rods were placed in the mold at the selected locations prior to the injection of the urethane. These rods weighed 2.08 pound-per-foot of length.

Tests

Both the unreinforced and reinforced model blade sections were tested in bending, torsion, and free vibration. A special fixture was prepared to provide a rigid attachment for the test blade sections. The fixture was constructed of steel and weighed around 8000 pounds. The rigid fixture was bolted to the hooks of a rigid platform. Each hook of the platform is capable of carrying a 50-ton force. A photograph of the test blade attached to the support fixture is shown in figure 28. The base of the blade was inserted into a

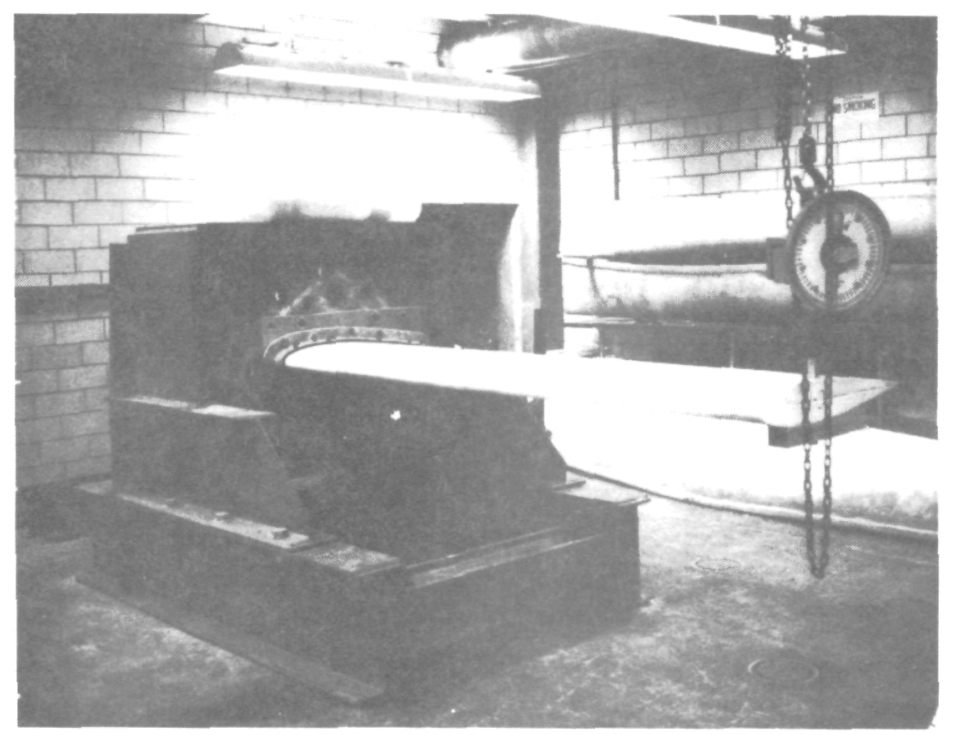

Figure 28. - Mode1 blade section in attachment fixture. 
sleeve that was attached to the back plate. Four vertical bolts were inserted through the blade to attach it to the sleeve. All tests were conducted in this setup.

Bending. - For the spanwise bending tests, a vertical load $P$ was applied gradually at the free end of the blade at the shear center until the blade failed at the fixed end. The vertical load was applied with a 3000pound Sampson Crane Scale as shown in figure 29. Readings of vertical deflection were taken at every 100-pound increment of load.

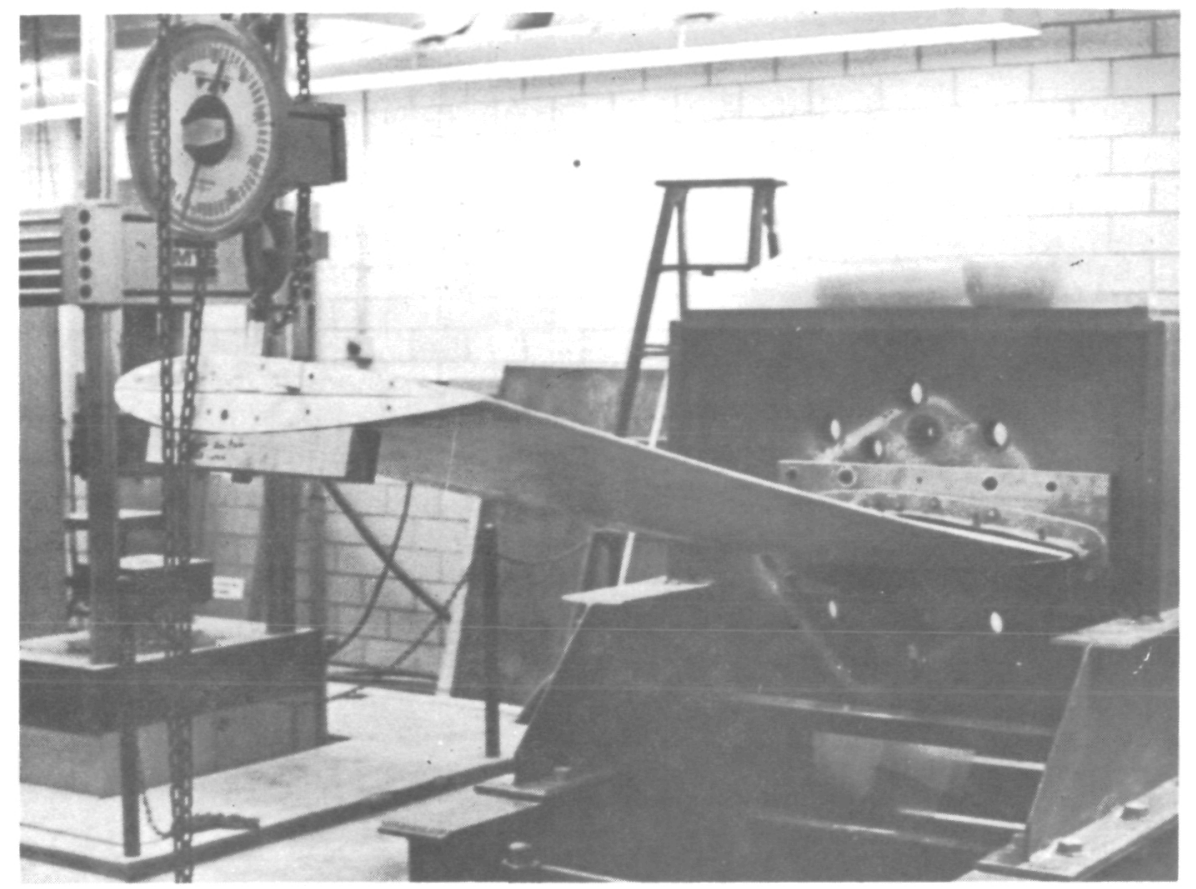

Figure 29. - Model blade section under bending load.

For the unreinforced blade, the section broke at the fixed end when the applied load reached 950 pounds for a maximum moment of 81166 inch-pound. The data collected are recorded in appendix $\mathrm{D}$. Also shown in the appendix is the calculation of deflection and bending stress as predicted from the relations for a cantilever beam with concentrated load at the free end.

Figure 30 shows the measured moment-deflection plot and the variation in calculated deflection. Measured deflection is linear with applied moment for nearly the entire range. The maximum measured deflection of the blade section is quite large (around 22 in. compared to 84 in. of length). Furthermore, the measured deflection is considerably larger than the corresponding calculated value ( 22.25 compared to $10.43 \mathrm{in.)}$. This large difference is most likely the result of some local yielding and rotation in the blade base attachment.

A source of section weakening at the root of the blade section is the four vertical bolts that were used to secure the base section of the blade to the 


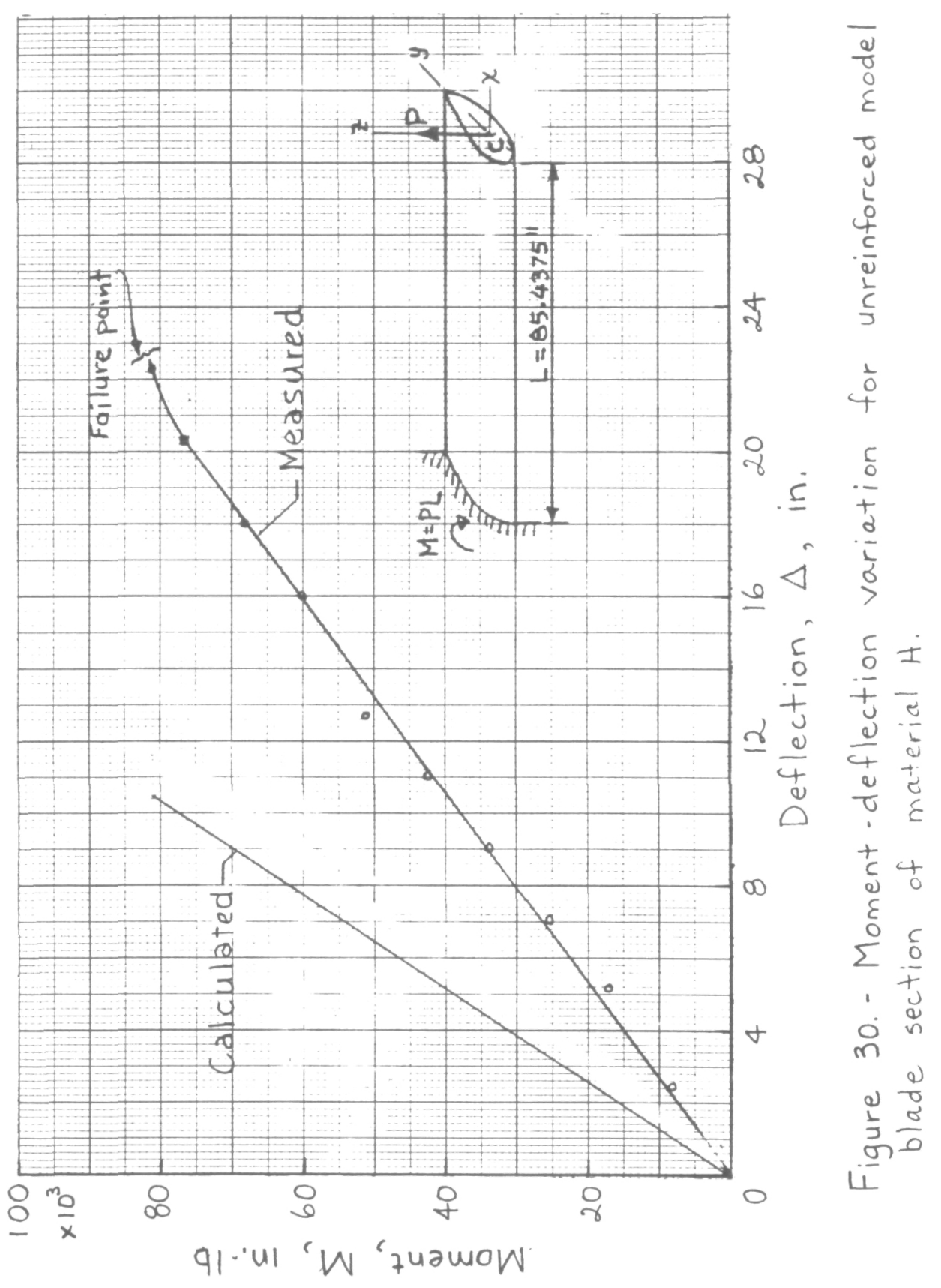




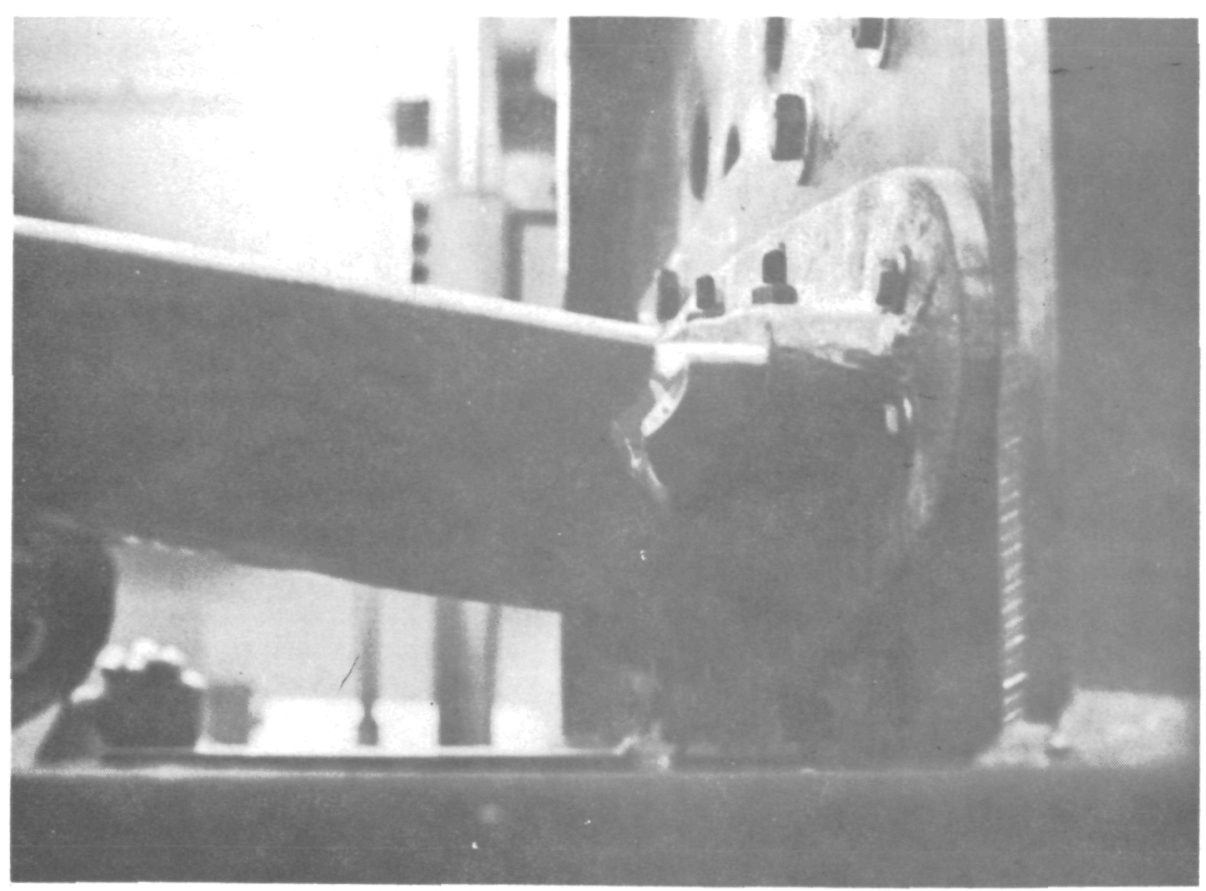

(a) View of trailing edge, blade attached.

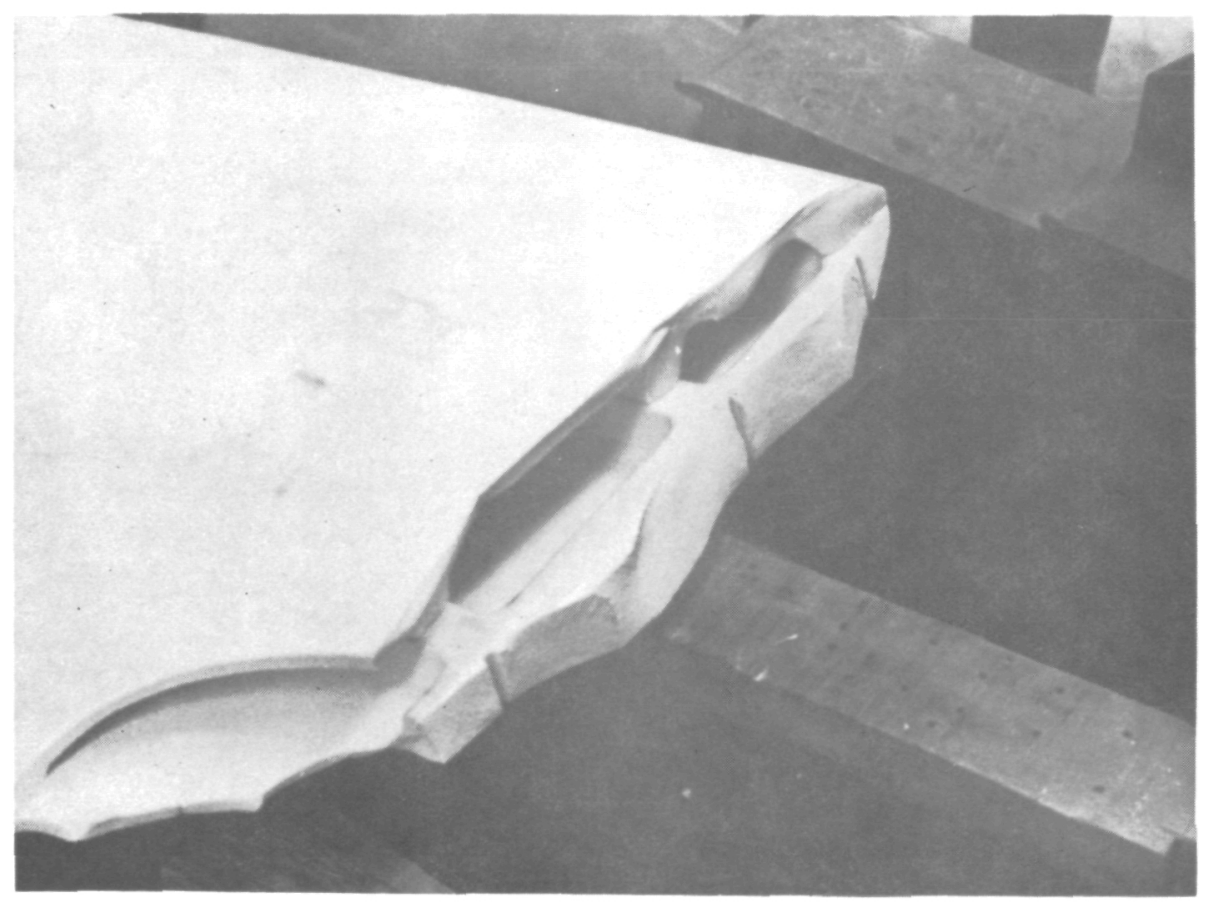

(b) View of blade part of failed root section.

Figure 31. - Photographs of failure of root section of unreinforced urethane blade section. 


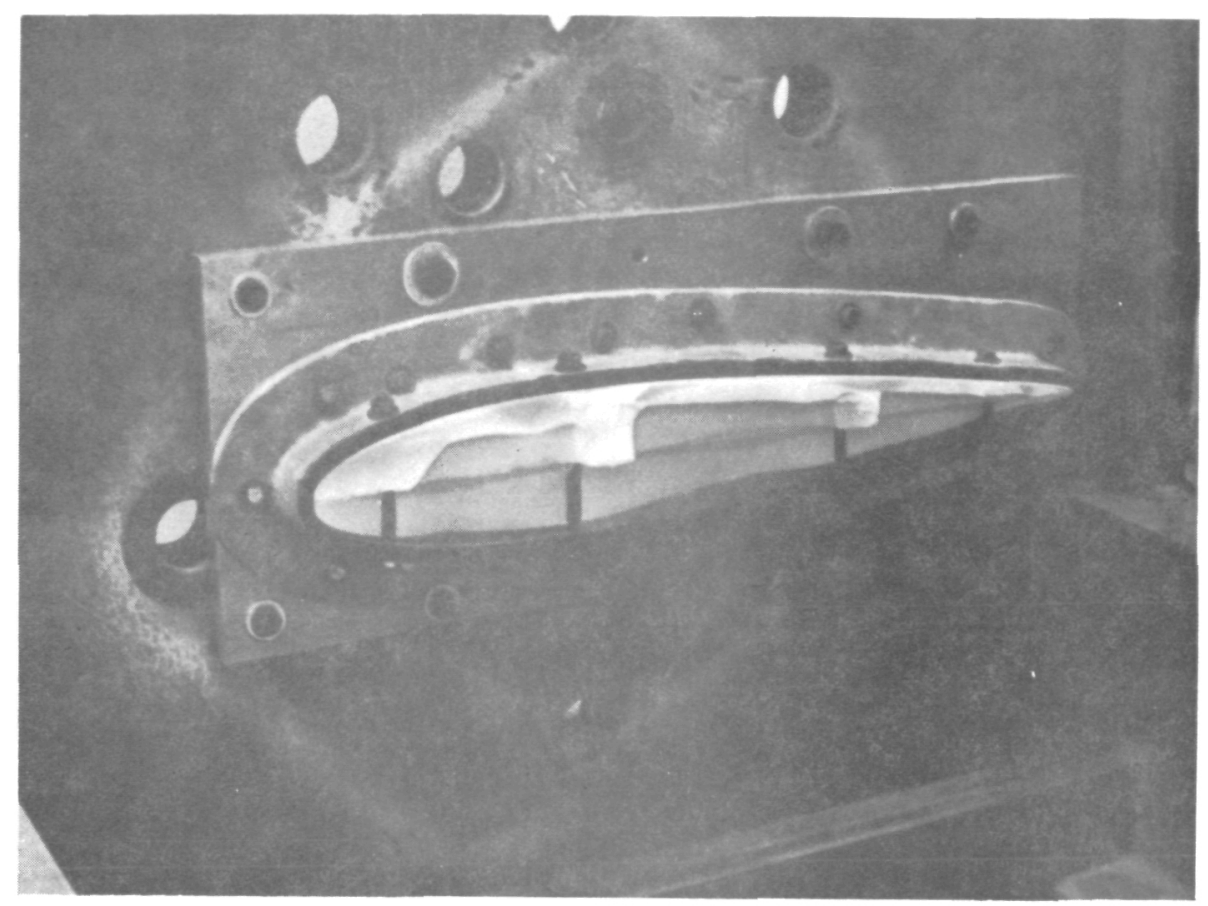

(c) View of attachment part of failed root section.

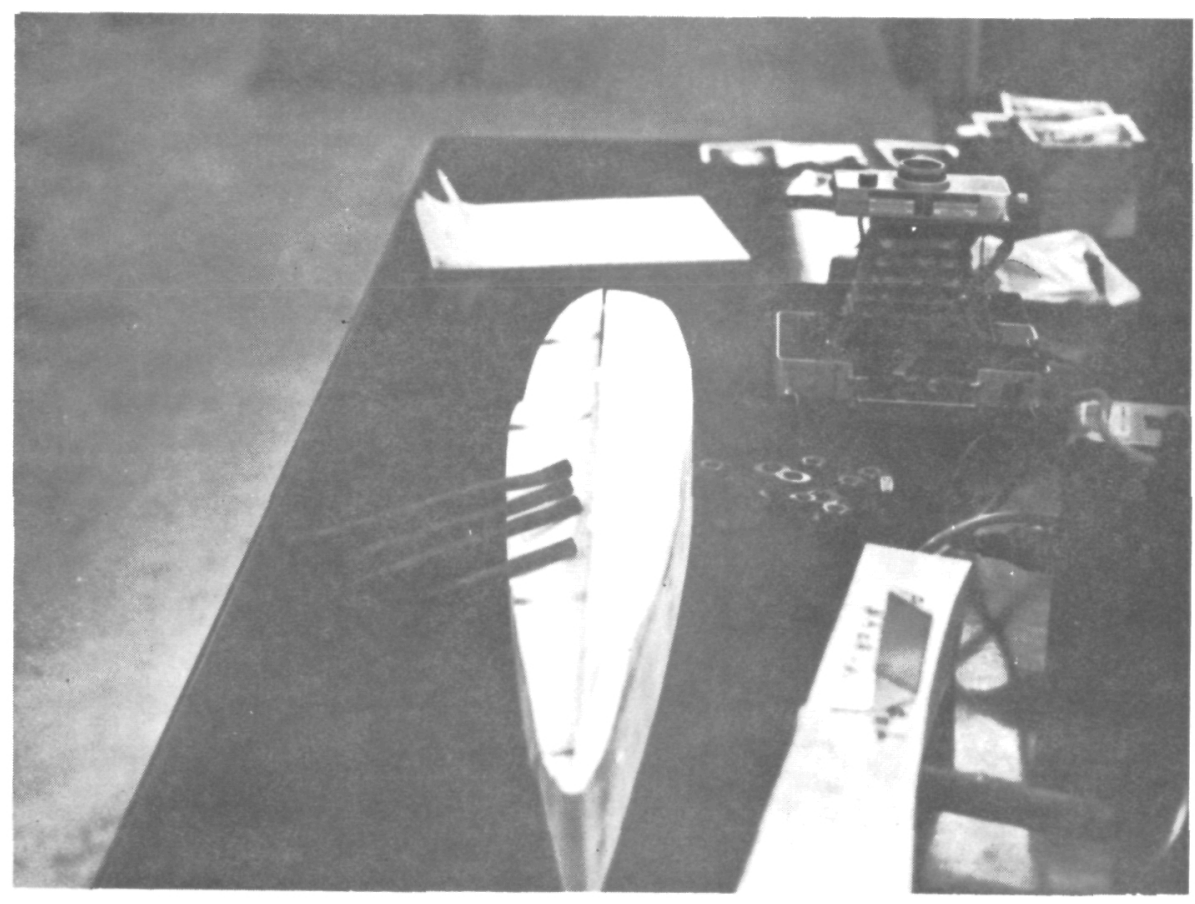

(d) Base section removed from attachment sleeve.

Figure 31. - Concluded. 
fixture sleeve. As shown by the series of photographs of the blade failure in figure 31, failure occurred in the plane of the three forward bolt holes in the lower half of the blade. These bolt holes reduced the value of section I by about 10 percent at the blade root and also created local stress concentrations.

In view of the relatively short depth of the attachment sleeve at the blade root, it is probable that a rigidly fixed end was not achieved with the test setup used, However, for this effect to be the cause of the large measured deflection, the blade base would have had to rotate approximately $6.8^{\circ}$ in the sleeve during the loading.

The calculated maximum bending stress at the base of the test section is plotted in figure 32. At failure, a calculated stress of 2267 psi was obtained based on the moment of inertia of the full blade section. The stress variation

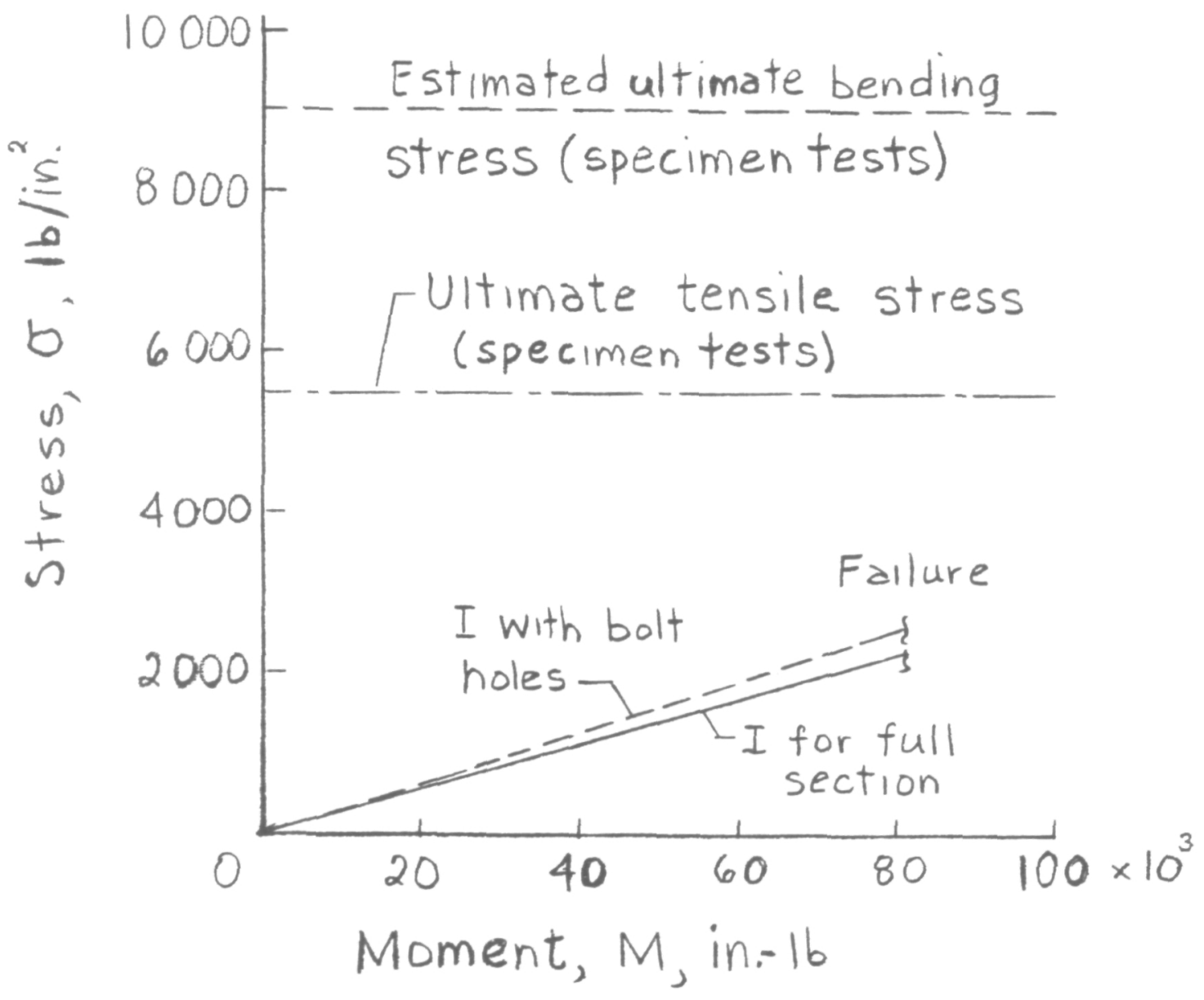

Figure 32. - Maximum bending stress for unreinforced model blade section of material $\mathrm{H}$. 
for the I reduced by the bolt holes is shown by the dashed line on the figure. The difference between the dashed line at failure (2518 psi) and the ultimate tensile strength of 5473 psi (determined from specimen tensile tests for material H) can be regarded as a form of stress concentration. The stress concentration factor for these data is $f_{c}=2.17$. Such a value is not unreasonable for the effect of bolt holes in brittle materials.

The calculated bending stress at failure (with the stress concentration factor) is considerably below the value of estimated ultimate bending stress as determined from specimen flexure tests (upper dashed line). The value of 9000 pound per square inch was selected for material $\mathrm{H}$ based on values of 9387 pounds per square inch and 7467 pounds per square inch determined in specimen flexure tests on materials $D$ and $B$, respectively, which have approximately similar values of modulus and tensile strength (table VI). The reason for the large discrepancy between the calculated bending stress at failure for the blade section and the apparent ultimate bending stress of the test specimen is not known. Perhaps the departure from linearity of local stress with distance from the neutral axis as failure is approached is markedly different for the blade cross section compared to the square test specimen cross section. Further testing of blade sections with strain gages would probably be necessary to resolve the questions raised by this preliminary investigation.

Load and deflection data for the blade section reinforced with two steel rods is tabulated in appendix $D$ and plotted in figure 33. The momentdeflection variation in the figure is linear for a good part of the range, but the linearity does not go through the origin. It is also seen in the plot that the blade apparently yielded when the load $P$ reached 1000 pounds. The applied load $P$ was reduced to 950 pounds, but the material regained strength and the load was increased again. The blade broke by bending at the fixed end when $P$ reached 980 pounds. This is the first time that apparent yield was distinctly observed in the material, probably due to the presence of the steel reinforcement, or to slip between the reinforcing bars and the urethane.

The maximum bending moment at the fixed end is 87750 inch-pound, only slightly higher than the value for the unreinforced blade. However, inasmuch as the reinforcing rods were not attached to the base supporting structure, they would not be expected to influence the failure situation to any significant degree. The largest gain in the use of reinforcement for the urethane was in the reduction of the vertical deflection at the free end of the blade (fig. 33). Maximum deflection was reduced from 22.25 to 16.42 inches; further large reductions would require a much greater amount of reinforcement.

The reinforced urethane blade section also did not behave as a true composite cantilever beam. For the composite blade, the tip deflection was calculated to be around 0.4 that of the all-urethane blade. The measured ratio was 0.6 , which is considerably larger. It is possible that the increased deflection for the reinforced blade may have been the result of some slippage between the rods and the urethane (the rods are not attached to the base). However, if the blade did act as a composite beam, it would be necessary for the blade base to rotate $6.5^{\circ}$ in the attachment sleeve in order to produce the observed tip deflection at maximum moment. This value is very close to the 


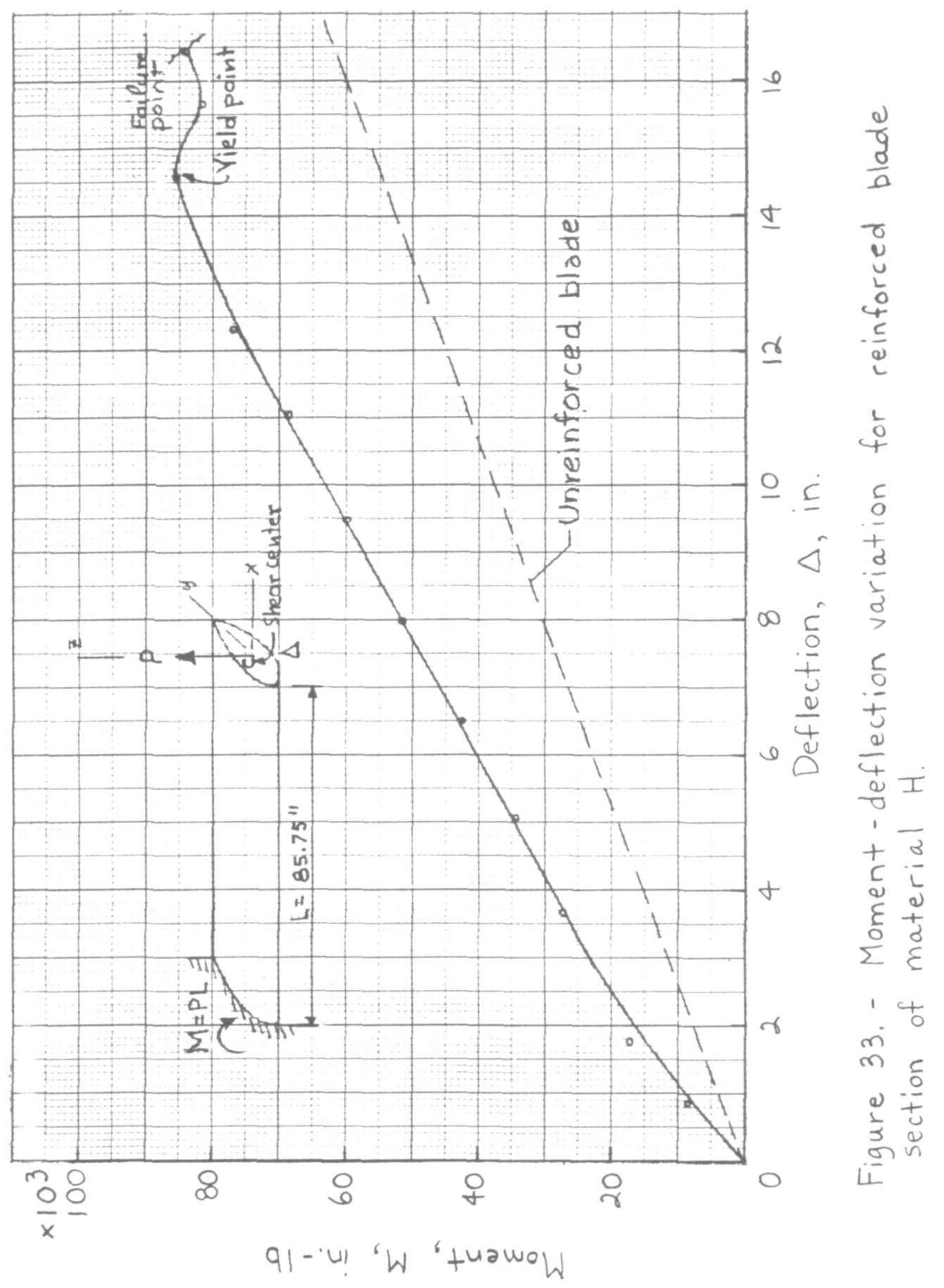


$6.8^{\circ}$ calculated earlier for the apparent rotation of the all-urethane blade. It thus appears that the same problem was present in both tests, and that the most probable cause of the problem is a deficiency in the base attachment.

Torsion. - A torsion test was conducted with a reinforced blade section. Torque was applied at the free end of the blade through a fixture on which weights were hung. The torsion test setup is shown in figure 34. The torsion end fixture and available loads, however, were not large enough to fail the blade by torsion.

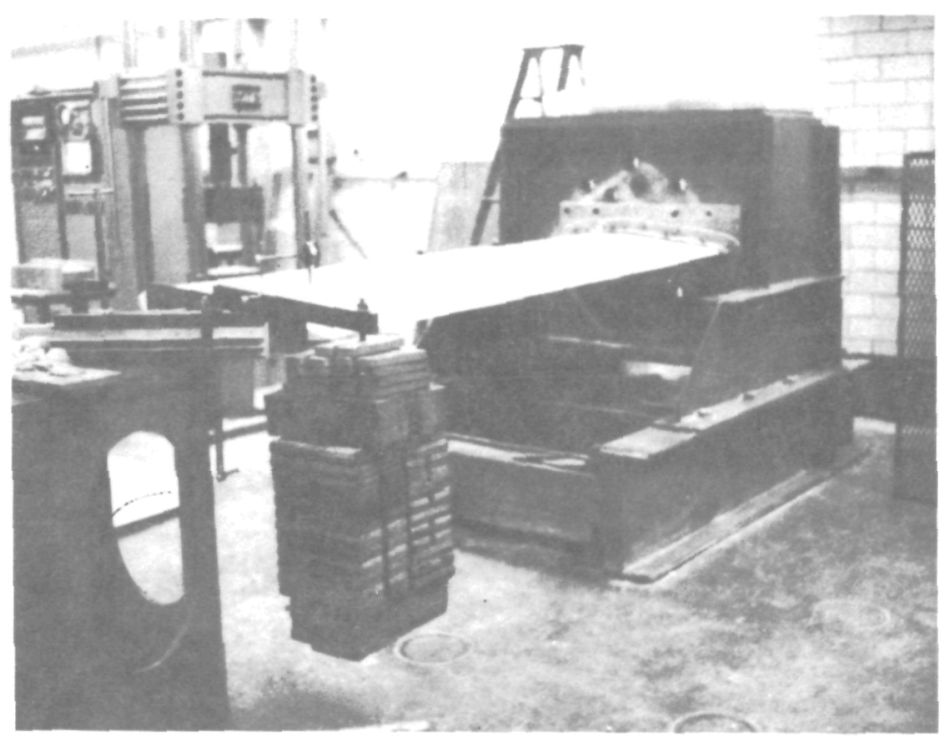

Figure 34. - Blade torsion test setup.

Readings of angular twist $\phi$ were recorded for a range of values of torque during both loading and unloading. Values are tabulated in appendix D and plotted in figure 35. The torque-angular twist variation is essentially linear as load is increased, but a shift in the curve occurs, as shown in the figure when the torque reached about 12000 inch-pound. The observed shift in the curve may be due to some form of yielding, reading error, or other reason not related to the torsion resistance of the blade. The observed permanent deformation of $0.3^{\circ}$ would probably not be present if the curve shift had not occurred. During loading and unloading, the creep was negligible.

The maximum torque that it was possible to apply to the blade section with the test setup used was 20000 inch-pound. Preliminary computations indicated that the blade section could resist around 200000 inch-pound of torque before failure in torsion. Thus, it was not possible to investigate the ultimate torsion resistance of the blade section.

Vibration. - Both the reinforced and unreinforced blade sections were tested for spanwise natural frequencies. An accelerometer was placed at the 


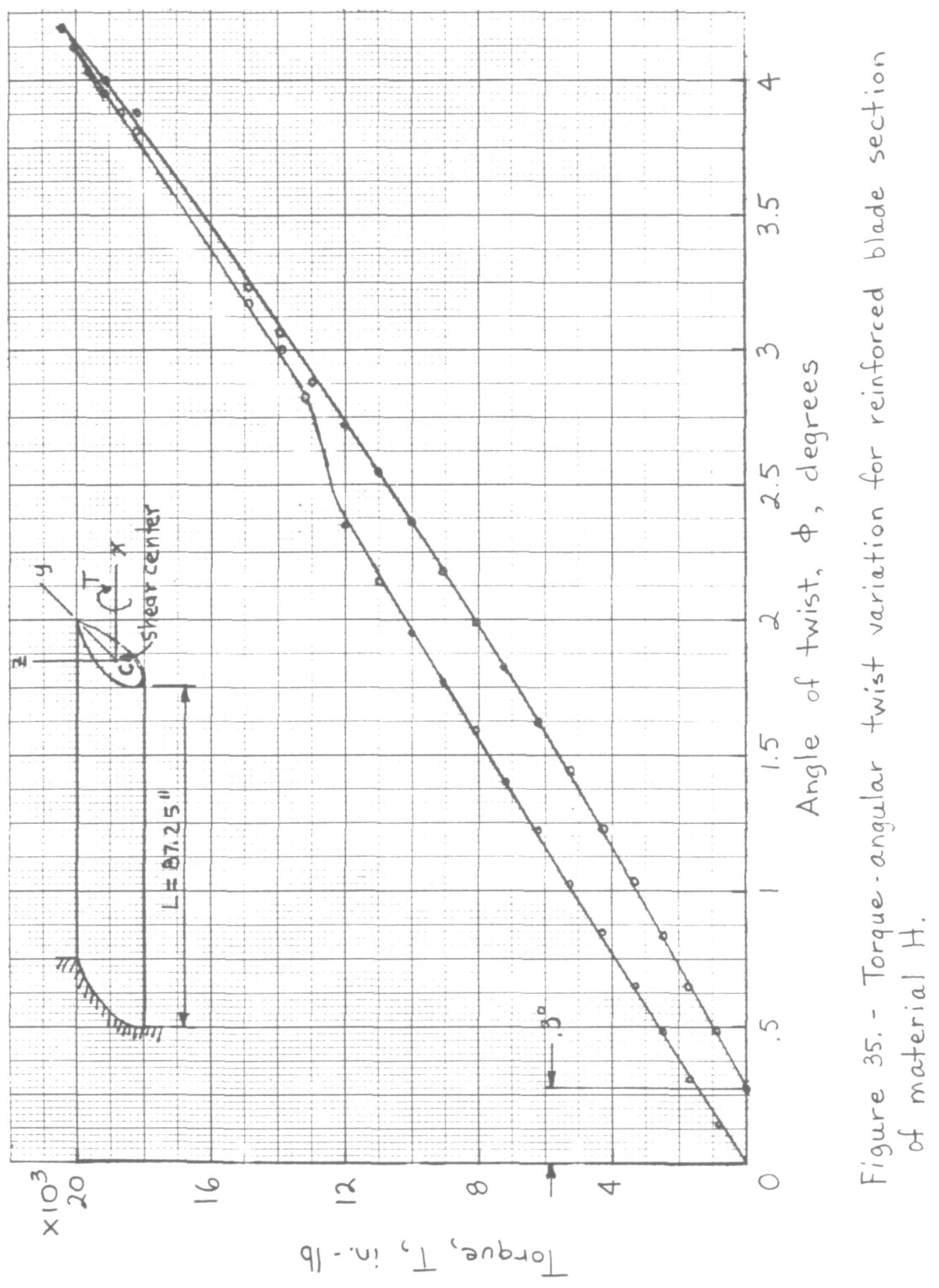


free end of the blade and the blade was excited to vibrate at its natural fundamental frequency. The frequency was recorded by a BLH strip recorder with a paper speed of 20 millimeter per second. The test setup is shown in figure 36 .

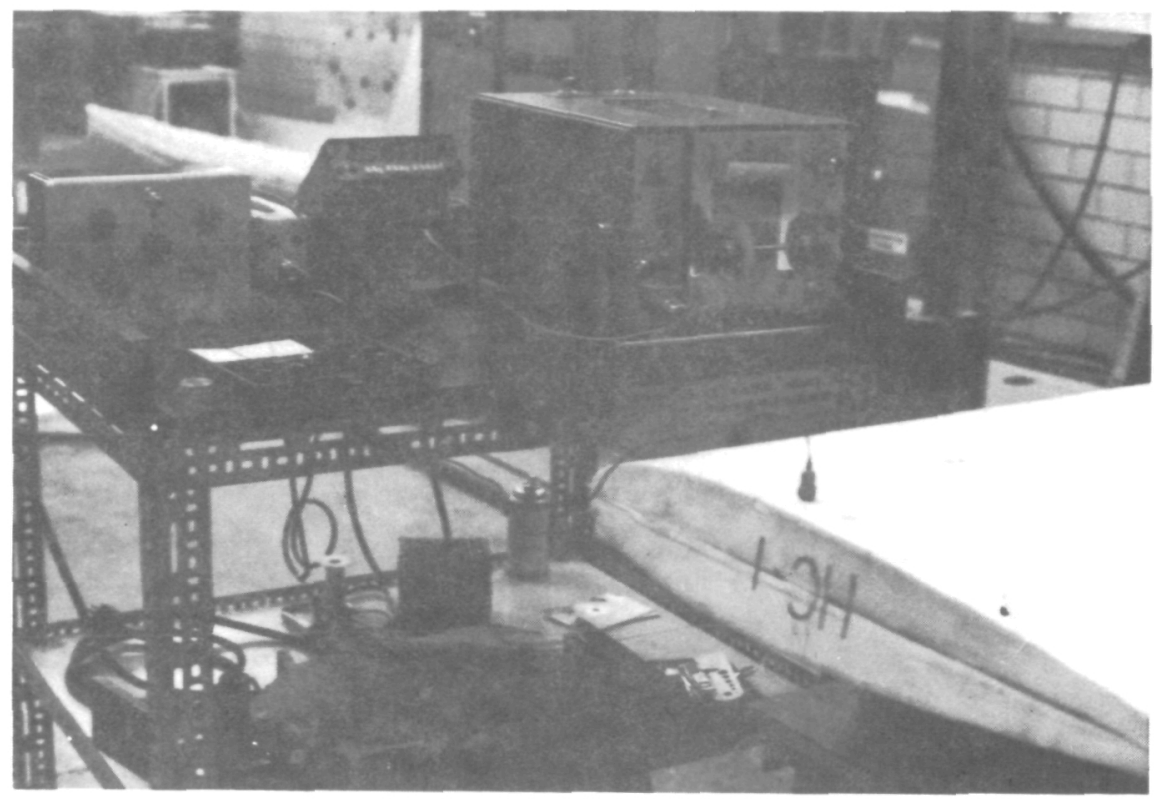

Figure 36. - Blade vibration setup.

The frequency waves for the unreinforced and reinforced blades are shown, respectively, in figures $37(\mathrm{a})$ and (b). The unreinforced blade produced a fundamental frequency of 4.3 hertz, and the reinforced one yielded a fundamental frequency of 5.5 hertz, which reflects the increased stiffness provided by the steel reinforcement.

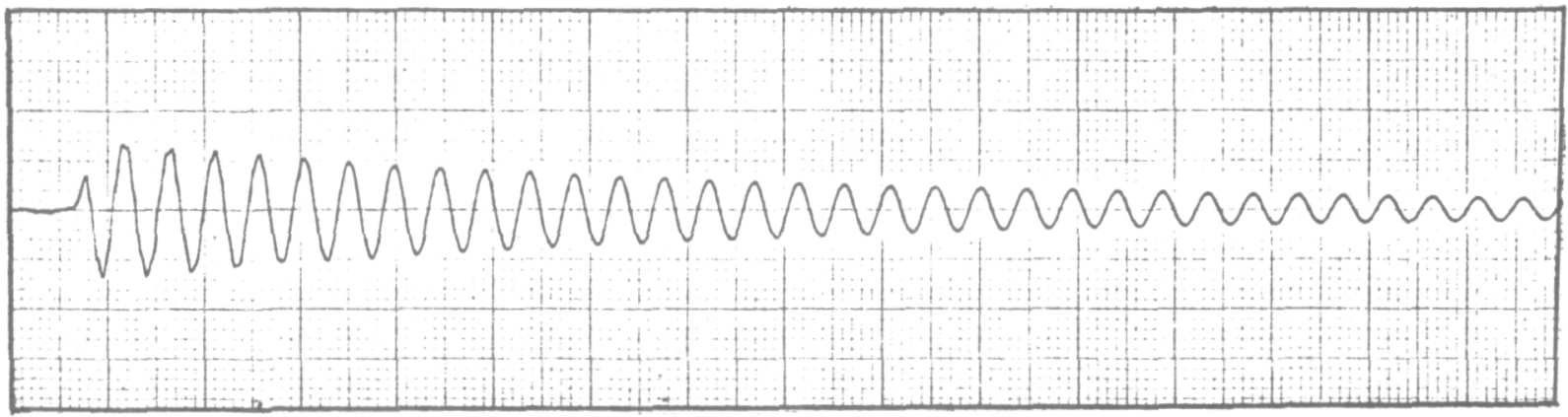

(a) Unreinforced blade section.

Figure 37. - Frequency data for blade sections of material H. 


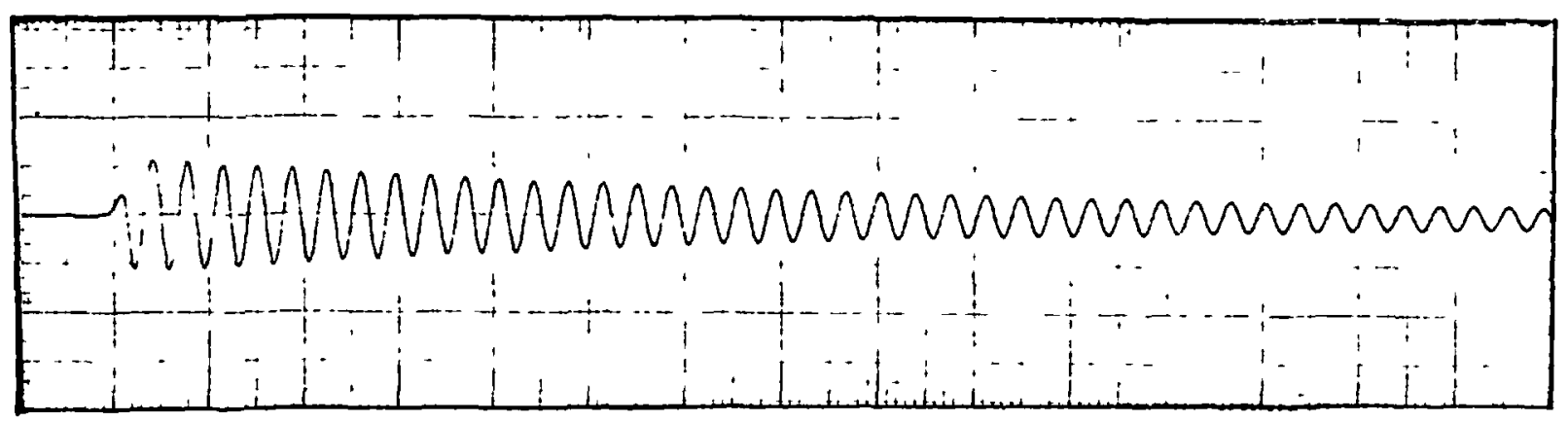

(b) Reinforced blade section.

Figure 37. - Concluded.

\section{PART II. BLADE DESIGN ANALYSIS}

The earlier specimen tests and model blade section tests indicated that some degree of metal reinforcement of the urethane is required in order to increase the stiffness and moment resistance of the material for potential fullscale blade application. This consideration was examined in more detail by a preliminary analysis of the section characteristics and total weight of a fullscale rotor blade design composed of reinforced urethane. The analytical design of the blade was based on the geometry and design specifications of the 62.5-foot long blade for the MOD-0 wind turbine rotor (ref. 2).

\section{APPROACH AND ASSUMPTIONS}

The basic approach of this preliminary analysis is to analytically determine the spanwise variation of blade section properties for two cross-sectional configurations of a reinforced urethane rotor blade. The blade is composed of symmetrical airfoil sections along the entire span in order to facilitate lowcost casting fabrication (two half sections bonded together). The metal reinforcement is added as thin aluminum or steel plates imbedded in the upper and lower surfaces of the urethane blade, so that the outer surface of the plate is continuous with the contour of the blade profile. The insert for the reinforcement plate can be part of the mold or cut into the urethane after casting. The metal reinforcement plates are assumed to be bonded to the urethane.

For the full-scale blade, both the section chord length and the maximum thickness ratio increase linearly toward the base of the blade $\left(r / r_{t}=0.1\right)$. The specific blade geometry is plotted in figure 38. Any blade twist which might be required in a real design is neglected for the analytical developments.

Two cross-sectional configurations for the urethane blade were considered for the analysis. The first cross section was taken to be similar to the blade section constructed for the model blade tests discussed previously. This configuration is referred to as the reference blade section. The second blade configuration considered as an arbitary modification of the reference section 

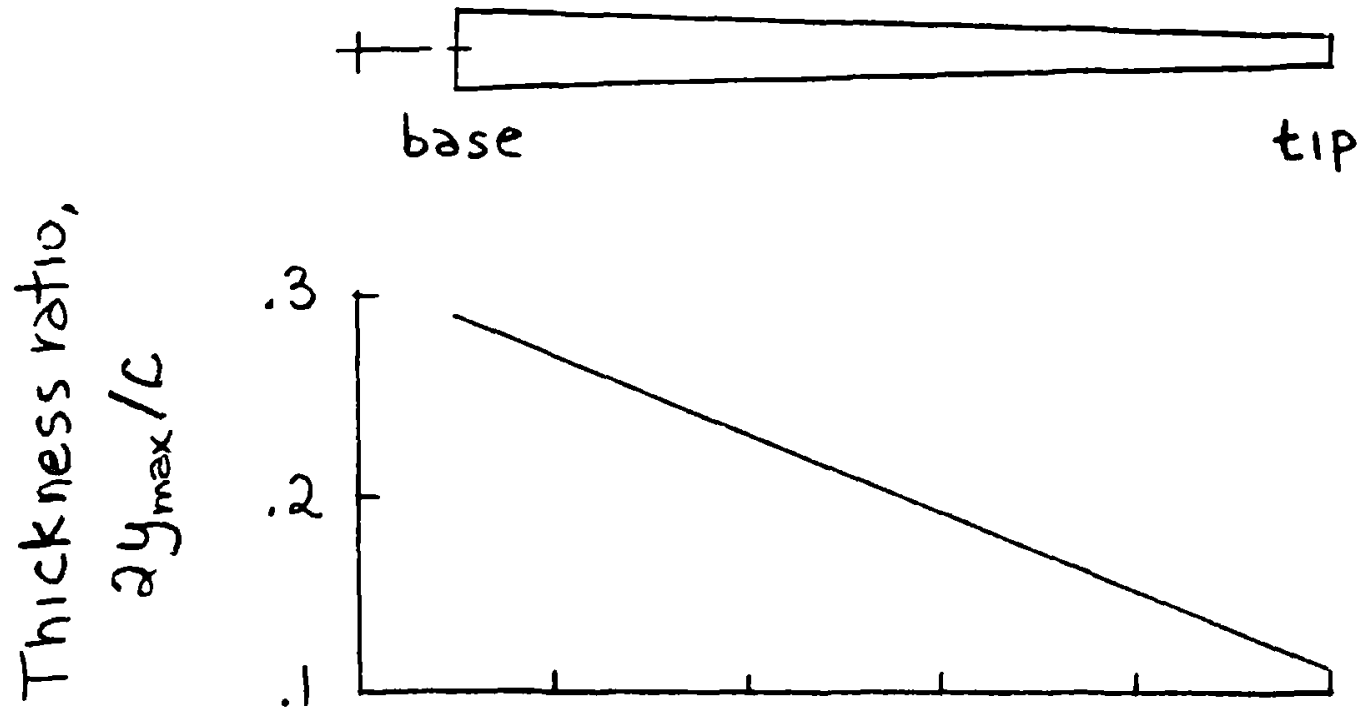

(a) Maximum thickness ratic.

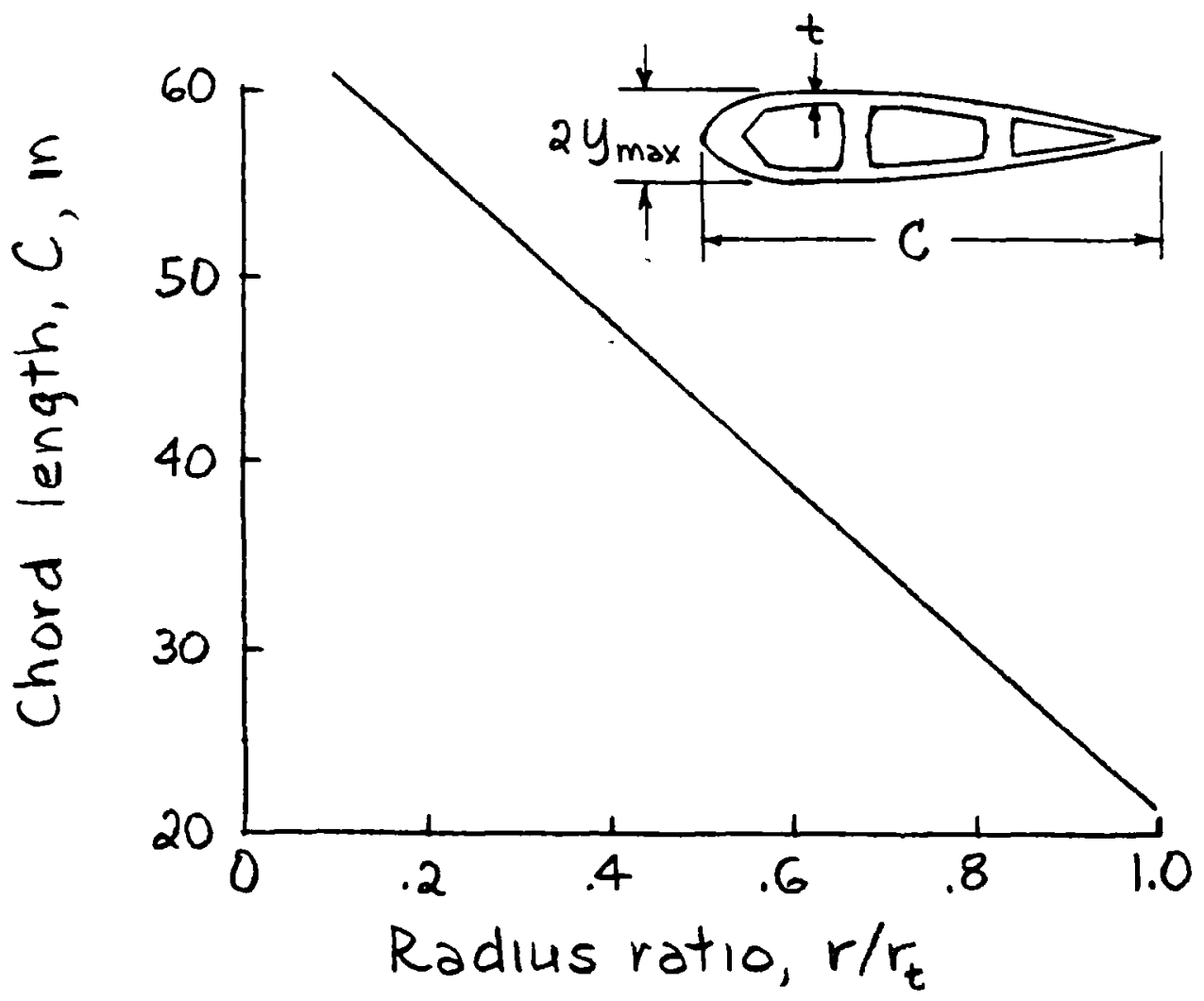

(b). Chord length

Figure 38. - Blade geometry used for design analysis. TIP radius, $r_{t}=62.5$ feet. 
to reduce the urethane material so that a lighter blade could be obtained. The two section configurations could thus indicate the range of total blade weights that might be obtained in a practical design. Specifically, the design analysis determines the dimensions of the reinforcement plates required to satisfy the design specifications of moment resistance and stiffness along the radius of the blade. From these dimensions, the total weight of the blade is obtained as the sum of the weights of the urethane and metal portions.

In order to indicate the sensitivity of total blade weight to the design specifications, high and low values of the strength requirements were included. The high values of strength for the urethane blade were taken from the specifications of stiffness $E I$ and moment resistance $M_{r}$ for the original MOD-0 aluminum blades. It was believed that these values would constitute a worst case for a urethane blade. Specifically, the spanwise variation of EI was basically the same as that for the MOD-0 blade. The spanwise variation of $M_{r}$ was determined from a constant value of aerodynamic pressure along the span (varying force due to varying chord length) with the value of bending moment at the base of the blade $\left(r / r_{t}=0.1\right)$ the same as that for the MOD-0 blade. The low values of EI and $M_{r}$ were then arbitrarily selected to be three quarters of the high values determined above.

The high and low design specifications for required moment resistance and stiffness are given in table $X$, together with the prescribed variations of blade chord and maximum thickness ratio. Formulation $E$ was prescribed for the urethane, since it produced the highest values of modulus (458 000 psi) and tensile strength (6054 psi) in the specımen tests (table VI).

TABLE X. - DESIGN SPECIFICATIONS FOR REINFORCED URETHANE BLADE [ $T$ ip radius, $r_{t}=62.5 \mathrm{ft}$. ]

\begin{tabular}{|c|c|c|c|c|c|c|}
\hline \multirow[t]{3}{*}{$\begin{array}{c}\text { Location, } \\
r / r_{t}\end{array}$} & \multirow{3}{*}{$\begin{array}{l}\text { Chord } \\
\text { length, } \\
\text { C, } \\
\text { in. }\end{array}$} & \multirow{3}{*}{$\begin{array}{c}\text { Maximum } \\
\text { thick- } \\
\text { ness } \\
\text { ratio, } \\
2 y_{\max } / \mathrm{C}\end{array}$} & \multicolumn{2}{|c|}{$\begin{array}{l}\text { Stiffness, EI, } \\
\text { in }^{2}-1 \mathrm{~b} \times 10^{9}\end{array}$} & \multirow{2}{*}{\multicolumn{2}{|c|}{$\begin{array}{c}\text { Moment resist- } \\
\text { ance, }{ }^{\mathrm{r}}{ }^{\prime} \\
\text { in - }-1 \mathrm{~b} \times 10^{6}\end{array}$}} \\
\hline & & & \multirow{2}{*}{$\begin{array}{l}\text { High } \\
\text { spec. }\end{array}$} & \multirow{2}{*}{$\begin{array}{l}\text { Low } \\
\text { spec }\end{array}$} & & \\
\hline & & & & & $\begin{array}{l}\text { High } \\
\text { spec. }\end{array}$ & $\begin{array}{l}\text { Low } \\
\text { spec. }\end{array}$ \\
\hline $\begin{array}{r}0.1 \\
.2 \\
.3 \\
.4 \\
.5 \\
.6 \\
.7 \\
.8 \\
.9 \\
1.0\end{array}$ & $\begin{array}{l}60.8 \\
56.4 \\
52.0 \\
47.6 \\
43.2 \\
38.8 \\
34.4 \\
30.0 \\
25.6 \\
21.2\end{array}$ & $\begin{array}{r}0.29 \\
.27 \\
.25 \\
.23 \\
.21 \\
.19 \\
.17 \\
.15 \\
.13 \\
.11\end{array}$ & $\begin{array}{r}17.70 \\
11.20 \\
7.20 \\
4.50 \\
2.70 \\
1.50 \\
75 \\
.32 \\
.12 \\
.04\end{array}$ & $\begin{array}{r}13.275 \\
8.40 \\
5.40 \\
3.375 \\
2.025 \\
1.125 \\
.563 \\
.240 \\
.090 \\
.030\end{array}$ & $\begin{array}{l}4.0 \\
3.209 \\
2.493 \\
1.859 \\
1.310 \\
.860 \\
.485 \\
.219 \\
.055 \\
0\end{array}$ & $\begin{array}{l}3.0 \\
2.407 \\
1.870 \\
1.394 \\
.983 \\
.645 \\
364 \\
.164 \\
.041 \\
0\end{array}$ \\
\hline
\end{tabular}


For the design analysis based on the reference blade configuration, it was specified that the cross section of the full-scale blade at 80 percent of the blade tip $\left(r / r_{t}=0.8\right)$ be identical to the urethane blade section constructed for the model blade tests discussed earlier. The cross-section of this symmetrical blade configuration was shown in figure 22(a). The area and moment of inertia are $45.62 \mathrm{in}^{2}$ and $81.62 \mathrm{in}^{4}$, respectively (appendix D).

\section{Analysis}

With cross-sectional area and moment of inertia known for the 80-percent location, analytical expressions are derived for these properties along the length of the span. Details of the developments are given in appendix $E$. The principal assumption for the design analysis is that the blade sections along the span are geometrically similar in form, with skin thickness varying directly with profile maximum thickness. For these assumptions, the moment of inertia $I_{u, f}$ and cross-sectional area $A_{u, f}$ of the all-urethane sections are obtained as functions of blade chord length $C$ and maximum thickness ratio $2 y_{\max } / C$ as (symbols are defined on p. 139)

$$
I_{u, f}=0.029855 c^{4}\left(\frac{2 y_{\max }}{c}\right)^{3}
$$

and

$$
A_{u, f}=0.33527 c^{2}\left(\frac{2 y_{\max }}{c}\right)
$$

Avallable section stiffness $\mathrm{EI}_{\mathrm{u}, \mathrm{f}}$ and moment resistance $\left(M_{r}\right)_{u, f}=\sigma_{u} I_{u, f} / y_{\max }$ for an all-urethane blade are then readily determined from values of $I_{u, f}$ from equation (1).

The width of the metal reinforcement plate required to meet the specified values of stiffness $E I$ and moment resistance $M_{r}$ were determined from consideration of the reinforced blade as a cantllever beam. From the development of appendix E, relations were determined for the required plate width $b_{R}$ in terms of $I_{u, f}$ (eqs. (E21) and (E26)). Substitution of equation (1) then provides equations in terms of the blade chord and maximum thickness ratio and the material properties.

For the moment resistance requirement, the plate width is 


$$
b_{\dot{R}}=\frac{\frac{M_{r}}{\sigma_{R}}-0.066344 c^{3}\left(\frac{2 y_{\max }}{C}\right)^{2}\left(\frac{E_{u}}{E_{R}}\right)}{0.9 t_{R} C\left(\frac{2 y_{\max }}{C}\right)\left[1-\frac{1.111\left(t_{R} / C\right)}{\left(2 y_{\max } / C\right)}\right]^{2}\left(0.9-\frac{E_{u}}{E_{R}}\right)}
$$

where $t_{R}$ is the prescribed thickness of the plate. For the stiffness requirement, the width is

$$
b_{R}=\frac{\frac{E I}{E_{R}}-0.029855 c^{4}\left(\frac{2 y}{c}\right)_{\max }^{3}\left(\frac{E_{u}}{E_{R}}\right)^{2}}{\frac{t_{R}}{2}\left(1-\frac{E_{u}}{E_{R}}\right)\left[0.9 c\left(\frac{2 y}{C}\right)-t_{R}\right]^{2}}
$$

With plate width known from equation (3) or (4), the weight per unit length for the reinforced blade is obtained from the urethane and metal portions from substitution in equation (E28) for $A_{u, f}$ from equation (2)

$$
\left(\frac{W}{L}\right)=0.33527 \rho_{u} c^{2}\left(\frac{2 y_{\max }}{C}\right)+2 t_{R} b_{R}\left(\rho_{R}-\rho_{u}\right)
$$

The maximum stress in the urethane material of the reinforced blade section is given by (from appendix E)

$$
\sigma_{u}=\sigma_{R}\left(1-\frac{t_{R}}{y_{\max }}\right)\left(\frac{E_{u}}{E_{R}}\right)
$$

where the maximum stress in the reinforcement plate is determined from the bending moment on the plate.

\section{Results}

The calculated variation of stiffness and moment resistance available from a blade composed only of urethane with cross sections similar to figure 22(a) is shown in figure 39. The moment resistance is plotted for a design urethane stress of $2000 \mathrm{psi}$. It is seen that the urethane alone is completely incapable of meeting the design requirements for both properties (shown by the dashed lines in the figure for the high and low design specififications). Thus, as expected, a full-scale blade would require a considerable amount of reinforcement. 


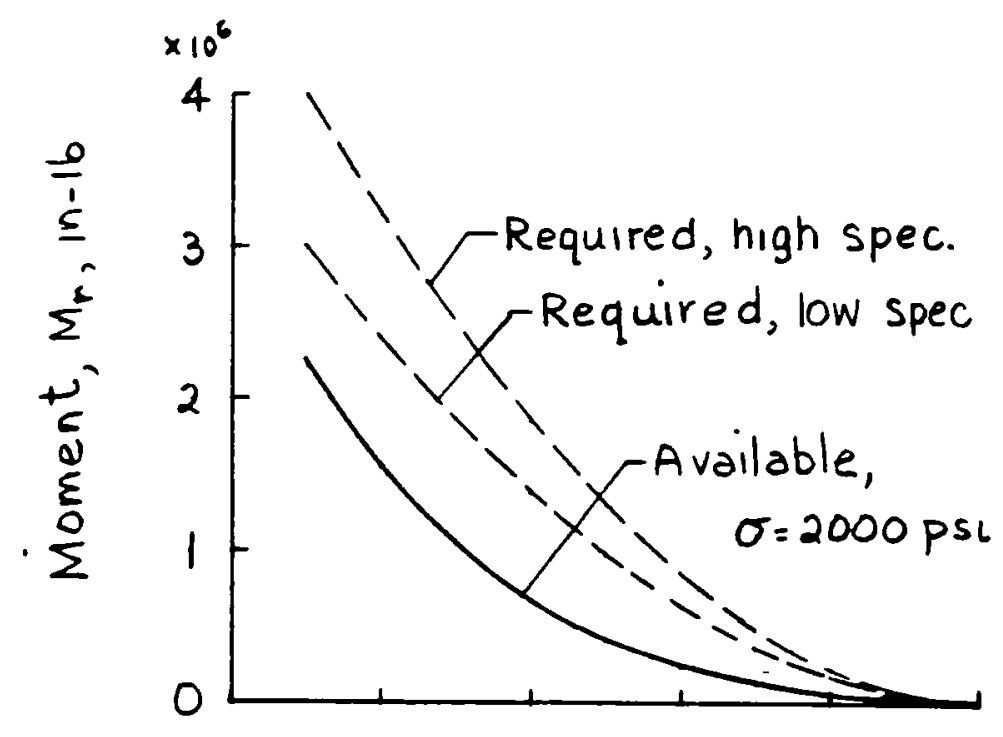

(a) Moment resistance

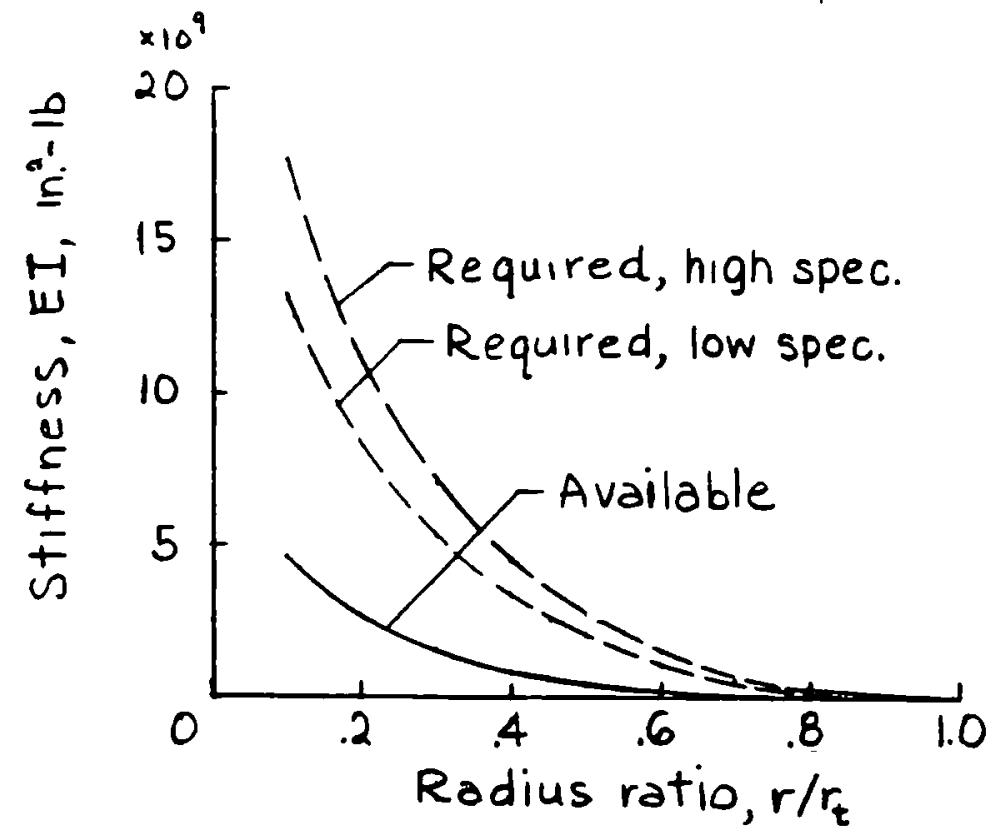

(b). Stiffiness.

Figure 39.- Section properties of all-urethane blade. Material $H$, reference blade section. 
The width of reinforcement plate $b_{R}$ required to, satisfy the design specifications of $E I$ and $M_{r}$ of table $X$ with a plate thickness of 0.25 inch (eqs. (3) and (4)) is shown in figure 40 for steel and aluminum plates. The moment resistance is determined for $100000 \mathrm{psi}$ for steel and $40000 \mathrm{ps} 1$ for aluminum. For both metals, the stiffness requirement is clearly controlling. Maximum plate widths of about 14 inches for steel and 45 inches for aluminum at the base are indicated by the calculations for the high stiffness specification. For the low specification, the maximum widths are reduced to about 10 and 30 inches, respectively.

Figure 41 illustrates several half blade cross sections with steel reinforcement plates for the high stiffness specifications (fig. $40(a)$ ) at three locations along the span of the blade. The required reinforcement material, depicted by the darkened area, is seen to constitute only a relatively small part of the cross-sectional area of the blade.

The unit weight breakdown of the composite blade (eq. (5)) is shown in figure 42 for the high stiffness specification and in figure 43 for the low specification. The predominant weight contributor is seen to be the urethane. Consequently, there is little difference between the total weight with steel or aluminum reinforcement or for the high or low design specifications. For the high specification, the calculated total weight is 4235 pounds for the blade reinforced with steel plates, and 4075 pounds for the blade reinforced with aluminum plates. For the low specification, the respective values are 4035 and 3909 pounds.

Results of the calculations for maximum stress in the urethane $\sigma_{u}$ for values of stress $\sigma_{R}$ in the 0.25 -inch-thick aluminum or steel reinforcement plates (from eq. (6)) is shown in figure 44. Figure 44(a) indicates that the maximum stress in the urethane occurs at the base of the blade. At this 1ocation, the urethane maximum stress varies with reinforcement stress as plotted in figure 44(b). For example, for a design urethane stress of about 2000 psi, allowable stresses in the reinforcement plates are about 45000 psi for aluminum and 135000 psi for steel.

A design stress level of about 2000 psi for the urethane has been mentioned frequently in the report. This value now seems to be entirely reasonable, as can be seen from the following considerations. The maximum ultimate tensile strength at room temperature $\sigma_{u l t}$ was found from the specimen tests to be 6054 psi for material E (table VI). A full-scale blade for a wind turbine application, however, will have to be designed for maximum ambient temperature, say about $100^{\circ} \mathrm{F}$. According to figure 5 , at $100^{\circ} \mathrm{F}$ the ultimate tensile strength is reduced by about $500 \mathrm{psi}$. Also, as indicated by the model blade tests, some stress concentration effects may occur. Finally, in view of a potential fatigue strength effect (unresolved in the specimen tests), a conservative safety factor is indicated. Thus, a design stress for the urethane might be established from

$$
\left(\sigma_{u}\right)_{d}=\frac{\sigma_{u 1 t}-500}{f_{s} f_{c}}
$$




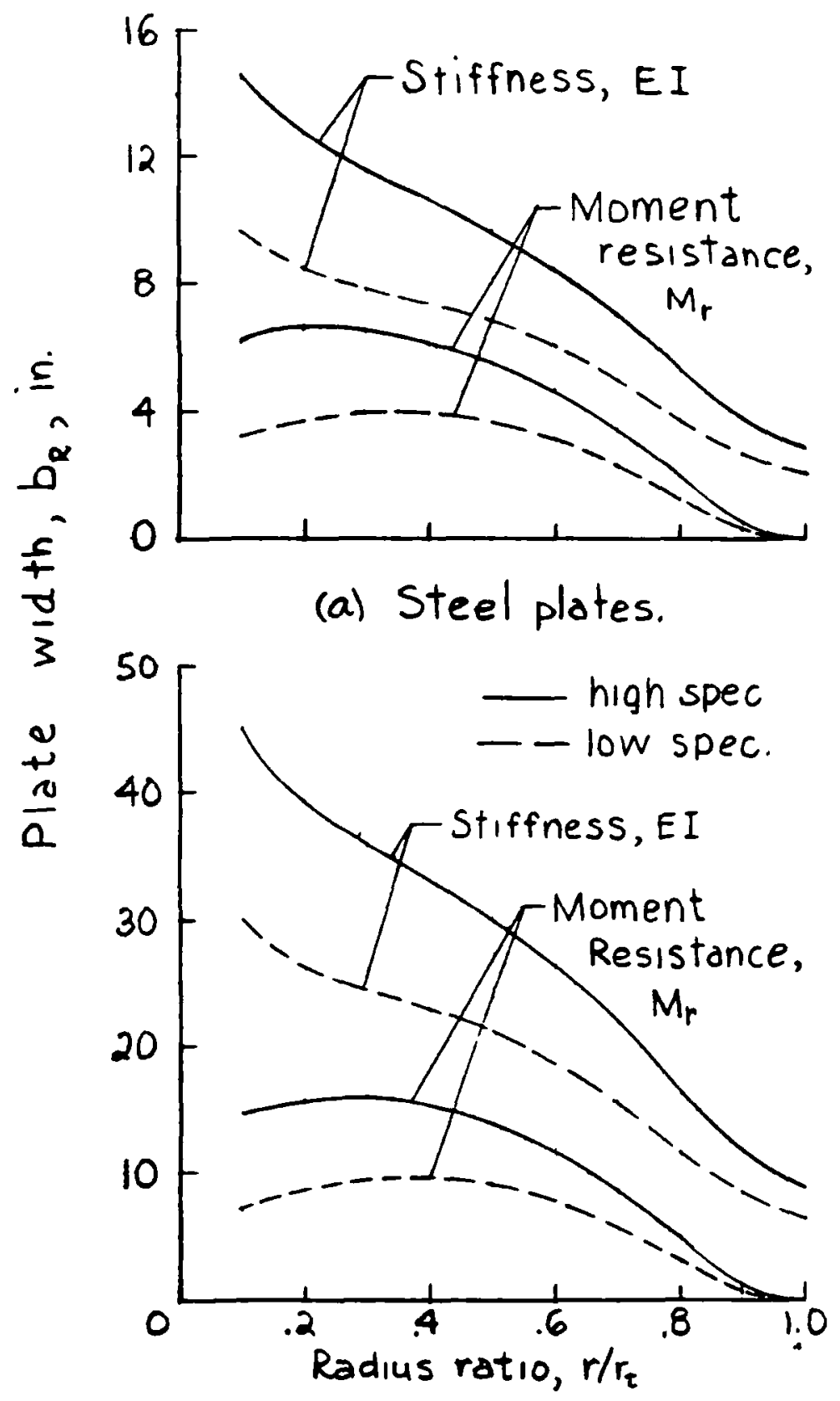

(b). Aluminum plates.

Figure 40-Reinforcement plate thickness needed to satisfy design specifications of stiffness and moment resistance. Plate thickness, $0.25 \mathrm{in}$; reference blade section. 


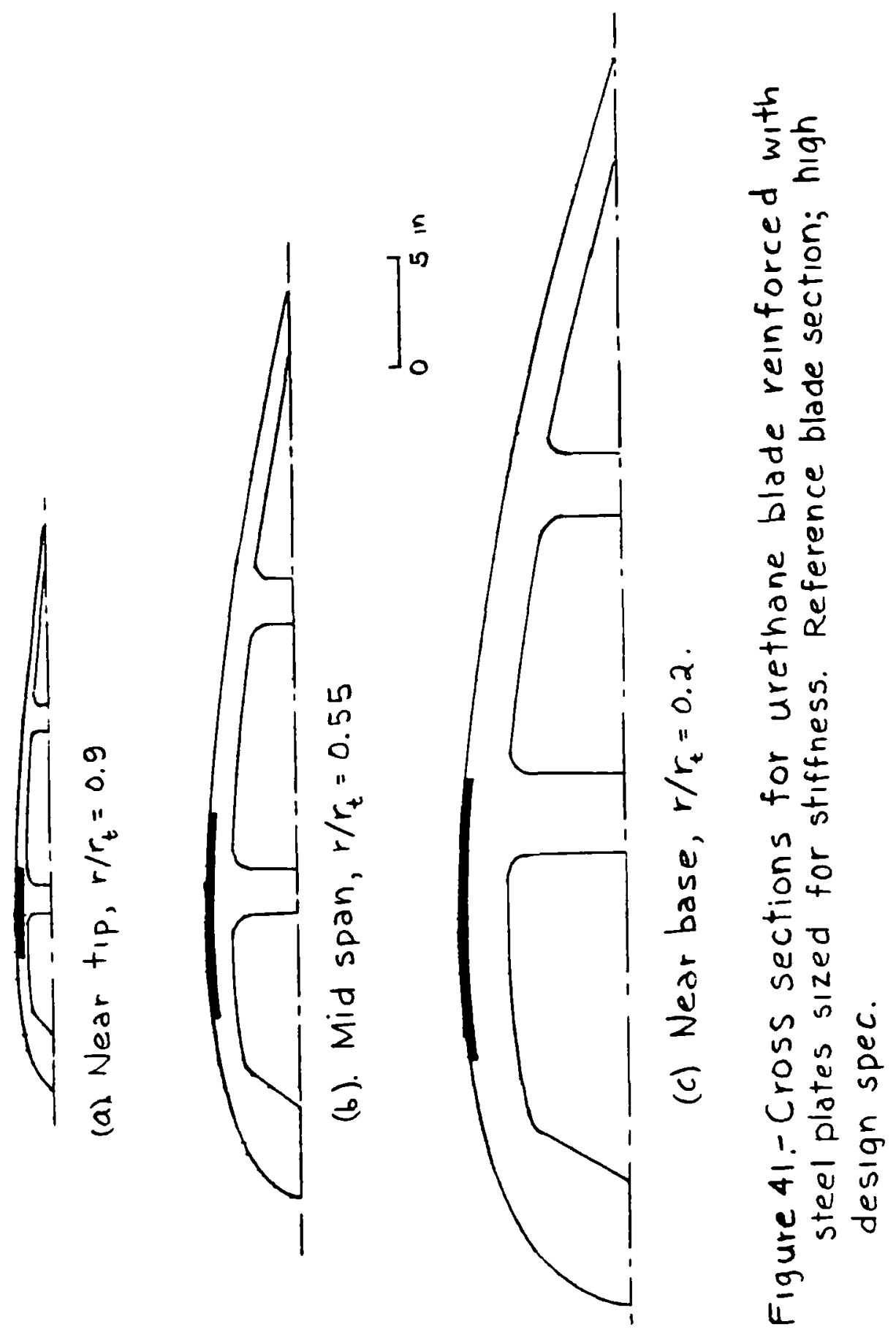




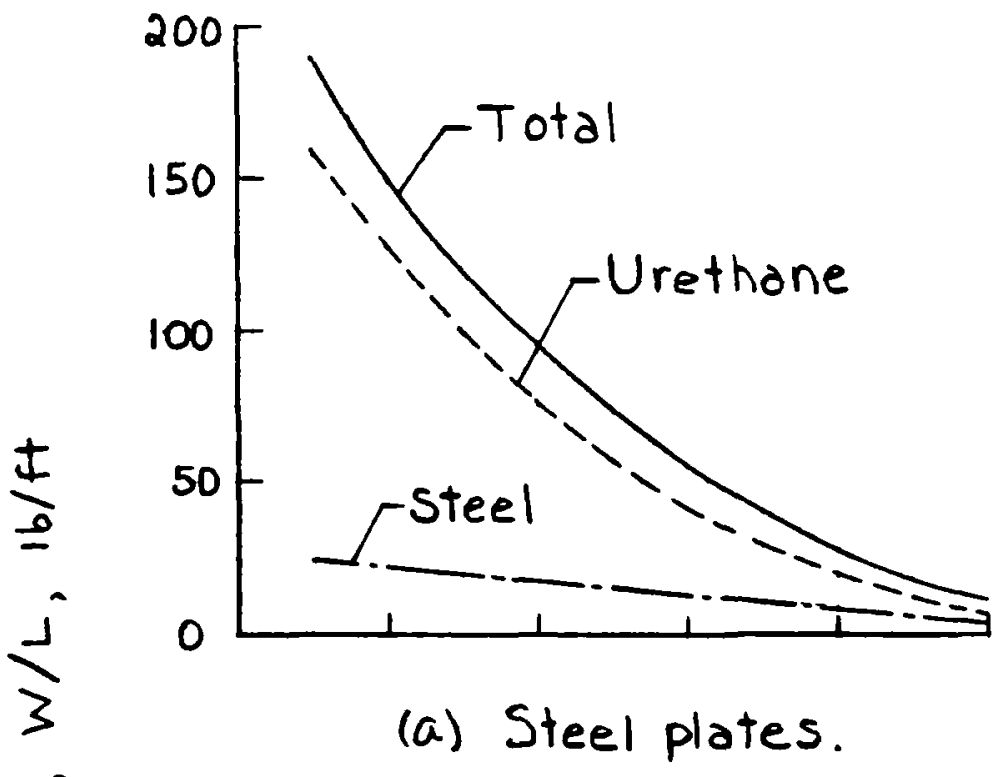

$\frac{5}{5}$

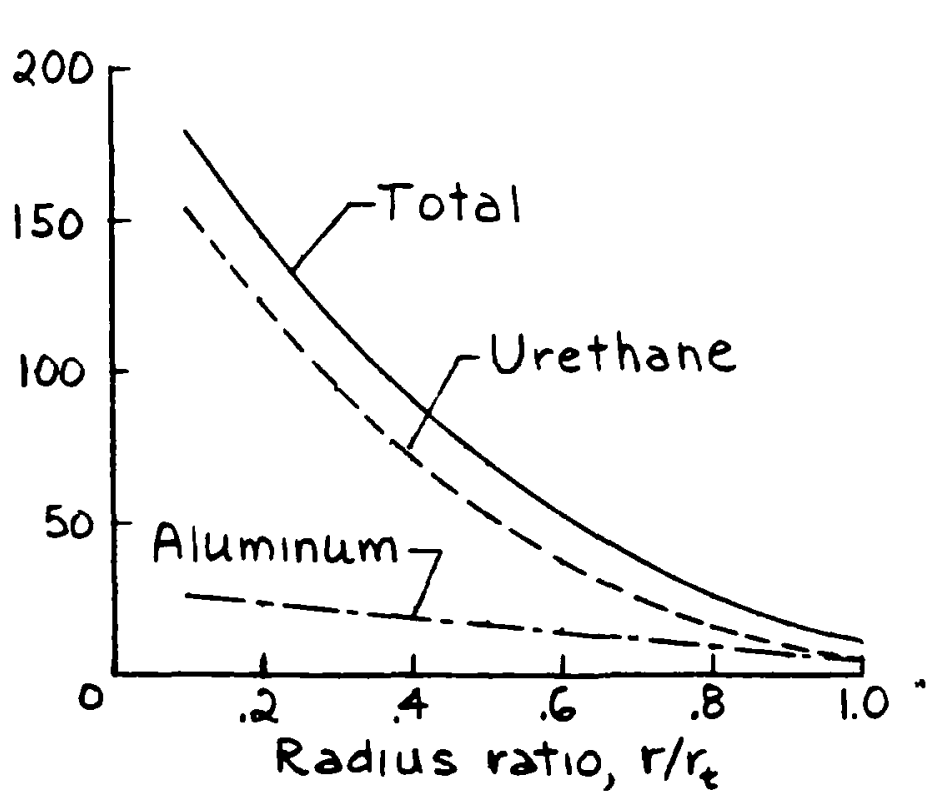

(b) Aluminum plates.

Figure 42:- Unit weight along span of reinforced urethane blade with reference blade sections. Plates sized for stiffness-high design spec. 

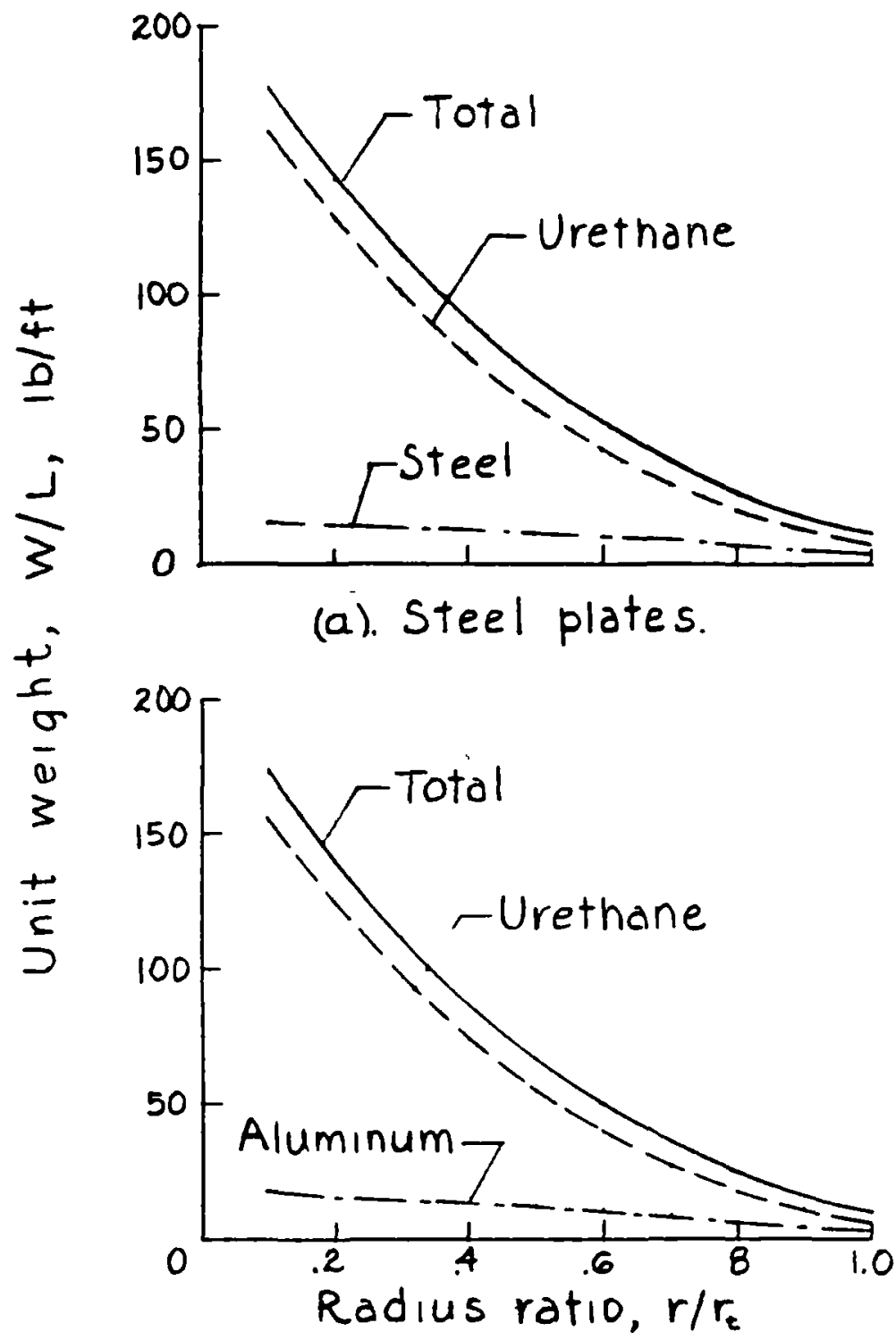

(b) Aluminum plates.

Figure 43. - Unit weight along span of reinforced urethane blade with reference blade sections. plates sized for stiffness- low design spec. 


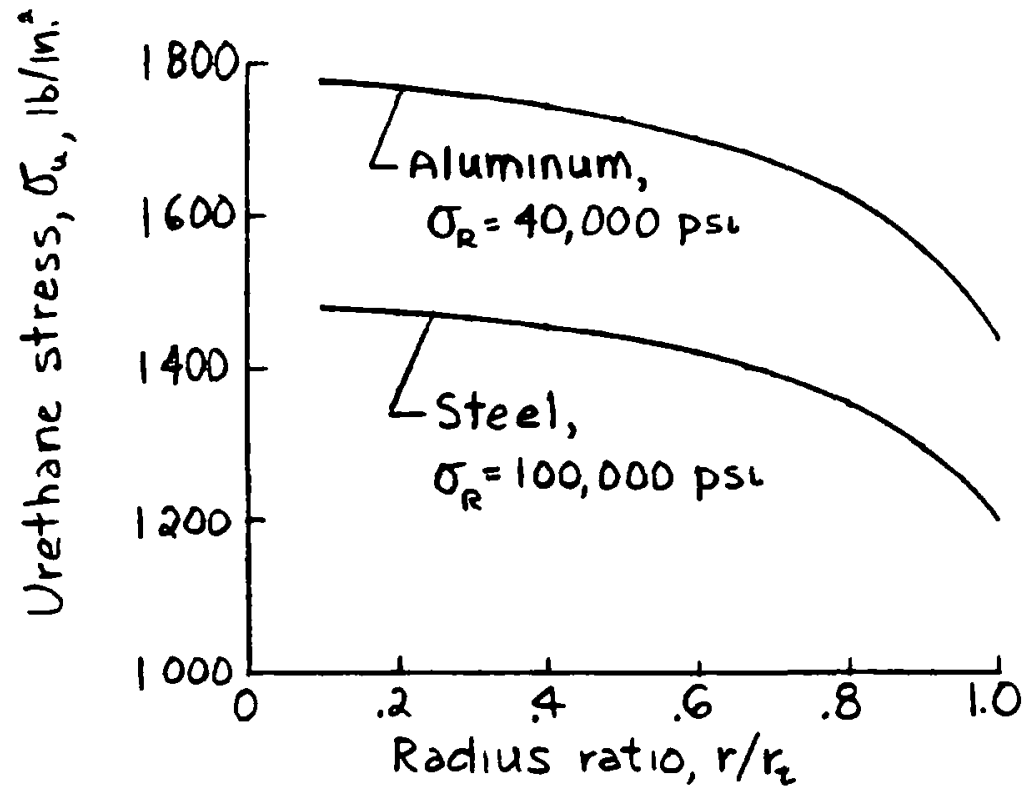

(a). Variation with radius

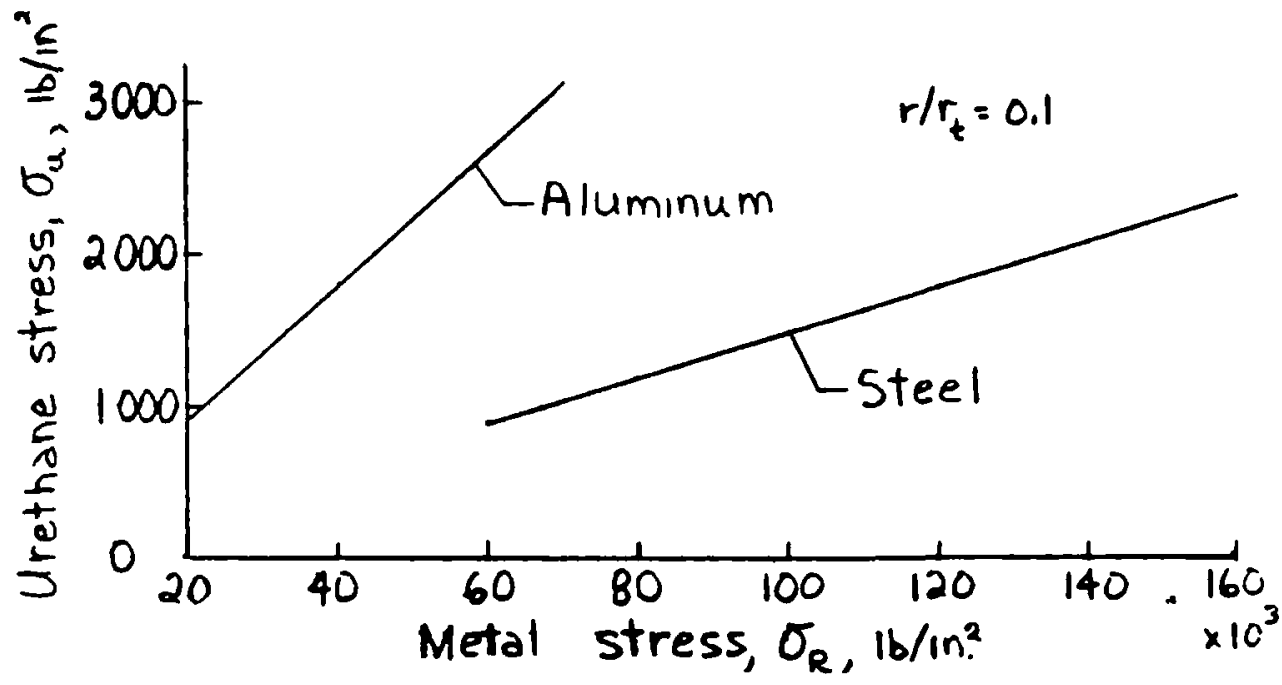

(b) Variation with metal reinforcement stress.

Figure 44-Maximum stress in urethane for blade with metal reinforcement plates. Plate thickness, 0.25 in.; reference blade section.

68 
where $f_{S}$ is the safety factor, and $f_{c}$ is the stress concentration factor. With the adoption of values $f_{c}=1.5$ and $f_{S}=1.85$ for material $E$,

$$
\left(\sigma_{u}\right)_{d}=2001 \text { psi }
$$

Thus, as long as the design stress in the reinforcement plates is less than 45000 psi for aluminum or $135000 \mathrm{psi}$ for steel (fig. 40(b)), the urethane maxtmum stress will be below a reasonable allowable value.

In figure 40, plate widths required to satısfy the moment resistance were determined for stresses of $100000 \mathrm{psl}$ in the steel plates and $40000 \mathrm{psi}$ in the aluminum plates. Thus, these widths are close to the minimum values that would result from a maximum allowable stress of $2000 \mathrm{psi}$ in the urethane. However, with the reinforcement plate sized for stiffness rather than moment resistance, the stresses in both the metal and the urethane will be substantially below their respective design or allowable values in a full-scale blade composed of reference cross sections.

\section{MODIFIED BLADE SECTION}

\section{Analysis}

For the reference blade configuration discussed in the previous section, it was found that the weight per unit length of the blade increased rapidly toward the base of the blade, and that most of the blade weight was in the urethane portion (fig. 42). Thus, if the potential for reducing blade weight is to be explored, a blade section with reduced cross-sectional area compared to the reference configuration (especially in the lower radius regions) should be considered. Such a modified blade section was obtained by arbitrarily reducing the skin thickness and the spar thickness of the blade section at the 20 percent radius point. In addition, the spar sections were moved forward to place the supports closer to the center of pressure. The modified cross section at $r / r_{t}=0.2$ is shown in figure 45 compared to the original reference configuration.

The moment of inertia of the modified blade section at $r / r_{t}=0.2$ was determined in appendix $\mathrm{F}$ to be $4275.7 \mathrm{in}^{4}$ (compared to $5945 \mathrm{in}^{4}$ for the reference section). The cross-sectional area is 200.2 in $^{2}$ (compared to 288.0 in $^{2}$ ). It was then assumed that the modified reduced-material section is tapered uniformly toward the tip of the blade so that the area of the modified section at $r / r_{t}=0.9$ is 10 percent less than that of the reference section at that radial position. By such means, linear spanwlse variations of moment of inertia $I_{u, f}$ and cross-sectional area $A_{u, f}$ were established for the modified allurethane cross sections. These values are listed in appendix $F$.

Values of required reinforcement plate width for the stiffness design specification were determined from the general equation for $b_{R}$ (eq. (E26)) with values of $I_{u, f}$ from the tabulation of appendix $F$. Both steel and aluminum reinforcement plates are considered for both the high and low design 


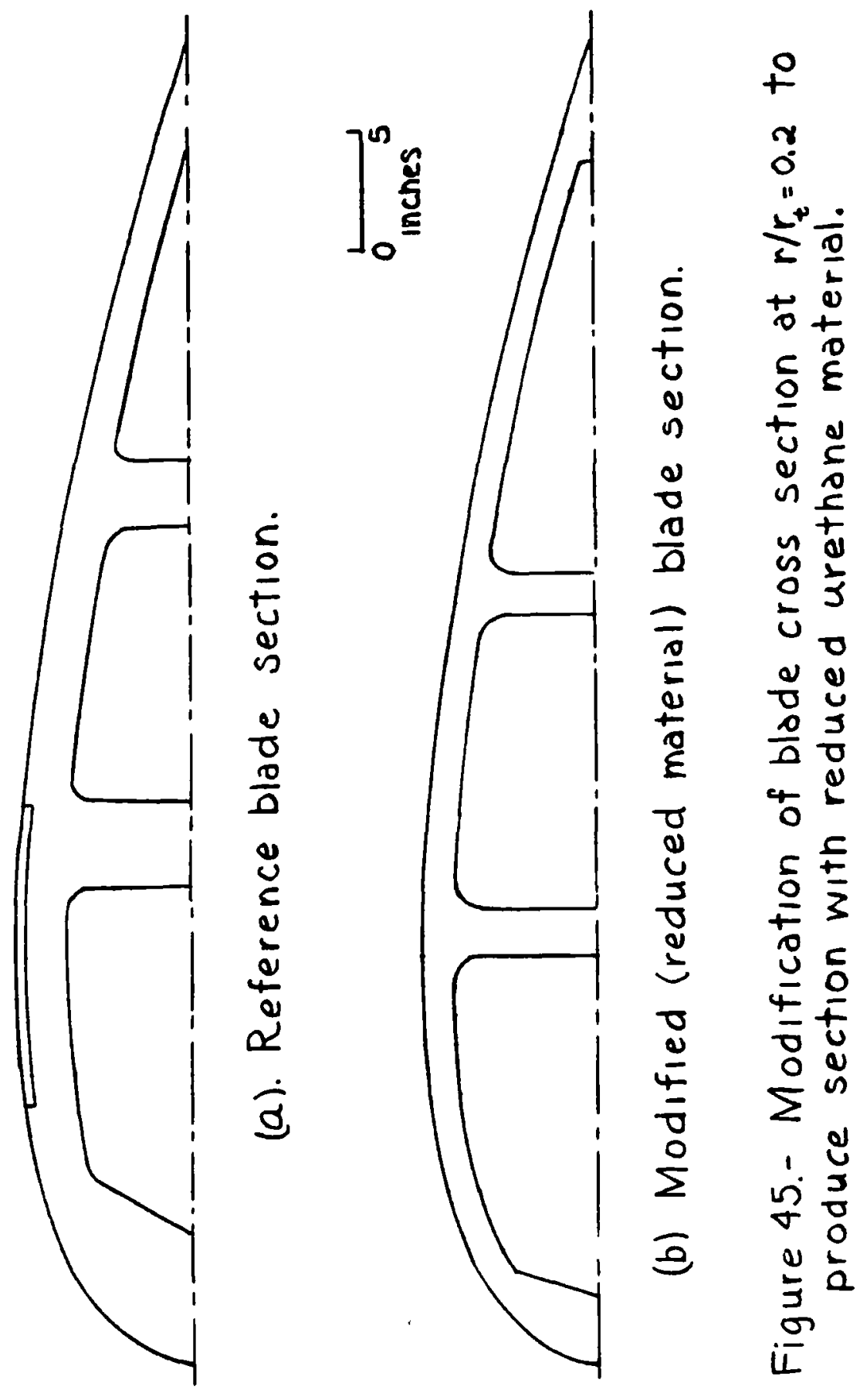


stiffness specifications. equation (eq. (E28)) with
Blade unit weight was determined from the general $A_{U, f}$ values from appendix $F$.

\section{Results}

Inasmuch as the moment of inertia of the modified reduced-material section is less than that for the reference blade section, the difference between required and available variations of stiffness EI for the modified all-urethane blade will be even larger than that for the reference blade (fig. 39). The comparison is shown in figure 46. Consequently, the width of reinforcement plate required to supply the specified stiffness will be greater than for the reference blade. Figures 47 and 48 show this comparison for a urethane blade reinforced with 0.25 -inch steel and aluminum plates, respectively, as required for the high and low stiffness specifications. Plate thickness for the modified cross section, compared to the reference blade section, is increased by a maximum of about 10 percent at the blade base for the high design specification and around 14 percent for the low specifications.

The unit weight breakdown for a reinforced blade with modified cross sections is shown in figures 49 and 50 for the high and low stiffness specifications. The urethane still constitutes the major contributor to the total weight, although the proportion is less than for the reference blade sections (fig. 42). The comparison of total unit weight for reinforced blades with the different urethane cross-section configurations is shown in figure 51. A substantial reduction in unit weight is seen near the base for the modified cross section blade in all cases. Total weight for the modified blade is calculated to be 3385 and 3167 pounds for the high and low design specifications for steel plates, and 3197 and 3031 pounds, respectively, for aluminum plates.

\section{WEIGHT COMPARISON}

Calculated total weights for the full-scale 62.5-foot reinforced urethane blades considered in the previous analysis are listed in table XI compared to

TABLE XI. - BLADE WEIGHT COMPARISON

\begin{tabular}{|l|c|c|c|c|c|}
\hline Material & \multicolumn{3}{|c|}{$\begin{array}{c}\text { Reinforced urethane } \\
\text { blade, Ib }\end{array}$} & $\begin{array}{c}\text { MOD-0 } \\
\text { blade, } \\
\text { 1b }\end{array}$ \\
\cline { 2 - 5 } & $\begin{array}{c}\text { Reference } \\
\text { sections }\end{array}$ & \multicolumn{2}{c|}{$\begin{array}{c}\text { Modified } \\
\text { sections }\end{array}$} & \\
\cline { 2 - 5 } & $\begin{array}{c}\text { High } \\
\text { spec. }\end{array}$ & $\begin{array}{c}\text { Low } \\
\text { spec. }\end{array}$ & $\begin{array}{c}\text { High } \\
\text { spec. }\end{array}$ & $\begin{array}{c}\text { Low } \\
\text { spec. }\end{array}$ & \\
\hline Stee1 & 4235 & 4035 & 3385 & 3167 & ---- \\
Aluminum & 4075 & 3909 & 3197 & 3031 & 2000 \\
Fiberglass & ---- & ---- & ---- & --- & 2400 \\
\hline a Weight includes hub adapter.
\end{tabular}




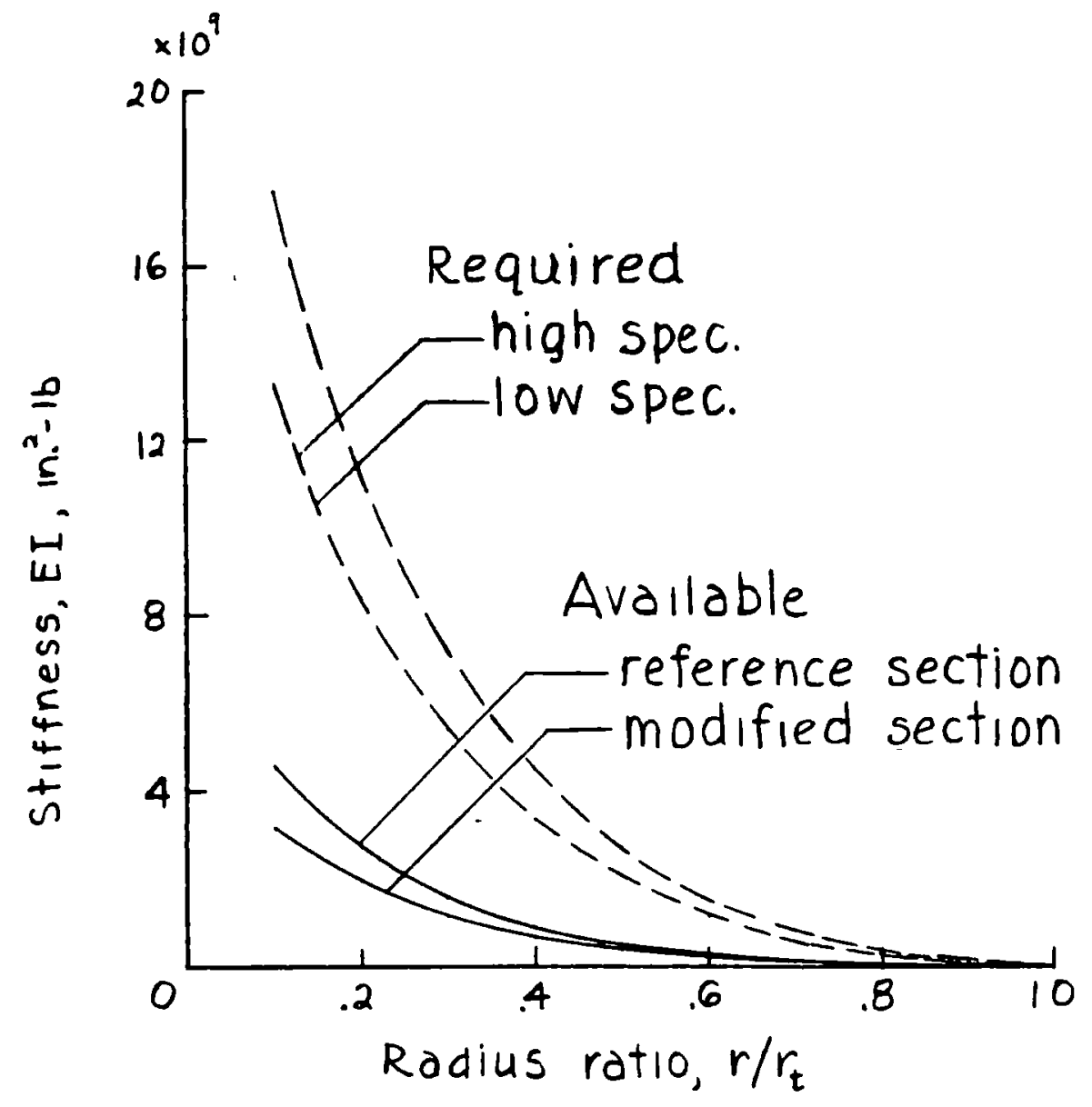

Figure 46.- Comparison of available and require stiffness for all-urethane blades, material $E$.

72 


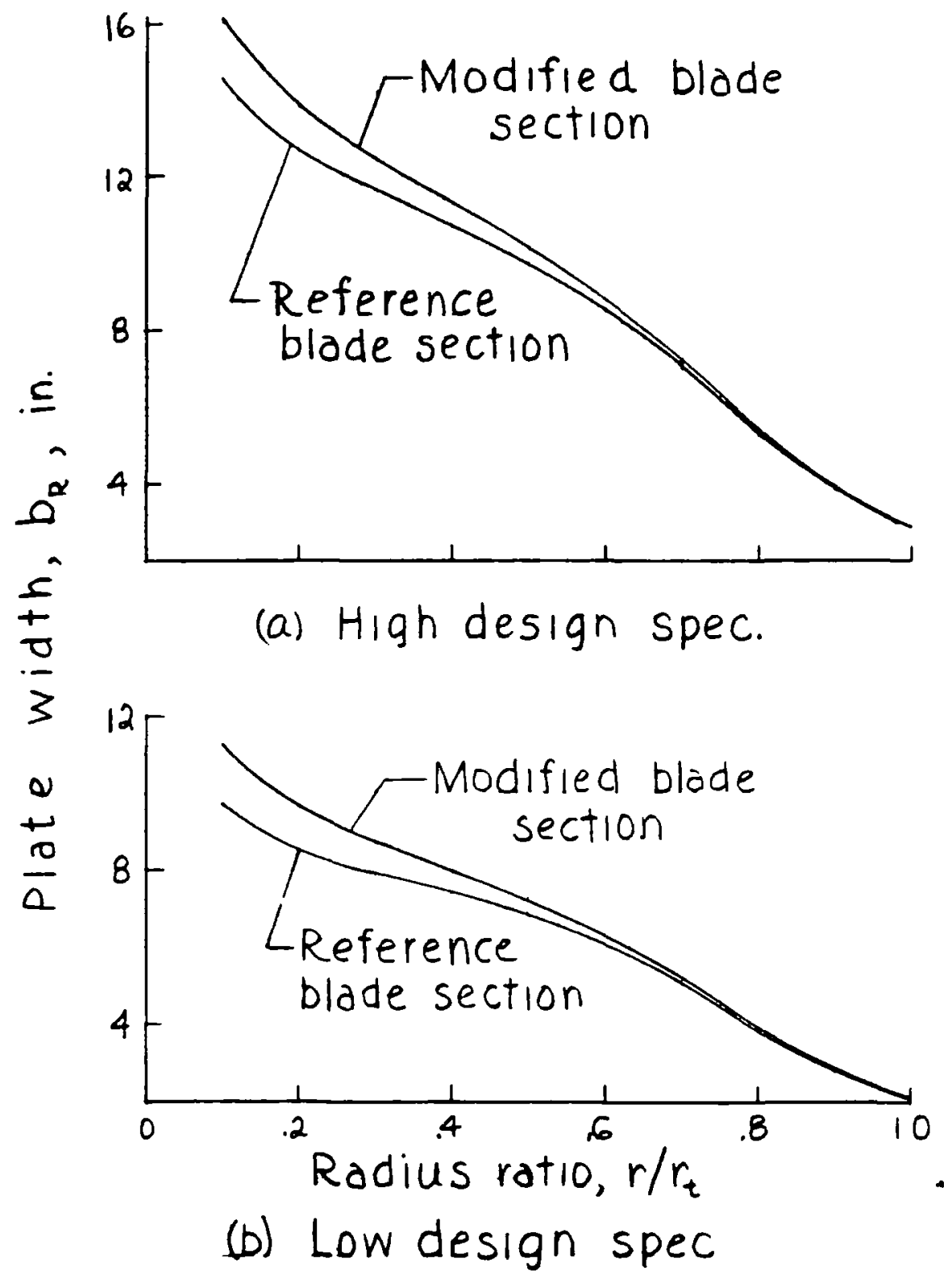

Figure 47.-Comparison of steel reinforcement plate width needed for stiffness design specification. Plate thickness, $0.25 \mathrm{in}$. 

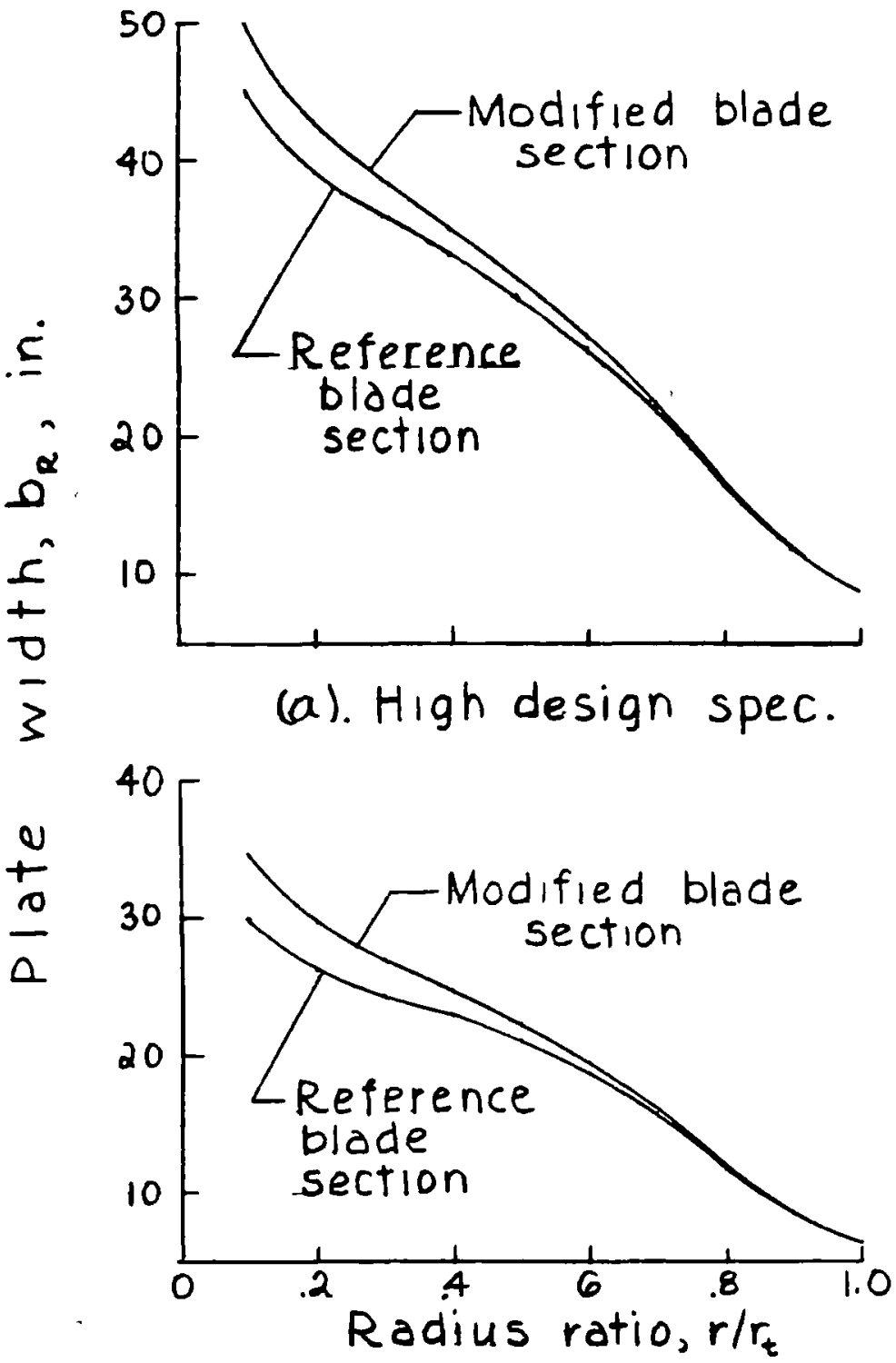

(b). Low design spec.

Figure 48. - Comparison of aluminum reinforcement plate width needed for stiffness design spec1. fication. Plate thickness, 0.25 in. 


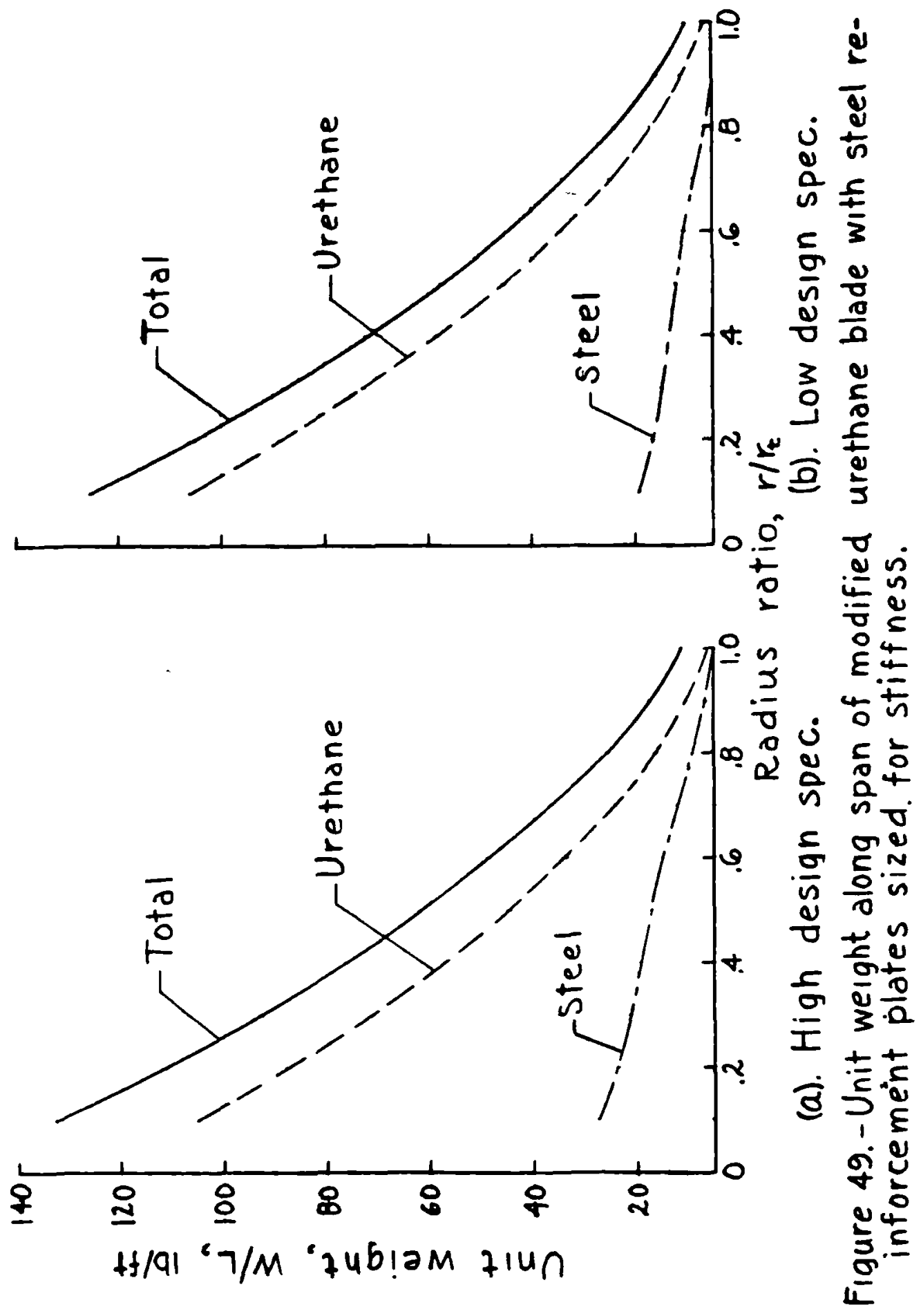




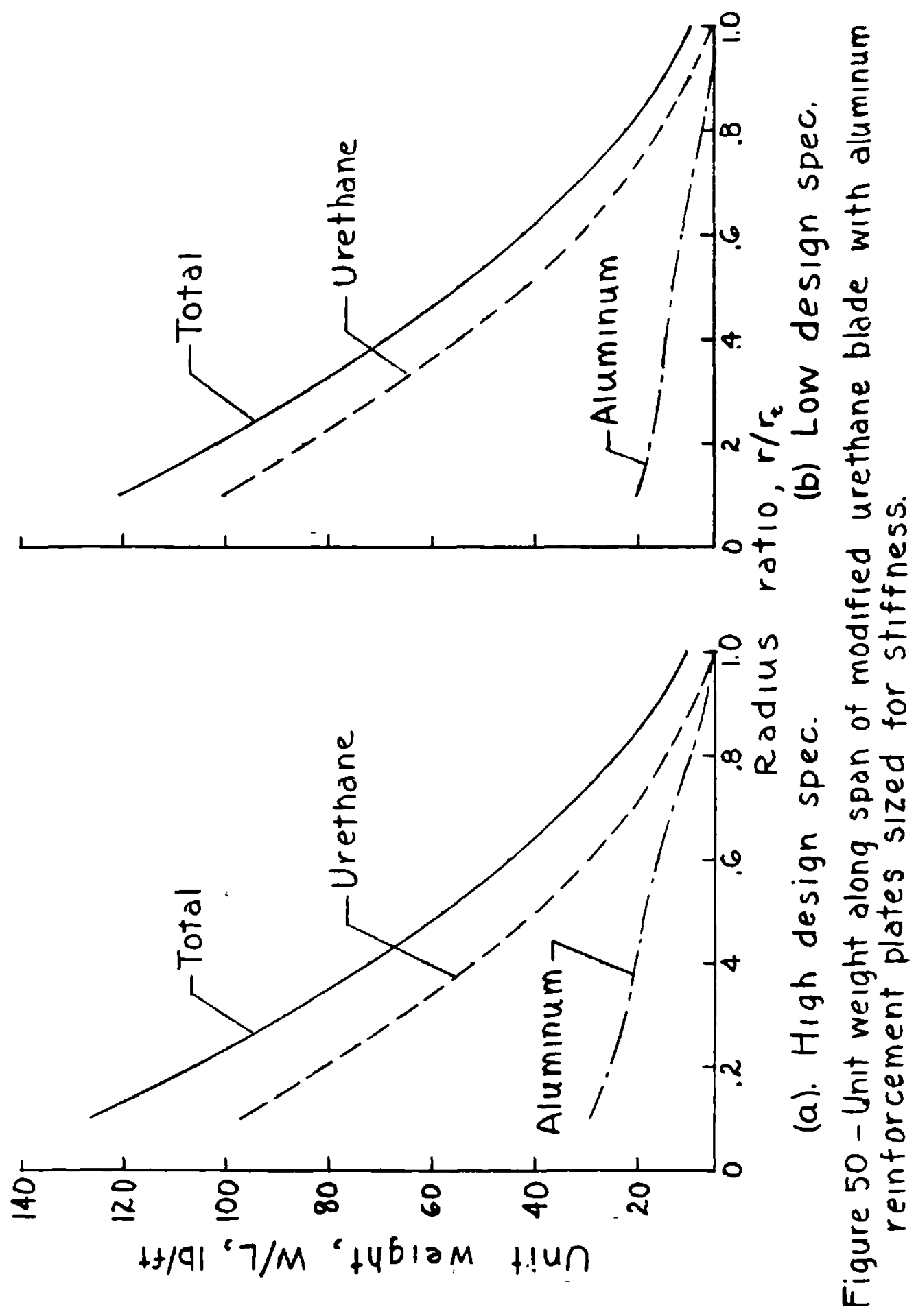




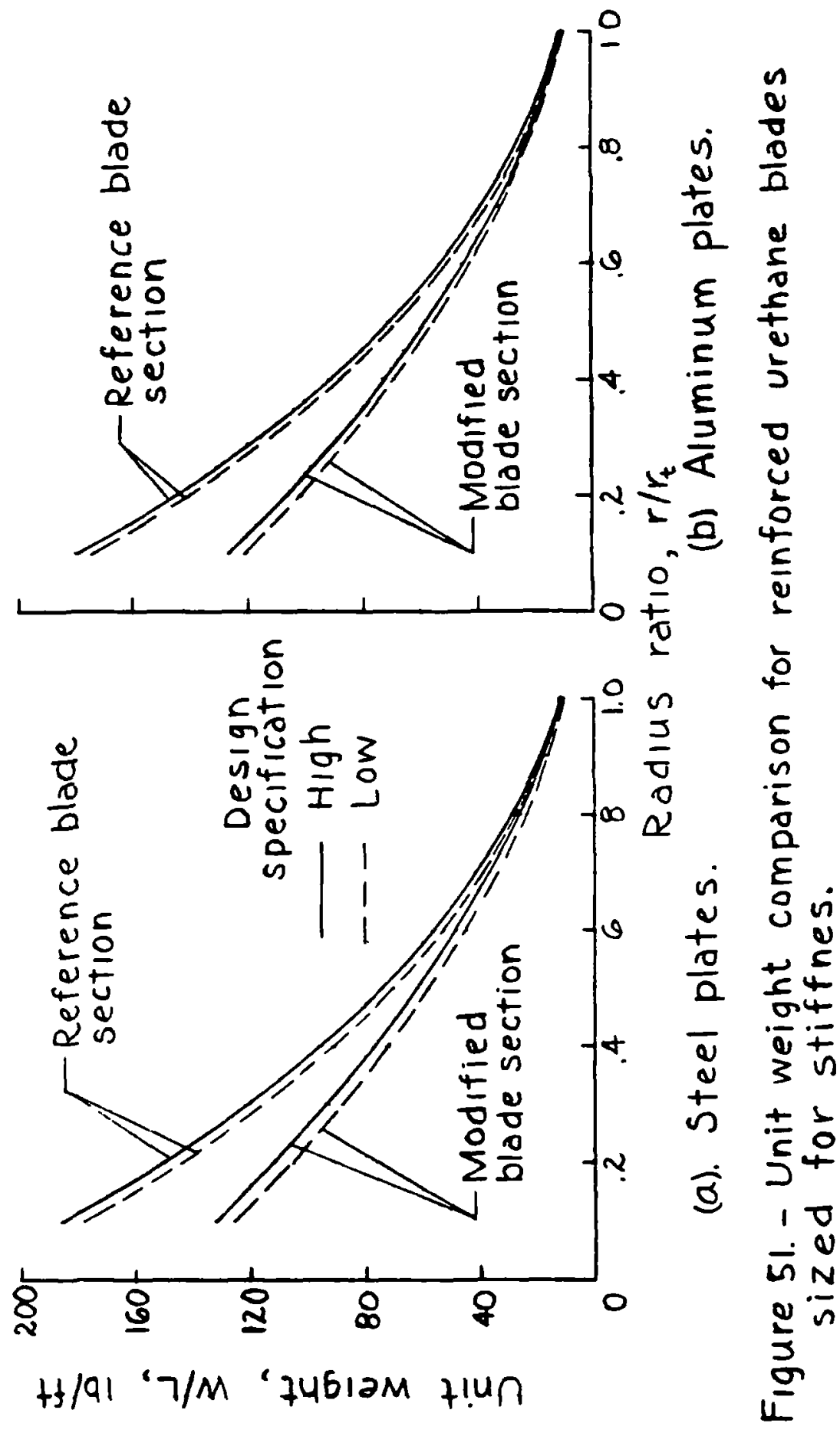


the blade weight for the MOD-0 wind turbine rotor. The reinforced urethane blade designs considered in this analysis are seen to be considerably heavier than a conventional airplane-type blade for application to the MOD-0 type of wind turbine. The tabulated values further indicate that a relieving of the design specifications of the magnitude considered in the analysis does not influence the blade total weight to any large degree. However, the crosssectional area of the blade profile appears to have a prime effect on blade weight.

Because of the exploratory nature of the design analysis, the two blade cross-sections considered were rather arbitrarily determined. A minimum design blade weight could therefore not be determined. The extent to which the blade design weight can be reduced below the values obtained from these profiles will depend on the minimum values of skin and spar thickness that can be tolerated for the urethane in a practical construction. Such determination is beyond the scope of this report, and should be a key concern in any further studies of the feasibility of urethane as a rotor blade material.

\section{CONCLUDING REMARKS}

The primary result of the exploratory evaluation of cast urethane as a construction material for wind turbine blades is that the major structural loads will have to be carried by metal reinforcement. The modulus of elasticity of urethane ( $<460000 \mathrm{psi}$ ) is much too low to accommodate the bending and stiffness requirements of the blades. Thus, the strength properties of the urethane need not be of paramount concern. For example, if the urethane can serve primarily as a bond or filler system, urethane types less brittle than the formulations considered in the investigation may be used. Brittleness assoclated with high-strength urethane formulations is not a desirable property for wind turbine blade applications.

Although the calculated weight of the reinforced urethane blade sections considered was substantially greater than that of the MOD-0 aluminum blades, it is not known what the minimum weight potential is for optimum blade crosssections. However, even if optimum reinforced urethane blades are somewhat heavier than conventional blades, that alone need not be a serious deterrent to its consideration. The principal question concerning its feasibility lies in the extent to which the casting approach can result in a considerable reduction in fabrication cost.

For the design urethane blade configurations examined, the required metal reinforcement constitutes a small fraction of the blade crosssectional area. Nevertheless, the bonding between the urethane and the reinforcement material, as well as the attachment to the blade hub, become issues of concern. Further studies of the fabrication aspects of reinforced urethane blades are therefore in order.

In the final analysis, the potential usefulness of cast urethane will depend on the integration and fabrication aspects of reinforced blade configurations. Of particular interest is whether such reinforced configurations can be successfully fabricated at considerably reduced costs compared to conventional blade construction techniques. Of further concern is the extent to which the cross-sectional area of the urethane blade profiles can be reduced in order to minimize the overall weight of the blade. 
Detalls of all the material specimens used in the test program are given in table Al. Included in the table are the identification numbers of each specimen, the number of specimens used, and a description of the specimen properties. Each of the nine urethane formulations (table I) is identified by the prefix letter in the first column.

The main purpose of the flexure tests was to determine the modulus of elasticity of each urethane material. A secondary objective was to observe the structural behavior of the beam specimens with regard to such considerations as deflection and hysteresis characteristics, deflection linearity, and permanent deformation.

Three-point loading ( $P$ ) was used for the $3 / 4$ in. by $3 / 4$ in. by 15 inches specimens, and four-point loading $\left(P_{L}\right.$ and $\left.P_{R}\right)$ was used for the ones with dimensions $3 / 4$ in. by $3 / 4$ in. by 30 inches. Material specimens $A$ through $F$ were first loaded gradually up to $P=P_{L}=P_{R} \cong 2000$ grams, and then gradually unloaded to zero grams. The deflections during loading and unloading were recorded for 100-gram loading increments. The results were examined in terms of the structural characteristics stated above, and also by observations on creep resistance when deflection measurements were recorded. For the three-point loading, the 2000-gram force corresponds to a maximum stress of $188 \mathrm{psi}$ in the specimen, and a maximum stress of 502 psi for the four-point loading specimen.

After unloading from the 2000-gram load, each specimen was loaded again gradually to much higher levels of stress, and then unloaded gradually to zero. With the second loading, the maximum bending stresses in the specimens reached as high as $2500 \mathrm{psi}$. This was still in the linear range of the load-deflection curves. The same observations and studies were made here as for the 2000-gram loading. Beam deflection is designated by $\Delta$.

The modulus of elasticity for each specimen was obtained from load and deflection values from the use of the appropriate beam deflection equations and a specimen nominal cross section of $3 / 4 \mathrm{in}$. by $3 / 4 \mathrm{in}$. The modulus equation for the three types of specimen sizes and loadings used is as follows:

$$
E\left(\frac{1 b}{i n}\right)=\text { Multiplier } \times \frac{P}{\Delta}\left(\frac{1 b}{i n .}\right)
$$

$\begin{array}{llllr} & \text { S1ze } & \text { Loading } & \text { Gage length } & \text { Multiplier } \\ 3 / 4 \times 3 / 4 \times 15 \text { in. } & \text { three-pt. } & 12 \mathrm{in.} & 1365.3 \\ 3 / 4 \times 3 / 4 \times 15 \text { in. } & \text { four-pt. } & 12 \mathrm{in.} & 2022.7 \\ 3 / 4 \times 3 / 4 \times 30 \text { in. } & \text { four-pt. } & 24 \mathrm{in.} & 16181.7\end{array}$

Values of $P / \Delta$ and $E$ were determined for all values of load $P \geq 500$ gram for the low-loading tests ( $P$ up to $2000 \mathrm{~g}$ ), and for all values of $P \geq 2000$ gram for the high-loading tests (up to $24000 \mathrm{~g}$ ). The flexure modulus for a given material was then obtained as the average of the local values of $E$. 
Results of the beam flexure tests were expressed in terms of tabulated and plotted values of load and deflection. The figure numbers and table numbers for the results for each of the urethane materials tested are listed below:

\begin{tabular}{|c|c|c|}
\hline Material & Table numbers & Figure number \\
\hline A & $\mathrm{A} 2, \mathrm{~A} 3$ & $\mathrm{~A} 1, \mathrm{~A} 2$ \\
\hline B & $A 4, A 6$ & A3,A4 \\
\hline C & $A 5, A 7$ & $\mathrm{~A} 5, \mathrm{~A} 6$ \\
\hline $\mathrm{D}$ & $\mathrm{A} 8, \mathrm{~A} 9, \mathrm{~A} 10, \mathrm{~A} 11$ & $A 7, A 8, A 9$ \\
\hline E & $\mathrm{A} 12, \mathrm{~A} 13$ & $\mathrm{~A} 10, \mathrm{~A} 11$ \\
\hline $\mathbf{F}$ & $\mathrm{A} 14, \mathrm{~A} 15, \mathrm{~A} 16$ & $\mathrm{~A} 12, \mathrm{~A} 13, \mathrm{~A} 14$ \\
\hline G & A17 & A15 \\
\hline $\mathrm{H}$ & VI & 6 \\
\hline GG & A18 & A16 \\
\hline
\end{tabular}

The results of the modulus calculations for the specimens covered in the flexure tests are given below.

FLEXURAL MODULUS FOR URETHANE MATERIALS

\begin{tabular}{|c|c|c|c|}
\hline Material & $\begin{array}{c}\text { Modulus, } \\
\mathrm{E}, \\
1 \mathrm{~b} / \mathrm{in}^{2} \times 10^{3}\end{array}$ & Material & $\begin{array}{c}\text { Modulus, } \\
\mathrm{E}, \\
1 \mathrm{~b} / \mathrm{in}^{2} \times 10^{3}\end{array}$ \\
\hline $\begin{array}{l}A 1^{a} \\
A 1^{b} \\
A 2^{a} \\
A 2^{b}\end{array}$ & $\begin{array}{l}35.3 \\
42.4 \\
67.4 \\
63.7\end{array}$ & $\begin{array}{l}\mathrm{D} 2^{\mathrm{b}} \\
\mathrm{D} 3_{\mathrm{b}}^{\mathrm{b}} \\
\mathrm{D} 3_{\mathrm{b}}^{\mathrm{b}} \\
\mathrm{D} 4^{\mathrm{a}}\end{array}$ & $\begin{array}{l}257.4 \\
274.6 \\
277.7 \\
266.2\end{array}$ \\
\hline $\begin{array}{l}\mathrm{B} 1_{\mathrm{b}}^{\mathrm{a}} \\
\mathrm{B} 1_{\mathrm{a}}^{\mathrm{a}} \\
\mathrm{B} 2^{\mathrm{b}}\end{array}$ & $\begin{array}{l}269.1 \\
266.7 \\
281.0 \\
277.3\end{array}$ & $\begin{array}{l}\mathrm{E} 1_{\mathrm{b}}^{\mathrm{a}} \\
\mathrm{E} 1_{\mathrm{a}}^{\mathrm{a}} \\
\mathrm{E} 2_{\mathrm{b}}^{\mathrm{b}} \\
\mathrm{E} 2^{\mathrm{a}}\end{array}$ & $\begin{array}{l}460.0 \\
460.9 \\
464.1 \\
447.7\end{array}$ \\
\hline $\begin{array}{l}\mathrm{C} 1_{\mathrm{b}}^{\mathrm{a}} \\
\mathrm{C} 1^{\mathrm{a}} \\
\mathrm{C} 2^{\mathrm{b}} \\
\mathrm{C} 2^{\mathrm{a}}\end{array}$ & $\begin{array}{l}157.9 \\
148.8 \\
174.2 \\
167.9\end{array}$ & $\begin{array}{l}F 1_{b}^{a} \\
F 1^{a} \\
F 2_{b}^{b} \\
F 2_{b}^{b}\end{array}$ & $\begin{array}{l}274.4 \\
273 \cdot 1 \\
255 \cdot 5 \\
269 \cdot 5\end{array}$ \\
\hline $\begin{array}{l}\mathrm{D} 1_{\mathrm{b}}^{\mathrm{a}} \\
\mathrm{D} 1^{-}\end{array}$ & $\begin{array}{l}221.3 \\
259.4\end{array}$ & $\mathrm{GG}^{\mathrm{b}}$ & $\begin{array}{l}388.5 \\
356.2\end{array}$ \\
\hline
\end{tabular}


TABLE A1. - DETAILS OF TEST SPECIMENS

\begin{tabular}{|c|c|c|}
\hline Identification & $\begin{array}{l}\text { Number } \\
\text { used }\end{array}$ & Description \\
\hline $\begin{array}{c}A-7556-90-1-1238 \\
8 / 24 / 1976\end{array}$ & 4 & $\begin{array}{l}\text { Duot 110, 80\% Blongation } \\
3 / 4^{n} 4 / 3^{d_{x}} 30^{n}, S_{0.0 .}=1.05\end{array}$ \\
\hline $\begin{array}{c}A-7556-90-2-1342 \\
8 / 24 / 1976\end{array}$ & 4 & 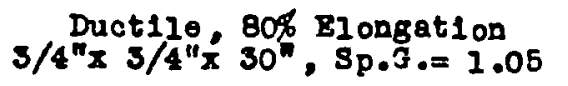 \\
\hline $\begin{array}{c}A-7556-80-6-639 \\
8 / 24 / 1976\end{array}$ & 4 & $\begin{array}{c}\text { Dact11e, } 80 \% \text { Elongation } \\
1 / 2^{n} 1 / 8^{n} \times 30^{n}, \mathrm{Sp} \cdot G=1.05\end{array}$ \\
\hline $\begin{array}{c}A-7556-90-7-617 \\
8 / 24 / 1976\end{array}$ & 4 & $\begin{array}{l}\text { Duot11e, 80\% Elongation } \\
1 / 2^{11} \times 1 / 2^{*} \times 30^{\circ}, 3 p .0 .=1.05\end{array}$ \\
\hline $\begin{array}{c}A-7556-90-3-1863 \\
8 / 24 / 1976\end{array}$ & 1 & 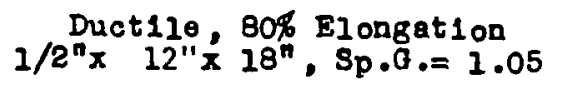 \\
\hline $\begin{array}{c}c-7556-91-2-346 \\
9 / 1 / 1976\end{array}$ & 4 & 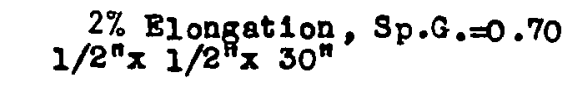 \\
\hline $\begin{array}{c}C-7556-91-3-1076 \\
9 / 1 / 1976\end{array}$ & 1 & $\begin{array}{l}2 \% \text { Elongat1on, } S_{p} \cdot O \cdot=0.70 \\
12^{n} 18^{n} \times 1 / 2^{H}\end{array}$ \\
\hline $\begin{array}{c}C-7556-91-5-341 \\
9 / 1 / 1976\end{array}$ & 4 & $\begin{array}{l}2 \% \text { Elongat1 on } S_{1 / 2^{n} \times 1 / 2^{n} \times 3} \cdot G=0.70 \\
30^{n}\end{array}$ \\
\hline $\begin{array}{c}c-7556-91-10-730 \\
9 / 1 / 1976\end{array}$ & 4 & 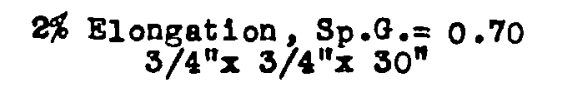 \\
\hline $\begin{array}{c}C-7556-91-11-710 \\
9 / 1 / 1976\end{array}$ & 4 & $\begin{array}{l}\text { 28 Elongation } \\
3 / 4^{n} \times 3 / 4^{n} \times 30^{n}\end{array}$ \\
\hline $\begin{array}{c}\text { B- } 7556-91-6-2331 \\
8 / 1 / 1976\end{array}$ & 1 & 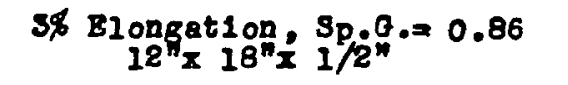 \\
\hline $\begin{array}{c}B-7556-91-7-494 \\
8 / 1 / 1976\end{array}$ & 4 & 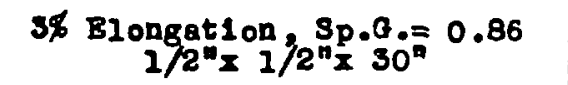 \\
\hline
\end{tabular}


TABLE A1 - Continued

\begin{tabular}{|c|c|c|}
\hline Identification & $\begin{array}{l}\text { Number } \\
\text { used }\end{array}$ & Description \\
\hline $\begin{array}{c}B-7556-91-8-483 \\
9 / 1 / 1976\end{array}$ & 4 & 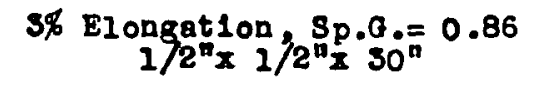 \\
\hline $\begin{array}{c}B-7556-91-12-1048 \\
9 / 1 / 1976\end{array}$ & 4 & 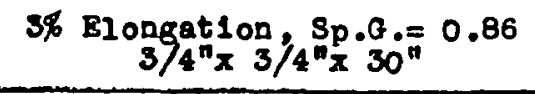 \\
\hline $\begin{array}{c}B-7556-91-13-1034 \\
9 / 1 / 1976 \\
\end{array}$ & 4 & 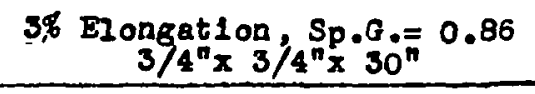 \\
\hline $\begin{array}{c}D-7556-93-5-1845 \\
9 / 9 / 1976\end{array}$ & 1 & 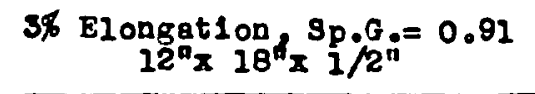 \\
\hline $\begin{array}{c}D-7556-93-3-1365 \\
9 / 9 / 1976\end{array}$ & 4 & $\begin{array}{c}38 \text { Elongat1 on } \\
3 / 4^{n} \times 3 / 4^{\prime \prime} \times 30^{n}\end{array}$ \\
\hline $\begin{array}{c}D-7556-98-8-1363 \\
9 / 9 / 1976\end{array}$ & 4 & 38 Elongat1on, ${ }_{3 / 4^{n} \times 3 / 4^{\prime \prime} \times 30^{n}}^{S p} \cdot 0.91$ \\
\hline $\begin{array}{c}D-7556-93-7-632 \\
9 / 9 / 1976\end{array}$ & 4 & $\begin{array}{c}3 \% \text { Elongat1 on, } s_{p} \cdot 3 \cdot=0.91 \\
1 / 2^{n \times} 1 / 2^{n} \times 30^{n}\end{array}$ \\
\hline $\begin{array}{c}D-7556-93-8-635 \\
9 / 9 / 1976 \\
\end{array}$ & 4 & 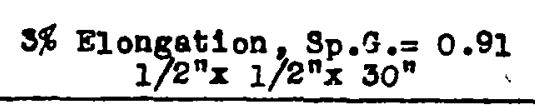 \\
\hline $\begin{array}{l}A-90-4 \\
9 / 9 / 1976\end{array}$ & 6 & $\begin{array}{l}80 \% \text { Elongation, sp.3. }=1.05 \\
12-1 n \text {. Tens1le spocimens }\end{array}$ \\
\hline $\begin{array}{l}C-91-4 \\
9 / 8 / 1976\end{array}$ & 6 & $\begin{array}{l}\text { 2\% Elongat1on, } s_{p .3}=0.70 \\
12-1 n \text {. Tens1ie spocimens }\end{array}$ \\
\hline $\begin{array}{l}8-81-14 \\
8 / 9 / 1976\end{array}$ & 6 & 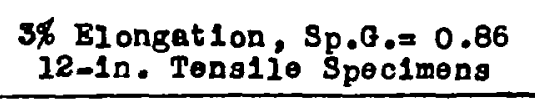 \\
\hline $\begin{array}{l}D-93-4 \\
9 / 9 / 1976\end{array}$ & 6 & 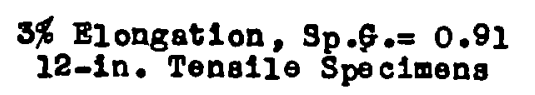 \\
\hline
\end{tabular}


TABLE A1 - Concluded

\begin{tabular}{|c|c|c|}
\hline Identification & $\begin{array}{l}\text { Number } \\
\text { used }\end{array}$ & Description \\
\hline $\begin{array}{c}E-105-2-1402 \\
10 / 20 / 76\end{array}$ & 3 & $\begin{array}{c}\text { About } 3 \phi_{2} \text { Elongat 1on, } S D \cdot G=1.0 \\
3 / 4 " x 3 / 4 " x 30^{n}=1\end{array}$ \\
\hline $\begin{array}{l}E-3-1406 \\
10 / 20 / 76\end{array}$ & 4 & 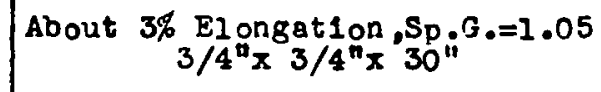 \\
\hline $\begin{array}{c}F-7556-109-1-1385 \\
10 / 28 / 76\end{array}$ & 4 & 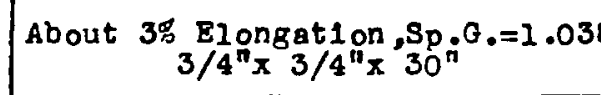 \\
\hline $\begin{array}{c}F-7556-109-1-1390 \\
10 / 28 / 76\end{array}$ & 4 & 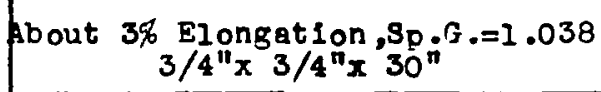 \\
\hline $\begin{array}{l}G \text { and } G G \\
18 / 28 / 76\end{array}$ & 20 & 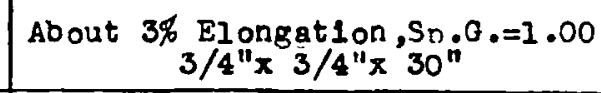 \\
\hline $12 / 28 / 76$ & 21 & $\begin{array}{c}\text { About 3\% Elongation, } \mathrm{Sp}_{\cdot}, \mathrm{s}_{0}=1.00 \\
12-1 \mathrm{n} \text {. Patigue Specimens }\end{array}$ \\
\hline $\begin{array}{l}G \text { or } G G \\
12 / 28 / 76\end{array}$ & 4 & $\begin{array}{c}\text { About 38 Elongat1on, } S_{0} S_{0}=1.00 \\
12^{n} \times 18^{n} \times 1 / 4^{\prime \prime} \text { spocimens }\end{array}$ \\
\hline$\stackrel{G G}{1 / 7 / 77}$ & 6 & $\begin{array}{l}\text { About 3\% Blongat1on, Sp. S. }=1.00 \\
3 / 4 " \text { round bars, } 30^{n} \text { long }\end{array}$ \\
\hline$\stackrel{\mathrm{R}}{1 / 27 / 77}$ & 16 & 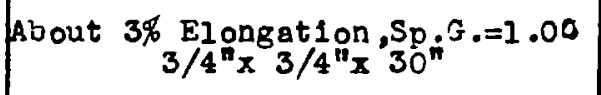 \\
\hline$\stackrel{\mathrm{H}}{1 / 27 / 77}$ & 3 & $\begin{array}{l}\text { About } 3 \% \text { Elongation, } S p \cdot G=1.00 \\
3 / 4 " \text { round bars, 30 long }\end{array}$ \\
\hline$\stackrel{\mathrm{H}}{1 / 27 / 77}$ & 15 & 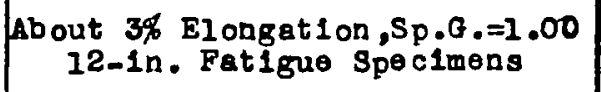 \\
\hline$\stackrel{\text { 旦 }}{1 / 27 / 77}$ & 4 & 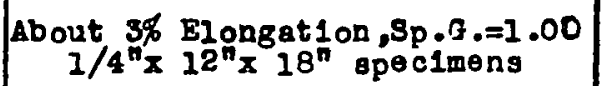 \\
\hline
\end{tabular}



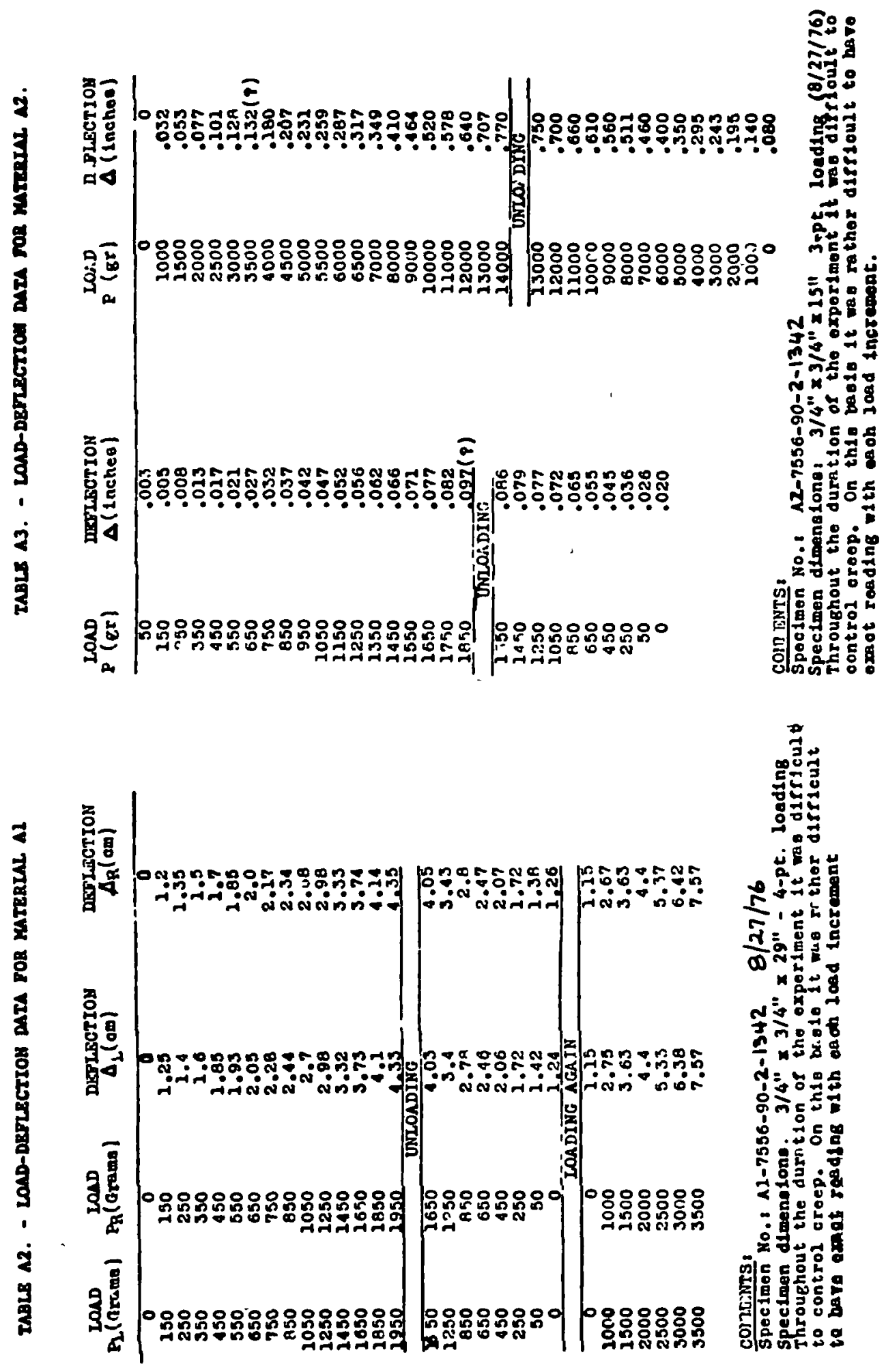

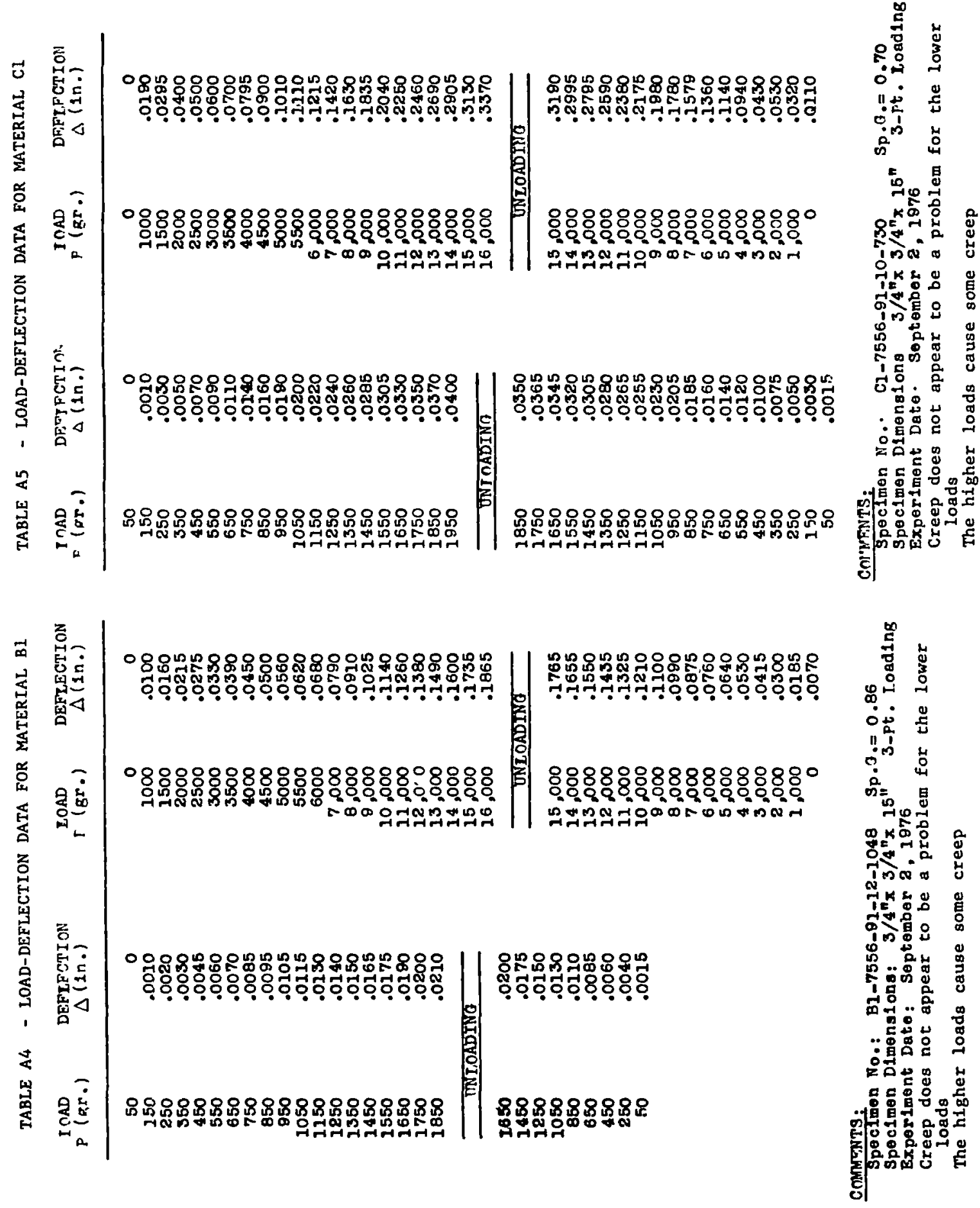


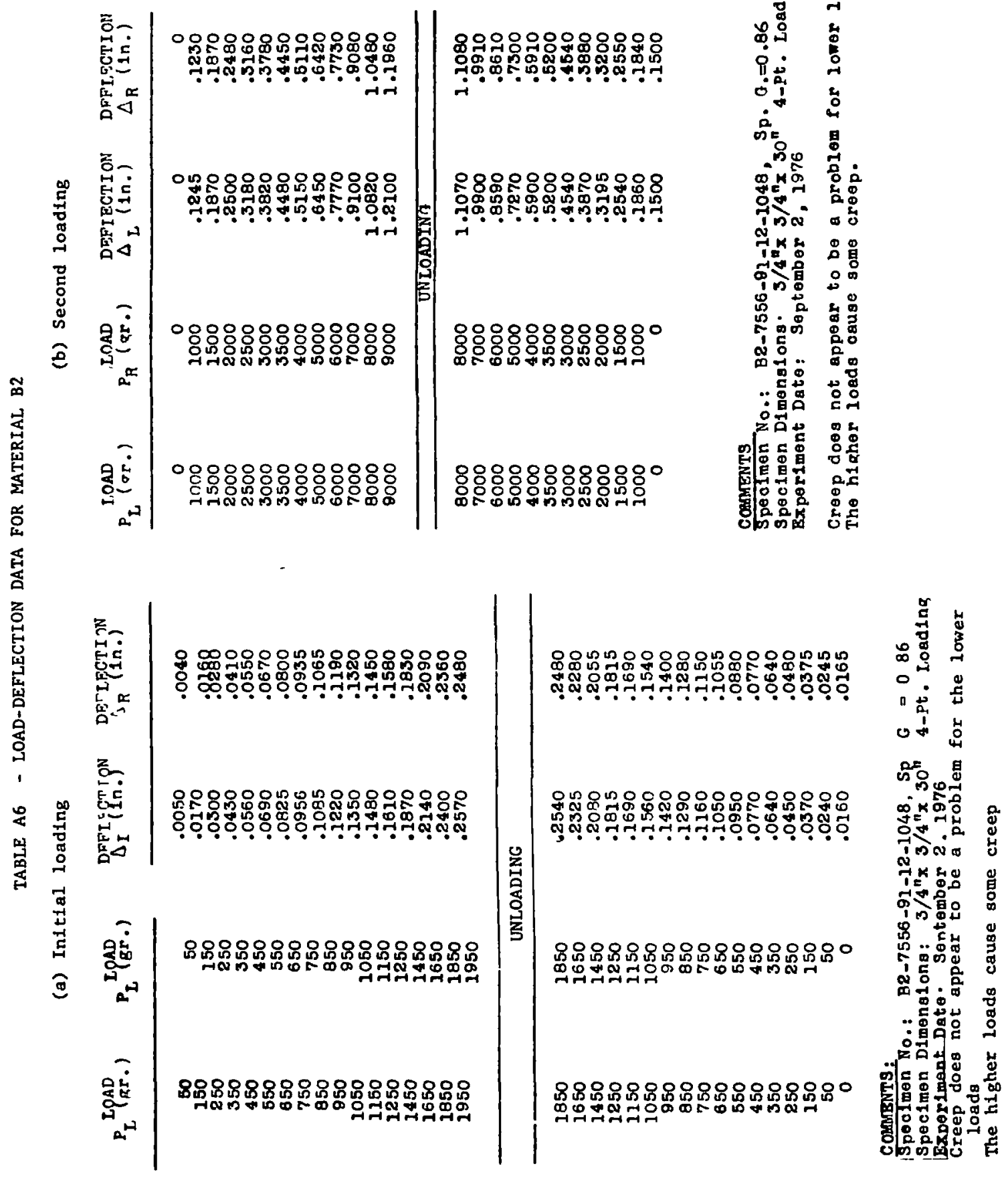




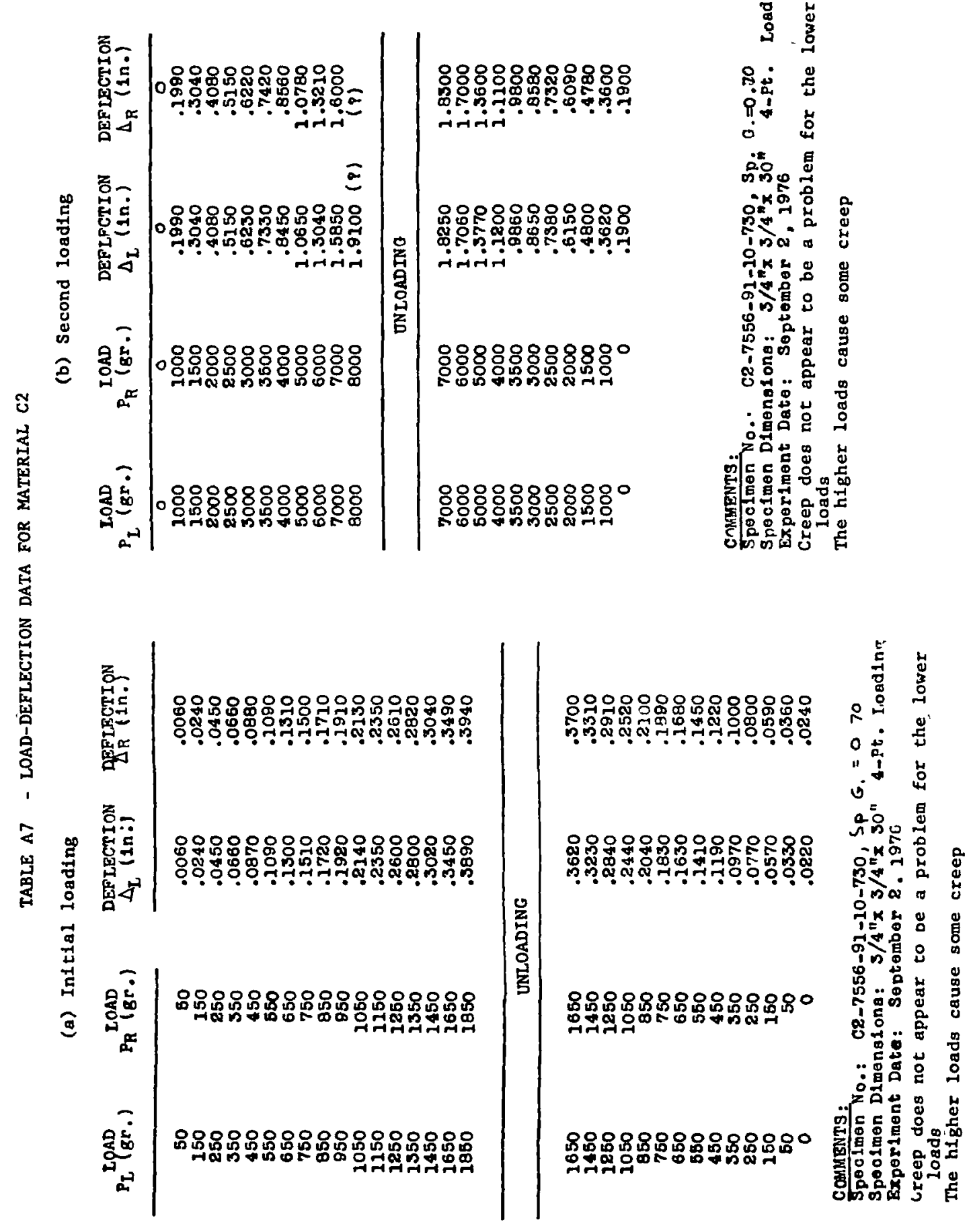



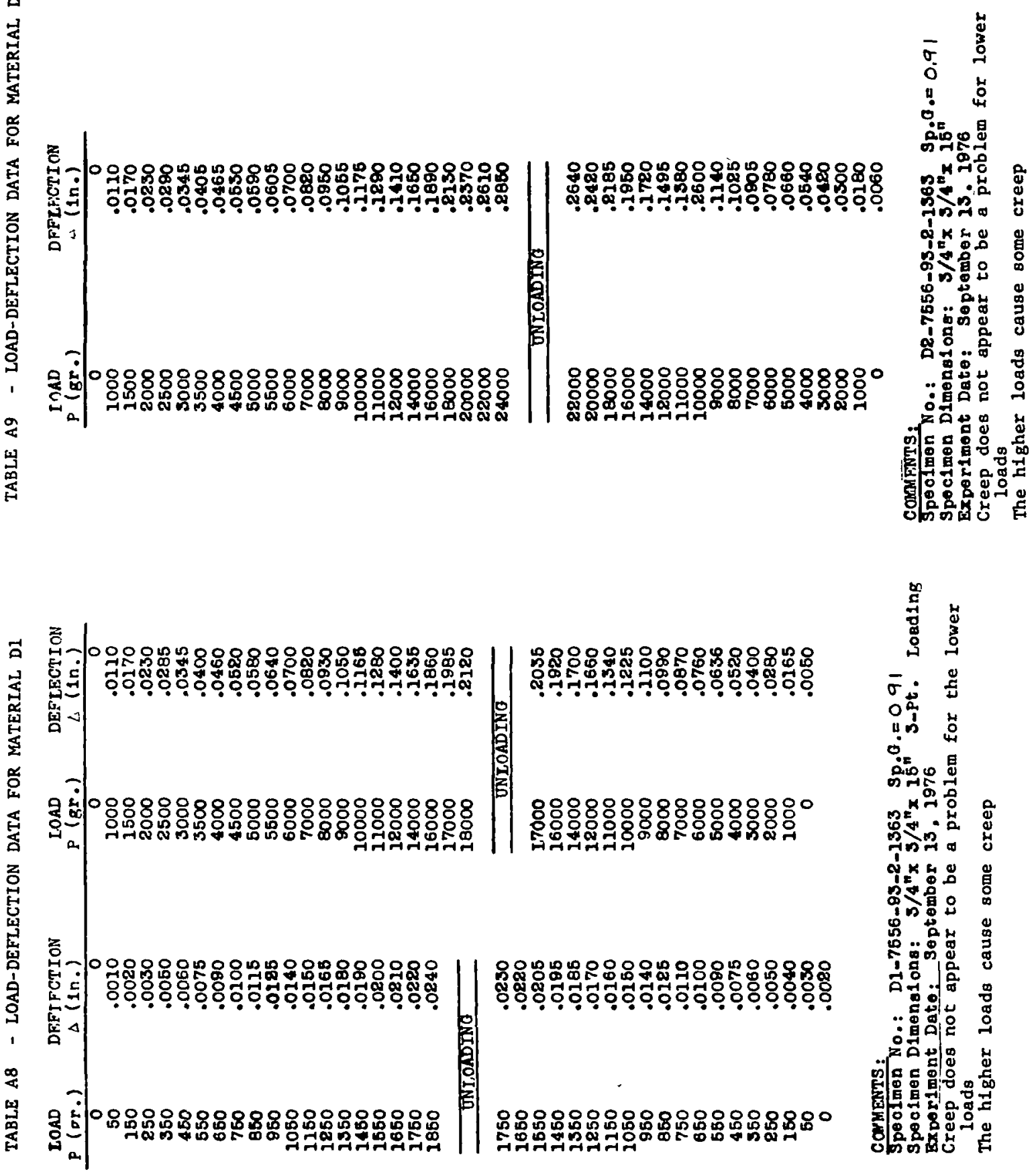


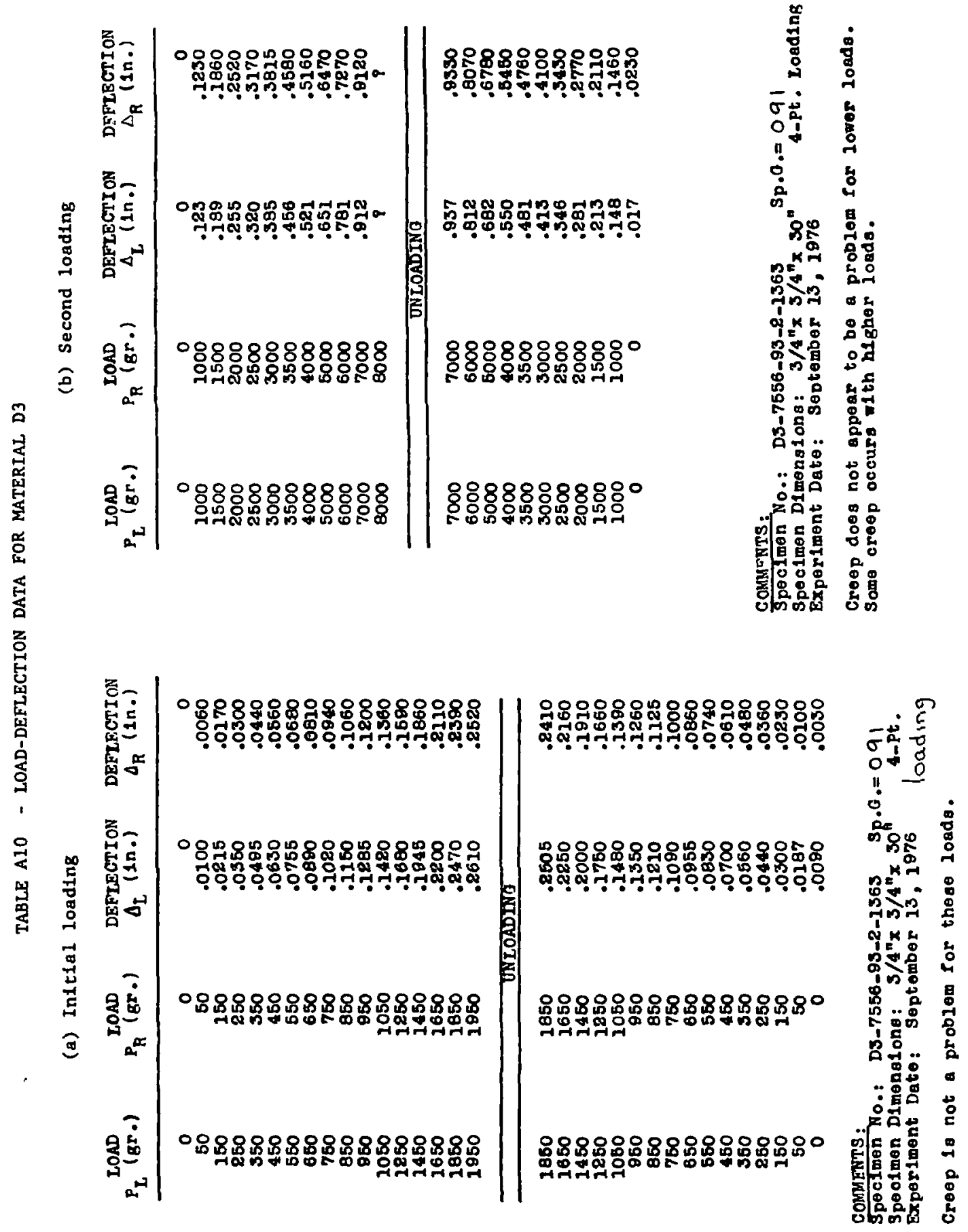



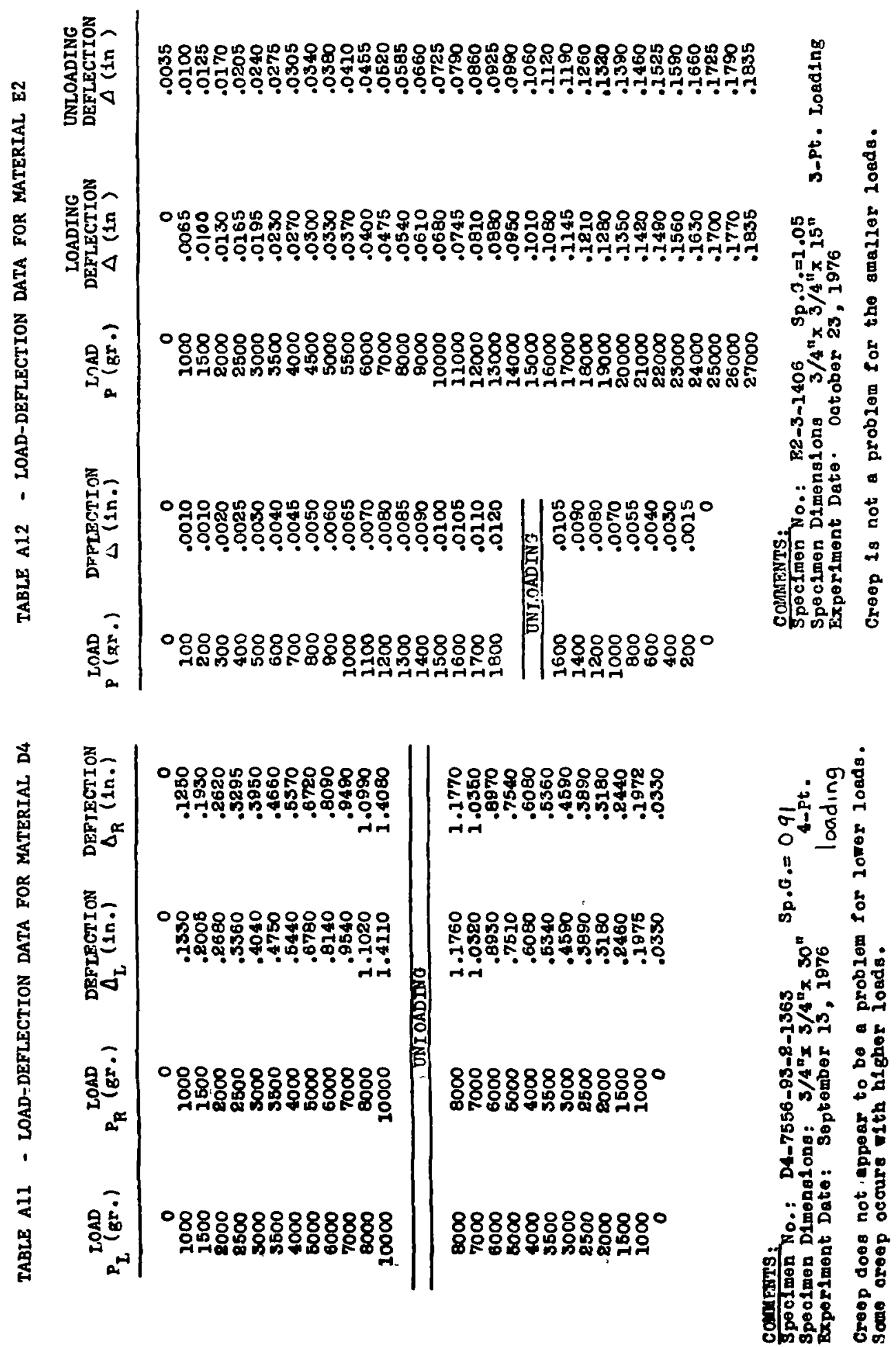


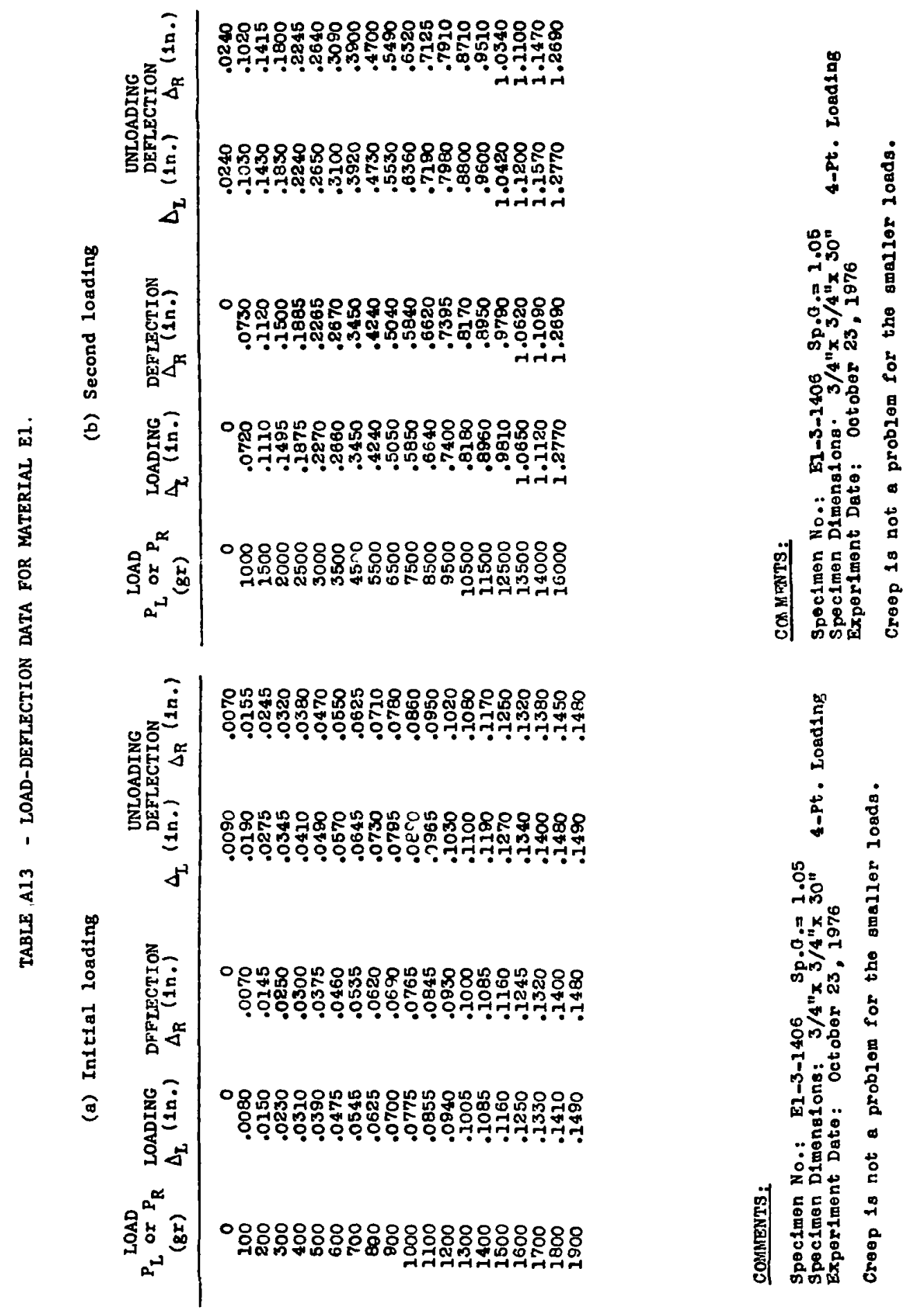



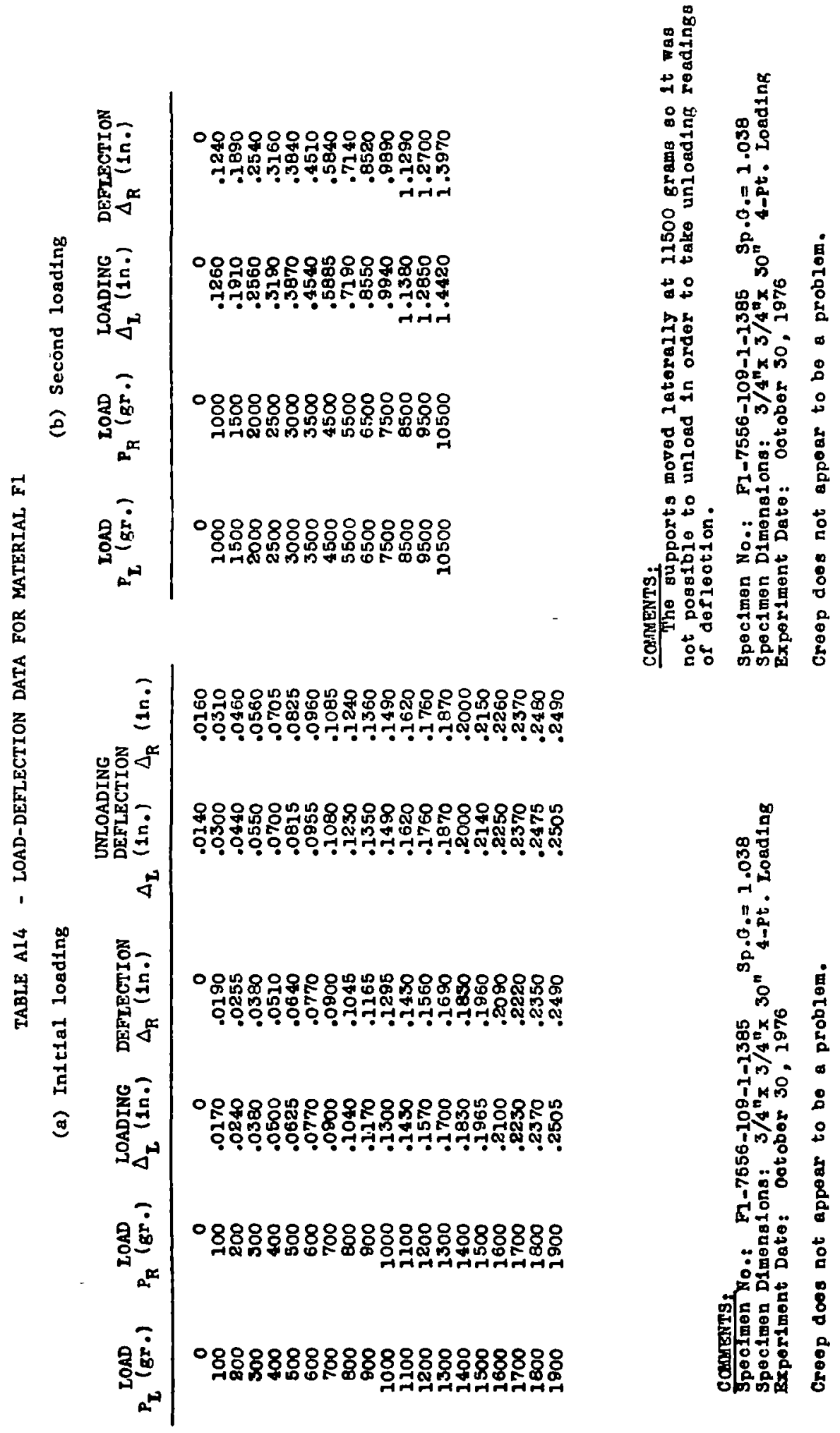

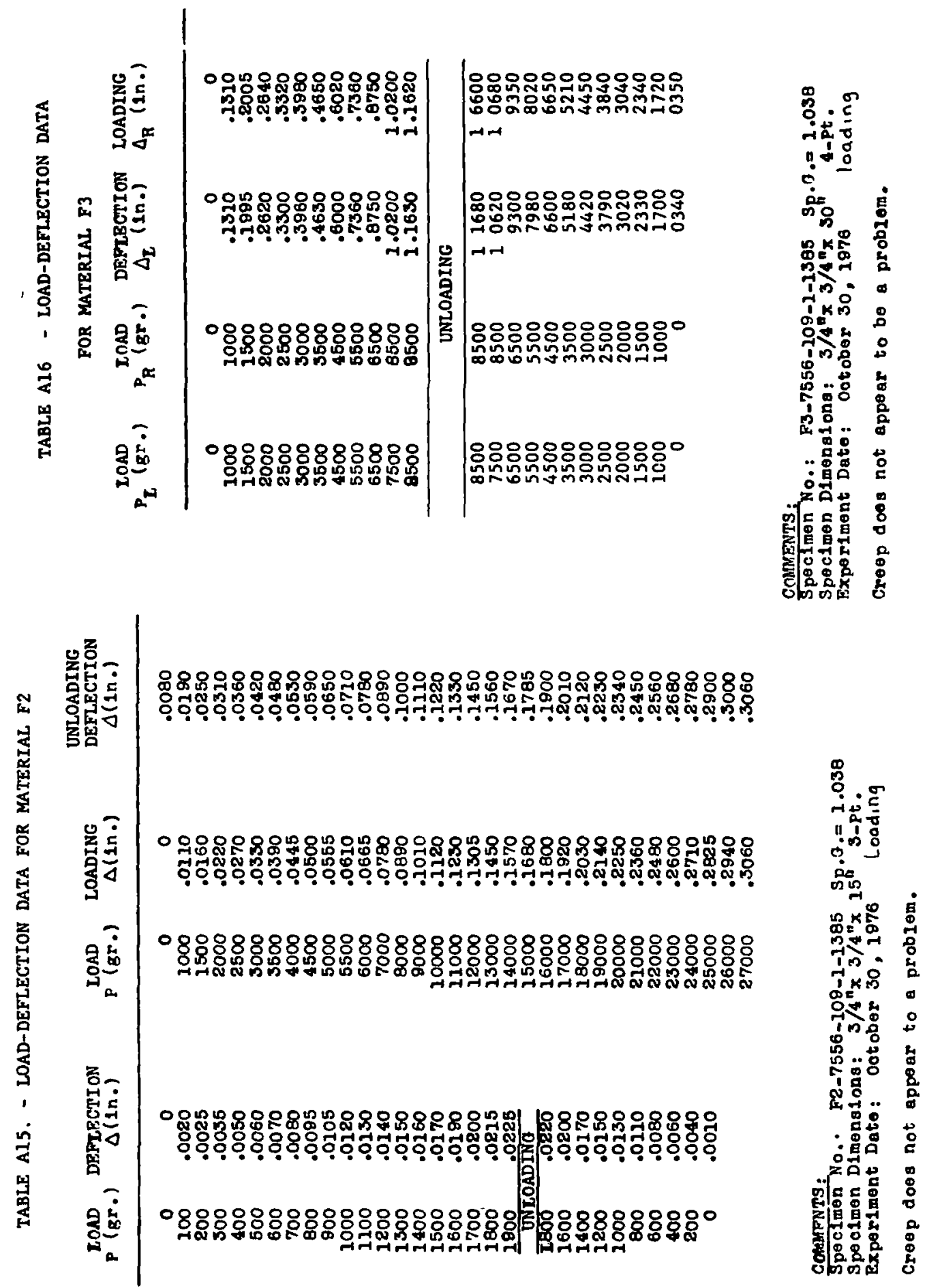

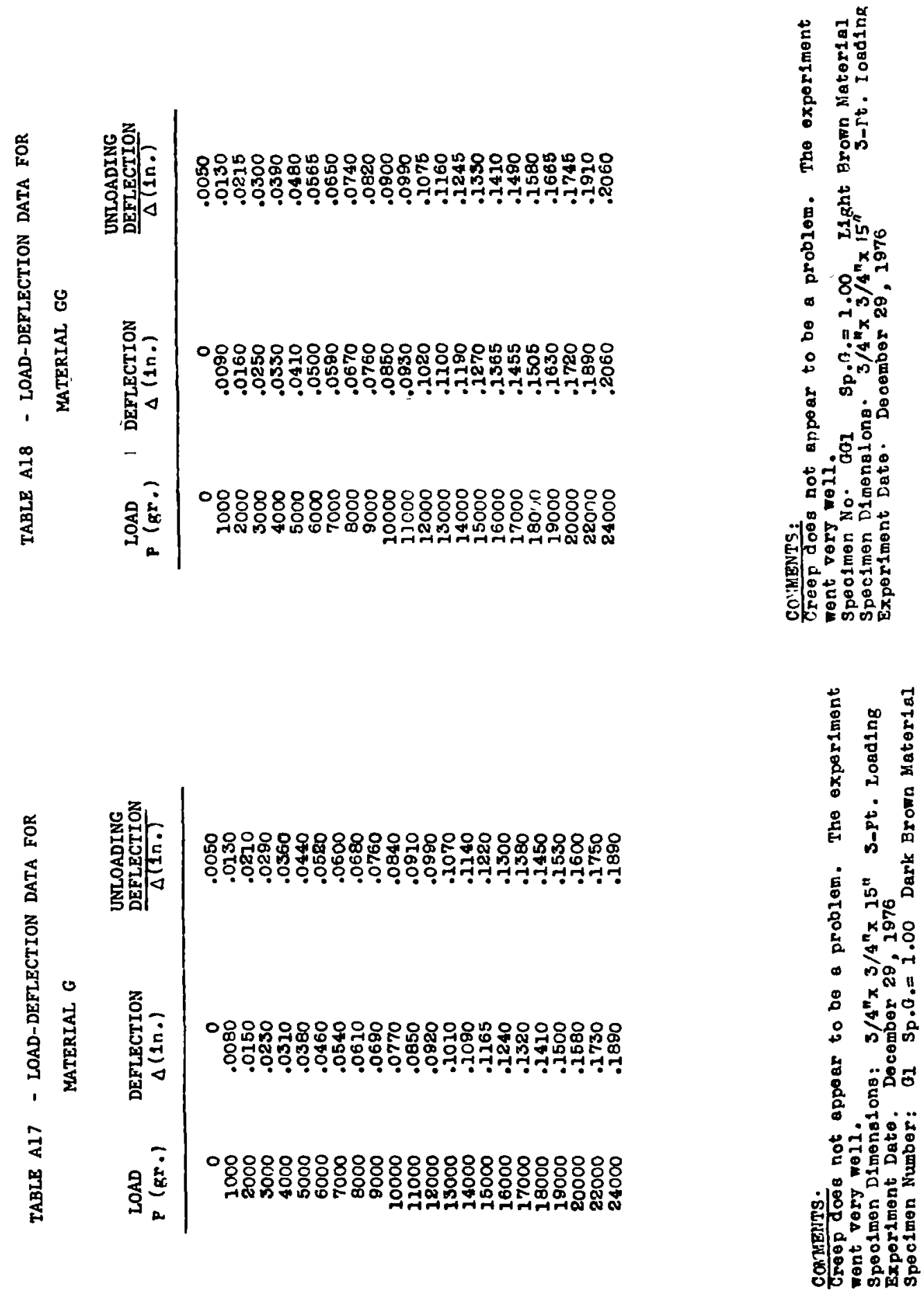


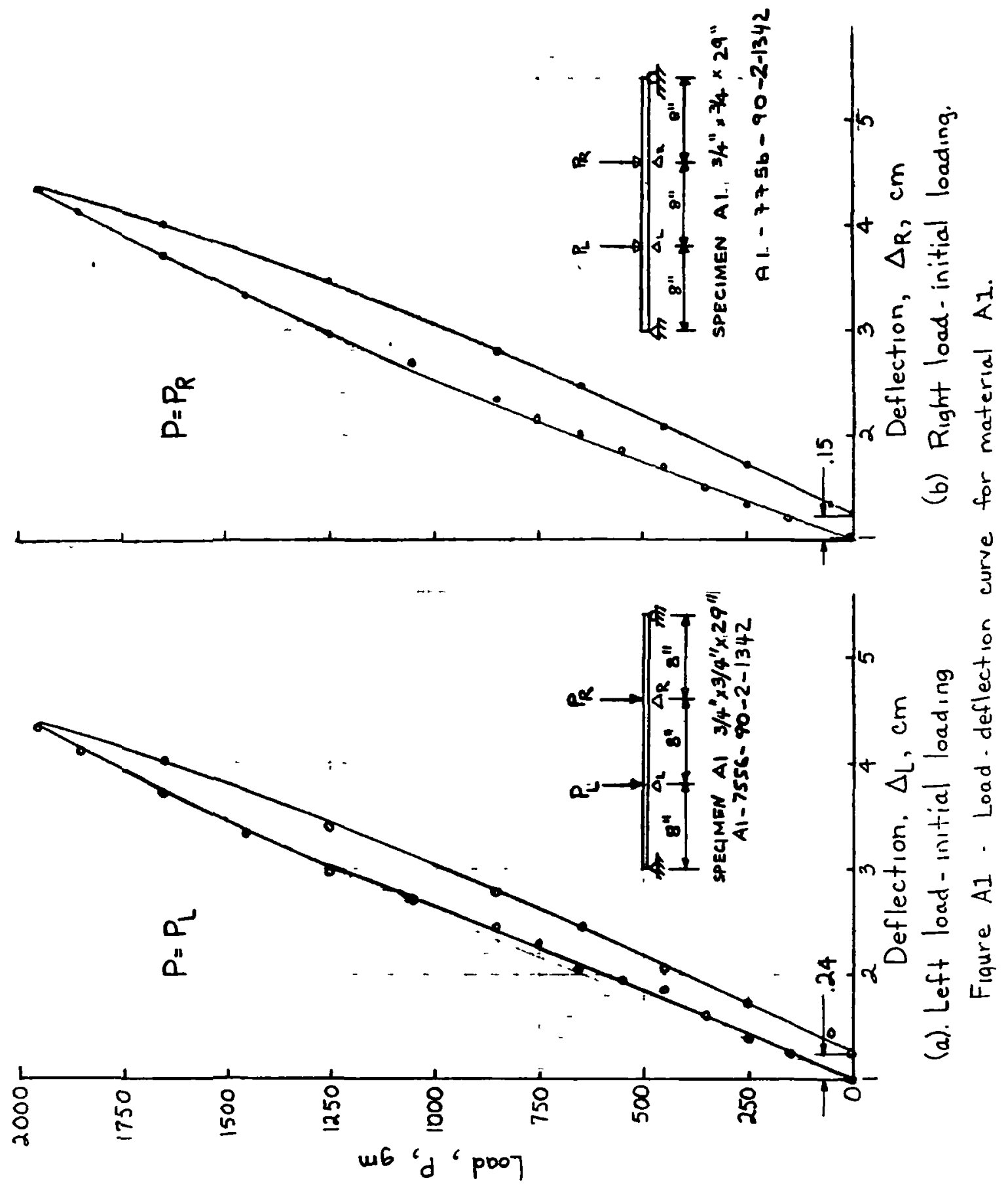




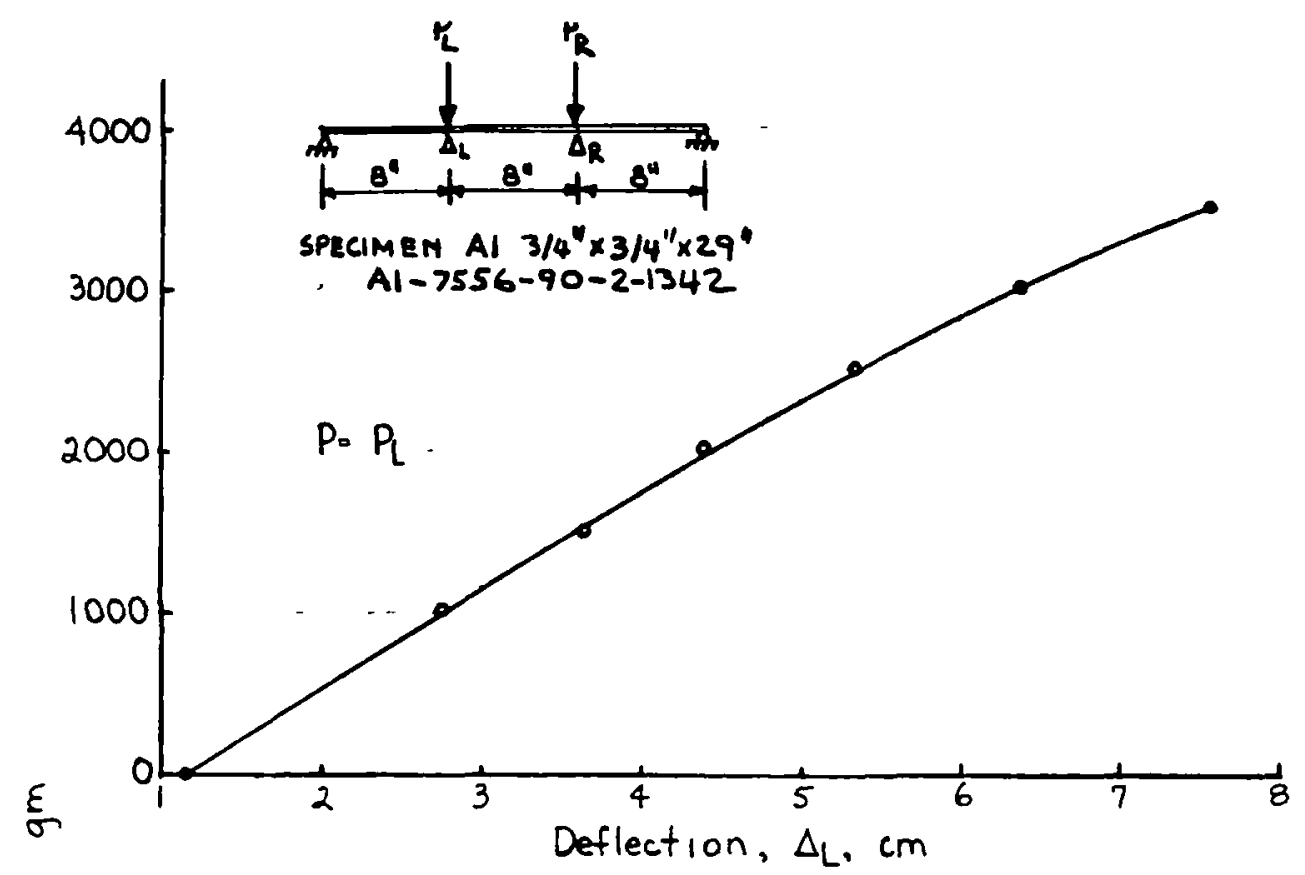

$a^{\circ} \quad(c)$. Left load - second loading.

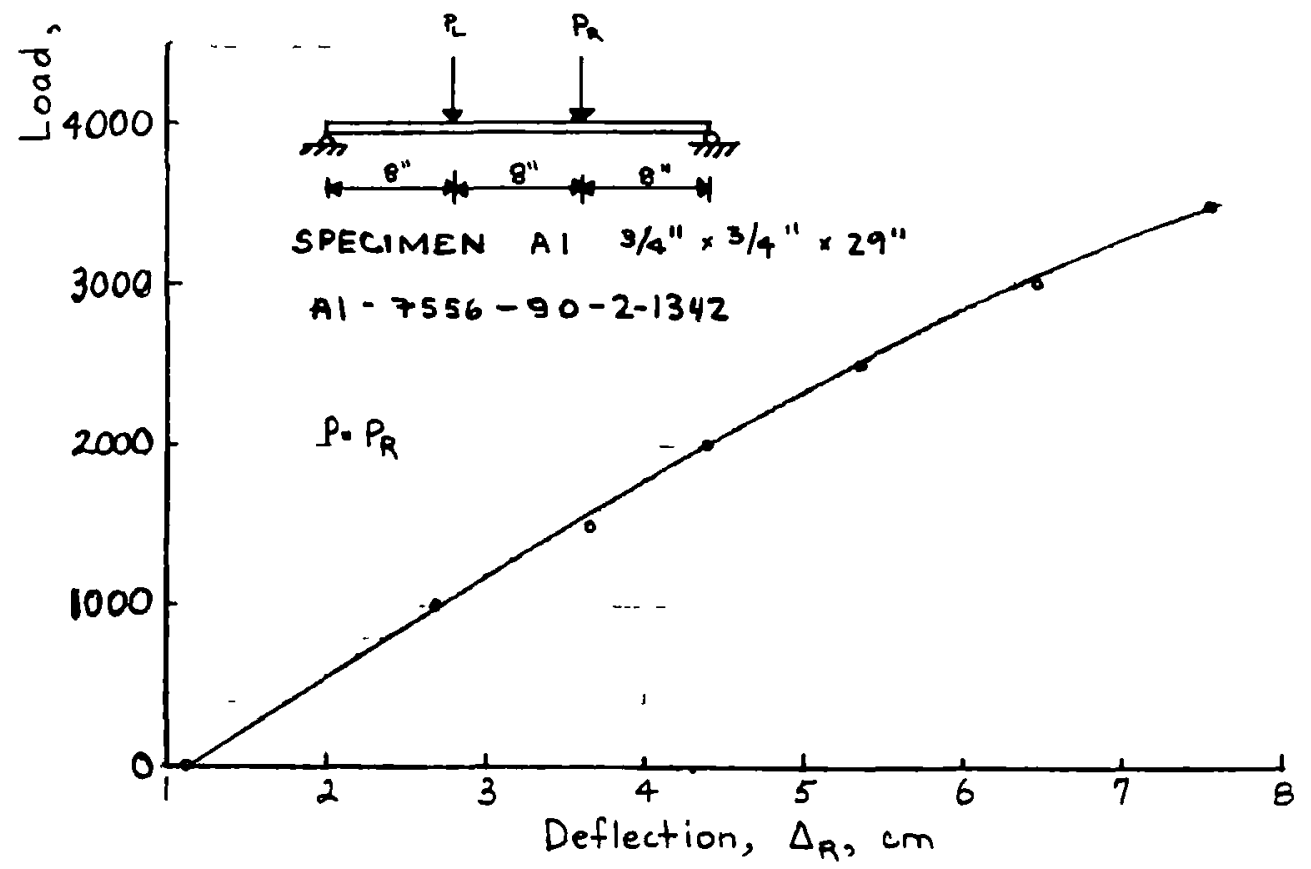

(d). Right load - second loading

Figure A1 - Concluded

96 


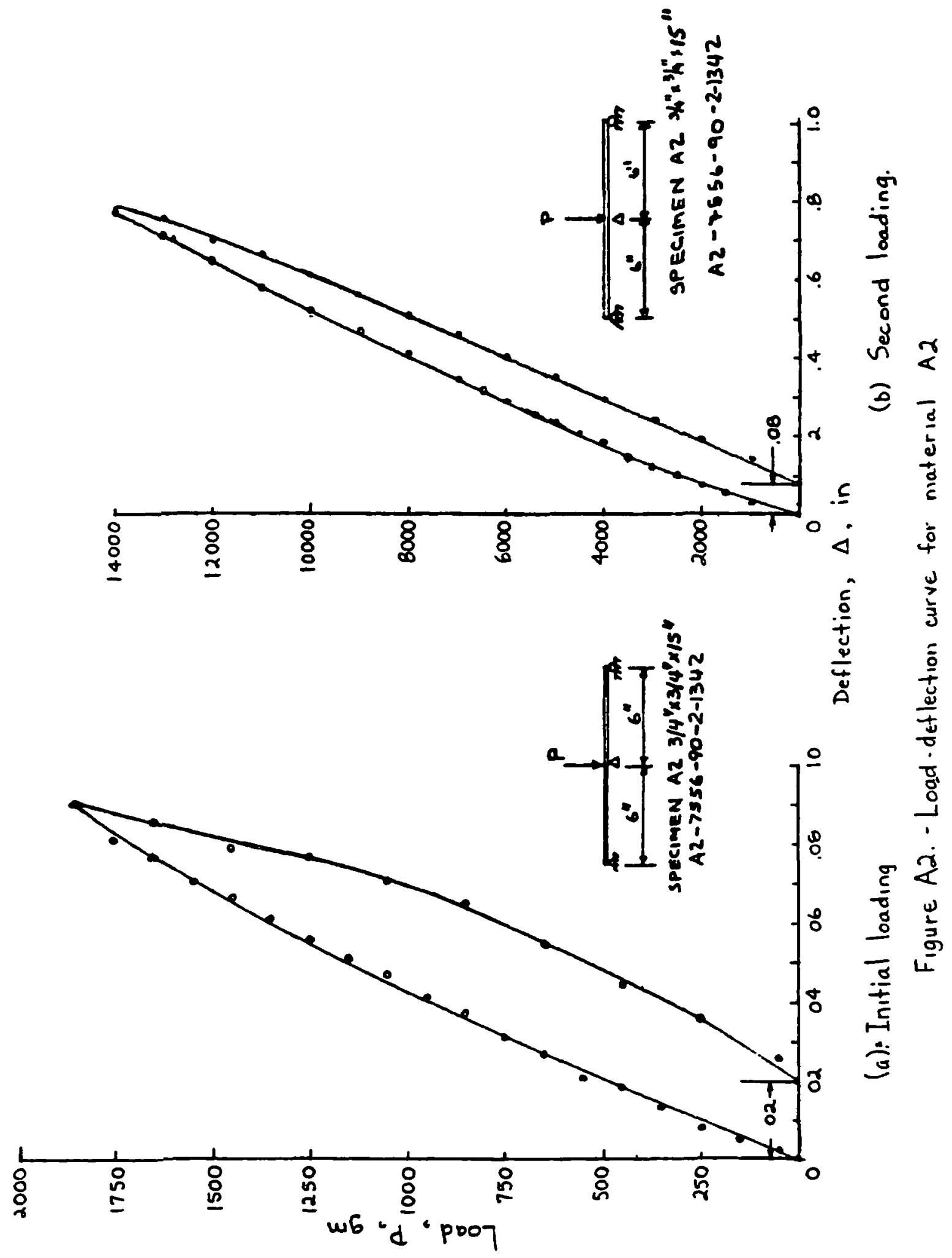




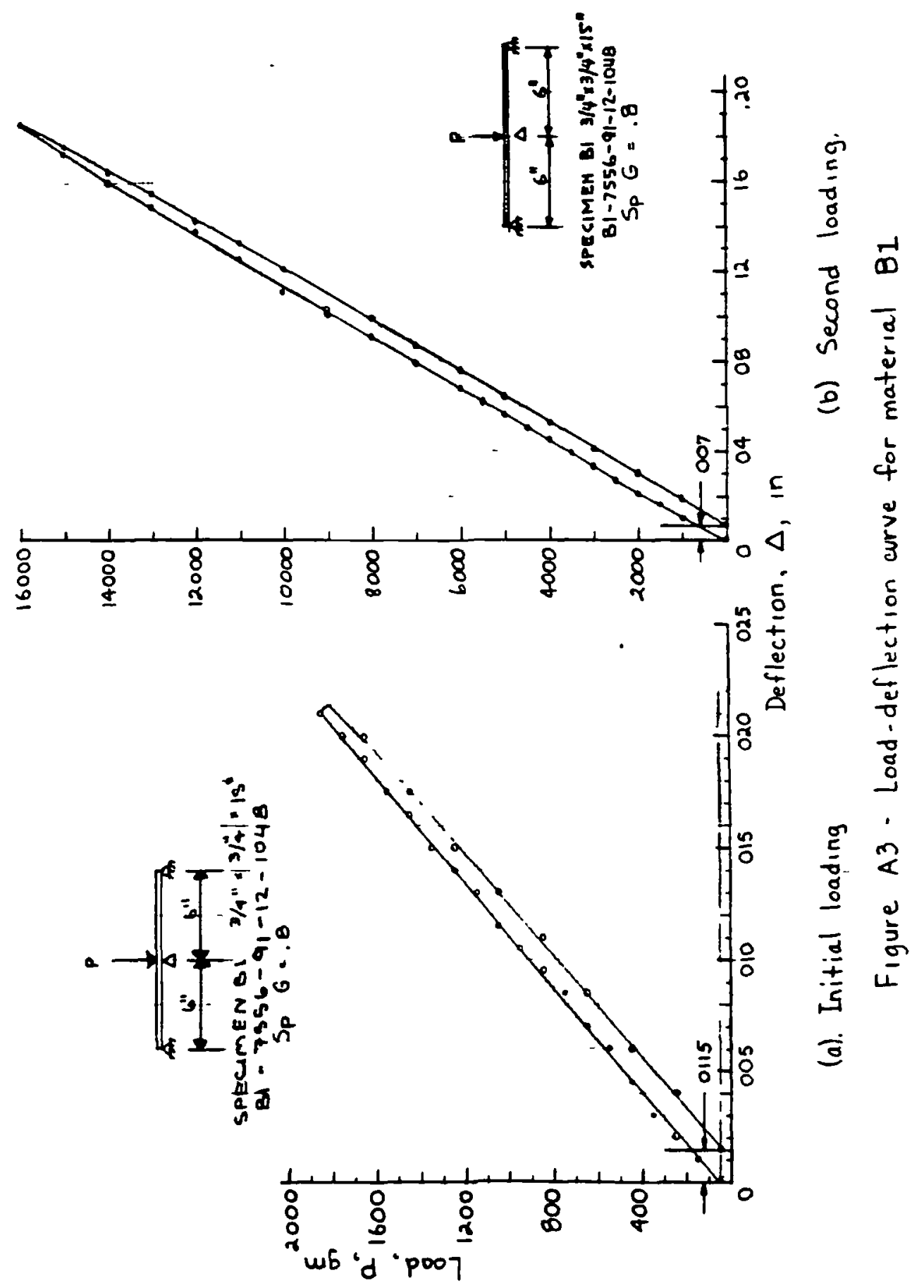




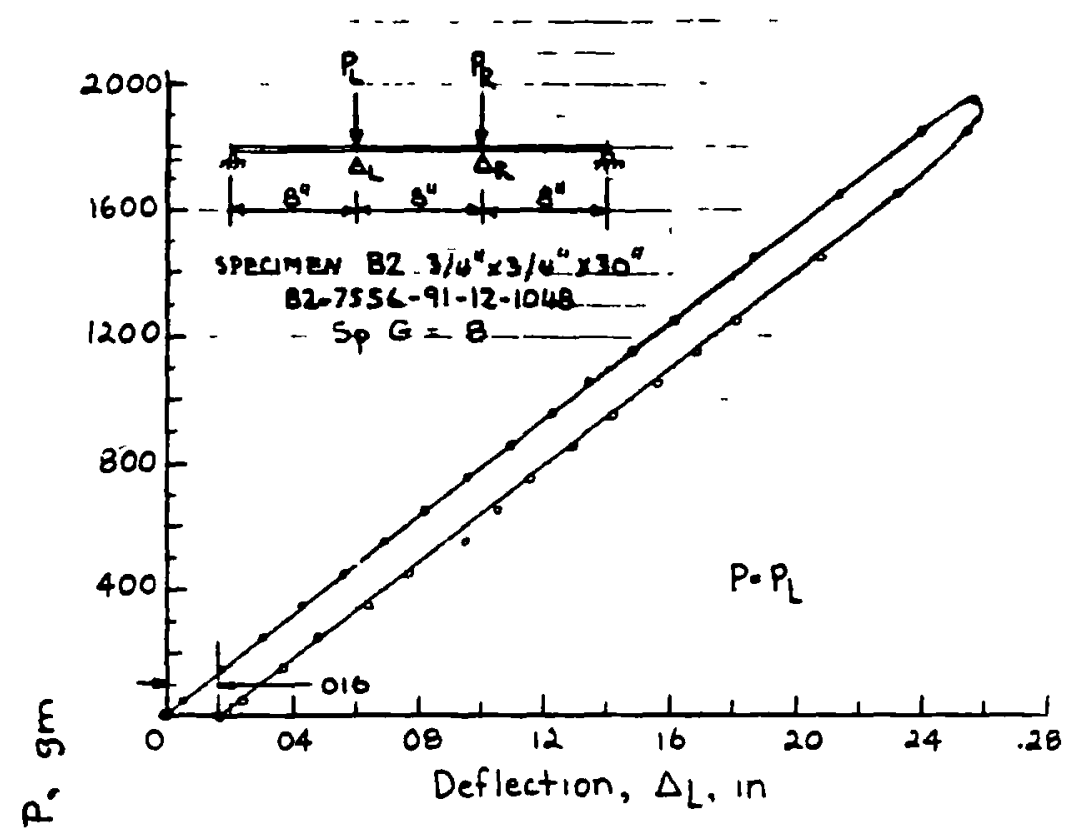

$a^{\circ}$

(a) Left load-initial loading

ช̊

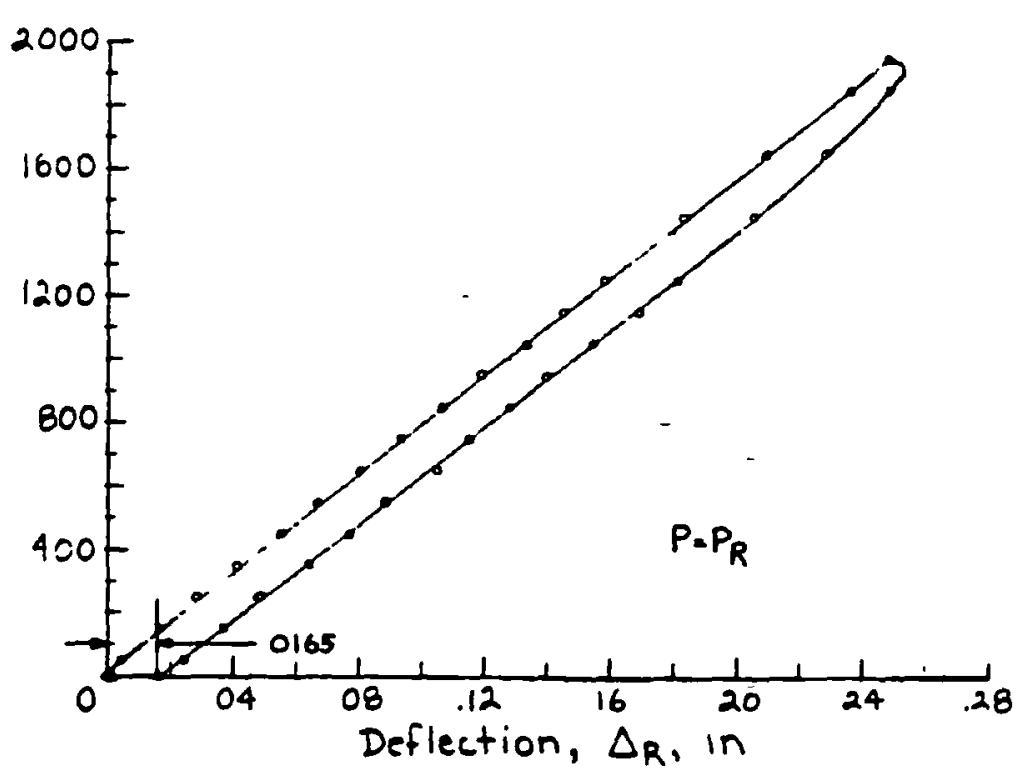

(b) Right load - initial loading

Figure A4-Load-deflection curve for material B2. 


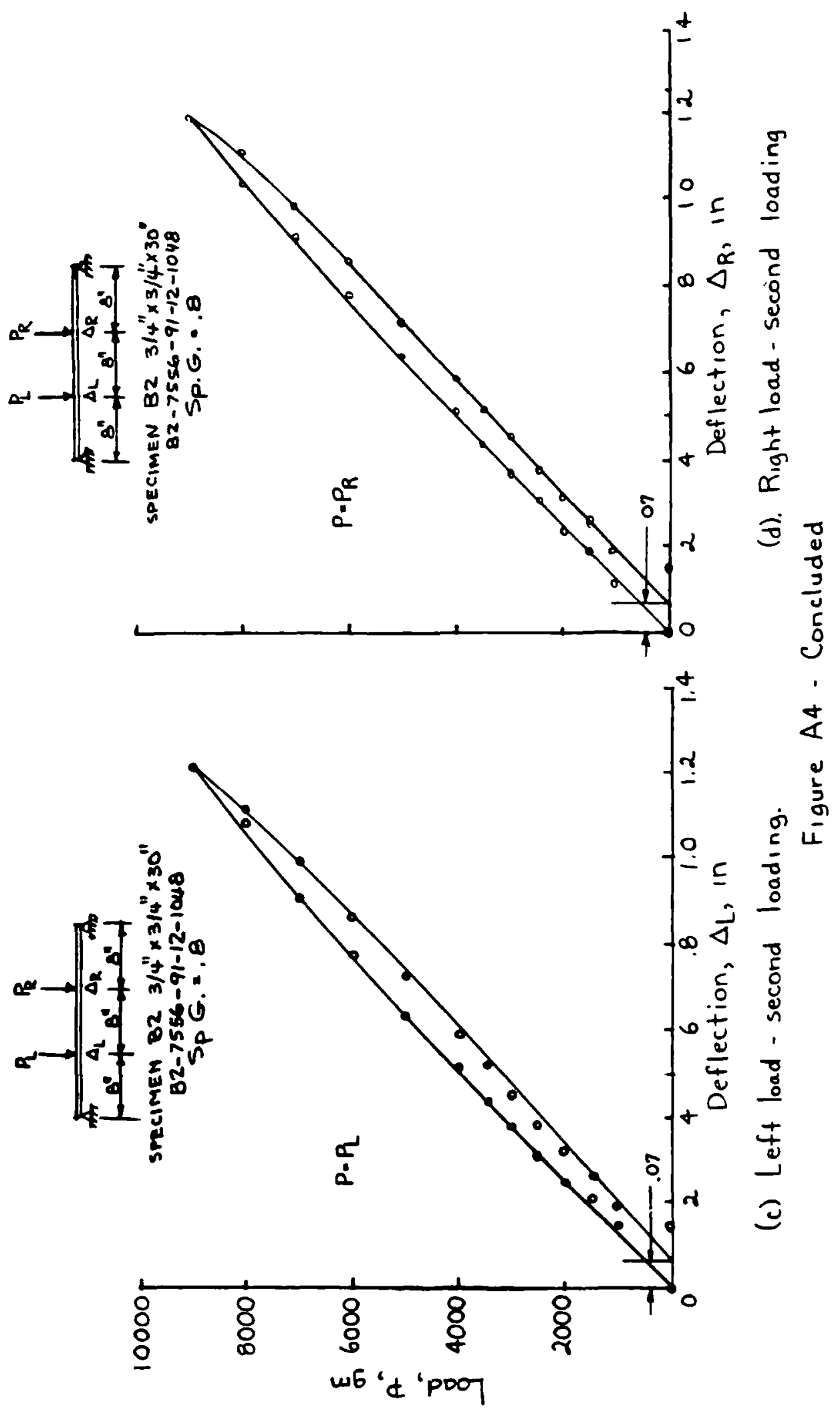




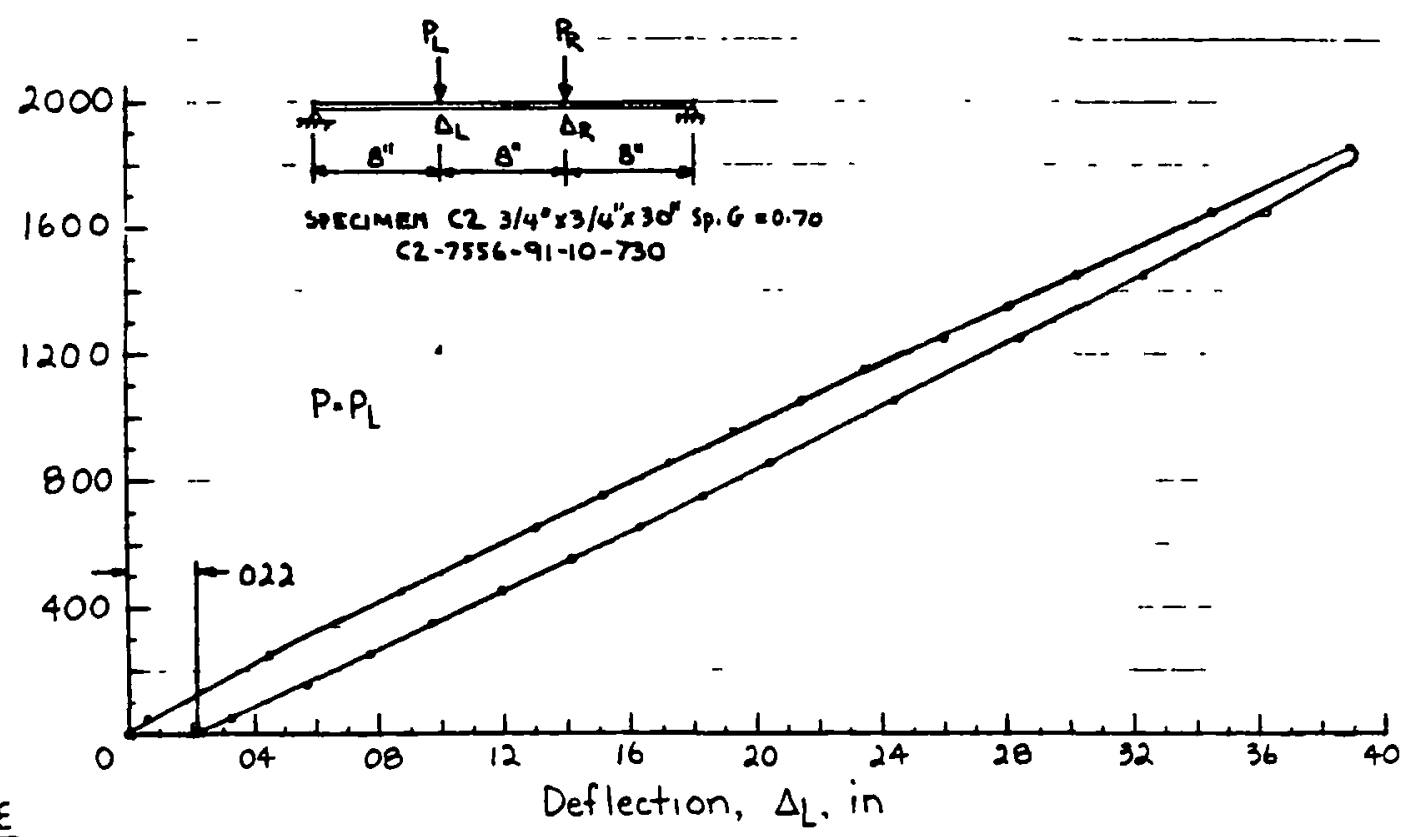

(a) Left load - initial loading

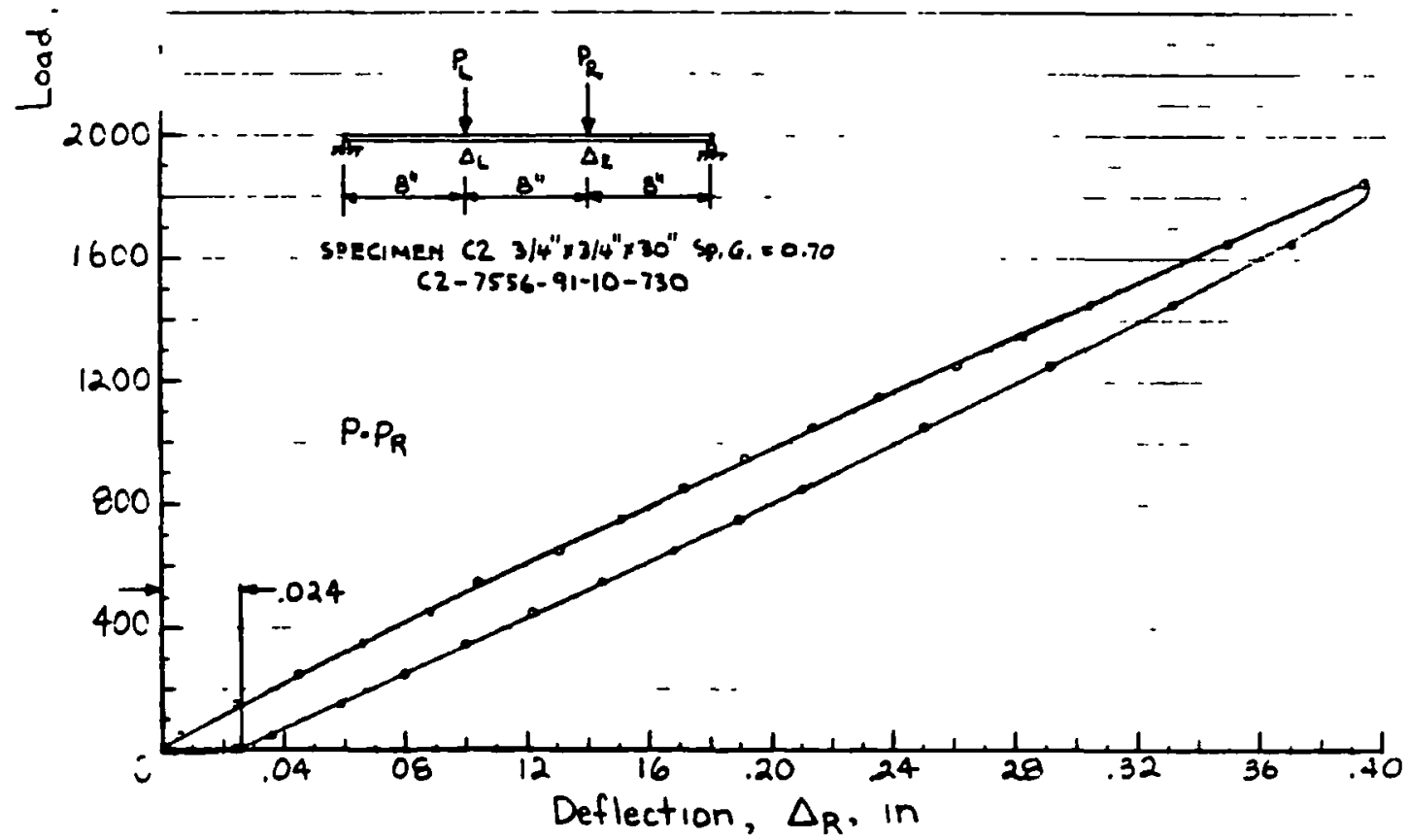

(b). Right load - initial loading

Figure A5. - Load-deflection curve for material $C_{2}$

101 


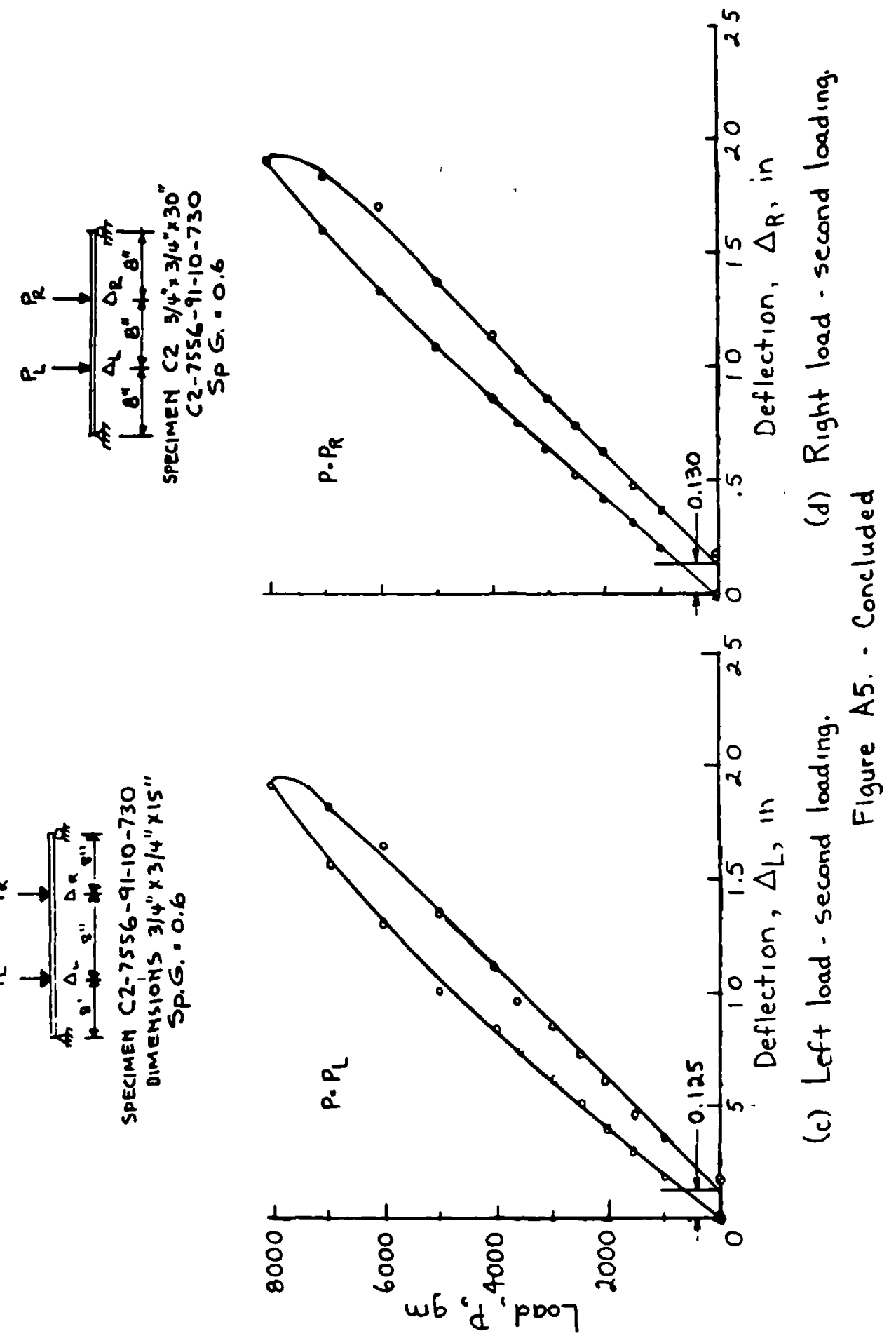




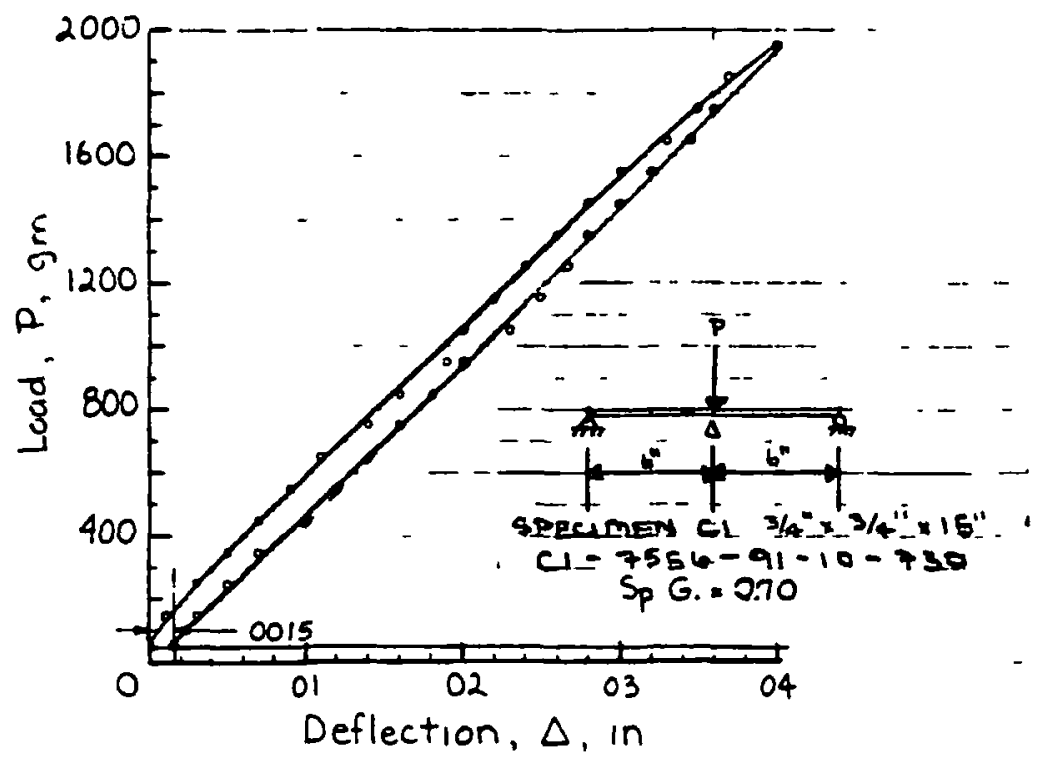

(a). Initial loading

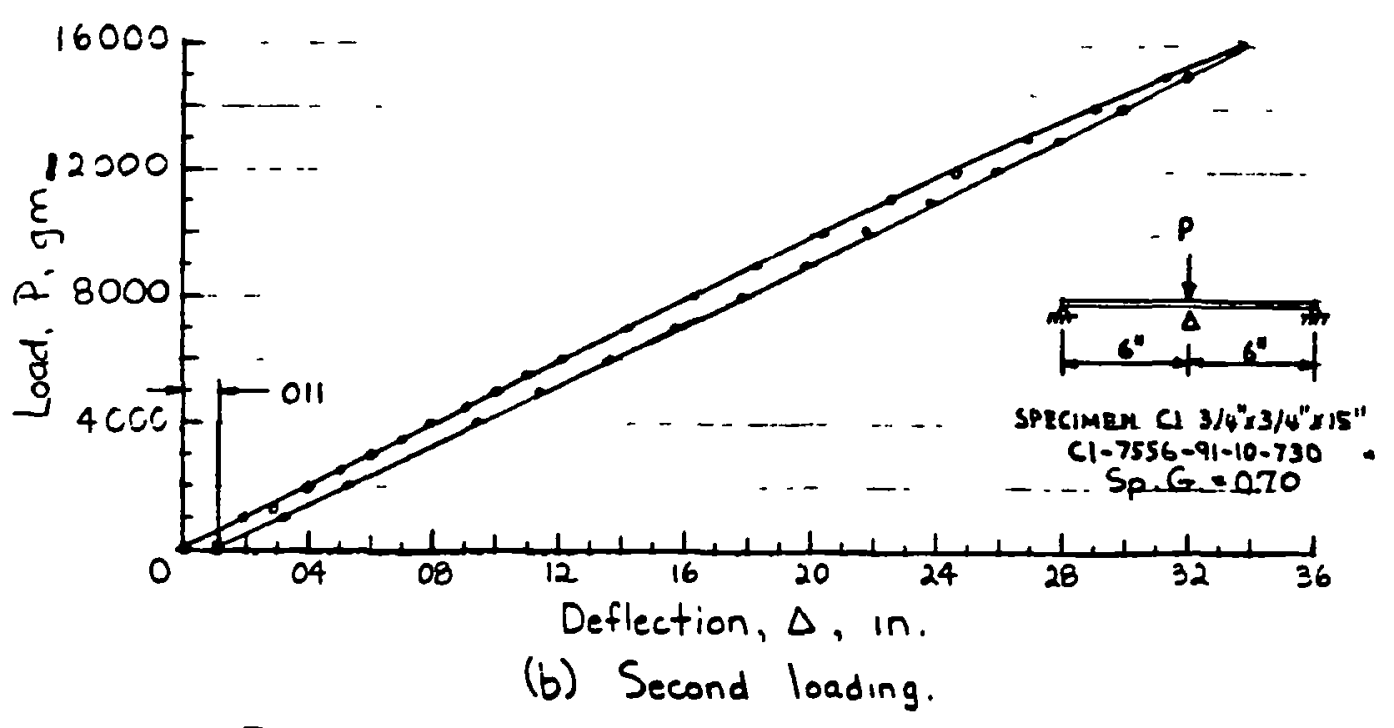

Figure A6 - Load-deflection curve for material $C_{1}$. 


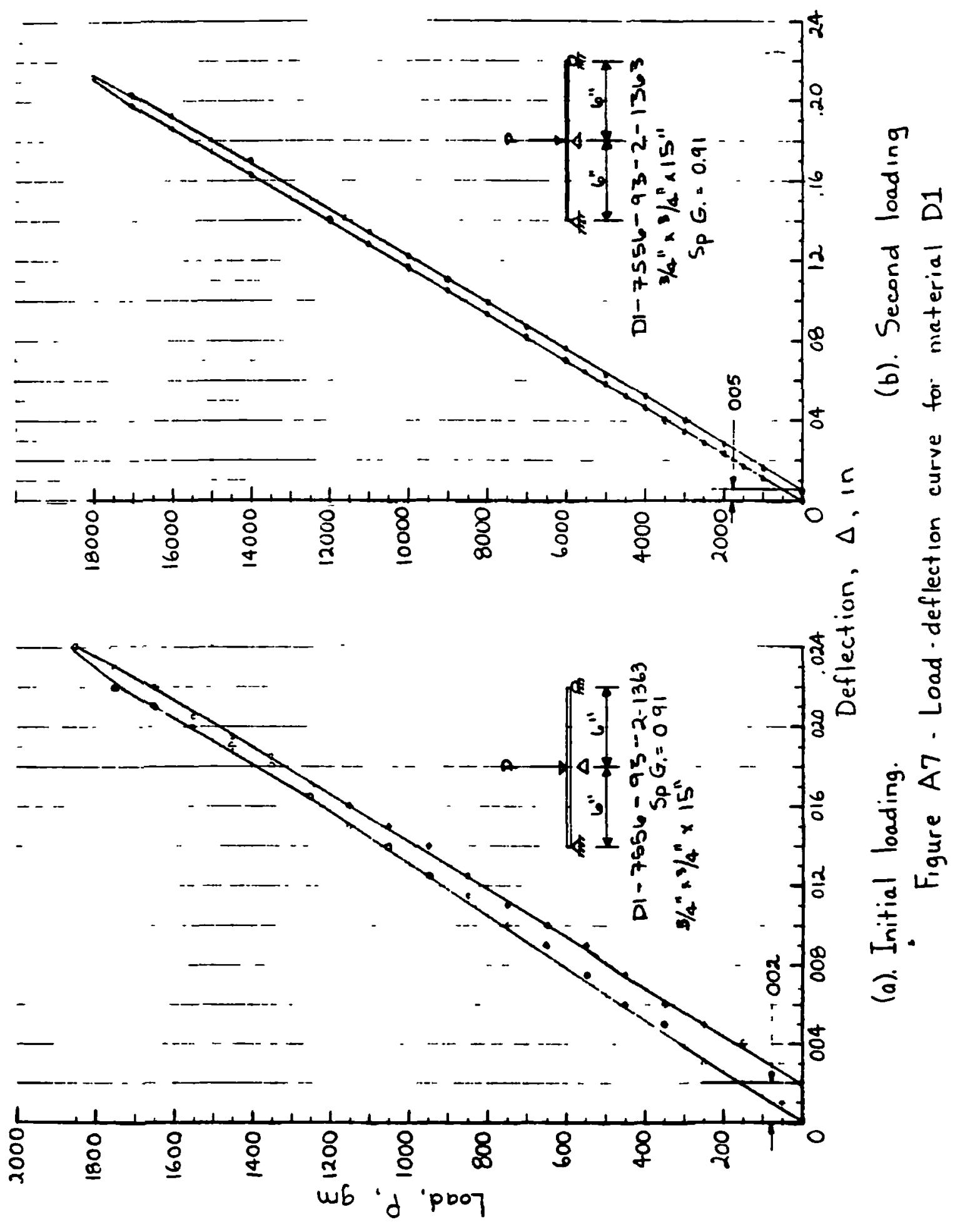




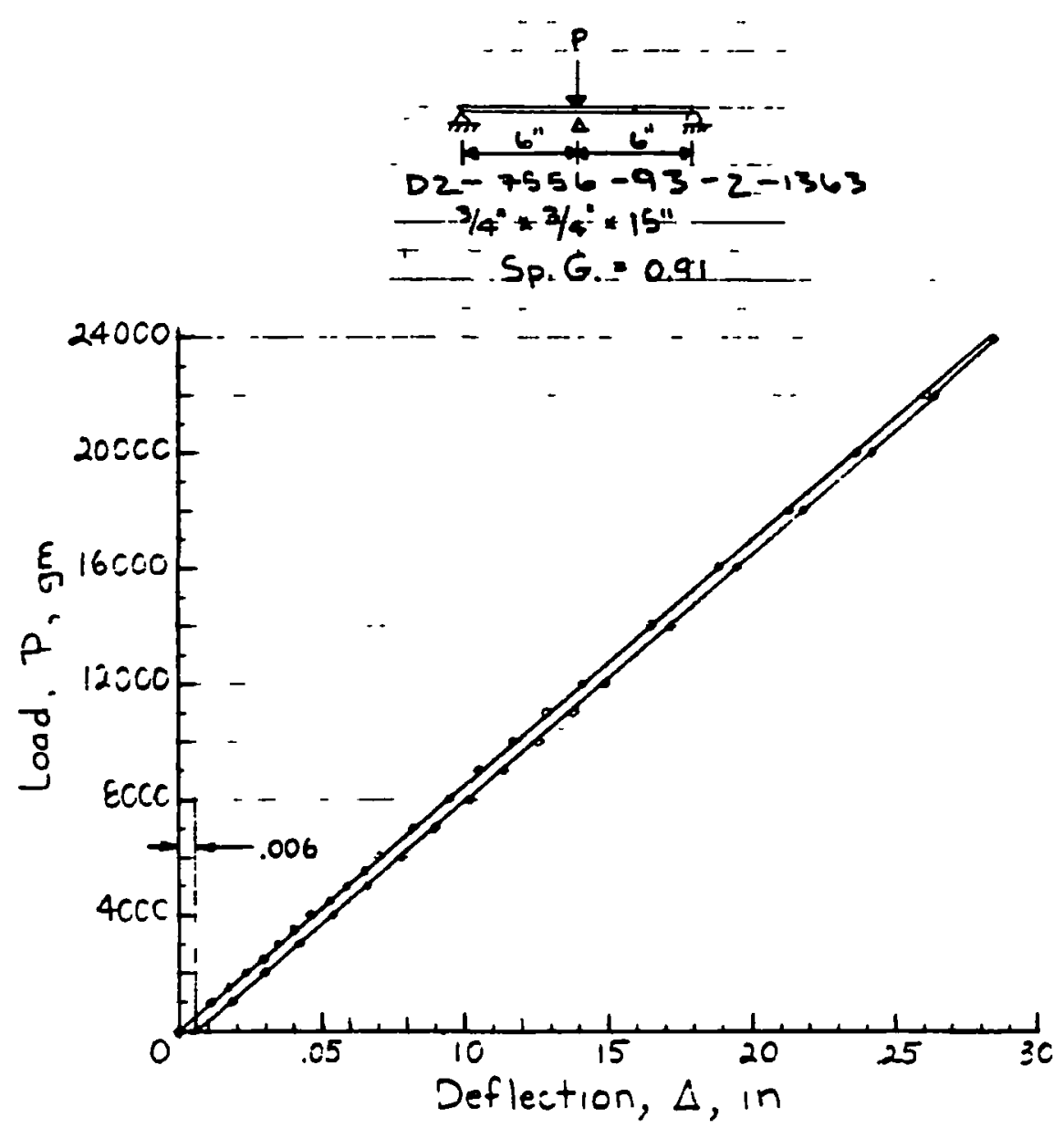

Figure A8.- Load-deflection curve for material 02 . 


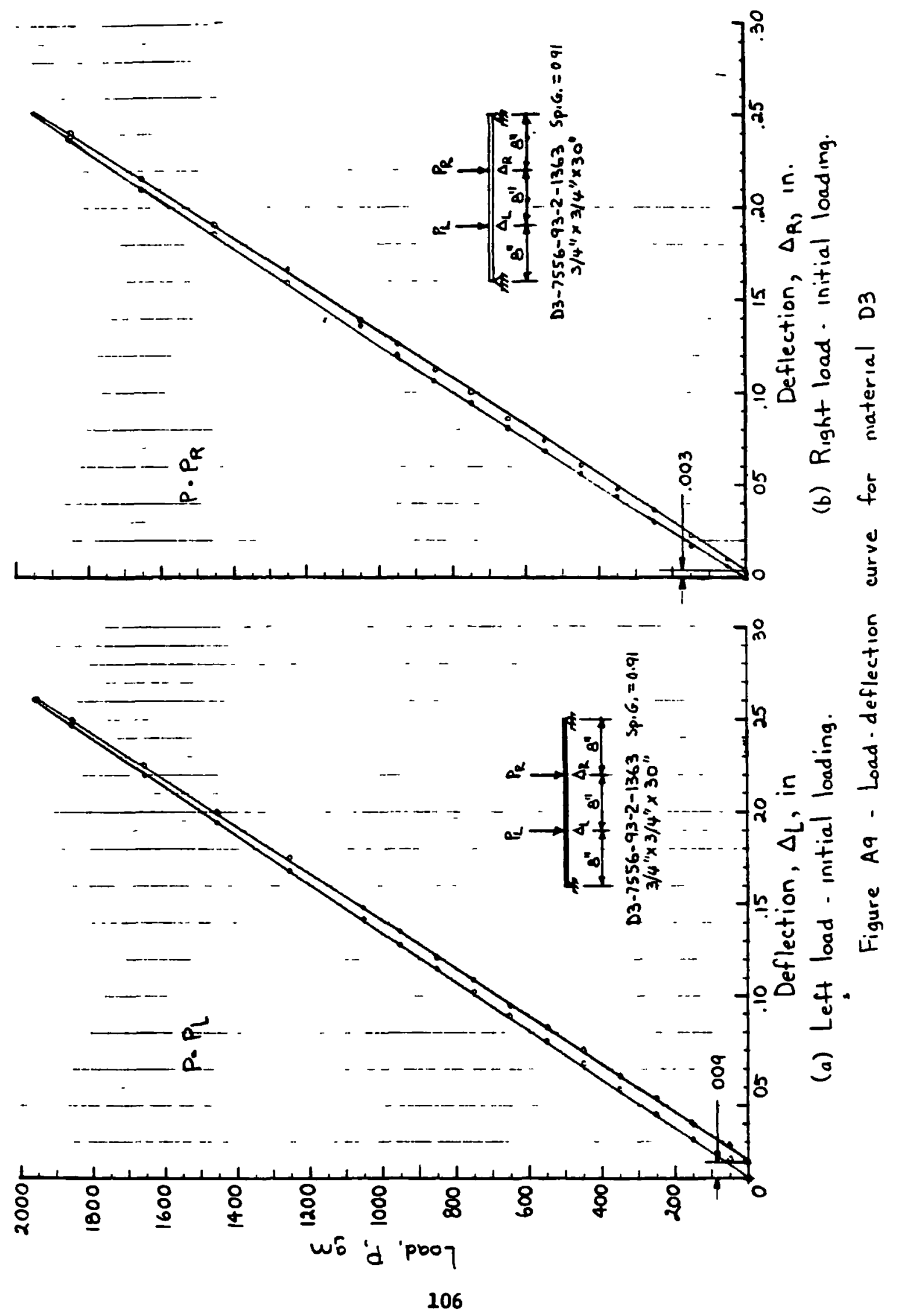




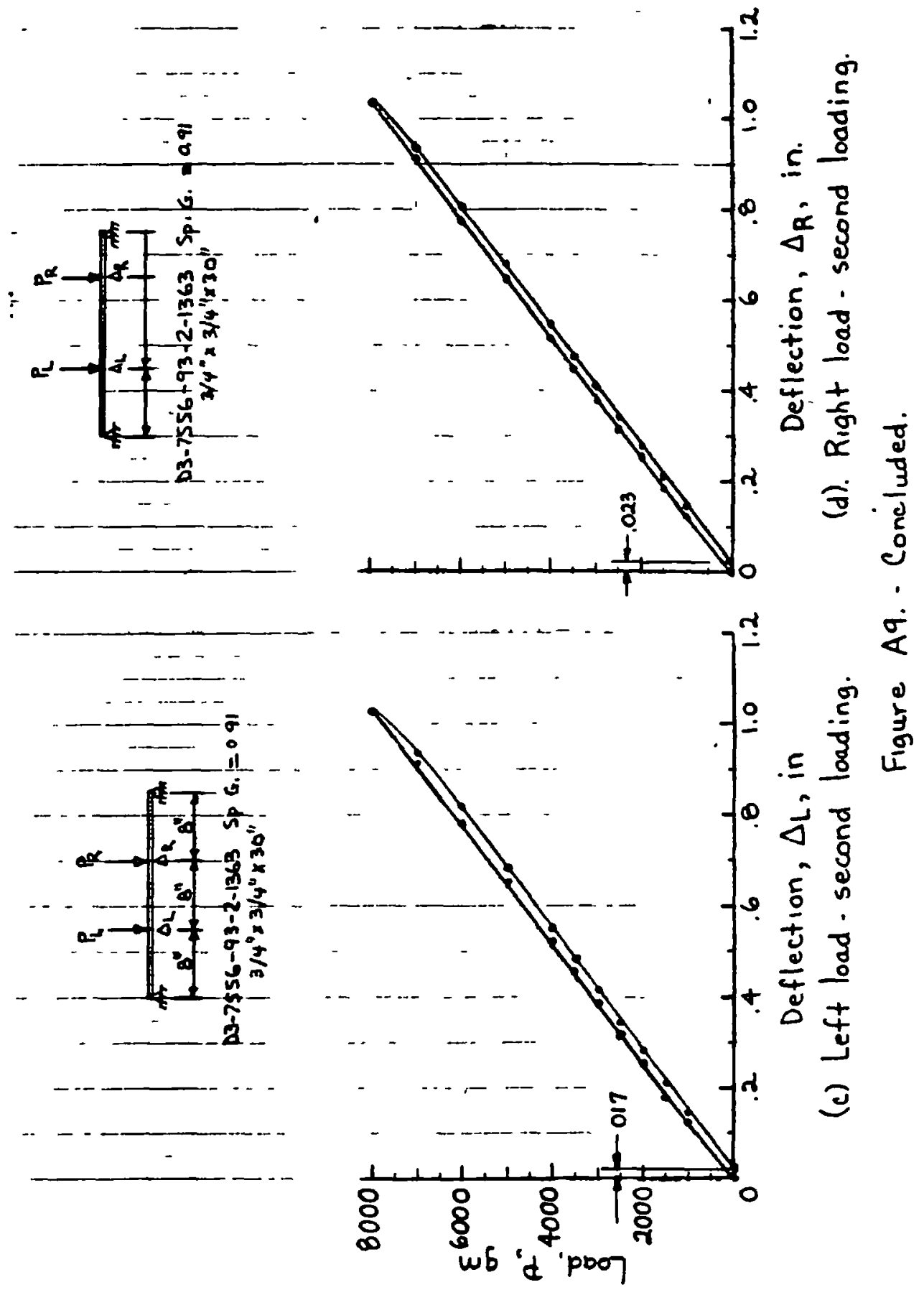




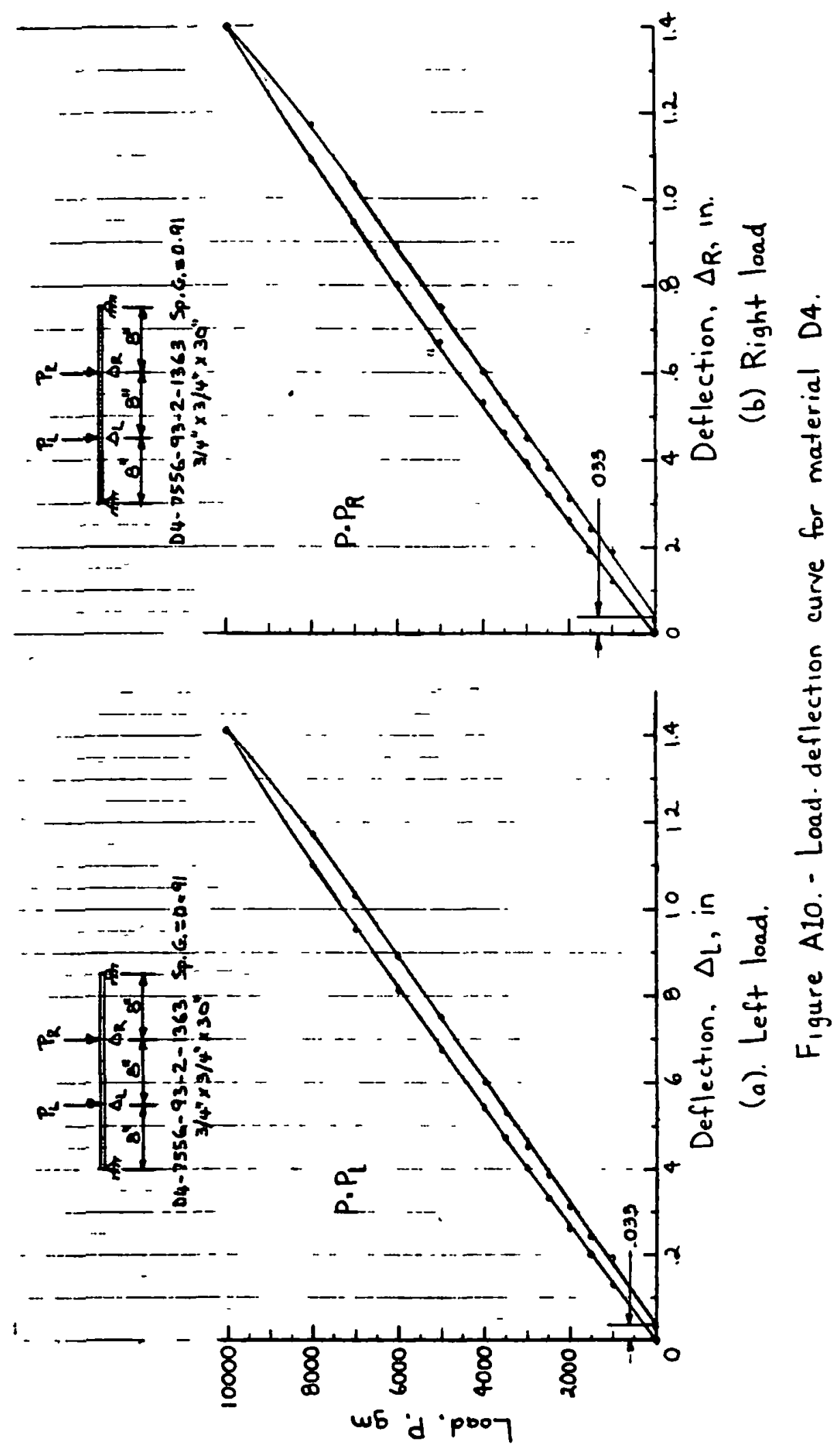




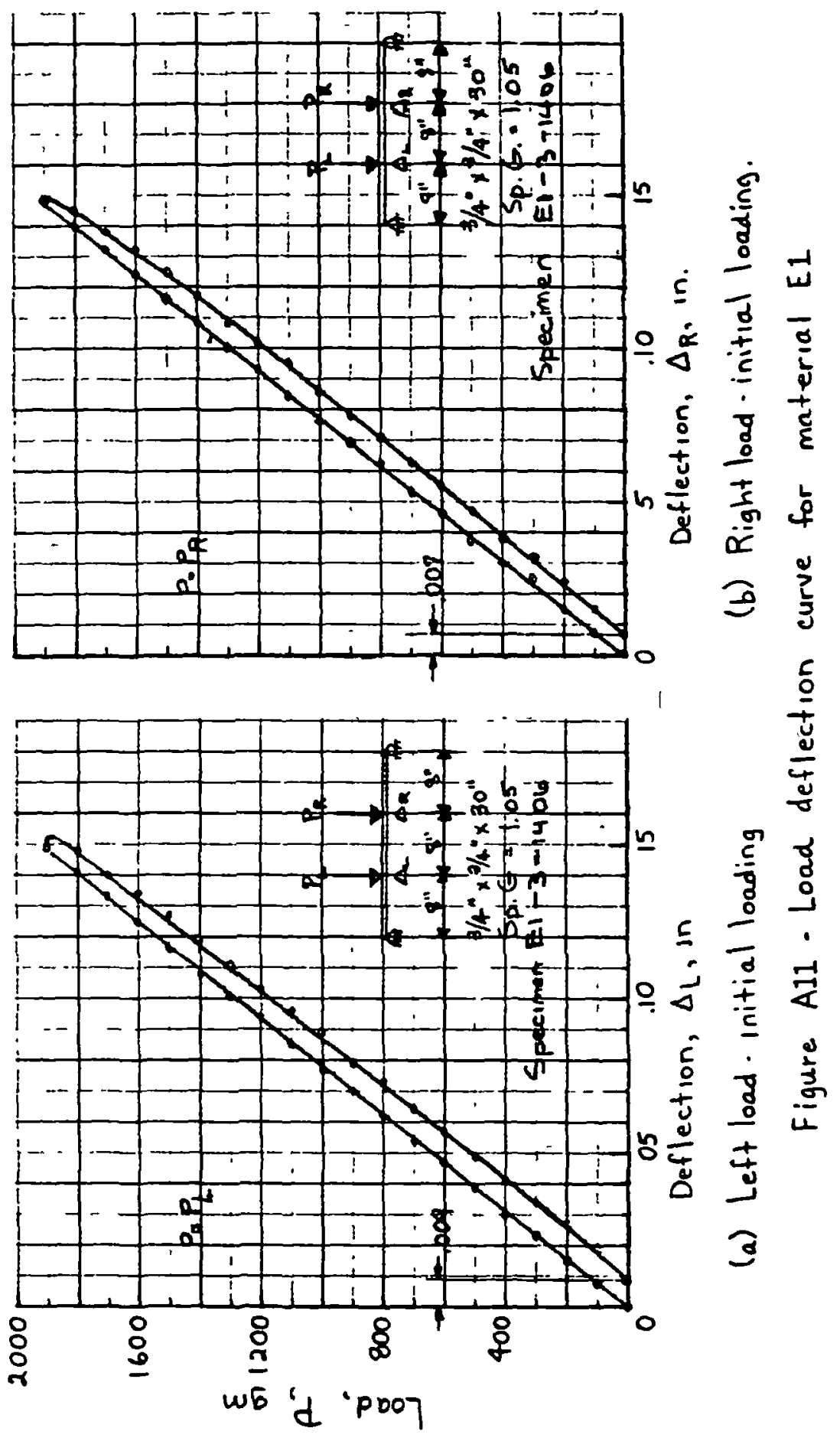




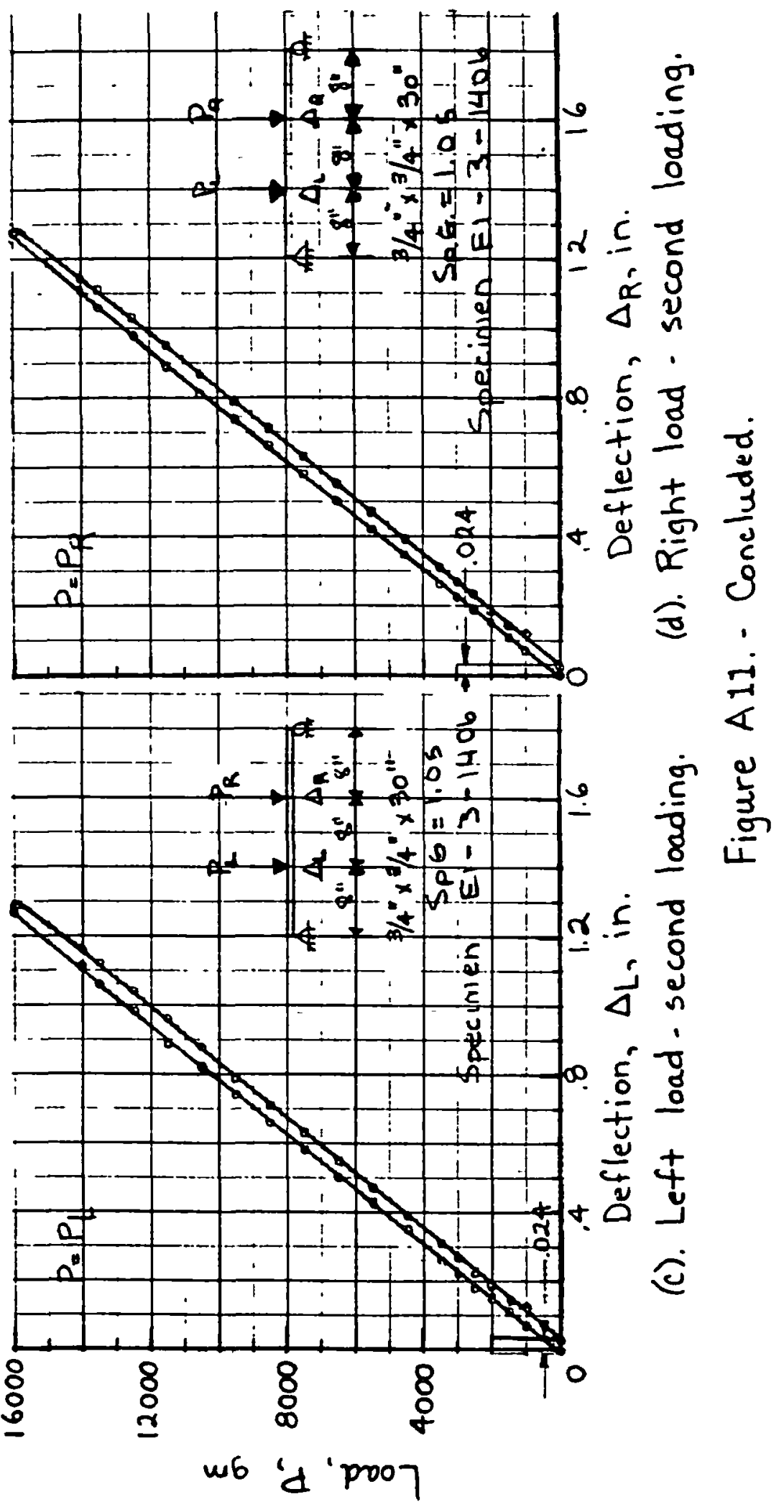




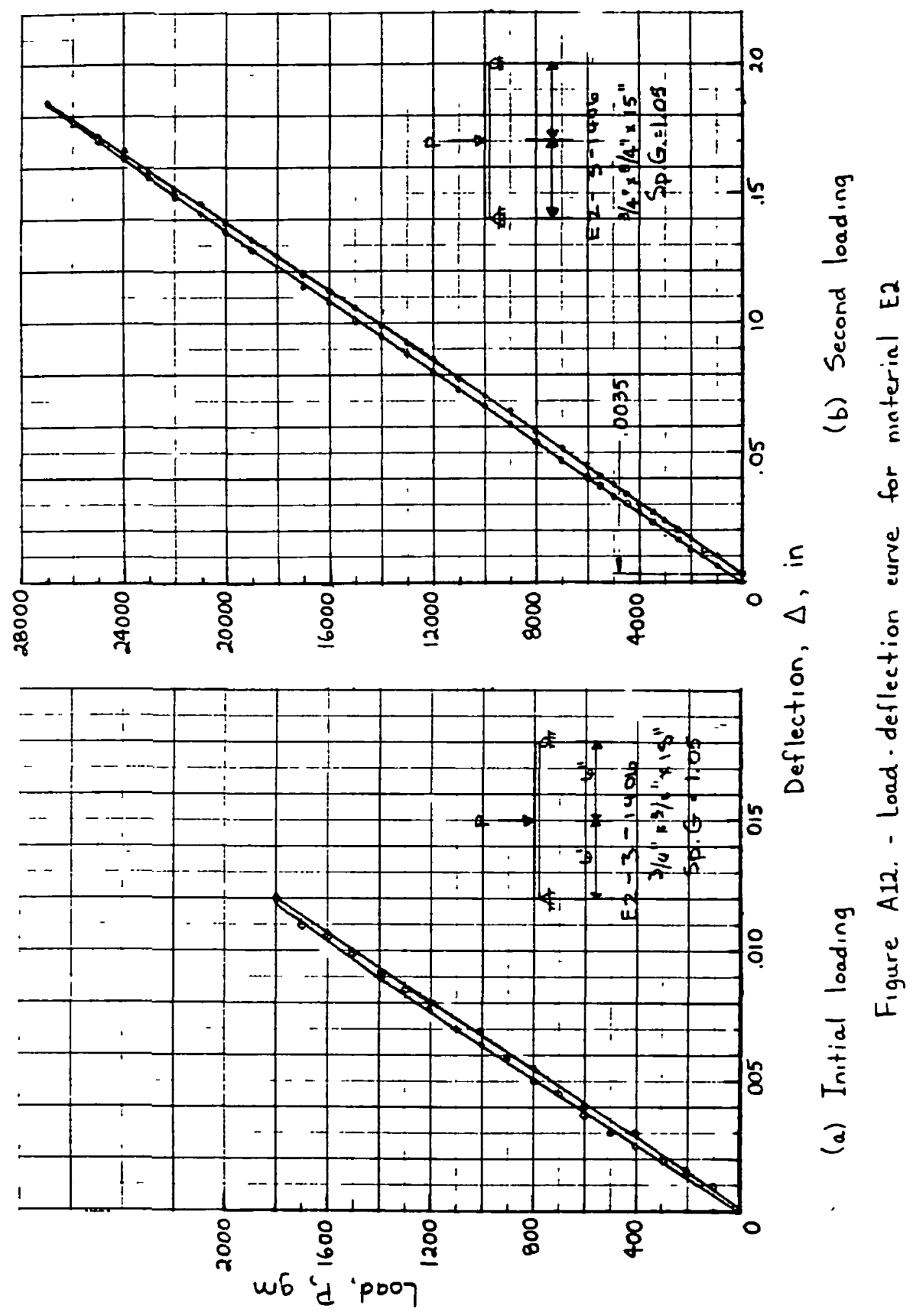




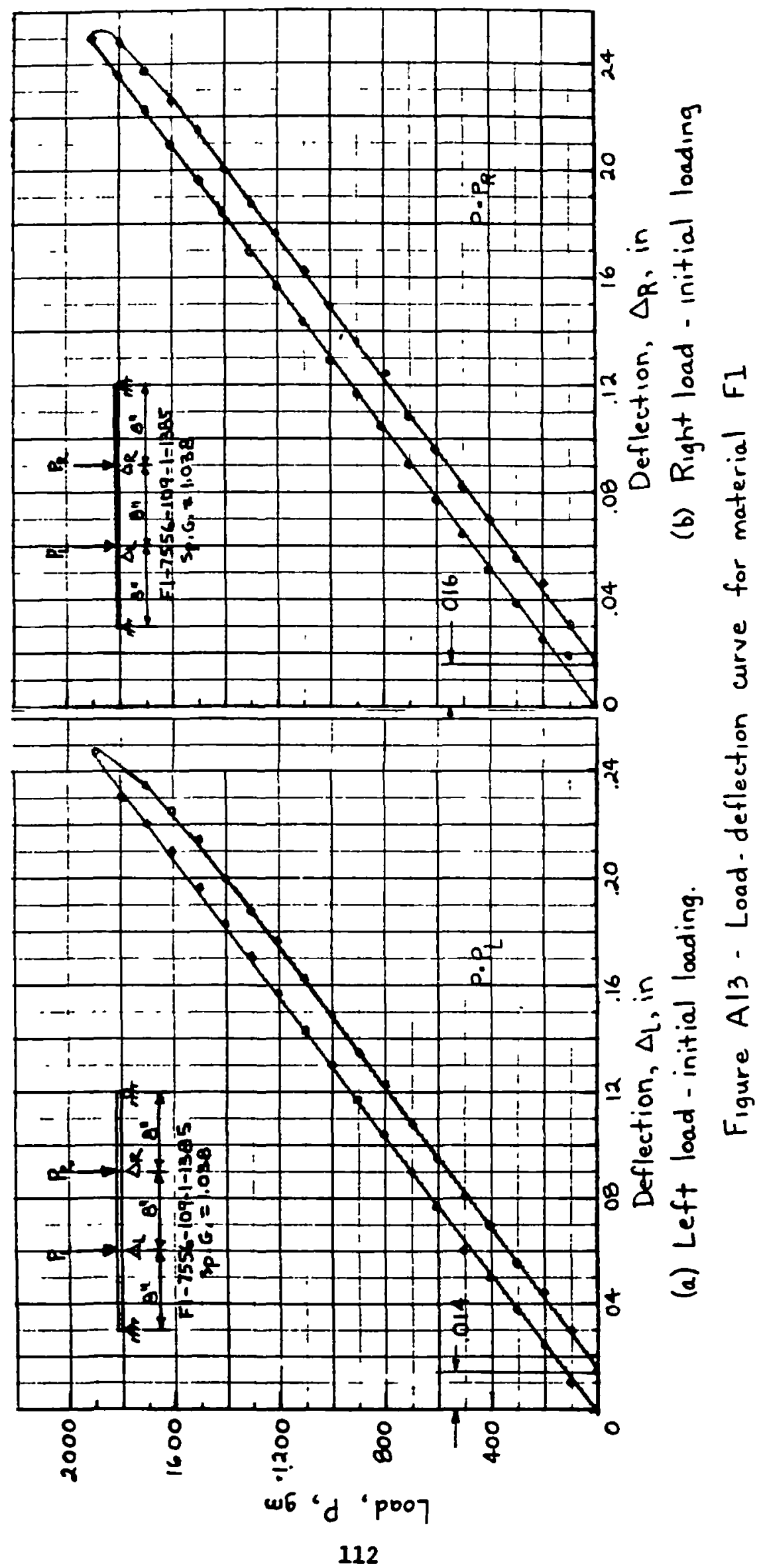



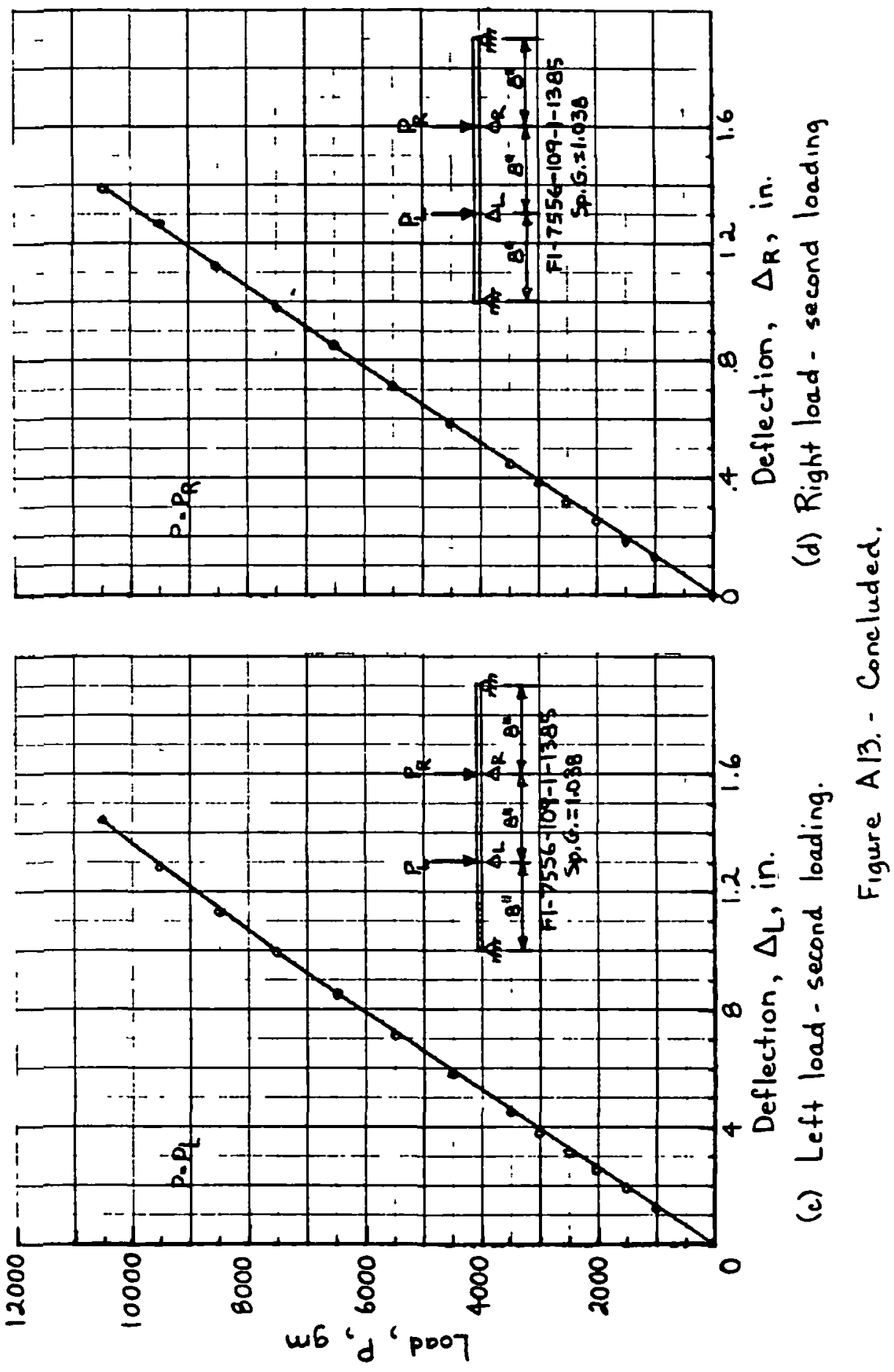


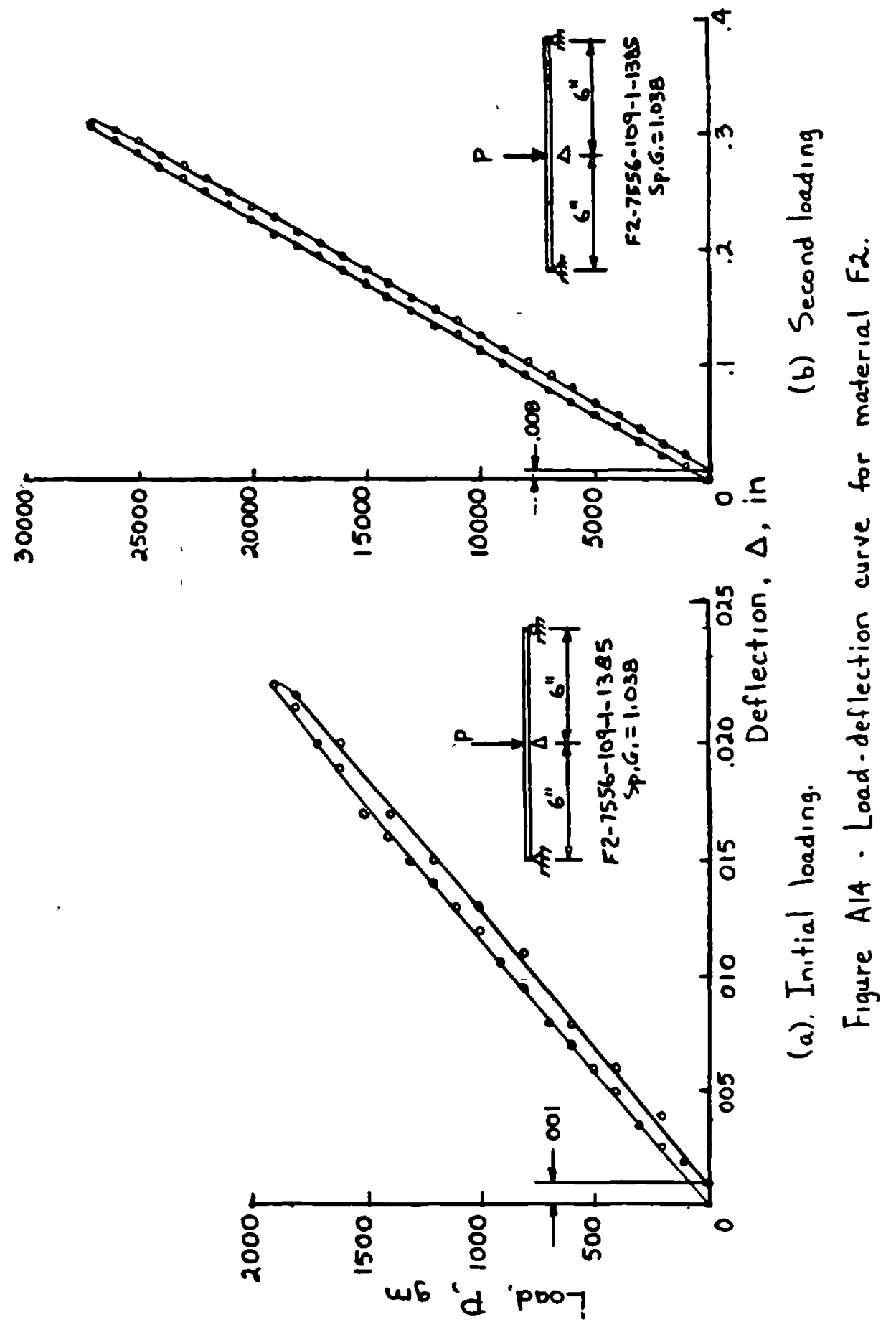




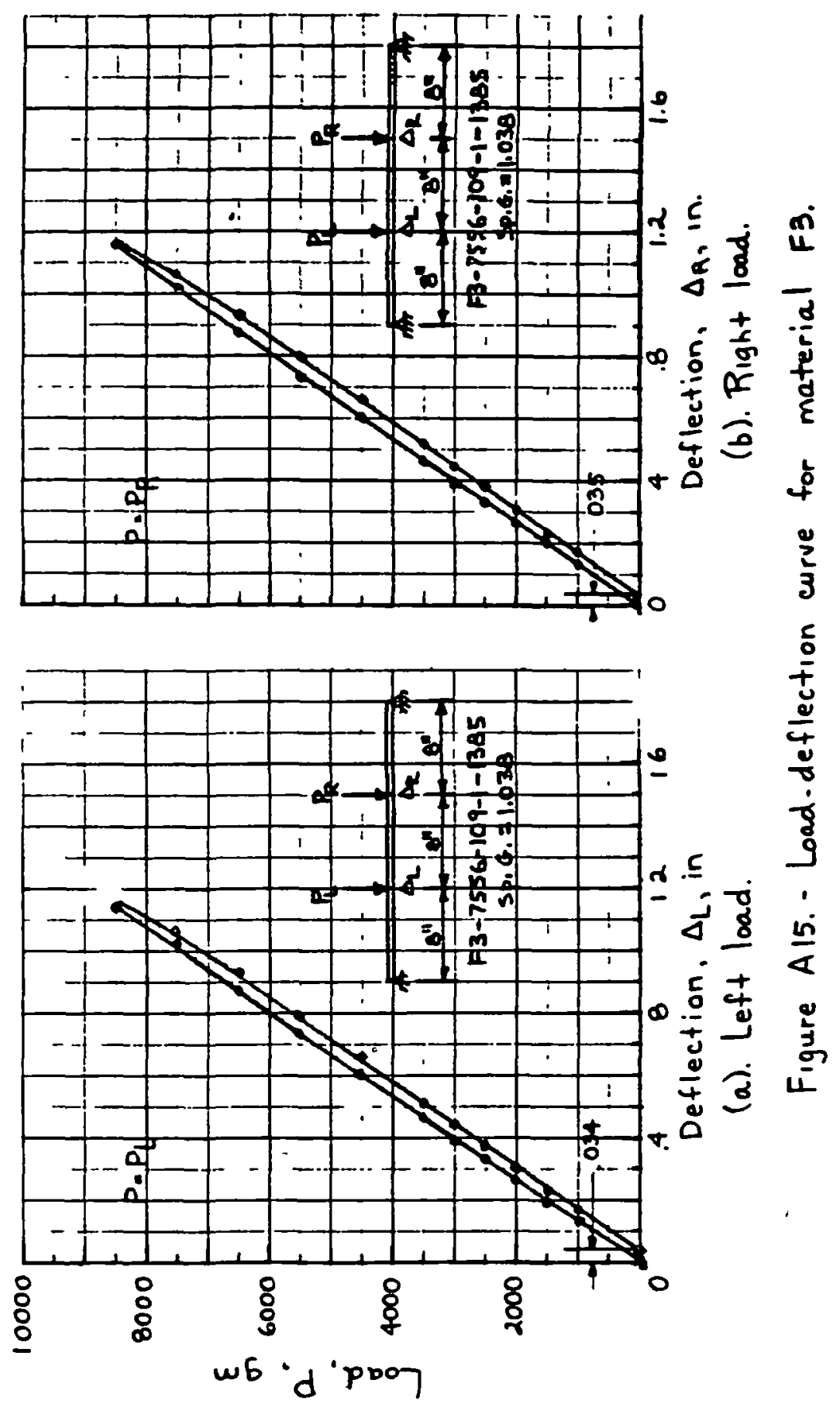



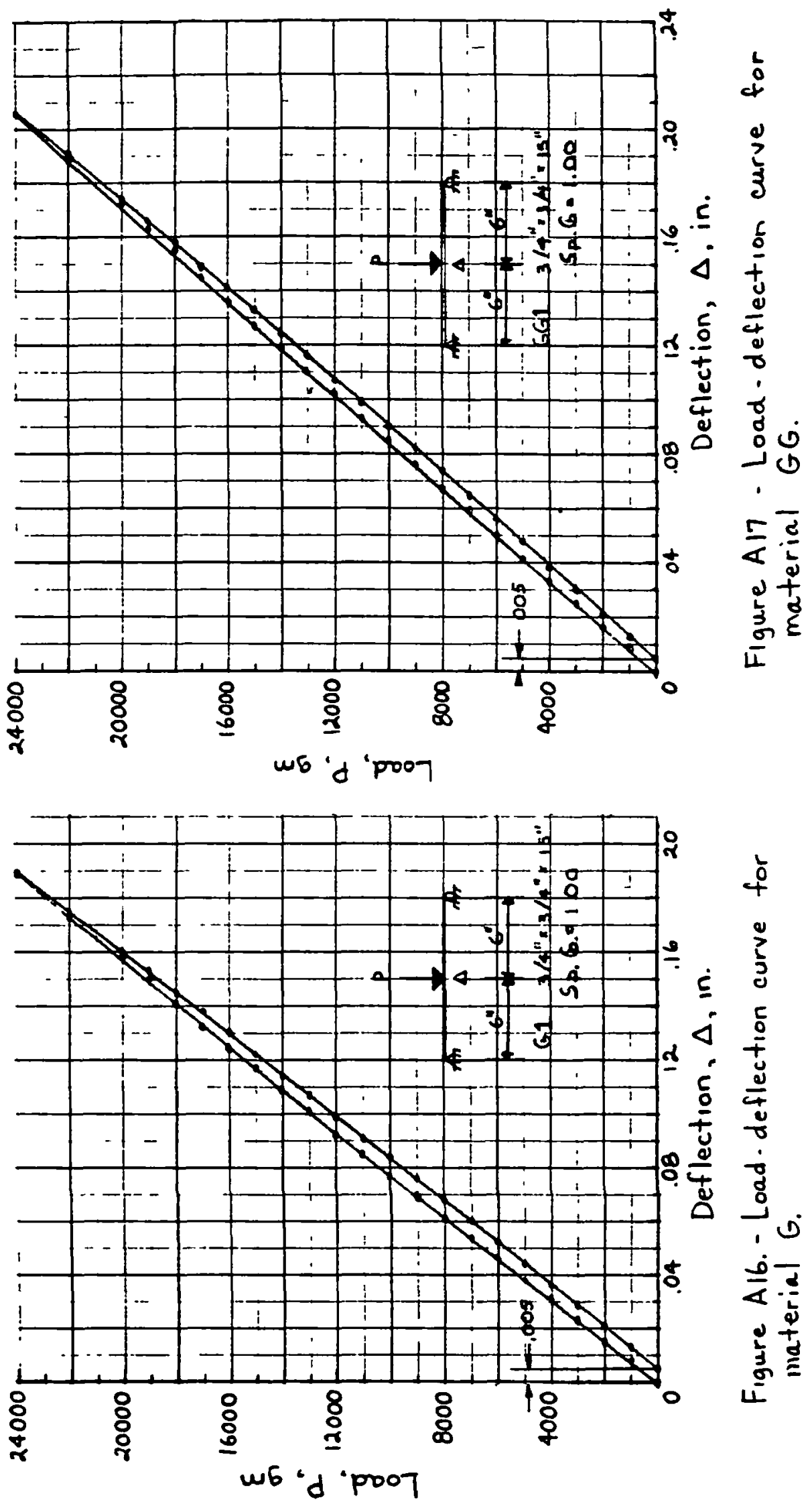


\section{APPENDIX B - FLEXURAL STRAIN TESTS}

Thls appendix presents the tabulated and plotted data obtained from the strain gage tests of beam specimens of urethane materials $D$ and $E$.

\section{Material D}

Measured values of strain for the individual gages are tabulated in table B1 for loading up to 17500 grams. Values of deflection under the two load points are listed in table B2. Also shown in this table is the calculation for determination of flexural modulus $E$ (from eq. (Al)). Plots of load against deflection are given in figure Bl.

Calculations for stress and deflection comparisons are detailed in figures B2 and B3. Figure B2 shows the construction for determination of the neutral axis and calculations for bending stress at maximum load determined from the strain equation and the beam equation.

\section{Material E}

The first loading for the specimens of material $E$ was up to 19000 grams. The values of strain obtained for the individual gages are listed in table B3. The measured deflections under the load points (from dial indicators) are listed in table B4 and plotted in figure B4. Also shown in table B4 are the calculations for modulus $E$ based on the two sets of deflection values. Because of the initial departure from linearity for the deflections under the right load, values of local slope were used in the modulus determination. The average from the two deflections was then taken as the value of $E$ for the specimen. Figure B5 shows the diagram for determination of neutral axis location and details of the calculated maximum stress obtained from the strain and beam equations.

Tabulated and plotted strain data for the second loading of material $E$ (up to $P_{L}=P_{R}=85 \mathrm{lb}$ ) are presented in table $B 5$ and figure $B 6$. The diagram for neutral axis location and comparative bending stress calculations are given in figure B7. The maximum value of strain at the maximum loading was obtained from extrapolation of the load-strain curve for strain gage 3. Data for the third and fourth loadings to 90 pounds are given in tables B6 and B7 and in figure B8. 
TABLE BI - MEASURED STRAIN FOR MATERIAL D.

\begin{tabular}{|c|c|c|c|c|c|c|}
\hline $\begin{array}{l}I \cap D D \\
P(Q \Gamma)\end{array}$ & $\begin{array}{l}\text { STPATN } \\
1 \text { ( } \mu \text { in } / 1 n\end{array}$ & $\begin{array}{l}\text { STPAIN: } \\
2\end{array}$ & $\begin{array}{l}\text { STPAATN } \\
3\end{array}$ & $\begin{array}{l}\text { STRAIN } \\
4\end{array}$ & $\begin{array}{l}\text { STRAIN } \\
5\end{array}$ & $\begin{array}{l}\text { STRAII } \\
6\end{array}$ \\
\hline $\begin{array}{r}0 \\
1000 \\
1500 \\
2500 \\
3500 \\
4500 \\
5500 \\
6500 \\
7500 \\
8500 \\
9500 \\
10500 \\
11500 \\
13500 \\
15500 \\
17500\end{array}$ & $\begin{array}{r}0 \\
-447 \\
-690 \\
-1162 \\
-1637 \\
-2112 \\
-2594 \\
-3048 \\
-3540 \\
-3991 \\
-4487 \\
-4957 \\
-5436 \\
-6400 \\
-7390 \\
-8325\end{array}$ & $\begin{array}{r}0 \\
113 \\
178 \\
290 \\
408 \\
529 \\
652 \\
775 \\
902 \\
1038 \\
1168 \\
1312 \\
1446 \\
1712 \\
2000 \\
2272\end{array}$ & $\begin{array}{r}0 \\
470 \\
709 \\
1178 \\
1664 \\
2140 \\
2630 \\
3112 \\
3600 \\
4073 \\
4585 \\
5178 \\
5573 \\
6560 \\
7605 \\
8623\end{array}$ & $\begin{array}{r}0 \\
-101 \\
-173 \\
-285 \\
-400 \\
-512 \\
-630 \\
-750 \\
-864 \\
-983 \\
-1100 \\
-1222 \\
-1344 \\
-1582 \\
-1840 \\
-2070\end{array}$ & $\begin{array}{r}0 \\
170 \\
253 \\
424 \\
597 \\
769 \\
945 \\
1126 \\
1306 \\
1482 \\
1668 \\
1849 \\
2035 \\
2400 \\
2783 \\
3147\end{array}$ & $\begin{array}{r}0 \\
-174 \\
-273 \\
-462 \\
-644 \\
-827 \\
-1007 \\
-1197 \\
-1393 \\
-1575 \\
-1766 \\
-1955 \\
-2141 \\
-2512 \\
-2896 \\
-3263\end{array}$ \\
\hline \multicolumn{7}{|c|}{ ONI NADTNG TO ZERO } \\
\hline
\end{tabular}

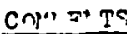

SpecImen No.- D7-7556-83-3-1365 Sp. 3.=0.91

Specimen Dimensions: $3 / 4^{n} \times 3 / 4^{n} \times 15^{n} 4-P t$. Ioadina

Actuel Specimen Dimensions Between Supoorts: $0.80^{n} x 0.76^{n} \times 12^{n}$

fxoeriment Date September 1B, 1976

TABLE B2 - MEASURED DEFLECTIONS FOR MATERIAL D

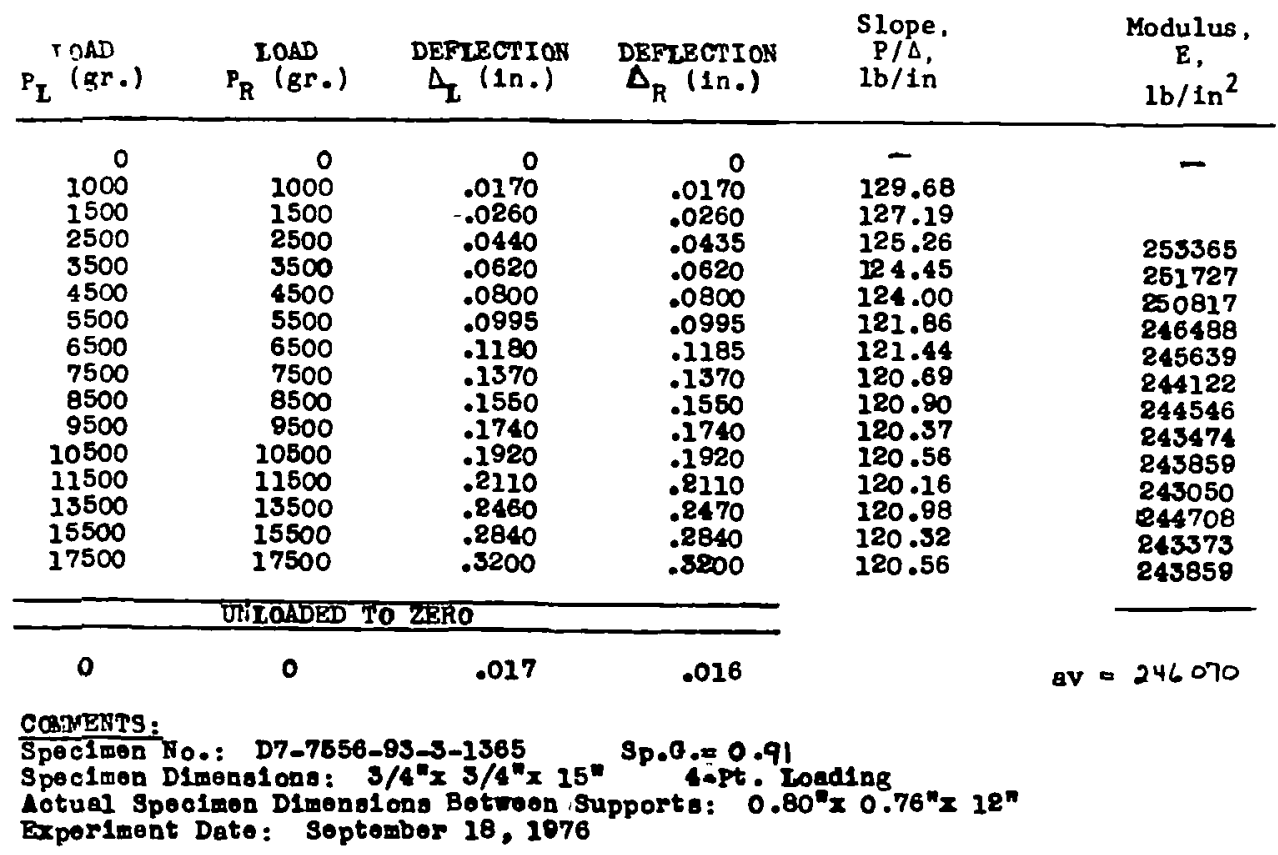


TABLE B3 - MEASURED STRAIN FOR MATERIAL E

[Maximum load, $19,000 \mathrm{gr}]$

\begin{tabular}{|c|c|c|c|c|c|c|}
\hline $\begin{array}{c}I \cap F E F \\
\pi=.\end{array}$ & $\begin{array}{r}\text { GAGE } 1 \\
\text { UIn / In }\end{array}$ & TAGE 2 & GAGE 3 & OAGE 4 & GAOE 5 & $G A=E 6$ \\
\hline $\begin{array}{r}0 \\
1000 \\
2000 \\
3000 \\
4000 \\
5000 \\
6000 \\
7000 \\
8000 \\
9000 \\
10000 \\
11000 \\
12000 \\
13000 \\
15000 \\
17000 \\
19000\end{array}$ & $\begin{array}{r}0 \\
-277 \\
-554 \\
-815 \\
-1091 \\
-1358 \\
-1640 \\
-1922 \\
-2177 \\
-2454 \\
-2737 \\
-3003 \\
-3274 \\
-3551 \\
-4073 \\
-4632 \\
-5175 \\
\end{array}$ & $\begin{array}{r}0 \\
-75 \\
-130 \\
-201 \\
-266 \\
-326 \\
-396 \\
-462 \\
-621 \\
-586 \\
-652 \\
-711 \\
-776 \\
-836 \\
-961 \\
-1091 \\
-1222 \\
\end{array}$ & $\begin{array}{r}0 \\
272 \\
548 \\
820 \\
1086 \\
1363 \\
1645 \\
1928 \\
2210 \\
2498 \\
2796 \\
3084 \\
3372 \\
3671 \\
4230 \\
4833 \\
5430 \\
\end{array}$ & $\begin{array}{r}0 \\
71 \\
130 \\
201 \\
266 \\
331 \\
402 \\
478 \\
543 \\
619 \\
695 \\
760 \\
831 \\
912 \\
1059 \\
1216 \\
1379 \\
\end{array}$ & $\begin{array}{r}0 \\
98 \\
201 \\
290 \\
396 \\
500 \\
603 \\
700 \\
904 \\
907 \\
1015 \\
1119 \\
1222 \\
1330 \\
1531 \\
1748 \\
1966\end{array}$ & $\begin{array}{r}0 \\
-103 \\
-206 \\
-299 \\
-396 \\
-500 \\
-597 \\
-695 \\
-798 \\
-896 \\
-994 \\
-1097 \\
-1195 \\
-1298 \\
-1493 \\
-1694 \\
-1895\end{array}$ \\
\hline
\end{tabular}

Cnip Dite

Speciren No. E5-3-1406 sp.c.= 1.05

Specimen Dlmensions. $3 / 4^{\prime \prime} \times 3 / 4^{\prime \prime} \times 15^{n} \quad 4-P t$. Loading

Experiment Date November 13, 1976

TABLE B4 - MEASURED DEFLECTIONS FOR MATERIAL E

[Maximum load, 19,000 gr]

LOAD LOAD DEFLECTION DEFLECTION SLOPE, MODULUS, LOCAL MODULUS, $\mathrm{P}_{\mathrm{L}},(\mathrm{gr}) \mathrm{P}_{\mathrm{R}^{\prime}}(\mathrm{gr}) \Delta_{\mathrm{L}}(\mathrm{In}) \quad \Delta_{\mathrm{R}}(\mathrm{In}) \quad(\mathrm{P} / \Delta)_{\mathrm{L}} \quad E_{\mathrm{L}^{\prime}}, \quad$ SLOPE, $E_{\mathrm{R}}$.

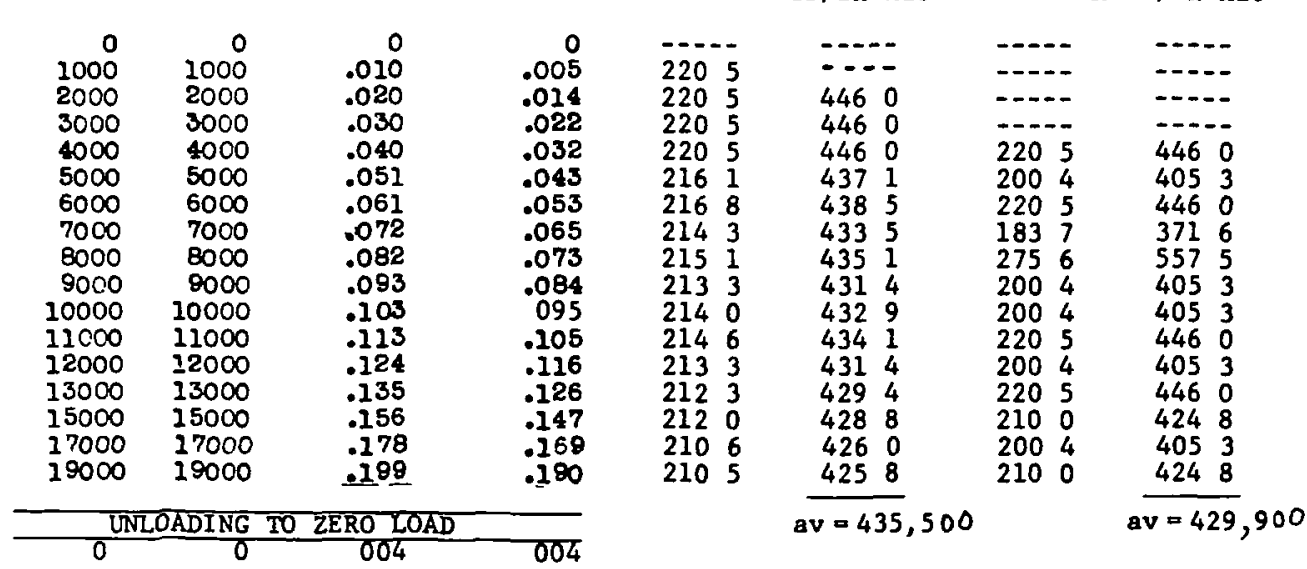

convints:

Spocimen No.- E5-3-1406 Sp.0.=1.05

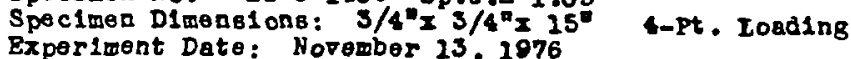


TABLE B5 - MEASURED STRAIN FOR MATERIAL E MAXIMUM LOAD $85 \mathrm{lb}$.

\begin{tabular}{|c|c|c|c|c|c|c|}
\hline$\underset{16}{\operatorname{LOAD}} \mathrm{P}$ & $\begin{array}{r}G A^{\wedge} E \text { I } \\
\text { uin / In }\end{array}$ & GAGE 2 & OAGE 3 & GAGE 4 & OAGE 5 & GAGE 6 \\
\hline $\begin{array}{r}0 \\
5 \\
10 \\
15 \\
20 \\
25 \\
30 \\
35 \\
40 \\
45 \\
50 \\
55 \\
60 \\
65 \\
70 \\
75 \\
80 \\
85\end{array}$ & $\begin{array}{r}0 \\
-744 \\
-1482 \\
-2025 \\
-2688 \\
-3253 \\
-4013 \\
-4588 \\
-5386 \\
-5815 \\
-6554 \\
-7032 \\
-7640 \\
-8275 \\
-8883 \\
-9394 \\
-1018 \\
-10686\end{array}$ & $\begin{array}{r}0 \\
-147 \\
-299 \\
-145 \\
-605 \\
-749 \\
-845 \\
-1102 \\
-1297 \\
-1423 \\
-1618 \\
-1759 \\
-1917 \\
-2096 \\
-2444 \\
-2400 \\
-2601 \\
-2742\end{array}$ & $\begin{array}{r}0 \\
771 \\
1471 \\
2191 \\
2731 \\
3361 \\
4100 \\
4860 \\
3593 \\
6098 \\
6864 \\
7461 \\
8064 \\
8862 \\
9508 \\
10165 \\
- \\
-\end{array}$ & $\begin{array}{r}0 \\
163 \\
320 \\
500 \\
668 \\
858 \\
1059 \\
1292 \\
1499 \\
1656 \\
1884 \\
2080 \\
2444 \\
2514 \\
2710 \\
2927 \\
3160 \\
3383\end{array}$ & $\begin{array}{r}0 \\
272 \\
489 \\
739 \\
939 \\
1178 \\
1442 \\
1732 \\
1949 \\
2150 \\
2400 \\
2623 \\
2818 \\
3122 \\
3323 \\
3584 \\
3823 \\
4078\end{array}$ & $\begin{array}{r}0 \\
-315 \\
-527 \\
-787 \\
-972 \\
-1222 \\
-1434 \\
-1749 \\
-1949 \\
-2150 \\
-2368 \\
-2585 \\
-2753 \\
-3041 \\
-3215 \\
-3464 \\
-3665 \\
-3904\end{array}$ \\
\hline
\end{tabular}

UNLOADING TO ZERO

$\begin{array}{rrrrrrr}0 & -163 & 0 & 250 & 54 & 22 & -33(10: 00 \mathrm{~g} \cdot \mathrm{m} .) \\ 0 & -285 & -82 & 152 & 87 & 0 & -60(10: 10 \mathrm{~g} . \mathrm{m})\end{array}$

ComRENT:

This epecimen ves loaded once before this test to 18000 grams. Speoimen Hos E5-3-1406 Sp.0.-1.05

Specimen Dimenaiong: $3 / 4^{n} \geq 3 / 4^{n} x 15^{\circ} 4-p t$. Loading

Experiment Date: November 20, 1976 
TABLE B6 - MEASUREd STRAIN FOR MATERIAL E MAXIM UM LOPD, GO _o (a) First loading

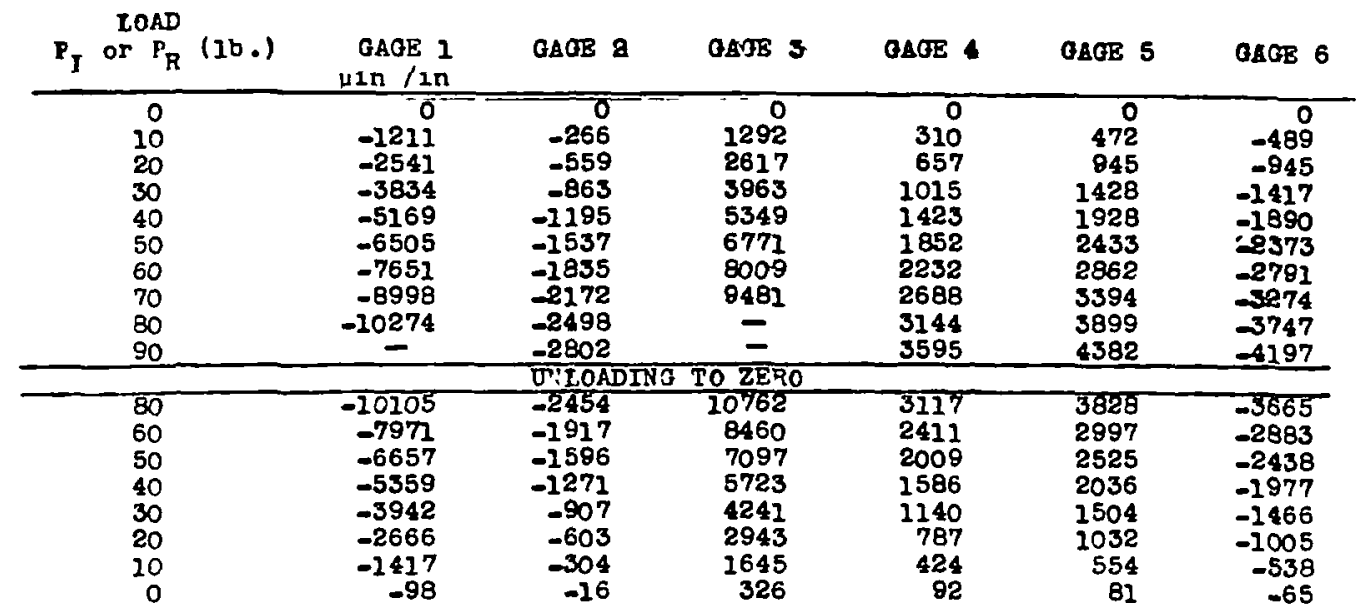

CMYENTS:

The specimen was once again loaded to 19000 grams and once more to $P_{L}=P_{R}=85168$. The strain gage readings in all oages are closely the same.

Spec1men No.- E5-3-1406 Sp. S.: 1.05

Specimen Dimensions. $3 / 4^{\prime \prime} \times 3 / 4^{4} \times 15^{n} \quad 4-P t$. Loadiag

Experiment Date: December 8, 1976

(b) Second loading

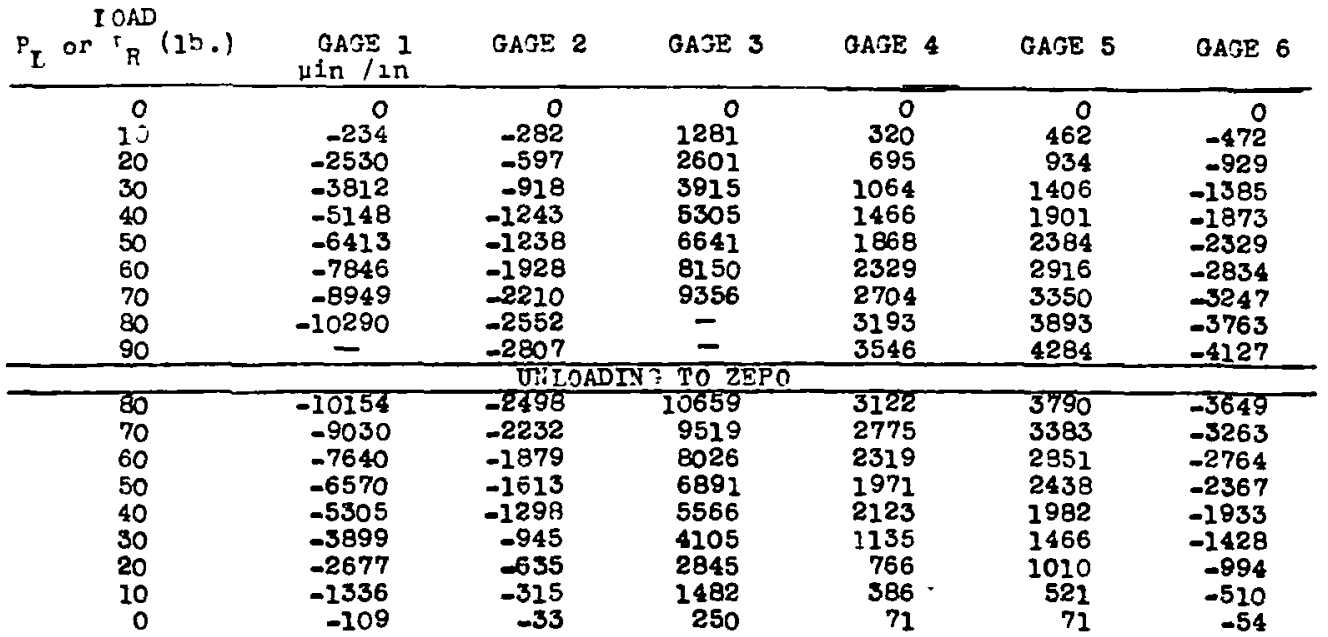

ColnenTs:

The specimen was loaded before to 19000 grams, to $P_{I}=P_{R}=851 \mathrm{~b}$, and to $P_{L}=P_{R}=901$ b. The strain gage roadings in all cases are about the oame.

Specimen No.. B5-3-1406 $3 p .3 .=1.05$

Specimen Dimensions. $3 / 4^{n} \times 3 / 4^{\circ} \times 15^{n}$-Pt. Loading

Exper1ment Date Dooomber 13, 1976 


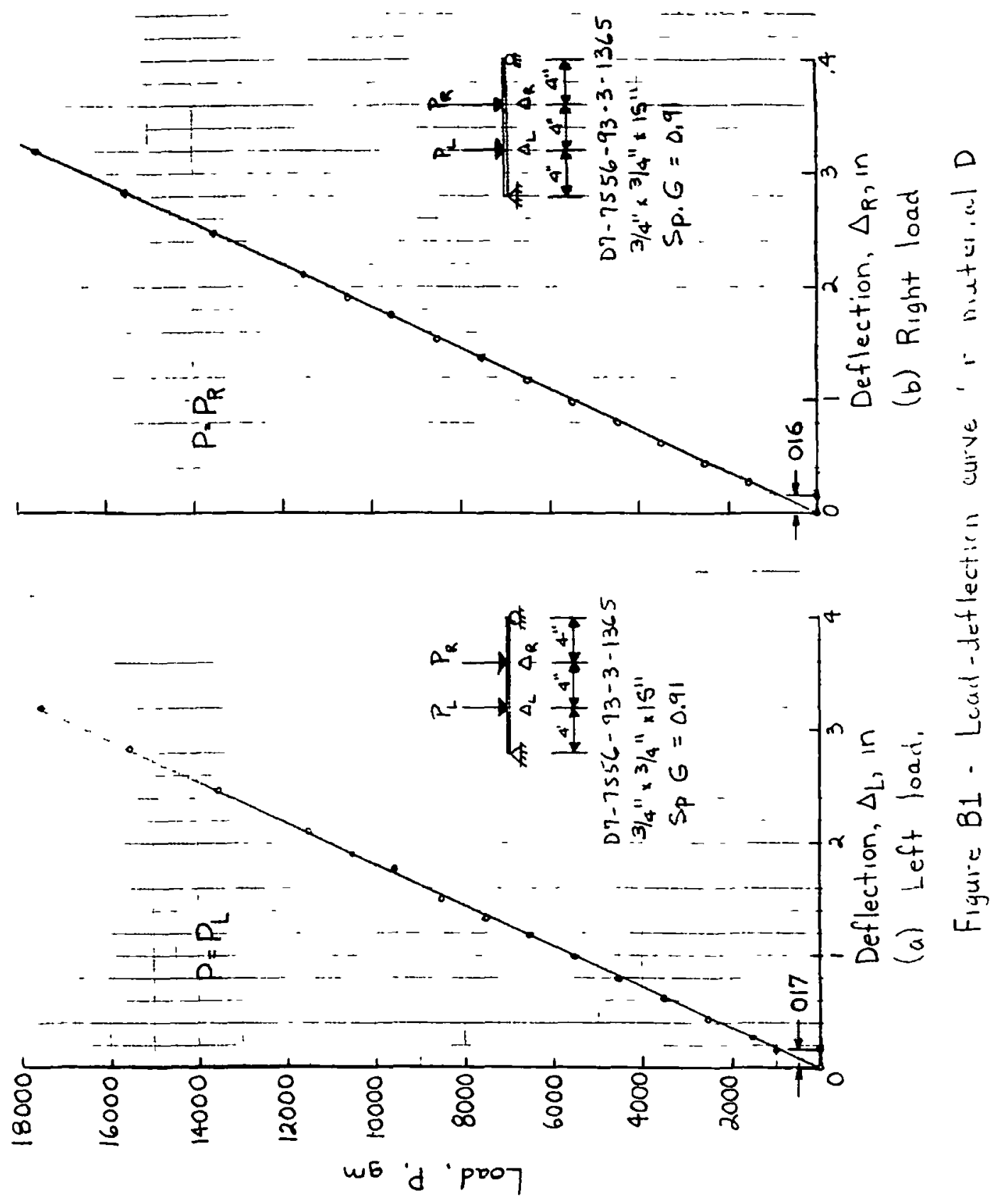



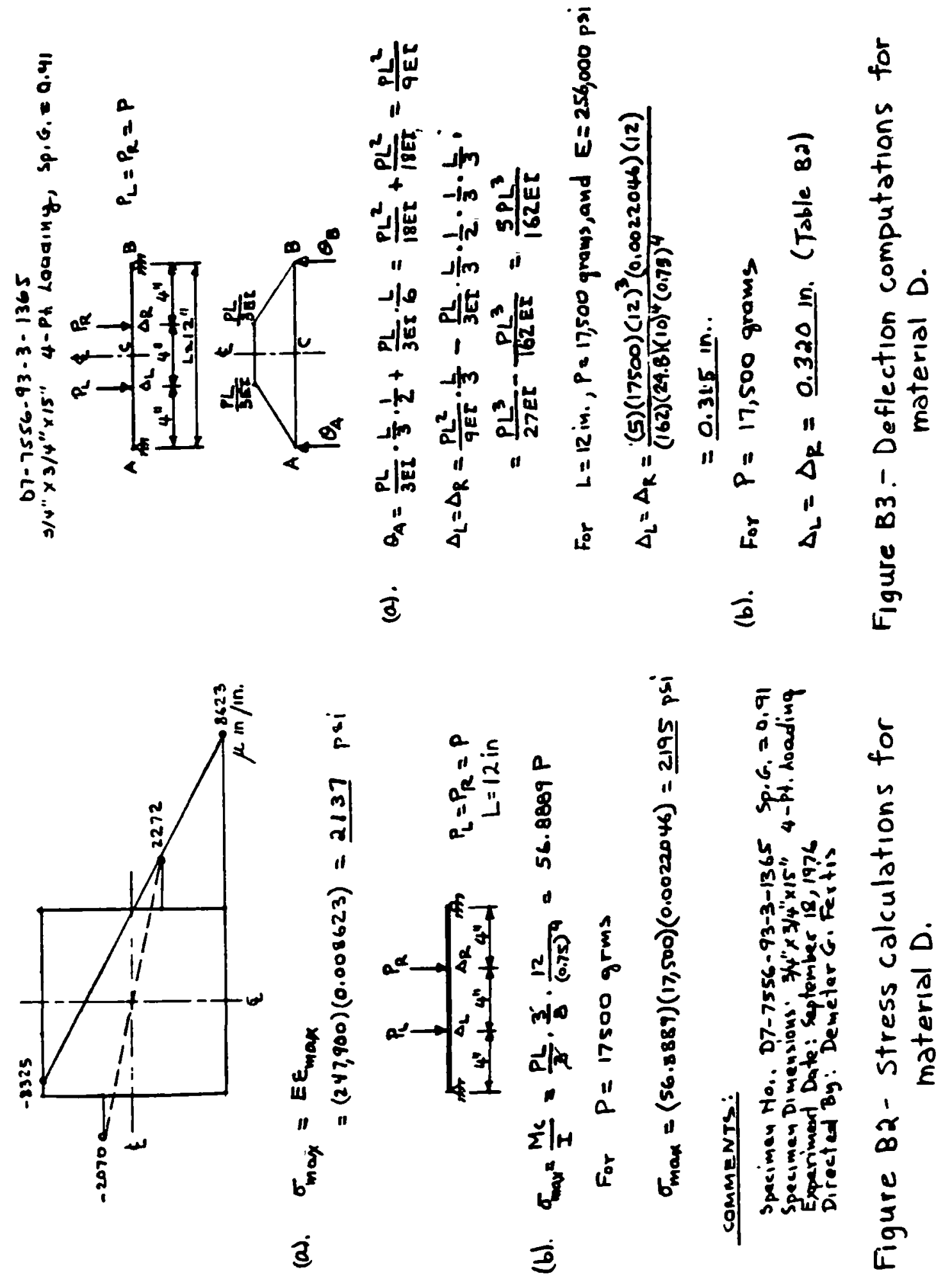

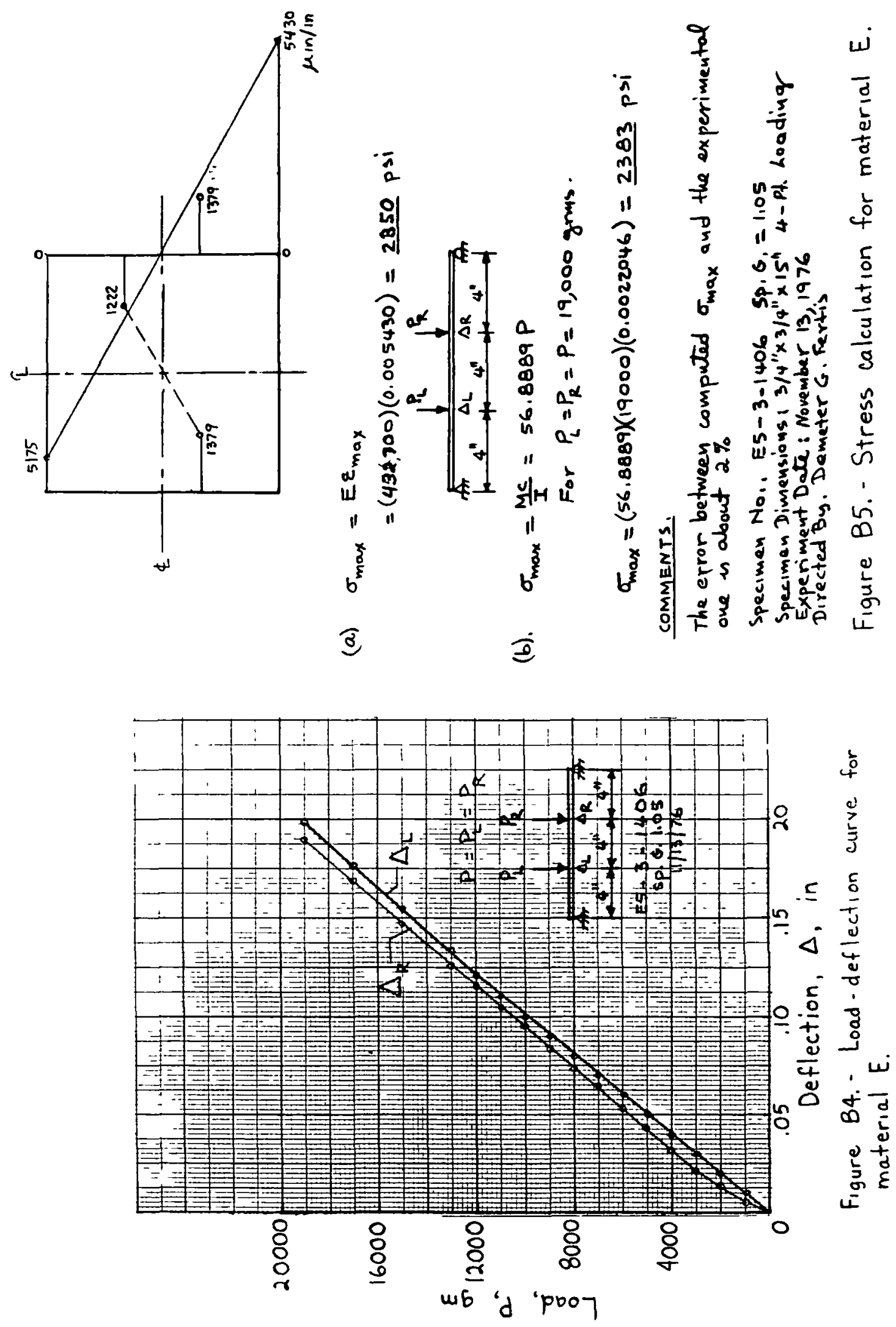

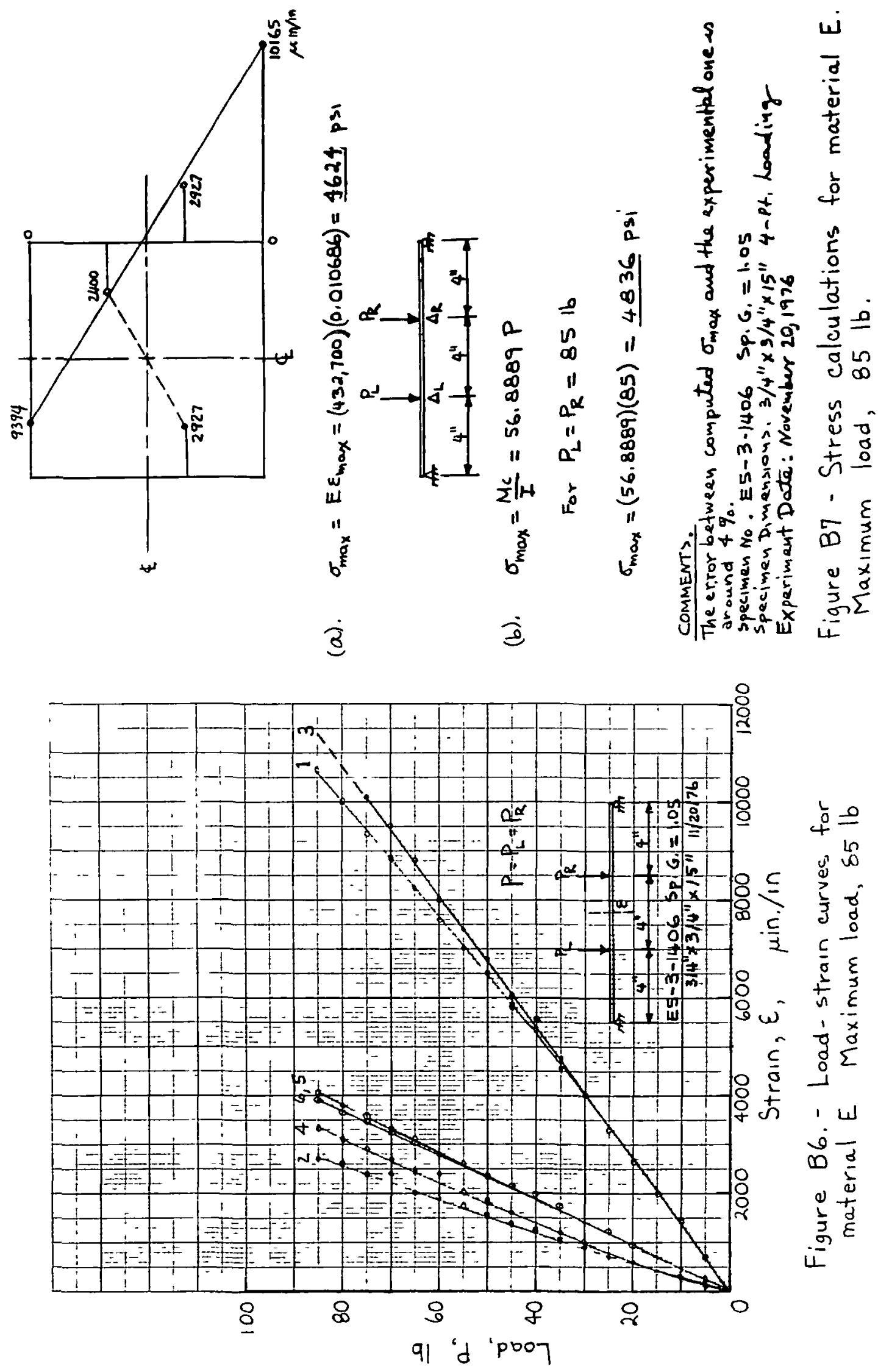





This appendix presents tabulated data from the bending and tensile creep resistance tests. The bending creep tests contained an initial screening of the nine urethane materials based on short-term loadings (210 to $300 \mathrm{~min}$ ). An example of the data obtained in these tests is given in table $\mathrm{Cl}$ which lists the specimen deflections obtained for material B under three levels of loading. Notes on these tests are given in table C2. Creep values were determined as the increase in elongation from time zero, $\Delta-\Delta_{0}$. Similar tabulations were obtained for the other materials.

Results of the long-duration bending creep test on material $E$ are shown in table C3. Included in the table are the deflection and creep values and the time and room temperature (daytime values) of the readings.

Results of the tensile creep tests on round specimens of material GG are listed in table C4. Included are the specimen length and creep values and the times and daytime room temperatures. 


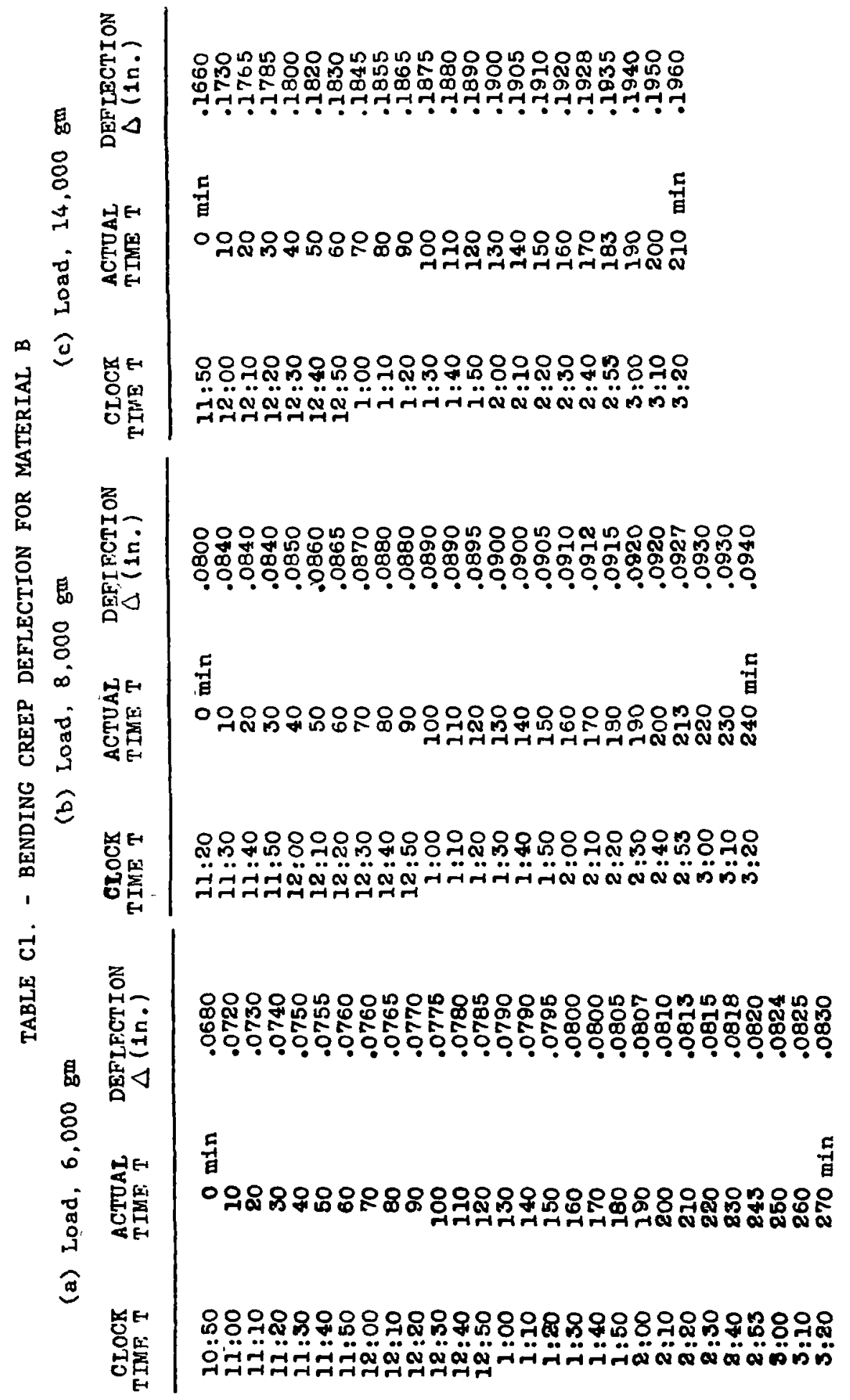


TABLE C2. - NOTES FOR BENDING CREEP

TESTS OF MATERIAL B

(a) Load, 6,000 gm

COMMENTS:

We unloaded the specimen slowly to zero at $3: 24$ F.N. . and we got a permanent deformation of $0.01601 \mathrm{n}$. At 3:30 P.M. the deformation was 0.0130 in. The movement was very slow from there on.

Specimen No.: B3-7556-91-12-1048 Sp.G. $=0.86$

Specimen Dimensions: $3 / 4^{\prime \prime} \times 3 / 4^{n} \times 15^{\mathrm{h}}$

Experiment Date: September 8, 1976

(b) Load, 8,000 gm

CONMENTS:

We unloaded the specimen slowly to zero at $3: 27$ P.V. and we got a permanent deformation of 0.0120 in. At 3:30 P.M. the deformation was 0.01001n. Specimen about stabli1zed.

Spec1men No.: B4-7556-91-12-1049 Sp. $G_{1}=0.86$ Specimen Dimensions: $3 / 4^{n} \times 3 / 4^{n} \times 15^{n}$

Experiment Date: September 8, 1976

(c) Load, 14,000 gm

COMMENTS:

We unloadid the specimen slowly to zero at 3:32 P.M. and we got a permanent deformation of 0.0325 in. At $3: 39$ P.M. the deformation was 0.0240 in. Specimen about stabilized. Changing slowly about 0.001 in. per 2 minutes.

Specimen No.: B5-7556-91-12-1048 Sp. G. $=0.86$ Specimen Dimensions: $3 / 4^{n \times} 3 / 4^{n} \times 15^{n}$

Experiment Date: September 8, 1976 
TABLE C3. - BENDING CREEP DATA FOR MATERIAL E

[Load, 21,000 gm.]

\begin{tabular}{|c|c|c|c|c|}
\hline $\begin{array}{l}\text { CIOCK } \\
\text { TIME }\end{array}$ & DATE & $\begin{array}{l}\text { ACTOAL } \\
\text { TIME T }\end{array}$ & $\begin{array}{c}\text { DEFIECTION } \\
\Delta\left(1 \mathrm{n}^{\circ}\right)\end{array}$ & $\begin{array}{l}\text { CREEP, } \\
\Delta-\Delta_{0}, \\
\operatorname{In} .\end{array}$ \\
\hline
\end{tabular}

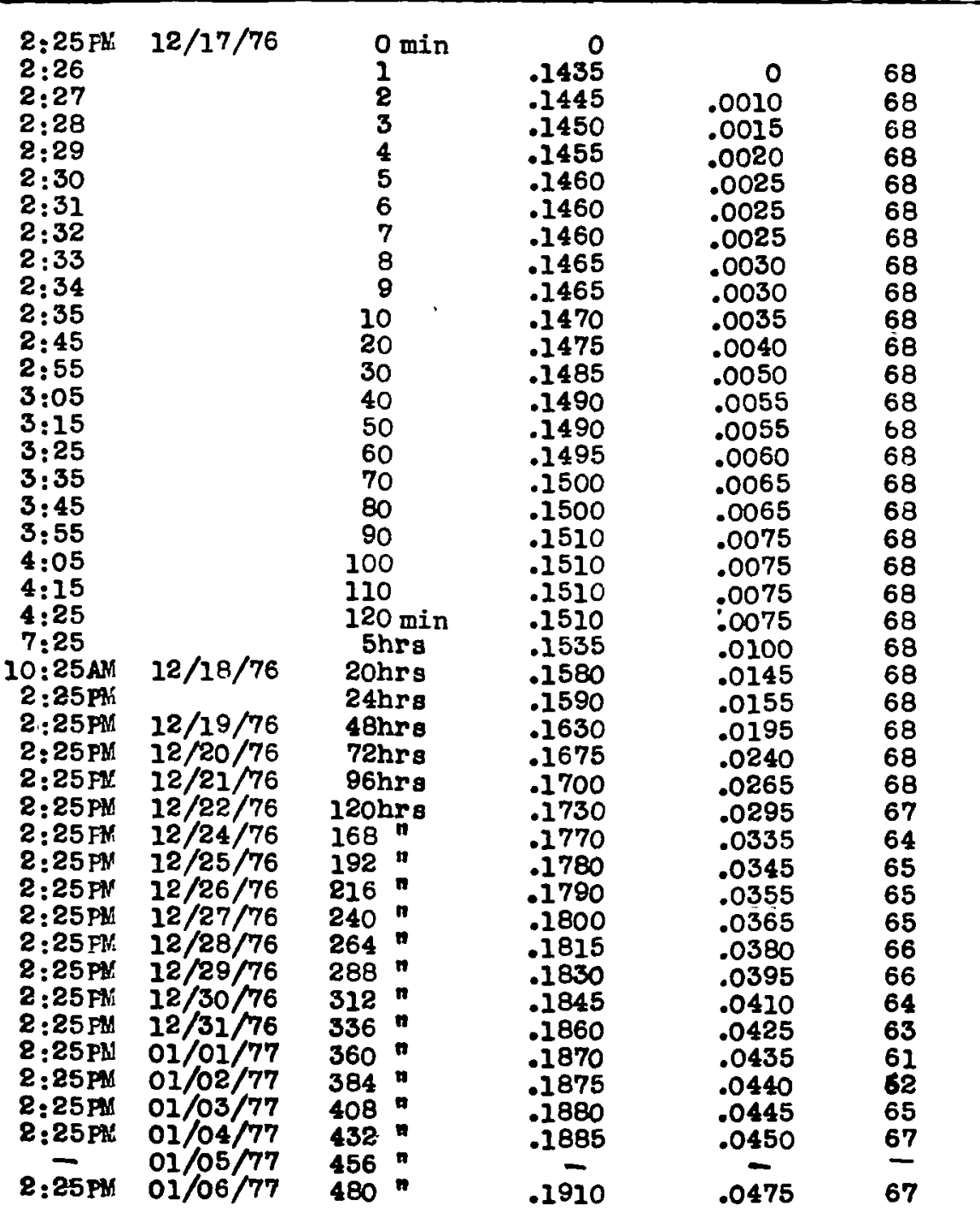


TABLE C3 - Concluded.

\begin{tabular}{|c|c|c|c|c|}
\hline $\begin{array}{l}\text { ET nCr. } \\
\text { Tn'E }\end{array}$ & DATE & $\begin{array}{l}\text { ACTUAL } \\
\text { TIME T }\end{array}$ & $\begin{array}{l}\text { DEFLECTION } \\
\Delta(\text { In.) }\end{array}$ & $\begin{array}{l}\text { CREEP, } \\
\Delta-\Delta_{0}, \\
\text { in. }\end{array}$ \\
\hline
\end{tabular}

\begin{tabular}{|c|c|c|c|c|c|c|c|}
\hline $\begin{array}{l}2: 25 \\
2: 25 \\
2: 25 \\
2: 25 \\
2: 25 \\
2: 25 \\
2: 25 \\
2: 25 \\
2: 25 \\
2: 25 \\
2: 25 \\
2: 25 \\
2: 25 \\
2: 25 \\
2: 25 \\
2: 25 \\
2: 25 \\
2: 25 \\
2: 25 \\
2: 25 \\
2: 25 \\
2: 25 \\
2: 25 \\
2: 25 \\
2: 25 \\
2: 25 \\
2: 25 \\
2: 25 \\
2: 25 \\
2: 25 \\
2: 25\end{array}$ & 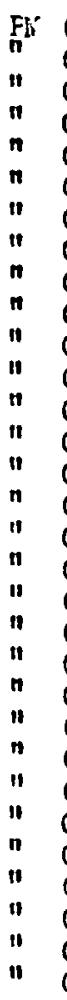 & $\begin{array}{l}01 / 07 / 77 \\
01 / 08 / 77 \\
01 / 09 / 77 \\
01 / 10 / 77 \\
01 / 11 / 77 \\
01 / 12 / 77 \\
01 / 13 / 77 \\
01 / 14 / 77 \\
01 / 15 / 77 \\
01 / 17 / 77 \\
01 / 19 / 77 \\
01 / 20 / 77 \\
01 / 22 / 77 \\
01 / 24 / 77 \\
01 / 25 / 77 \\
01 / 26 / 77 \\
01 / 29 / 77 \\
01 / 30 / 77 \\
02 / 01 / 77 \\
02 / 02 / 77 \\
02 / 03 / 77 \\
02 / 04 / 77 \\
02 / 05 / 77 \\
02 / 07 / 77 \\
02 / 08 / 77 \\
02 / 09 / 77 \\
02 / 10 / 77 \\
02 / 11 / 77 \\
02 / 12 / 77 \\
02 / 14 / 77 \\
02 / 15 / 77\end{array}$ & $\begin{array}{r}504 \\
528 \\
552 \\
576 \\
600 \\
624 \\
648 \\
672 \\
696 \\
744 \\
792 \\
816 \\
864 \\
912 \\
935 \\
960 \\
1032 \\
1056 \\
1104 \\
1128 \\
1152 \\
1176 \\
1200 \\
1248 \\
1272 \\
1296 \\
1320 \\
1344 \\
1368 \\
1416 \\
1440\end{array}$ & $\begin{array}{l}\text { nrs. } \\
n \\
n \\
n \\
n \\
n \\
n \\
n \\
n \\
n \\
n \\
n \\
n \\
n \\
n \\
n \\
n \\
n \\
n \\
n \\
n \\
n \\
n \\
n\end{array}$ & $\begin{array}{l}.1920 \\
.1935 \\
.1945 \\
.1950 \\
.1960 \\
.1970 \\
.1975 \\
.1975 \\
.1975 \\
.1990 \\
.1990 \\
.1990 \\
.1990 \\
.1990 \\
.1995 \\
.1995 \\
.2000 \\
.2000 \\
.2005 \\
.2005 \\
.2010 \\
.2010 \\
.2010 \\
.2015 \\
.2015 \\
.2020 \\
.2020 \\
.2020 \\
.2025 \\
.2030 \\
.2030\end{array}$ & $\begin{array}{l}.0485 \\
.0500 \\
.0510 \\
.0515 \\
.0525 \\
.0535 \\
.0540 \\
.0545 \\
.0545 \\
.0560 \\
.0560 \\
.0560 \\
.0560 \\
.0560 \\
.0565 \\
.0565 \\
.0570 \\
.0570 \\
.0575 \\
.0575 \\
.0580 \\
.0580 \\
.0580 \\
.0585 \\
.0585 \\
.0590 \\
.0590 \\
.0590 \\
.0595 \\
.0600 \\
.0600\end{array}$ & $\begin{array}{l}67 \\
67 \\
65 \\
65 \\
64 \\
63 \\
63 \\
63\end{array}$ \\
\hline
\end{tabular}

rongrems:

Speclimen iNo.: EB-105-2-1402 Sp.G.=1.05

Specimen Dimensions: $3 / 4 " x 3 / 4 " x 15 " 3-$ Pt. Loading

Directed By: Demeter G. Fertis

Pxperiment Date: December 17, 1976-February 15, 1977

Results look excelient. 
TABLE C4. - TENSION CREEP DATA FOR MATERIAL GG

[Load, 20 lb.]

\begin{tabular}{|c|c|c|c|c|c|c|c|}
\hline $\begin{array}{l}\text { STOSK } \\
\text { TIR: }\end{array}$ & & DATE & $\begin{array}{l}\text { ACT'T } \\
\text { TIPT }\end{array}$ & & $\begin{array}{l}\text { LENGTH } \\
\text { I. (In.) }\end{array}$ & $\begin{array}{l}\text { CREEP, } \\
\mathrm{L}-\mathrm{L}_{0} \text {. } \\
\text { in. }\end{array}$ & $\underset{\mathrm{O}_{\mathrm{F}}}{\mathrm{TEP}}$. \\
\hline $\begin{array}{l}10: 33 \\
10: 34 \\
10: 35 \\
10: 36 \\
10: 37 \\
10: 38 \\
10: 39 \\
10: 40 \\
10: 41 \\
10: 42 \\
10: 43 \\
10: 53 \\
11: 03 \\
11: 13 \\
11: 23 \\
11: 33 \\
3: 33 \\
10: 33 \\
10: 33 \\
10: 33 \\
10: 33 \\
10: 33 \\
10: 33 \\
10: 33 \\
10: 33 \\
10: 33 \\
10: 33 \\
10: 33 \\
10: 33 \\
10: 33 \\
10: 33 \\
10: 33 \\
10: 33 \\
10: 33 \\
10: 33 \\
10: 33 \\
10: 03\end{array}$ & $\begin{array}{l}\text { AM! } \\
n \\
n \\
n \\
n \\
n \\
n \\
n \\
n \\
n \\
n \\
n \\
n \\
n \\
n \\
n \\
n \\
n \\
n \\
n \\
n \\
n \\
n \\
n \\
n \\
n \\
n \\
n\end{array}$ & $\begin{array}{l}1 / 14 / 77 \\
1 / 14 / 77 \\
1 / 14 / 77 \\
1 / 14 / 77 \\
1 / 14 / 77 \\
1 / 14 / 77 \\
1 / 14 / 77 \\
1 / 14 / 77 \\
1 / 14 / 77 \\
1 / 14 / 77 \\
1 / 14 / 77 \\
1 / 14 / 77 \\
1 / 14 / 77 \\
1 / 14 / 77 \\
1 / 14 / 77 \\
1 / 14 / 77 \\
1 / 14 / 77 \\
1 / 15 / 77 \\
1 / 17 / 77 \\
1 / 20 / 77 \\
1 / 21 / 77 \\
1 / 22 / 77 \\
1 / 24 / 77 \\
1 / 25 / 77 \\
1 / 26 / 77 \\
1 / 31 / 77 \\
2 / 01 / 77 \\
2 / 02 / 77 \\
2 / 03 / 77 \\
2 / 04 / 77 \\
2 / 07 / 77 \\
2 / 08 / 77 \\
2 / 09 / 77 \\
2 / 10 / 77 \\
2 / 14 / 77 \\
2 / 15 / 77 \\
2 / 18 / 77\end{array}$ & $\begin{array}{r}0 \\
1 \\
2 \\
3 \\
4 \\
5 \\
6 \\
7 \\
8 \\
9 \\
10 \\
20 \\
30 \\
40 \\
50 \\
60 \\
5 \\
24 \\
72 \\
144 \\
168 \\
198 \\
240 \\
264 \\
288 \\
408 \\
432 \\
456 \\
480 \\
504 \\
576 \\
600 \\
624 \\
648 \\
744 \\
768 \\
840\end{array}$ & $\begin{array}{l}n 10 \\
n \\
n \\
n \\
n \\
n \\
n \\
n \\
n \\
n \\
n \\
n \\
n n s \\
n \\
n \\
n \\
n \\
n \\
n \\
n \\
n \\
n \\
n \\
n \\
n \\
n \\
n \\
n \\
n\end{array}$ & $\begin{array}{l}1.9340 \\
1.9480 \\
1.9480 \\
1.9480 \\
1.9480 \\
1.9480 \\
1.9480 \\
1.9480 \\
1.9480 \\
1.9480 \\
1.9480 \\
1.9520 \\
1.9520 \\
1.9520 \\
1.9520 \\
1.9520 \\
1.9560 \\
1.9565 \\
1.9565 \\
1.9570 \\
1.9550 \\
1.9550 \\
1.9560 \\
1.9550 \\
1.9550 \\
1.9540 \\
1.9540 \\
1.9550 \\
1.9550 \\
1.9560 \\
1.9560 \\
1.9560 \\
1.9560 \\
1.9565 \\
1.9565 \\
1.9570 \\
1.9570\end{array}$ & $\begin{array}{l}0 \\
.0140 \\
.0140 \\
.0140 \\
.0140 \\
.0140 \\
.0140 \\
.0140 \\
.0140 \\
.0140 \\
.0140 \\
.0180 \\
.0180 \\
.0180 \\
.0180 \\
.0180 \\
.0220 \\
.0225 \\
.0225 \\
.0230 \\
.0215 \\
.0215 \\
.0220 \\
.0215 \\
.0215 \\
.0205 \\
.0205 \\
.0215 \\
.0215 \\
.0225 \\
.0225 \\
.0225 \\
.0225 \\
.0230 \\
.0230 \\
.0235 \\
.0235\end{array}$ & $\begin{array}{l}63 \\
63 \\
63 \\
63 \\
63 \\
63 \\
63 \\
63 \\
63 \\
63 \\
63 \\
63 \\
63 \\
63 \\
63 \\
63 \\
63 \\
58 \\
53 \\
57 \\
60 \\
53 \\
63 \\
67 \\
65 \\
52 \\
57 \\
60 \\
64 \\
65 \\
62 \\
62 \\
63 \\
67 \\
67 \\
66 \\
66\end{array}$ \\
\hline
\end{tabular}

Cosmants:

Specimen No.: SGE SP. G. $=1.00$

Specimen Typo: $1 / 2^{n}$ diameter round specimen olth $3^{n}$ gauge length. Experiment Date: January 14,1977-February 18,1977 


\section{APPENDIX D - MODEL BLADE SECTION}

\section{Section Properties}

In order to determine the cross-sectional area and moment of inertia of the model blade section of figure 22(a), the profile was divided into a number of chordwise elements. The blade contour in each element was then approximated by an equivalent rectangle as shown in the sketch of table DI. The cross sectional area and moment of inertia are then obtained as

$$
A=2 \sum_{i=1}^{n} A_{i}
$$

and

$$
I=2 \sum_{i=1}^{n} I_{i}
$$

where the subscript $i$ refers to an individual element, and $n$ is the total number of elements.

For the nomenclature of an element as shown in the adjacent sketch

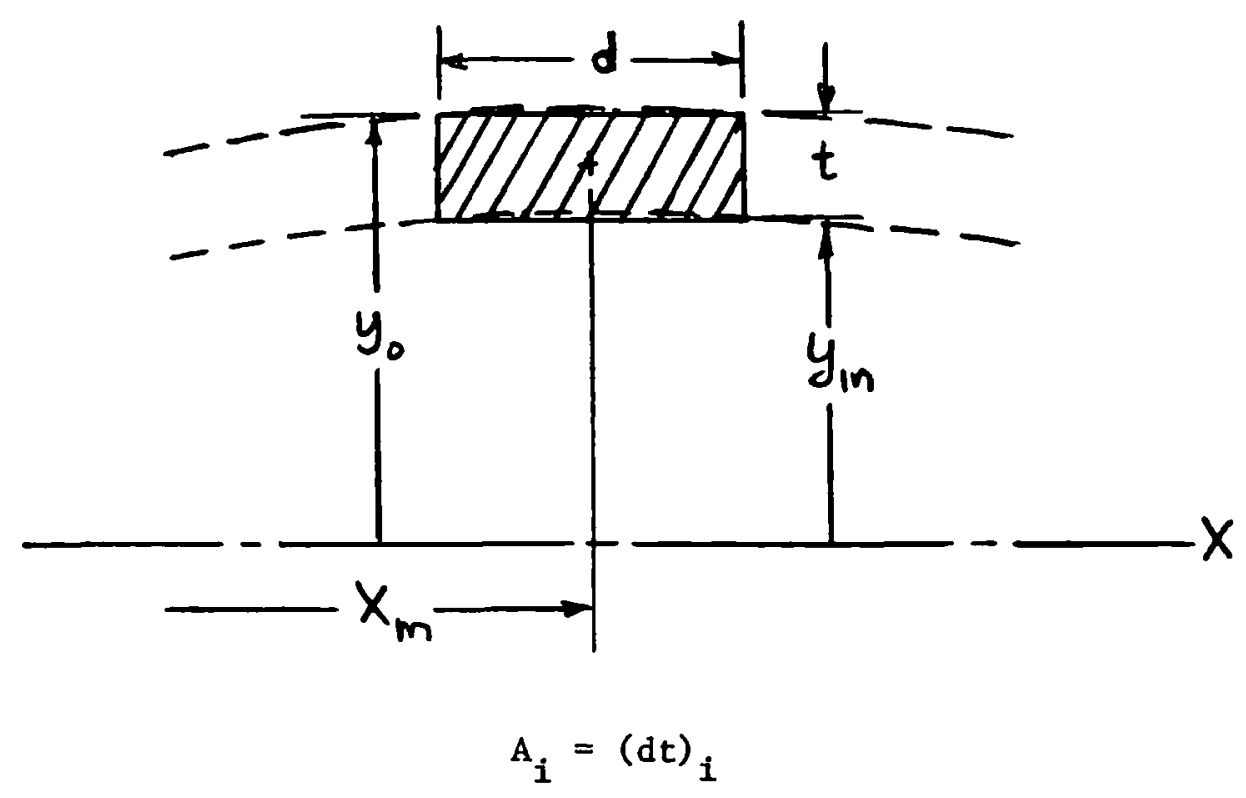

and

$$
I_{i}=\frac{1}{12}\left(d t^{3}\right)_{i}+(d t)_{1}\left(y_{0}-\frac{t}{2}\right)_{i}^{2}
$$


The moment resistance of the blade section, $M_{r}$ under the assumption that it acts as a solid body, is given by

$$
M_{r}=\sigma \frac{I}{y_{\max }}
$$

where $\sigma$ is the maximum tensile or compressive fiber stress $\left(1 \mathrm{~b} / \mathrm{in}^{2}\right), \mathrm{y}_{\max }$ is the maximum distance from the centerline (maximum half thickness), and I is the moment of inertia of both half sections (eqs. (D2) and (D4)). From the calculations of table $\mathrm{D} 1, \mathrm{I}=2 \times 40.808 \mathrm{in}^{4}$, and $\mathrm{y}_{\max }=2.28 \mathrm{in}$, , so that

$$
M_{r}=35.796 \sigma \quad(i n-1 b)
$$

The weight per foot of length for the section is

$$
\frac{W}{L}=\rho A
$$

and with $\mathrm{A}=2 \times 22.631 \mathrm{in}^{2}$ (from table D1), and density $\rho$ in $1 \mathrm{~b} / \mathrm{ft}^{3}$

$$
\frac{W}{L}=0.3143 \rho \quad(1 b / f t)
$$

\section{Test Results}

Bending. - Values of bending deflection and stress were calculated for the unreinforced blade section from consideration of the blade as a cantilever beam with a concentrated load at the free end. The deflection at the free end is then given by

$$
\Delta=\frac{1}{3} \frac{\mathrm{PL}^{3}}{\mathrm{EI}}=\frac{1}{3} \frac{\mathrm{ML}^{2}}{\mathrm{EI}}
$$

With $L=85.44$ inches, $E=232 \times 10^{3}$ pounds per square 1nch, and $I=81.616$ in $^{4}$, equation (D9) is

$$
\Delta=0.1285 \times 10^{-3} \mathrm{M}
$$

The corresponding maximum stress at the attached end is

$$
\sigma=M \frac{y_{\max }}{I}
$$


and, with $y_{\max }=2.28$ inches,

$$
\sigma=0.02794 \mathrm{M}
$$

Calculated values of $\Delta$ and $\sigma$ are listed in table D2(a) together with the measured data for the unreinforced blade section. The measured data for the reinforced blade section is given in section (b) of the table.

Torsion. - The readings of measured angular twist $\phi$ for the range of values of applied torque for a reinforced blade section are tabulated in table D3. Values were recorded for blade loading and unloading. 
TABLE D1. - SECTION PROPERTIES OF MODEL BLADE SECTION

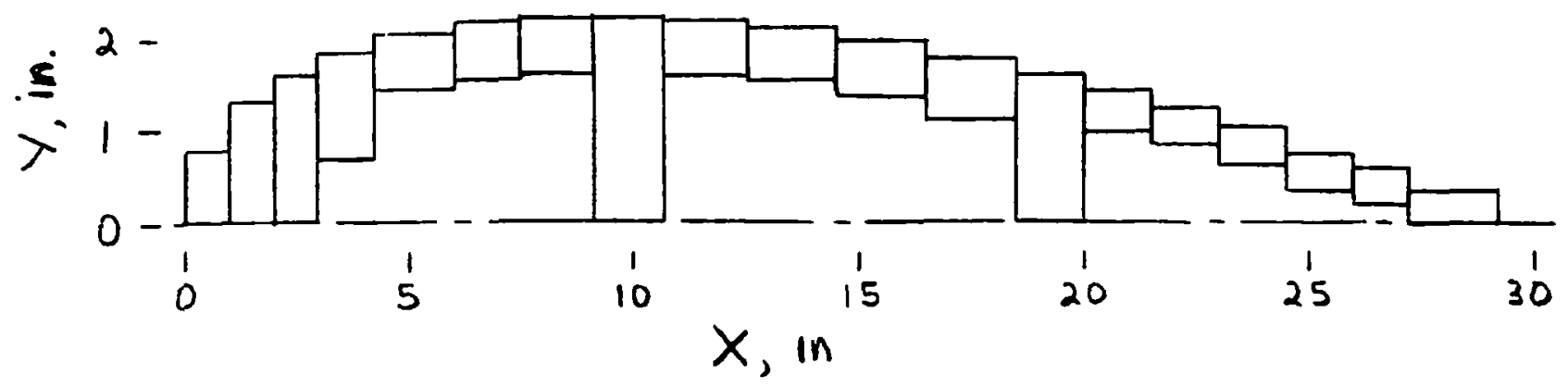

\begin{tabular}{|c|c|c|c|c|c|c|c|}
\hline \multirow[t]{2}{*}{$\begin{array}{l}\text { Element } \\
\text { range }\end{array}$} & \multirow{2}{*}{$\begin{array}{l}\text { Width, } \\
\text { d, } \\
\text { in. }\end{array}$} & \multirow{2}{*}{$\begin{array}{l}\text { Midpoint, } \\
\text { X }_{m} \text {, } \\
\text { in. }\end{array}$} & \multicolumn{2}{|c|}{$\begin{array}{c}\text { Contour, } \\
\text { in. }\end{array}$} & \multirow{2}{*}{$\begin{array}{c}\text { Thickness, } \\
t, \\
\text { in. }\end{array}$} & \multirow{2}{*}{$\begin{array}{c}\text { Area, } \\
\text { dt, } \\
\text { in }\end{array}$} & \multirow{2}{*}{$\begin{array}{l}\text { Moment of } \\
\text { inertia, } \\
I_{i} \\
\text { in }^{4}\end{array}$} \\
\hline & & & $\mathrm{y}_{\text {in }}$ & $y_{0}$ & & & \\
\hline $\begin{array}{r}0-1.0 \\
1.0-2.0 \\
2.0-2.9 \\
2.9-4.2 \\
4.2-6.0 \\
6.0-7.5 \\
7.5-9.1 \\
9.1-10.7 \\
10.7-12.5 \\
12.5-14.5 \\
14.5-16.5 \\
16.5-18.5 \\
18.5-20.0 \\
20.0-21.5 \\
21.5-23.0 \\
23.0-24.5 \\
24.5-26.0 \\
26.0-27.2 \\
27.2-29.1\end{array}$ & $\begin{array}{l}1.0 \\
1.0 \\
.9 \\
1.3 \\
1.8 \\
1.5 \\
1.6 \\
1.6 \\
1.8 \\
2.0 \\
2.0 \\
2.0 \\
1.5 \\
1.5 \\
1.5 \\
1.5 \\
1.5 \\
1.2 \\
1.9\end{array}$ & $\begin{array}{l}0.50 \\
1.50 \\
2.45 \\
3.65 \\
5.10 \\
6.75 \\
8.3 \\
9.9 \\
11.6 \\
13.5 \\
15.5 \\
17.5 \\
19.5 \\
20.75 \\
22.25 \\
23.75 \\
25.25 \\
26.6 \\
28.15\end{array}$ & $\begin{array}{l}0 \\
0 \\
0 \\
.70 \\
1.48 \\
1.58 \\
1.62 \\
0 \\
1.60 \\
1.55 \\
1.39 \\
1.22 \\
0 \\
.99 \\
.84 \\
.61 \\
.34 \\
.20 \\
0\end{array}$ & $\begin{array}{l}0.80 \\
1.33 \\
1.62 \\
1.87 \\
2.08 \\
2.20 \\
2.27 \\
2.28 \\
2.21 \\
2.13 \\
1.98 \\
1.79 \\
1.62 \\
1.44 \\
1.25 \\
1.04 \\
.76 \\
.60 \\
.36\end{array}$ & $\begin{array}{r}0.80 \\
1.33 \\
1.62 \\
1.17 \\
.60 \\
.62 \\
.65 \\
2.28 \\
.60 \\
.60 \\
.59 \\
.58 \\
1.62 \\
.45 \\
.44 \\
.43 \\
.42 \\
.40 \\
.36\end{array}$ & $\begin{array}{l}0.800 \\
1.330 \\
1.458 \\
1.521 \\
1.080 \\
.930 \\
1.040 \\
3.648 \\
1.080 \\
1.200 \\
1.180 \\
1.160 \\
2.430 \\
.675 \\
.660 \\
.645 \\
.630 \\
.480 \\
.684\end{array}$ & $\begin{array}{l}0.171 \\
.784 \\
1.275 \\
2.685 \\
3.454 \\
3.352 \\
3.971 \\
6.321 \\
3.931 \\
4.143 \\
3.385 \\
2.677 \\
2.126 \\
1.008 \\
.752 \\
.460 \\
.200 \\
.083 \\
.030\end{array}$ \\
\hline & & & & & & 22.631 & 40.808 \\
\hline
\end{tabular}


TABLE D2. - BENDING TEST DATA FOR MODEL BLADE SECTIONS

(a) Unreinforced blade, L $=85.44$ in.

\begin{tabular}{|c|c|c|c|c|}
\hline $\begin{array}{c}\text { Load P, } \\
\text { in. }\end{array}$ & $\begin{array}{c}\text { Moment M, } \\
\text { in-1b }\end{array}$ & $\begin{array}{c}\text { Measured } \\
\text { deflection, } \\
\Delta \text { (in.) }\end{array}$ & $\begin{array}{c}\text { Calculated } \\
\text { deflection, } \\
\text { in. }\end{array}$ & $\begin{array}{c}\text { Calculated } \\
\text { stress, } \\
\text { Ib/in }\end{array}$ \\
\hline 0 & 85 & 0 & 0 & 0 \\
100 & 874 & 2.44 & 1.10 & 239 \\
200 & 17088 & 5.16 & 2.20 & 477 \\
300 & 25631 & 7.01 & 3.29 & 716 \\
400 & 34175 & 8.98 & 4.39 & 955 \\
500 & 42719 & 11.14 & 5.49 & 1193 \\
600 & 51263 & 12.72 & 6.59 & 1432 \\
700 & 59806 & 16.14 & 7.69 & 1671 \\
800 & 68350 & 18.03 & 8.78 & 1909 \\
900 & 76834 & 20.35 & 9.87 & 2146 \\
950 (failed) & 81166 & 22.25 & 10.43 & 2267 \\
\hline
\end{tabular}

(b) Reinforced blade, L $=85.25$ in.

\begin{tabular}{|c|c|c|}
\hline $\begin{array}{c}\text { Load } \\
1 b\end{array}$ & $\begin{array}{c}\text { Moment M, } \\
\text { in-1b }\end{array}$ & $\begin{array}{c}\text { Deflection, } \\
\Delta \text { (in.) }\end{array}$ \\
\hline 0 & 8575 & 0 \\
100 & 17150 & 1.87 \\
200 & 25725 & 3.66 \\
300 & 34300 & 5.04 \\
400 & 42875 & 6.50 \\
500 & 51450 & 7.95 \\
600 & 60025 & 9.49 \\
700 & 68600 & 11.02 \\
800 & 77125 & 12.28 \\
900 & 85750 & 14.57 \\
1000 (yield) & 81463 & 15.63 \\
950 (failed) & 84035 & 16.42 \\
980 (faile & \\
\hline
\end{tabular}


TABLE D3. - TORSION TEST DATA FOR REINFORCED BLADE SECTION $[\mathrm{L}=87.25$ in. $]$

\begin{tabular}{|c|c|c|c|}
\hline \multirow{2}{*}{\multicolumn{2}{|c|}{$\begin{array}{c}\text { Torque } T \\
\text { in-1b }\end{array}$}} & \multicolumn{2}{|c|}{ Angular twist, $\phi$, deg } \\
\hline & & Loading & Unloading \\
\hline & 0 & 0 & 0.2991 \\
\hline & 840 & .1432 & .4905 \\
\hline 1 & 680 & .3186 & .6686 \\
\hline & 520 & .4836 & .8434 \\
\hline 3 & 360 & .6492 & 1.0313 \\
\hline 4 & 320 & .8405 & 1.2256 \\
\hline 5 & 280 & 1.0279 & 1.4421 \\
\hline 6 & 240 & 1.2284 & 1.6077 \\
\hline 7 & 200 & 1.4003 & 1.7985 \\
\hline 8 & 160 & 1.5882 & 1.9893 \\
\hline 9 & 120 & 1.7699 & 2.1738 \\
\hline 10 & 080 & 1.9544 & 2.3554 \\
\hline 11 & 040 & 2.1423 & 2.5434 \\
\hline 12 & 000 & 2.3617 & 2.7152 \\
\hline 12 & 960 & 2.8264 & 2.8871 \\
\hline 13 & 920 & 3.0046 & 3.0590 \\
\hline 14 & 880 & 3.1799 & 3.2275 \\
\hline 18 & 240 & 3.7976 & 3.8640 \\
\hline 18 & 720 & 3.8772 & \\
\hline 19 & 200 & 3.9597 & 4.0044 \\
\hline 19 & 680 & 4.0359 & \\
\hline 20 & 160 & 4.1190 & \\
\hline 20 & 400 & 4.1889 & 4.1889 \\
\hline
\end{tabular}




\section{APPENDIX E - BLADE DESIGN ANALYSIS}

The objective of this analysis is to develop equations for the spanwise variation of section properties, reinforcement dimensions, and unit weight for a full-scale reinforced urethane rotor blade designed to meet certain specifications. The spanwise varlations of blade profile geometry (C and $\left.2 y_{\max } / C\right)$, section stiffness $E I$, and section moment resistance $M_{r}$ specified for the design are listed in table XI. The radius of the blade at the tip is $r_{t}=62.5$ feet. The cross section of the blade at the 80 percent radius point $r / r_{t}=0.8$ is assumed to be that of the model blade section built for the bending tests ( $f$ ig. 22(a)). All sections of the full-scale blade are prescribed to be symmetrical profiles similar to the section at $r / r_{t}=0.8$. The section properties of the $r / r_{t}=0.8$ section are given in table $D 1$. This cross-sectional configuration is referred to as the reference blade section.

In the ensuing sections, equations are developed first for an al1-urethane blade, then for the metal reinforcement plates, and finally for the reinforced blade as a composite beam.

\section{Symbols}
A
area
b
width of reinforcement plate
$\mathrm{C}$
blade chord length
d
chordwise width of blade element
E modulus of elasticity
I moment of inertia
$\mathrm{K}_{1}, \ldots, \mathrm{K}_{5} \quad$ constants
L
blade length
$\mathbf{M}_{\mathbf{r}}$
moment resistance
$\mathbf{r}$
blade radius
t
thickness of reinforcement plate
W
weight
$\mathrm{X}$
distance along chord
y
distance normal to chord
normal distance to outer contour of blade profile 


$\begin{array}{ll}y_{R} & \text { normal distance to outer fiber of reinforcement plate } \\ y_{\max } & \text { maximum half thickness of blade profile } \\ \rho & \text { material density } \\ \sigma & \text { stress }\end{array}$

Subscripts :

R reinforcement

t blade tip

u urethane

$u, f \quad$ full urethane section

\section{Al1-Urethane Blade}

For the all-urethane blade with reference blade sections, the blade crosssection at $r / r_{t}=0.8$ was divided into a number of individual chordwise elements for which the blade material was represented by an equivalent rectangle as illustrated by the half section sketch in figure Dl of appendix $D$. The resultant equations for moment of inertia $I_{i}$ and area $A_{i}$ for each element are given by equations (D3) and (D4), respectively.

Under the assumption of similar profiles along the blade span, it is specified that for each element, along the radius of the blade,

$$
\begin{aligned}
& \left(\frac{d}{c}\right)_{i}=\text { Constant }=k_{1, i} \\
& \left(\frac{t}{y_{\max }}\right)_{1}=\text { Constant }=k_{2, i} \\
& \left(\frac{y_{0}}{y_{\max }}\right)_{1}=\text { Constant }=k_{3, i}
\end{aligned}
$$

The properties $K_{1,1}$ and $K_{3, i}$ are specifically required to maintain similar section profiles along the span, while $\mathrm{K}_{2,1}$ is an arbitrary specification for the radial variation of skin thickness. For these conditions, the section moment of Inertia at a given radial position becomes

$$
I=\frac{1}{4} c^{4}\left(\frac{2 y_{\max }}{c}\right)^{3} k_{4}
$$


where

$$
\mathrm{K}_{4}=\sum_{i=1}^{\mathrm{n}}\left\{\mathrm{K}_{1, i} \mathrm{k}_{2, i}\left[\left(\frac{\mathrm{k}_{2, i}}{12}\right)^{2}+\left(\mathrm{k}_{3, i}-\frac{\mathrm{k}_{2, i}}{2}\right)^{2}\right]\right\}
$$

By evaluating equation (E2) at $r / r_{t}=0.8$ for which the property is known from table $D 4$ ( $I=2 \times 40.808$ ), it is found that $K_{4}=0.11942$. The moment of inertia for the full urethane section then becomes

$$
I_{u, f}=0.029855 c^{4}\left(\frac{2 y_{\max }}{c}\right)^{3}
$$

The moment resistance of the section is now

$$
\left(\mathrm{M}_{\mathrm{r}}\right)_{\mathrm{u}, \mathrm{f}}=\sigma\left(\frac{\mathrm{I}_{\mathrm{u}, \mathrm{f}}}{\mathrm{y}_{\max }}\right)=0.05971 \mathrm{c}^{3}\left(\frac{2 \mathrm{y}_{\max }}{\mathrm{c}}\right)^{2} \sigma
$$

where the allowable stress for the urethane is taken as $\sigma=2000 \mathrm{psi}$, and the stiffness of the section is

$$
\mathrm{EI}_{\mathrm{u}, \mathrm{f}}=0.029855 \mathrm{C}^{4}\left(\frac{2 \mathrm{y}_{\max }}{\mathrm{C}}\right)^{3} \mathrm{E}
$$

where $\mathrm{E}$ is taken as $458000 \mathrm{psi}$.

The weight of the urethane section per unit length of blade is, for the urethane density $\rho$

$$
\left(\frac{W}{L}\right)_{u, f}=A_{u, f} \rho
$$

The cross-sectional area is obtained from equations (D1), (D3), and (E1) are

$$
A_{u, f}=c^{2}\left(\frac{2 y_{\max }}{c}\right) K_{5}
$$


where

$$
\mathrm{K}_{5}=\sum_{i=1}^{n}\left(\mathrm{~K}_{1, i}, \mathrm{~K}_{2, i}\right)
$$

By evaluating equation (E9) at $r / r_{t}=0.8$ for which $A=2 \times 22.631$ in $^{2}$ (table D4), it is found that $K_{5}=0.33527$. Thus,

$$
A_{u, f}=0.33527 c^{2}\left(\frac{2 y_{\max }}{c}\right)
$$

and

$$
\left(\frac{W}{L}\right)_{u, f}=0.33527 \rho^{2}\left(\frac{2 y_{\max }}{C}\right)
$$

For urethane formulation $E, P=65.4$ pounds per cubic foot.

\section{Metal Reinforcement}

The metal reinforcement required, for the urethane will be added in the form of a thin plate imbedded in each outer surface of the blade in the region of the maximum thickness of the profile, as shown by sketch E-1. For calcula-

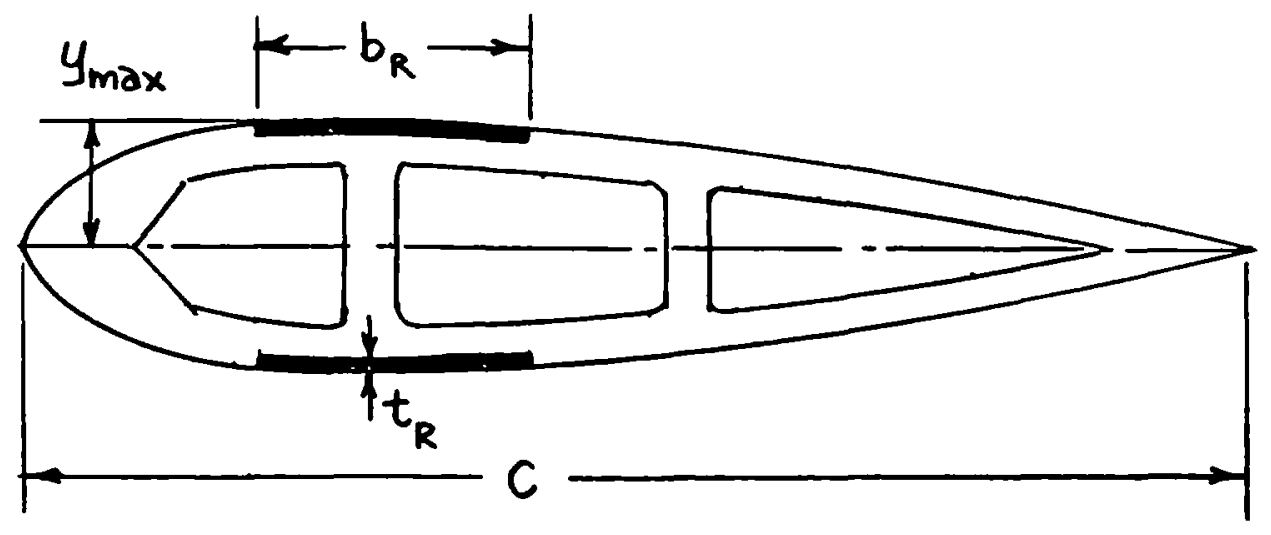

Sketch E-1

tion purposes, the reinforcement is represented by a thin rectangular plate located at a distance $y_{R}$ from the neutral axis of the blade profile (sketch $\mathrm{E}-2$ ). 


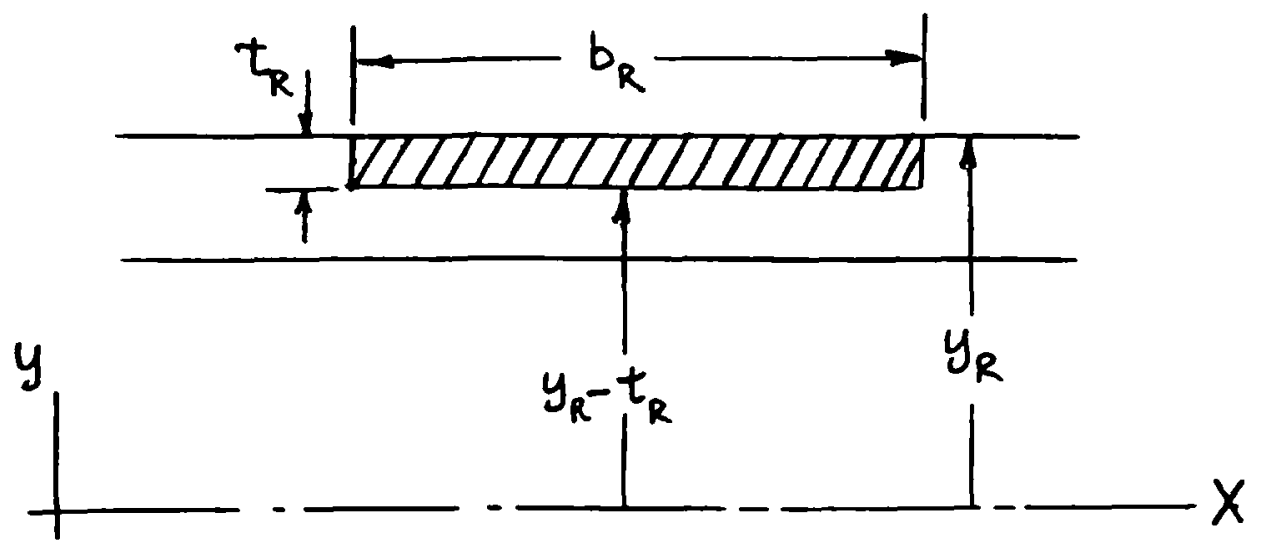

Sketch E-2

Since the plate thickness $t_{R}$ will generally be small compared to $y_{R}$, the approximation form is used for the moment of inertia, that is,

$$
I_{R}=2 b_{R} t_{R}\left(y_{R}-\frac{t_{R}}{2}\right)^{2}
$$

It is further specified for purposes of analysis that the reinforcement plate is of constant thickness $t_{R}$, but of varying width $b_{R}$ along the span. Also, the location of the plate $y_{R}$ is at a fixed position with respect to the maximum half thickness $y_{\max }$. The moment resistance of the plates can then be shown to be given by

$$
\left(M_{r}\right)_{R}=\sigma_{R} b_{R} t_{R} c\left(\frac{2 y_{\max }}{c}\right)\left(\frac{y_{R}}{y_{\max }}\right)\left[1-\frac{t_{R}}{c}\left(\frac{y_{\max }}{y_{R}}\right)\left(\frac{c}{2 y_{\max }}\right)\right]^{2}
$$
to be

The stiffness of the reinforcement plates was derived in a similar fashion

$$
(E I)_{R}=E_{R} b_{R} t_{R} c^{2}\left(\frac{2 y_{\max }}{c}\right)^{2}\left(\frac{y_{R}}{y_{\max }}\right)^{2}\left[1-\frac{t_{R}}{c}\left(\frac{y_{\max }}{y_{R}}\right)\left(\frac{C}{2 y_{\max }}\right)\right]^{2}
$$

For the calculations, it was taken that $t_{R}=0.25$ inch and $y_{R} / y_{\max }=0.90$. For steel $E_{R}=30 \times 10^{6} \mathrm{psi}$, and for aluminum, $E_{R}=10 \times 10^{6} \mathrm{psi}$.

The unit weight of the reinforcement plates is

$$
\left(\frac{W}{L}\right)_{R}=2 \rho_{R} b_{R} t_{R}
$$


in which for steel, $\rho_{R}=490$ pounds per cubic foot, and for aluminum, $\rho=168$ pounds per cubic foot.

\section{Reinforced Blade}

In the determination of the moment resistance and stiffness of the reinforced urethane blade, it is necessary to consider the blade as a composite (two-material) beam. In particular, the blade is regarded as a low-strength material with metal reinforcement on top and bottom as shown in sketch E-1. The plate thickness $t_{R}$ is a fixed value, which for the most part, is small compared to the blade maximum half thickness $\left(t_{R} \leq 0.1\right.$ yax $)$. It is assumed that the metal plates are rigidly attached to the urethane, so that they act together as a unit (i.e., unit strains of the fibers vary directly with distance from the neutral axis). Accordingly, the unit strains of the plates and the urethane are equal at the interface.

Urethane stress. - The maximum stress in the urethane is taken to occur at the interface between the urethane and the metal plate at the chordwise location of the point of maximum profile thickness, as shown in sketch E-3.

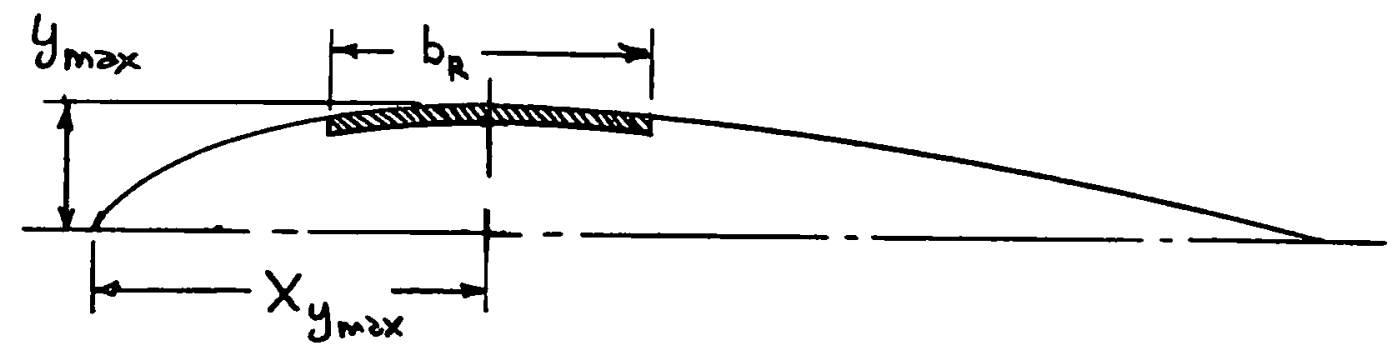

Sketch E-3

At the point $y=y_{\max }-t_{R}$,

$$
\sigma_{R}=\varepsilon_{R} E_{R} \quad \text { and } \quad \sigma_{u}=\varepsilon_{u} E_{u}
$$

so that for a given stress in the plate $\sigma_{R}$ at the outermost fiber $y-y_{\max }$,

$$
\max \cdot \sigma_{u}=\left(\sigma_{R}\right)\left(\frac{E_{u}}{E_{R}}\right)\left[1-\left(\frac{t_{R}}{y_{\max }}\right)\right]
$$

Moment resistance. - The moment resistance of the reinforced blade section acting as a composite beam is the sum of the resistance of the urethane and metal portions

$$
M_{r}=\left(M_{r}\right)_{u}+\left(M_{r}\right)_{R}
$$


and, from the flexure formula

$$
M_{r}=\sigma\left(\frac{I_{u}}{y_{R}}\right)+\sigma_{R}\left(\frac{I_{R}}{y_{\max }}\right)
$$

The moment of inertia of the urethane portion $I_{u}$ is related to the moment of inertia of the full urethane section $I_{u, f}$ through the subtraction

$$
I_{u}=I_{u, f}-I_{R}
$$

With equations (E16) and (E18), the moment resistance becomes for $\sigma_{R}$

$$
M_{r}=\sigma_{R}\left(\frac{y_{\max }}{y_{R}}\right)\left(\frac{E_{u}}{E_{R}}\right)\left(\frac{I_{u, f}}{y_{\max }}\right)+\sigma_{R} \frac{I_{R}}{y_{R}}\left(\frac{y_{R}}{y_{\max }}-\frac{E_{u}}{E_{R}}\right)
$$

and the required value of section modulus for the reinforcement plate is

$$
\frac{I_{R}}{y_{R}}=\frac{\frac{{ }_{r}}{\sigma_{R}}-\left(\frac{y_{\max }}{y_{R}}\right)\left(\frac{E_{u}}{E_{R}}\right)\left(\frac{I_{u, f}}{y_{\max }}\right)}{\frac{y_{R}}{y_{\max }}-\frac{E_{u}}{E_{R}}}
$$

The section modulus for the plate can also be obtained from equation (E12) as

$$
\frac{I_{R}}{y_{R}}=b_{R} t_{R}\left(1-\frac{t_{R}}{2 y_{R}}\right)^{2}=b_{R} t_{R}\left[1-\left(\frac{t_{R}}{c}\right)\left(\frac{y_{\max }}{y_{R}}\right)\left(\frac{c}{2 y_{\max }}\right)\right]^{2}
$$

The equating of equations (E19) and (E20) then produces

$$
b_{R}=\frac{\frac{M_{r}}{\sigma_{R}}-\left(\frac{y_{\max }}{y_{R}}\right)\left(\frac{E_{u}}{E_{R}}\right)\left(\frac{I_{u, f}}{y_{\max }}\right)}{t_{R}\left[1-\left(\frac{t_{R}}{C}\right)\left(\frac{y_{\max }}{y_{R}}\right)\left(\frac{c}{2 y_{\max }}\right)\right]^{2}\left(\frac{y_{R}}{y_{\max }}-\frac{E_{u}}{E_{R}}\right)}
$$

Then, with $\mathrm{I}_{\mathrm{u}, \mathrm{f}}$ from equation (E4), the plate width for the reference blade section is 


$$
b_{R}=\frac{\frac{M_{r}}{\sigma_{R}}-0.05971 c^{3}\left(\frac{2 y_{\max }}{c}\right)^{2}\left(\frac{y_{\max }}{y_{R}}\right)\left(\frac{E_{u}}{E_{R}}\right)}{t_{r} c\left(\frac{2 y_{\max }}{c}\right)\left(\frac{y_{R}}{y_{\max }}\right)\left[1-\frac{t_{R}}{c}\left(\frac{y_{\max }}{y_{R}}\right)\left(\frac{c}{2 y_{\max }}\right)\right]^{2}\left(\frac{y_{R}}{y_{\max }}-\frac{E_{u}}{E_{R}}\right)}
$$

Stiffness. - The stiffness of the composite blade is

$$
E I=(E I)_{u}+(E I)_{R}
$$

The value for the urethane portion of the blade is related to the value for the full section as

$$
{ }^{(E I)_{u}}=E_{u}\left(I_{u, f}-I_{R}\right)
$$

so that the moment of inertia of the reinforcement plates is given by

$$
I_{R}=\frac{\frac{E I}{E_{R}}-\left(\frac{E_{u}}{E_{R}}\right)_{u, f}}{1-\frac{E_{u}}{E_{R}}}
$$

The substitution of equation (E12) for $I_{R}$ then gives, after rearrangement,

$$
b_{R}=\frac{\frac{E I}{E_{R}}-\left(\frac{E_{u}}{E_{R}}\right) I_{u, f}}{\left(1-\frac{E_{u}}{E_{R}}\right) \frac{t_{R}}{2}\left[c\left(\frac{2 y_{\max }}{C}\right)\left(\frac{y_{R}}{y_{\max }}\right)-t_{R}\right]^{2}}
$$

Then, with $I_{u, f}$ from equation (B4), the plate thickness for the reference blade section is

$$
b_{R}=\frac{\frac{E I}{E_{R}}-0.029855 c^{4}\left(\frac{2 y_{\max }}{C}\right)^{3}\left(\frac{E_{u}^{\prime}}{E_{R}}\right)^{2}}{\left(1-\frac{E_{u}}{E_{R}}\right) \frac{t_{R}}{2}\left[c\left(\frac{2 y_{\max }}{C}\right)\left(\frac{y_{R}}{y_{\max }}\right)-t_{R}\right]^{2}}
$$


For the calculations with equations (E22) and (E27), $t_{R}=0.25$ inch, and $\mathrm{y}_{\mathrm{R}} / \mathrm{y}_{\max }=0.9$.

Weight. - The unit weight of the composite section is the sum of W/L for the urethane portion $(W / L)_{u}$ and the reinforcement plate portion $(W / L)_{R}$. With $(W / L)_{R}$ from equation $(E 15)$ and $(W / L)_{u}$ from

$$
\left(\frac{W}{L}\right)_{u}=\sigma_{u}\left(A_{u, f}-2 b_{R} t_{R}\right)
$$

The total unit weight is

$$
\left(\frac{W}{L}\right)=\rho_{u} A_{u, f}+2 b_{R} t_{R}\left(\rho_{R}-\rho_{u}\right)
$$

For the reference blade section, with $A_{u, f}$ from equation (E10),

$$
\frac{W}{L}=0.33527 \rho_{u} c^{2}\left(\frac{2 y_{\text {max }}}{C}\right)+2 b_{R} t_{R}\left(\rho_{R}-\rho_{u}\right)
$$

The total weight of the blade is then obtained as a summation of $W / L$ values along the span of the blade,

$$
W=\sum_{0.1}^{1.0}\left(\frac{W}{L}\right)_{r / r_{t}}
$$




\section{APPENDIX F - MODIFIED BLADË SECTION}

The modified urethane blade section with reduced cross-sectional area described by figure 45 was divided into 18 chordwise segments of rectangular cross section that approximated the local area of the blade material. The idealized blade section is shown in table F1. Blade section moment of inertia and area were then determined from summation of the element properties as 1isted in table Fl. The section properties of the modified configuration compared to the reference configuration discussed in the previous section are $A_{\text {mod }} / A_{\text {ref }}=0.719$, and $I_{\text {mod }} / I_{\text {ref }}=0.695$.

It was then assumed that modified cross section thus determined for $r / r_{t}=0.2$ would be tapered uniformly toward the tip of the blade, so that at $r / r_{t}=0.9$, the area of the modified section would be 10 percent less than that of the reference blade section at that radial position. Thus, a linear variation of area ratio based on the two points $A_{\text {mod }} / A_{r e f}=0.719$ at $r / r_{t}=0.2$ and $A_{\text {mod }} / A_{\text {ref }}=0.9$ at $r / r_{t}=0.9$ provides the spanwise area schedule for the reduced-material blade.

Inasmuch as the ratios of moment of inertia and cross-sectional area are fairly close for the reference and modified blade sections, it is reasonable to also prescribe that $I_{\text {mod }} / I_{\text {ref }}=0.9$ at $r / r_{t}=0.9$. Thus, a linear variation of moment of inertia ratio was obtained to provide values of $I$ along the span for the modifled blade.

Values of A, I, and EI for the modified all-urethane blade $(E=458000$ psi, material E) are listed in table F2. 


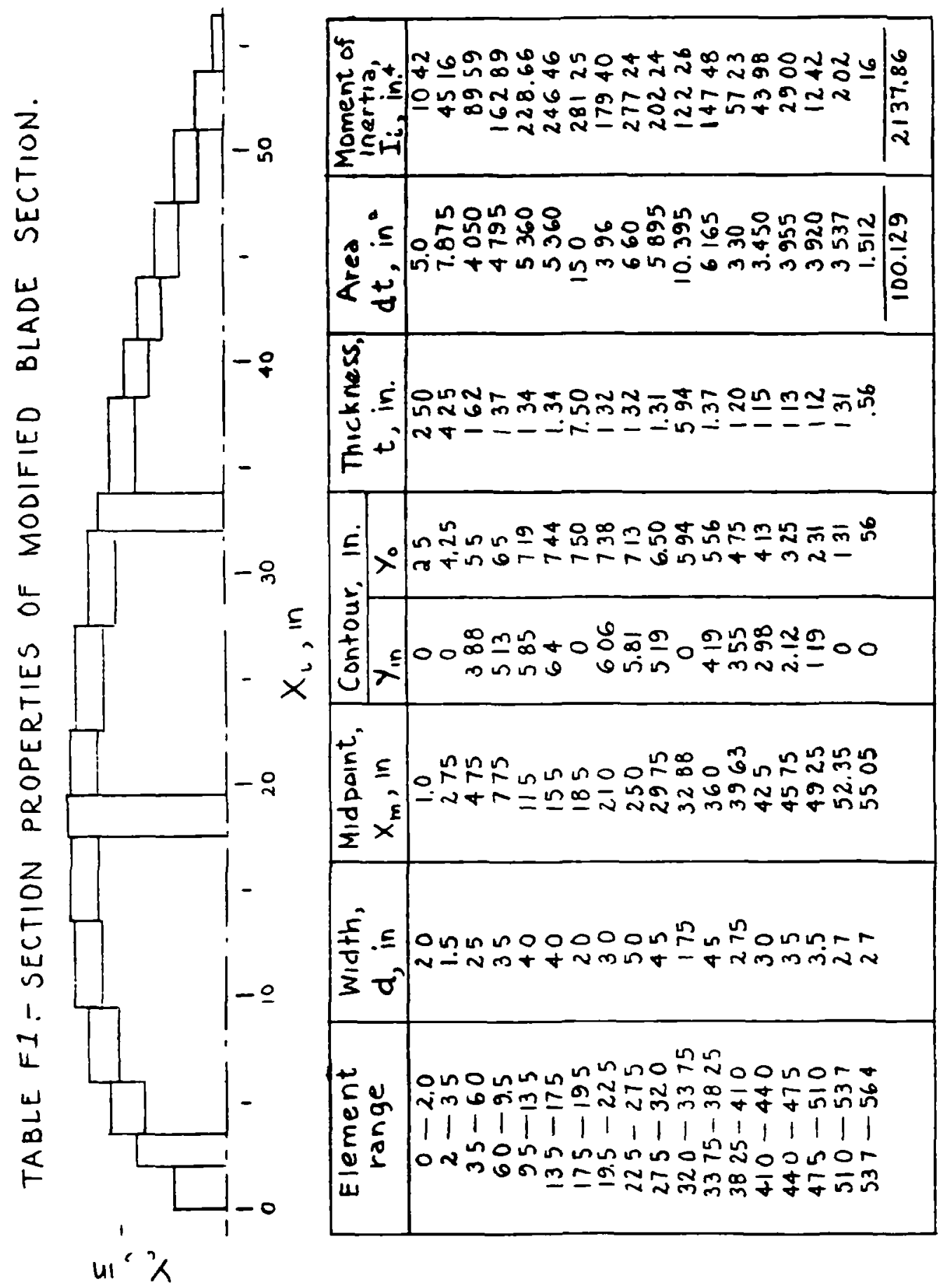


TABLE F2. - PROPERTIES OF ALL-URETHANE BLADE WITH MODIFIED REDUCED-MATERIAL SECTIONS

\begin{tabular}{|c|c|c|c|}
\hline $\begin{array}{c}\text { Radius } \\
\text { ratio, } \\
\text { r/rt }\end{array}$ & $\begin{array}{c}\text { Cross- } \\
\text { sectional } \\
\text { area, } \\
\mathrm{A}_{\mathrm{u}, \mathrm{f}}, \\
\text { in }^{2}\end{array}$ & $\begin{array}{c}\text { Moment of } \\
\text { inertia, } \\
\mathrm{I}_{\mathrm{u}, \mathrm{f}}, \\
\text { in }^{4}\end{array}$ & $\begin{array}{c}\text { Stiffness, } \\
\mathrm{EI}_{\mathrm{u}, \mathrm{f}}, \\
\text { in }^{2}-\mathrm{lb}\end{array}$ \\
\hline 0.1 & 239.0 & 6915 & $3.167 \times 10^{9}$ \\
.2 & 200.1 & 4276 & 1.958 \\
.3 & 164.3 & 2549 & 1.167 \\
.4 & 131.7 & 1442 & .6604 \\
.5 & 102.9 & 768.4 & .3519 \\
.6 & 77.87 & 382.4 & .1751 \\
.7 & 56.73 & 174.6 & .0800 \\
.8 & 39.38 & 71.42 & .0327 \\
.9 & 25.70 & 25.35 & .0116 \\
1.0 & 15.42 & 7.428 & .0034 \\
\hline
\end{tabular}


1. Anon.: Summary Report, Federal Wind Energy Program. Energy Research and Development Administration. ERDA-77-32, Jan. 1977.

2. Puthoff, Richard L.: Fabrication and Assembly of the ERDA/NASA 100-Kilowatt Experimental Wind Turbine. NASA TM X-3390, April 1976. 


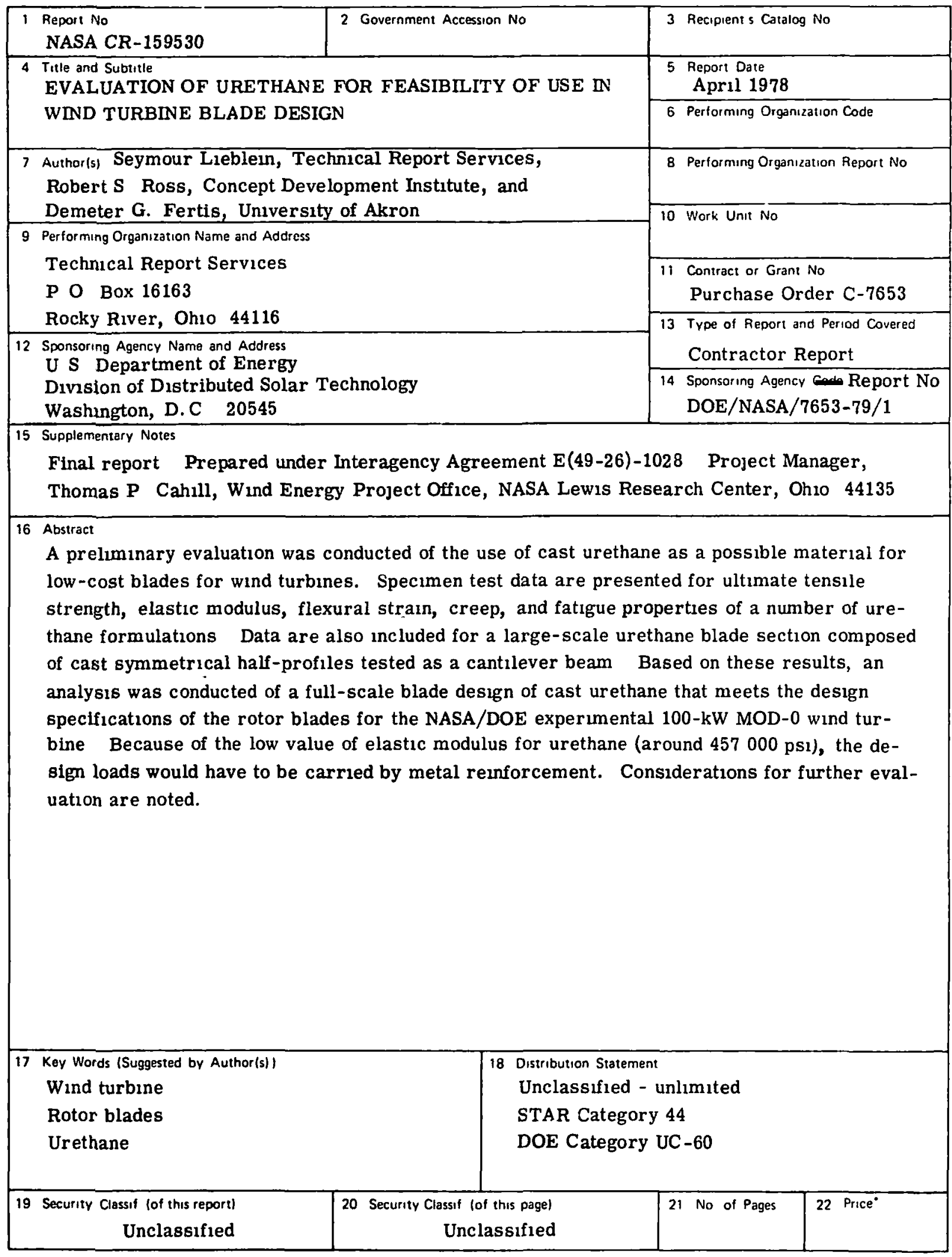

- For sale by the Natıonal Technical Information Service Sprıngfield Virgina 22161 